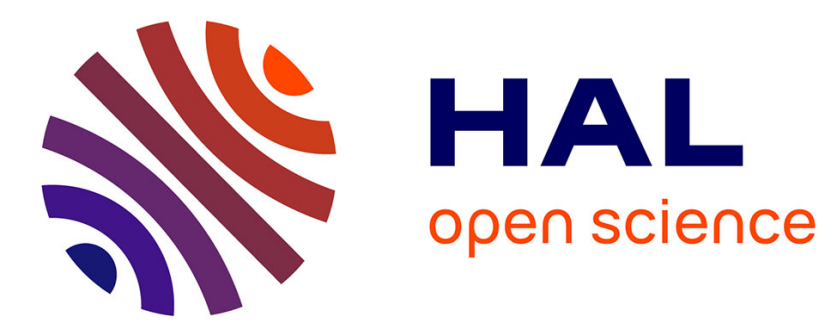

\title{
Drug delivery to the central nervous system
}

\author{
Rita Milagros Nieto Montesinos
}

\section{To cite this version:}

Rita Milagros Nieto Montesinos. Drug delivery to the central nervous system. Neurobiology. Université de Franche-Comté, 2014. English. NNT : 2014BESA3002 . tel-01139027

\section{HAL Id: tel-01139027 https://theses.hal.science/tel-01139027}

Submitted on 3 Apr 2015

HAL is a multi-disciplinary open access archive for the deposit and dissemination of scientific research documents, whether they are published or not. The documents may come from teaching and research institutions in France or abroad, or from public or private research centers.
L'archive ouverte pluridisciplinaire HAL, est destinée au dépôt et à la diffusion de documents scientifiques de niveau recherche, publiés ou non, émanant des établissements d'enseignement et de recherche français ou étrangers, des laboratoires publics ou privés. 


\section{THESE}

\section{VECTORISATION DE MOLECULES \\ THERAPEUTIQUES AUX TISSUS \\ CEREBRAUX}

UNIVERSITE DE FRANCHE-COMTE

Ecole doctorale : Environnement-Santé.

présentée et soutenue par

Rita Milagros NIETO MONTESINOS

le 19 Février 2014 à Besançon

en vue de l'obtention du diplôme de Docteur de l'Université de Franche-Comté

\section{Jury}

Professeur Frédéric LAGARCE, president

Professeur Gilles PONCHEL, rapporteur Professeur Stéphanie BRIANCON, rapporteur Professeur Alf LAMPRECHT, directeur Docteur Yann PELLEQUER, co-directeur Docteur Sandrine BOURGEOIS, examinateur
Université d'Angers

Université de Paris-Sud Université de Lyon

Université de Franche-Comté Université de Franche-Comté Université de Lyon 


\title{
DRUG DELIVERY TO THE CENTRAL NERVOUS SYSTEM
}

\author{
THESIS
}

\section{UNIVERSITY OF FRANCHE- COMTE Graduate school: Environment-Health.}

presented and defended by

\section{Rita Milagros NIETO MONTESINOS}

\author{
on February $19^{\text {th }} 2014$ in Besançon
}

\section{in partial fulfillment of the requirements for the degree of Doctor of Philosophy}

\section{Jury}

Professor Frédéric LAGARCE, president Professor Gilles PONCHEL, reviewer Professor Stéphanie BRIANCON, reviewer Professor Alf LAMPRECHT, supervisor Doctor Yann PELLEQUER, co-supervisor Doctor Sandrine BOURGEOIS, examiner
University of Angers

University of Paris-Sud University of Lyon University of Franche-Comté University of Franche-Comté University of Lyon 


\section{ACKNOWLEDGEMENTS}

The work presented in this thesis was carried out at the Laboratory of Pharmaceutical Engineering, Faculty of Medicine and Pharmacy, University of Franche-Comte. I am grateful to the region of Franche-Comté for financial support, grant $\mathrm{N}^{\circ} 2009 \mathrm{C}-07455$, which made it possible for me to start my PhD. I am equally grateful to the Graduate school "HumanEnvironment-Health" for funding my participation in international conferences and courses.

I would like to express my sincere gratitude to all those who have contributed to this thesis especially:

My supervisor, Professor Alf Lamprecht, for his supervision and for giving me the opportunity to work at the Laboratory of Pharmaceutical Engineering.

My co-supervisor, Doctor Yann Pellequer, for taking the time to answer my questions, for sharing his knowledge and expertise as well as extraordinary scientific ideas with me.

Doctor Arnaud Béduneau for introducing me to the cell culture world and for sharing with me his skills while working with antibodies.

Professor Céline Demougeot and Doctor Katy Maguin Gate for their collaboration and help in the in vivo studies presented herein.

Professor Frédéric Lagarce, Professor Gilles Ponchel, Professor Stéphanie Briancon and Doctor Sandrine Bourgeois, members of my defense committee, for accepting judging this work.

The current and former members of the Laboratory of Pharmaceutical Engineering and the building mates for making this research experience a very pleasant adventure.

Y mi más profunda gratitud a Dios y a mi familia por apoyarme en todas mis decisiones y por esperarme siempre con los brazos abiertos. Dedicado a ustedes. 


\section{LIST OF ABBREVIATIONS}

$\mathrm{ABC}$

$\mathrm{ACN}$

ADP

ATP

AUC

AUMC

$\mathrm{AUCi}_{\mathrm{nf}}$

BBB

BCSFB

BSEP

$\mathrm{B} / \mathrm{P}$

BTB

BCRP

$\beta-\mathrm{CD}$

CDs

CDL

Chol

CL

CNS

CSF

CS

CV

DDS

DIMEB

DLE

DM- $\beta-C D$

DMEM

DMPC

DPPC

DSPC
ATP binding cassette

acetonitrile

adenosine diphosphate

adenosine triphosphate

area under the concentration-time curve

area under the moment curve

area under the concentration-time curve from time zero to infinity

blood-brain barrier

blood cerebrospinal fluid barrier

bile salt export pump

brain-to-plasma ratio

blood-testis barrier

breast cancer resistance protein

$\beta$-cyclodextrin

cyclodextrins

curved desolvation line

cholesterol

clearance

central nervous system

cerebrospinal fluid

calibration standard

coefficient of variation

drug delivery system

heptakis(2,6-di-O-methyl)- $\beta$-cyclodextrin

drug loading efficiency

dimethyl- $\beta$-cyclodextrin

Dulbecco's modified Eagle's medium

1,2-dimyristoyl-sn-glycero-3-phosphocholine

1,2-dipalmitoyl-sn-glycero-3-phosphocholine

1,2-distearoyl-sn-glycero-3-phosphocholine 
DSPE-PEG $_{2000}$

DSPE-PEG ${ }_{2000}-\mathrm{COOH}$

DSPE-PEG ${ }_{5000}-\mathrm{COOH}$

DPBS

$\mathrm{ED}_{50}$

EDC

EPC

ESI

$\mathrm{EtOH}$

FBS

GIT

HBSS

HEPES

HIV

HQCS

ITC

IV

IS

$\mathrm{Kp}$

LC-MS

LLOQ

LQCS

M- $\beta-C D$

MDR

$\mathrm{MeOH}$

MES

MRPs

MRT

MW

NBDs
1,2-distearoylS-sn-glycero-3-phosphoethanolamine-N[methoxy(polyethyleneglycol)-2000] (ammonium salt) 1,2-distearoyl-sn-glycero-3-phosphoethanolamine-N[carboxy(polyethyleneglycol)-2000] (ammonium salt) 1,2-distearoyl-sn-glycero-3-phosphoethanolamine- $\mathrm{N}$ [carboxy(polyethyleneglycol)-5000] (ammonium salt) Dulbecco's phosphate-buffered saline half-maximun effective dose $\mathrm{N}$-(3-dimethylaminopropyl)-N'ethyl-carbodiimide hydrochloride egg phosphocholine electrospray ionization ethanol fetal bovine serum Gastrointestinal tract Hanks' balanced salt solution 4-(2-hydroxyethyl)-1-piperazineethanesulfonic acid human immunodeficiency virus higher quality control sample International Transporter Consortium intravenous internal standard brain-to-plasma partition coefficient liquid chromatography-mass spectrometry lower limit of quantification lower quality control sample methyl- $\beta$-cyclodextrin multidrug resistance methanol

2-(N-morpholino)ethanesulfonic acid multidrug resistance-associated proteins mean residence time molecular weight nucleotide binding domains 
OX26

$\mathrm{PC}$

PE

PEG

PS

P-gp

QCS

QSARs

RES

SIM

sulfo-NHS

SPGP

$t_{1 / 2}$

$t$-BME

TMDs

$\mathrm{Vd}_{\mathrm{ss}}$
anti-Transferrin Receptor antibody

phosphatidylcholine

phosphatidylethanolamine

polyethylene glycol

phosphatidylserine

P-glycoprotein

quality control sample

quantitative structure-activity relationships

reticuloendothelial system

single ion monitoring

$\mathrm{N}$-hydroxysulfosuccinimide

sister of P-glycoprotein

half-life of elimination

tert-butyl methyl ether

transmembrane domains

apparent volume of plasma compartment 


\section{TABLE OF CONTENTS}

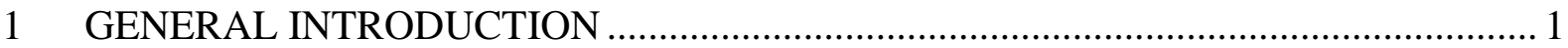

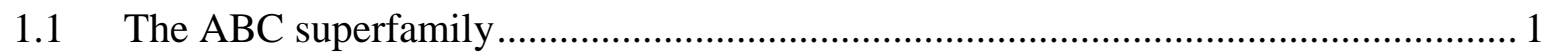

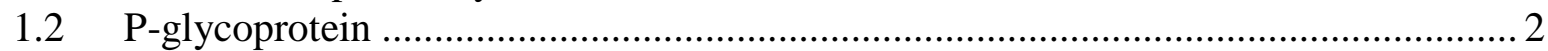

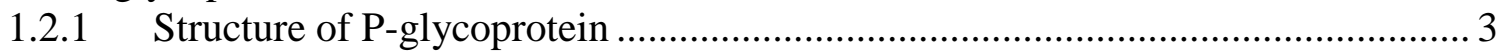

1.2.2 The transport cycle of P-glycoprotein .......................................................... 5

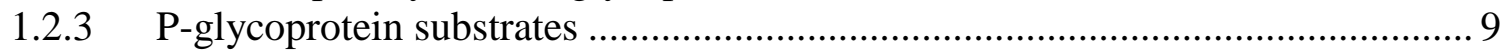

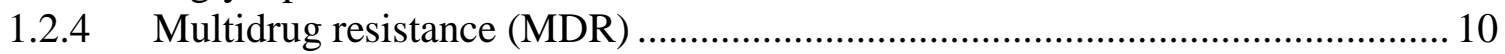

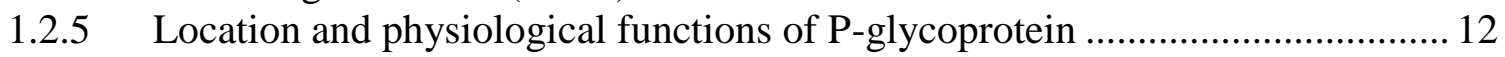

1.2.6 P-glycoprotein, a critical element of the blood brain barrier ............................ 13

1.2.7 Techniques to measure the drug transport across the blood-brain barrier ......... 16

2 DELIVERY OF P-GLYCOPROTEIN SUBSTRATES USING CHEMOSENSITIZERS AND NANOTECHNOLOGY FOR SELECTIVE AND EFFICIENT THERAPEUTIC

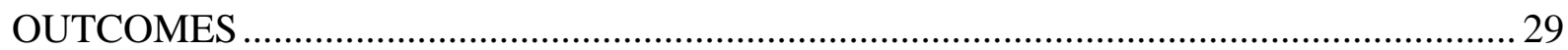

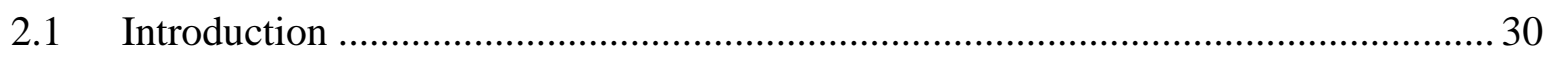

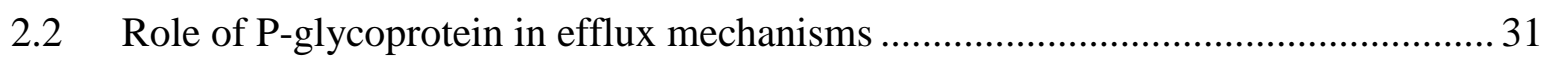

2.3 Therapeutic approaches using P-gp modulators ................................................... 33

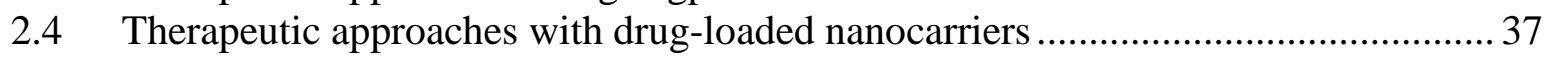

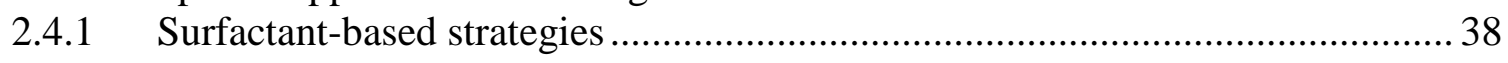

2.4.2 Amphiphilic copolymer-based strategy ....................................................... 39

2.4.3 Mechanisms of P-gp modulation using amphiphilic excipients and/or

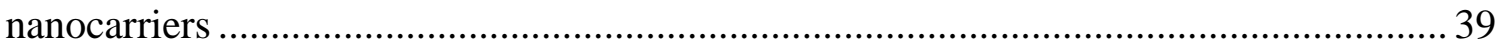

2.5 Synergistic combination of P-gp modulators with nanocarriers .............................. 43

2.5.1 Co-encapsulation of P-gp substrates and P-gp modulators in liposomes and

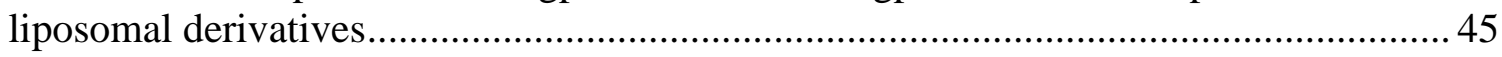

2.5.2 Co-encapsulation of P-gp substrates and P-gp modulators in nanoparticles ..... 47

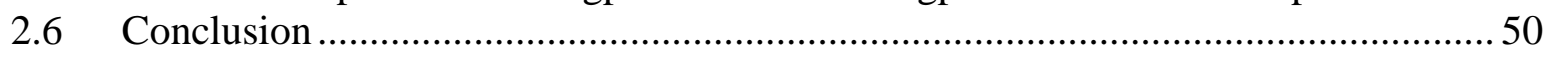

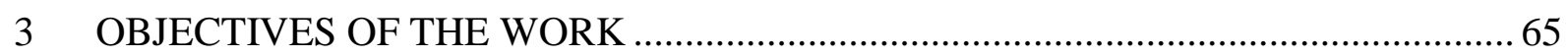

4 SIMULTANEOUS DETERMINATION OF LOPERAMIDE, ELACRIDAR AND TARIQUIDAR IN RAT PLASMA AND TISSUES BY LIQUID CHROMATOGRAPHY-

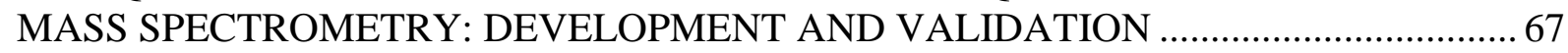

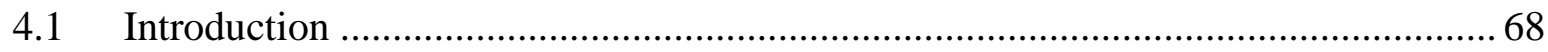

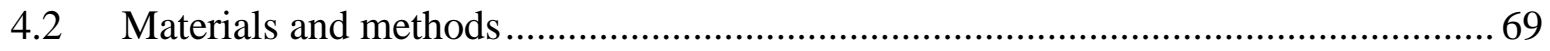

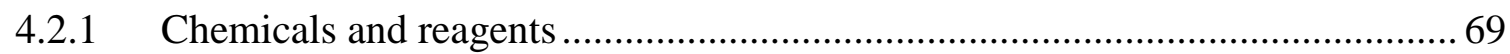

4.2.2 Stock solutions, calibration standards (CS), quality control samples (QCS) and

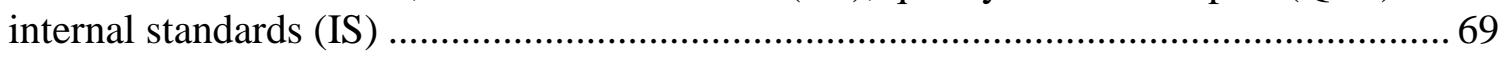

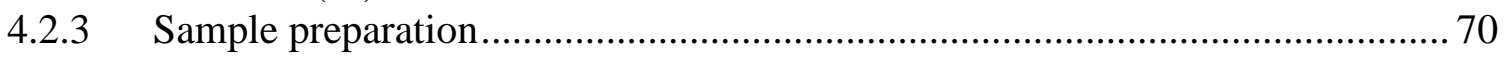

4.2.4 Instrumentation: Chromatographic and mass spectrometer conditions ............. 70

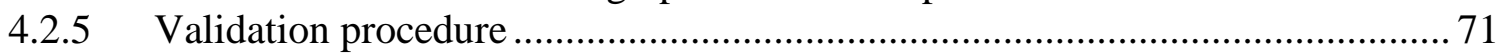

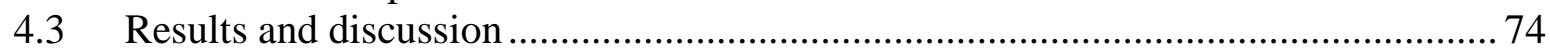

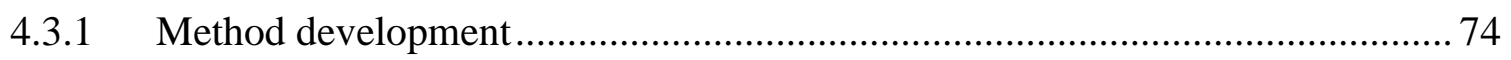

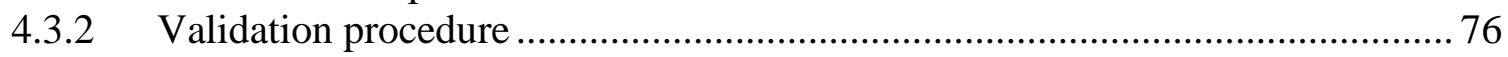

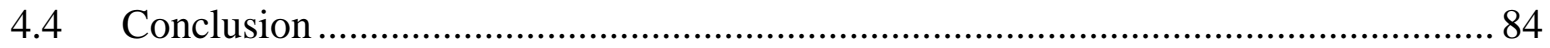

5 CO-ADMINISTRATION OF P-GLYCOPROTEIN MODULATORS ON LOPERAMIDE PHARMACOKINETICS AND BRAIN DISTRIBUTION ........................ 87

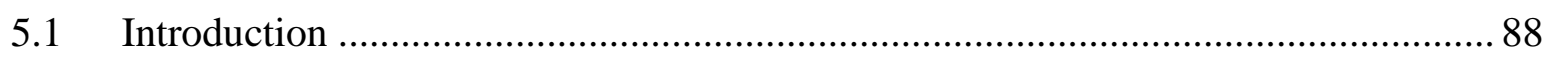

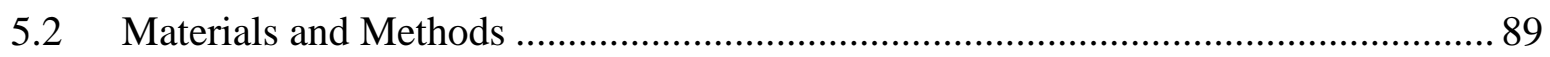

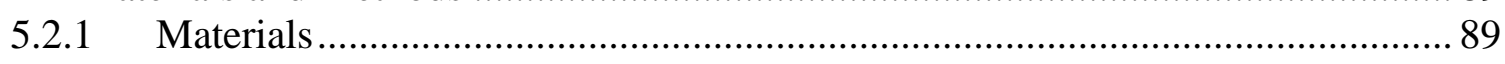

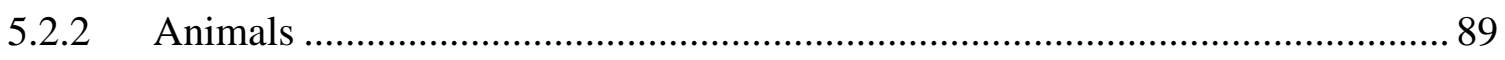




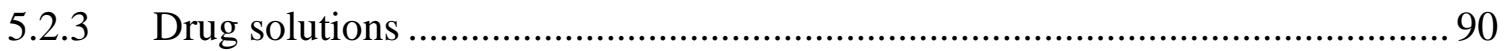

5.2.4 Study design .......................................................................................... 90

5.2.5 Analysis of loperamide, elacridar and tariquidar by Liquid Chromatography-

Mass Spectrometry (LC-MS) …………………………………………………......... 91

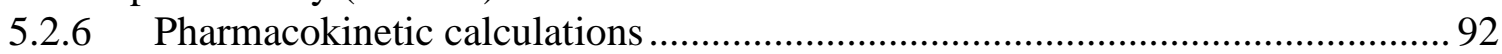

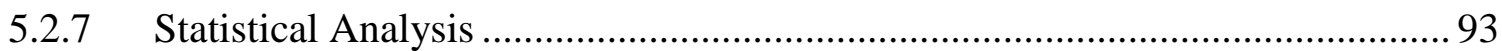

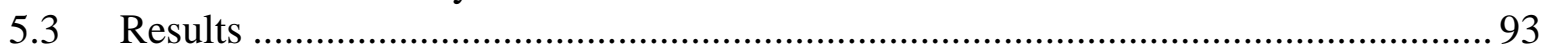

5.3.1 Analysis of loperamide, elacridar and tariquidar by Liquid Chromatography-

Mass Spectrometry (LC-MS) ……………………………………………………….... 93

5.3.2 Influence of the co-administration of elacridar and tariquidar on their plasma

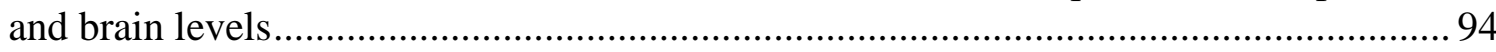

5.3.3 Influence of the co-administration of elacridar and tariquidar on loperamide

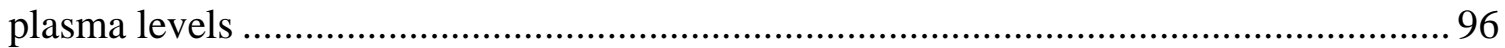

5.3.4 Influence of the co-administration of elacridar and tariquidar on loperamide

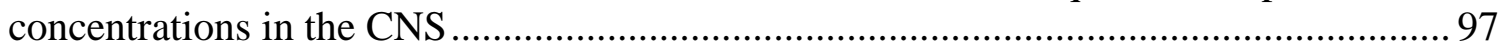

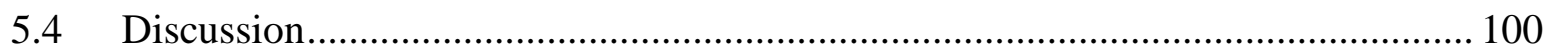

6 LIPOSOMES CO-LOADED WITH ELACRIDAR AND TARIQUIDAR TO

MODULATE THE P-GLYCOPROTEIN AT THE BLOOD-BRAIN BARRIER …………. 108

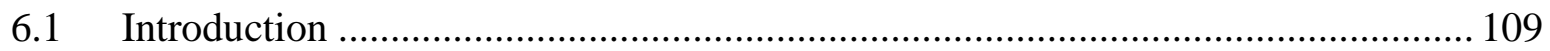

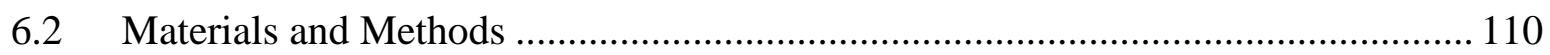

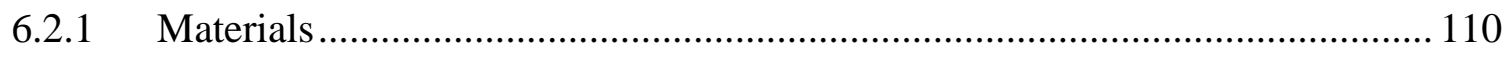

6.2.2 Preparation of OX26 F(ab') $)_{2}$ fragments ........................................................ 111

6.2.3 Preparation of liposomes ...................................................................... 112

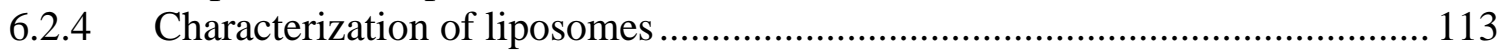

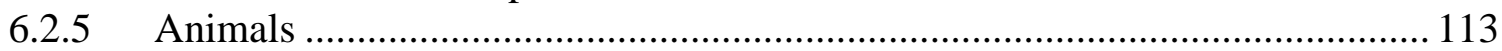

6.2.6 Study design ……………………………………………………….... 114

6.2.7 Analysis of loperamide, elacridar and tariquidar by Liquid Chromatography-

Mass Spectrometry (LS-MS) ……………………………………………………... 115

6.2.8 Pharmacokinetic calculations ..................................................................... 116

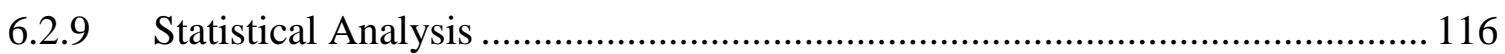

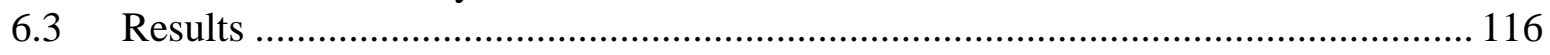

6.3.1 Characterization of liposomal formulations ……………………………….... 116

6.3.2 Drugs loading and antibody-liposomes coupling efficiencies ......................... 117

6.3.3 Pharmacokinetics of elacridar and tariquidar co-loaded in different types of

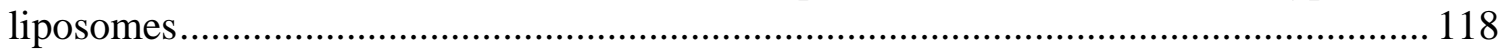

6.3.4 Brain distribution of elacridar and tariquidar co-loaded in different types of liposomes...

6.3.5 Tissues distribution of elacridar and tariquidar co-loaded in different types of liposomes.......

6.3.6 Effects of elacridar and tariquidar co-loaded in different types of liposomes on

the brain distribution of free loperamide ...................................................................... 122

6.3.7 Effects of elacridar and tariquidar co-loaded in different types of liposomes on the pharmacokinetics, liver and kidneys distribution of free loperamide ....................... 125

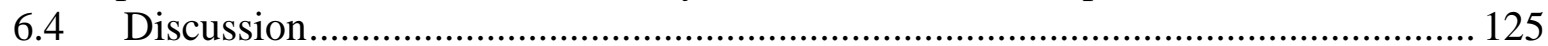

7 SEQUESTRATION OF P-GLYCOPROTEIN INHIBITORS BY NOCARRIERS ..... 133

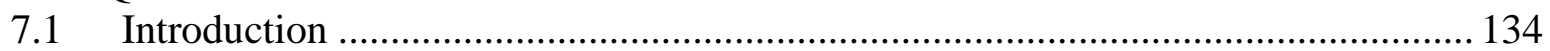

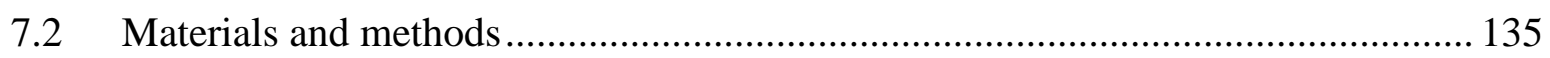

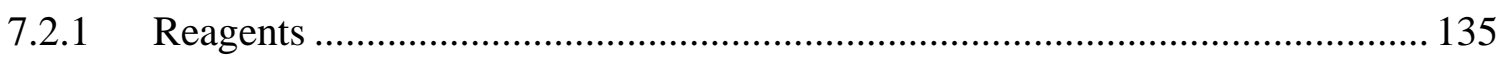

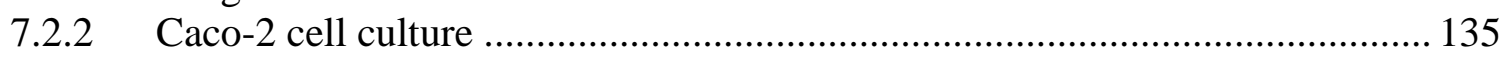

7.2.3 Selection of the P-gp inhibitors doses to be reversed......................................... 136 
7.2.4 Time-dependent reversal of the P-gp inhibitory activity of elacridar and

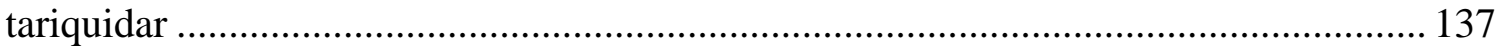
7.2.5 Effect of nanocarriers on P-glycoprotein inhibitory activity of elacridar and tariquidar .....

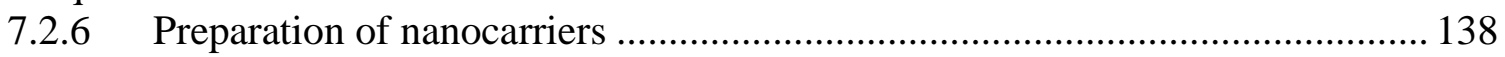

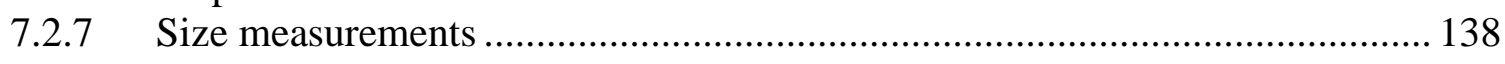

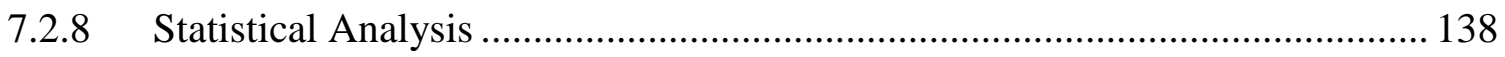

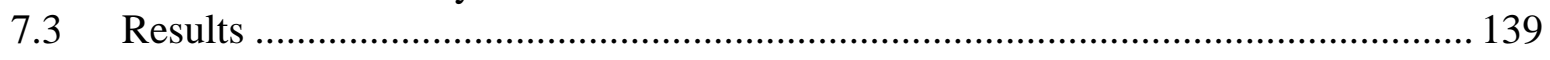

7.3.1 Selection of the P-gp inhibitors doses to be reversed...................................... 139

7.3.2 Time-dependent reversal of the P-gp inhibitory activity of elacridar and tariquidar

7.3.3 Effect of nanocarriers on P-glycoprotein inhibitory activity of elacridar and

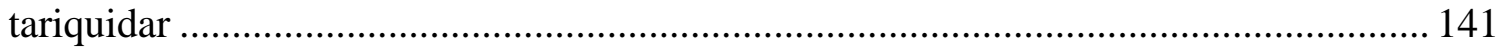

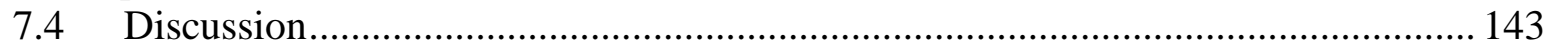

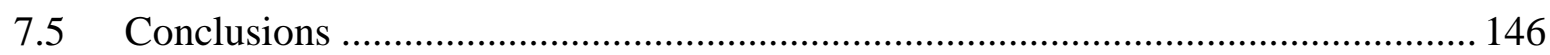

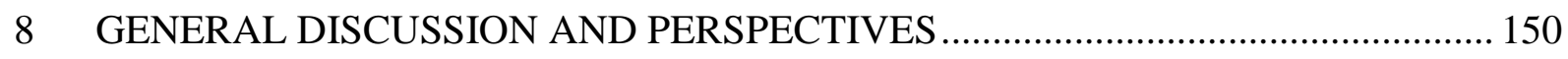




\section{GENERAL INTRODUCTION}

\subsection{The ABC superfamily}

Traditionally, it was believed that the physicochemical properties such as molecular weight, charge and lipophilicity and the metabolic processes were the major determinants of the bioavailability of most drugs [1]. However, recent progress has led us to understand why the minimal effective concentrations of certain drugs are not attained and why chemotherapy and the treatment of several brain disorders, immunosuppressive diseases and infectious diseases fail. Often, this mechanism is mediated by a large list of efflux transporters, most of which belong to the ATP-binding cassette (ABC) transporters super family [2, 3]. ABC transporters are transmembrane proteins that use the energy from the ATP hydrolysis to drive the efflux of lipids, peptides, amino acids, carbohydrates, vitamins, glucuronide and glutathione conjugates and xenobiotics across cellular membranes. Some members of the ABC superfamily show specificity for one substrate whereas others can transport a broad variety of structurally unrelated hydrophobic compounds [4].

The basic functional unit of an $\mathrm{ABC}$ transporter contains minimally four domains, two transmembrane domains (TMDs) and two cytoplasmic nucleotide binding domains (NBDs) (Fig1). These four domains form two symmetric halves. The TMDs form the pathway through which the substrates cross the membrane and the NBDs, also known as ABC domains, provide the nucleotide dependent engine that drives the transport. At the sequence level, the superfamily of $\mathrm{ABC}$ transporters is identified by a characteristic set of highly conserved motifs present in the NBDs. In contrast, the sequences and architectures of the TMDs are quite variable, reflecting the chemical diversity of the translocated substrates $[5,6]$ (Table 1). Various studies identified 49 human ABC proteins that can be grouped into seven subclasses or families (ABCA to $\mathrm{ABCG}$ ) based on the organization of their domains and amino acid homology [7]. Among the ABC transporters, P-glycoprotein (P-gp), multidrug resistanceassociated proteins (MRPs) and breast cancer resistance protein (BCRP) are the most critical efflux proteins due to their significant roles in restricting the permeability of several pharmacological agents $[8,9]$. 
Table 1: Therapeutic key ABC transporters and their principal characteristics.

\begin{tabular}{|c|c|c|c|c|}
\hline $\begin{array}{c}\text { Transporter } \\
\text { name }\end{array}$ & Size (aa) & Topology & $\begin{array}{l}\text { Polarized cell } \\
\text { localization }\end{array}$ & Location \\
\hline MDR1/P-gp & 1280 & $\begin{array}{l}\text { TMD1-NBD1- } \\
\text { TMD2-NBD2 }\end{array}$ & Apical & $\begin{array}{l}\text { GIT, lungs, stem cells, BBB, } \\
\text { BCSFB, BTB, placenta, } \\
\text { liver and kidney }\end{array}$ \\
\hline BSEP/SPGP & 1321 & $\begin{array}{l}\text { TMD1-NBD1- } \\
\text { TMD2-NBD2 }\end{array}$ & Apical & Liver \\
\hline MRP1 & 1531 & $\begin{array}{l}\text { TMD0-L0- } \\
\text { TMD1-NBD1- } \\
\text { TMD2-NBD2 }\end{array}$ & $\begin{array}{l}\text { Basolateral, apical } \\
\text { (in brain } \\
\text { endothealial cells) }\end{array}$ & $\begin{array}{l}\text { Lungs, placenta } \\
\text { and kidney }\end{array}$ \\
\hline MRP2 & 1545 & $\begin{array}{l}\text { TMD0-L0- } \\
\text { TMD1-NBD1- } \\
\text { TMD2-NBD2 }\end{array}$ & Apical & GIT, placenta, liver and kidney \\
\hline MRP3 & 1527 & $\begin{array}{c}\text { TMD0-L0- } \\
\text { TMD1-NBD1- } \\
\text { TMD2-NBD2 }\end{array}$ & Basolateral & GIT, placenta, liver and kidney \\
\hline MRP4 & 1325 & $\begin{array}{l}\text { TMD1-NBD1- } \\
\text { TMD2-NBD2 }\end{array}$ & Apical, basolateral & $\mathrm{BBB}, \mathrm{BCSFB}$, liver and kidney \\
\hline MRP5 & 1437 & $\begin{array}{l}\text { TMD1-NBD1- } \\
\text { TMD2-NBD2 }\end{array}$ & Basolateral, apical & $\mathrm{BBB}$ and liver \\
\hline BCRP/MXR & 655 & $\begin{array}{l}\text { TMD-NBD } \\
\text { (homodimer) }\end{array}$ & Apical & $\begin{array}{l}\text { GIT, stem cells, BBB, placenta, } \\
\text { mammary glands, liver and kidney }\end{array}$ \\
\hline
\end{tabular}

Gastrointestinal tract (GIT), blood- brain barrier (BBB), blood-cerebrospinal fluid barrier (BCSFB) and bloodtestis barrier (BTB).

\section{$1.2 \quad P$-glycoprotein}

Since its discovery in 1976 [10], P-glycoprotein is the most extensively studied ABC transporter and is often regarded as the prototype to understand the biochemical mechanism of all ABC transport proteins. Two factors make P-gp the most critical efflux transporter: (1) its broad substrate specificity eliciting multidrug resistance (MDR) [11] and (2) the prominent presence of P-gp in most excretory and barrier function tissues [3]. As a result of these aspects, P-gp is a major obstacle for the treatment of cancer and several brain disorders, as well as immunosuppressive and infectious diseases. 
Human P-gp is encoded by two multidrug resistance genes, MDR1 and MDR2 (also called $M D R 3)$ situated on chromosome 7q21.12. MDR1 is associated with a multidrug resistance phenotype, while the MDR2 isoform inefficiently mediates the efflux of MDR1 substrates; however, $M D R 2$ also functions as a phosphatidylcholine translocase [10, 12, 13].

In rodents, $\mathrm{P}$-gp is encoded by three genes, $m d r l a, m d r l b$ and $m d r 2$. The substrate specificity of P-gp encoded by mdrla and $m d r l b$ is different but partly overlapping. Together, these two rodent genes are expressed in roughly the same manner as the single human MDRl gene, suggesting that they perform the same set of functions in rodents as the MDRl P-gp in humans. The rodent $m d r 2$ gene is more homologous to human MDR2. [3]. According to the Human Genome Nomenclature Committee, the approved symbols for the human MDRl gene is $\mathrm{ABCB} 1$ and for the mouse and rat mdrla and mdrlb genes are Abcbla and Abcb1b, respectively.

Comparison between the rodent P-gp homologues and human P-gp over the equivalent nucleotide range (2866 base pairs) showed that mouse Abcb1a and Abcb1b shares an identity with human $\mathrm{ABCB} 1$ of $89.4 \%$ and $82.7 \%$, respectively and that rat Abcb1a and Abcb1b shares an identity with human ABCB1 of $89.5 \%$ and $83.3 \%$, respectively [14]. This high sequence identity makes the rodent models promising tools to predict $\mathrm{P}$-gp-drugs interactions at the human BBB.

\subsubsection{Structure of P-glycoprotein}

In humans, P-gp is a $170-\mathrm{kDa}$ polypeptide which consists of 1280 amino acids organized in two tandem repeats of 610 amino acids joined by a linker region of about 60 amino acids. Pgp appears to be encoded by a gene duplication event fusing two related half molecules, each consisting of one NBD and one TMD which is made up of six transmembrane domain segments ( $\alpha$ helices) [15].

In 2001, Loo and Clarke have succeeded in measuring the size of the drug-binding pocket (Fig. 1) by using thiol-specific methanethiosulfonate cross-linkers which were also P-gp substrates. These authors found that the substrate binding pocket is funnel shaped and narrow at the cytoplasmic side, with a diameter between 9 and $25 \AA$ in the central region and $50 \AA$ at its widest [16]. 


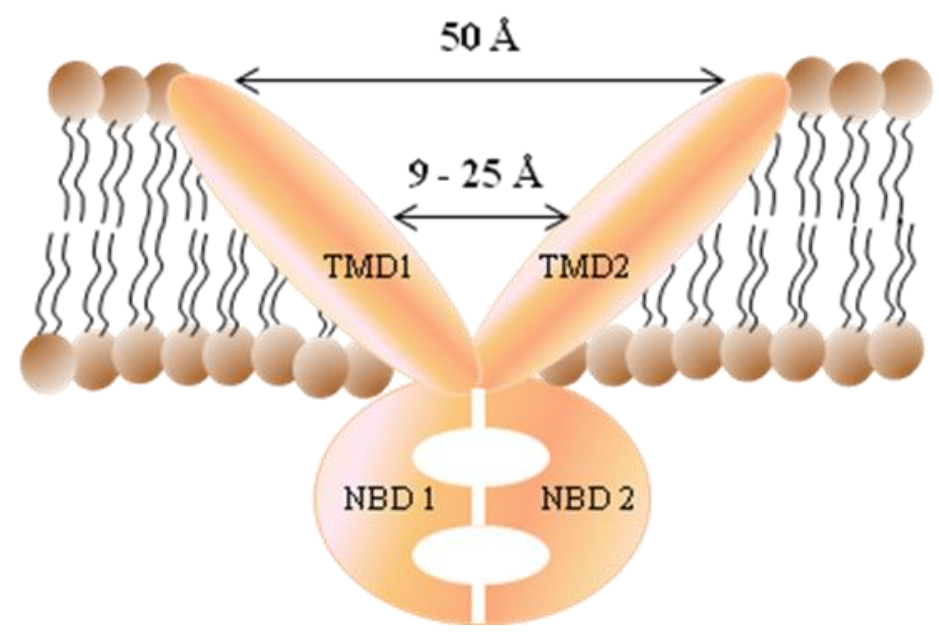

Figure 1. Structure of P-gp showing its four domains and its substrate-binding pocket.

Recently, Aller et al. has described the crystal structure of mouse P-gp at a $3.8 \AA$ resolution (Fig. 2) [17]. This P-gp structure represent the inward-facing conformation arranged as two "halves" spanning 136 A length and 70 A width with a $30 \AA$ separation of the two NBDs. The inward-facing conformation formed from two bundles of six helices, results in a large internal cavity of approximately $6000 \AA^{3}$ open to both, the cytoplasm and the inner leaflet of the membrane. The entry of the hydrophobic substrates from the membrane to the internal cavity involves the presence of two gates formed by two pairs of transmembrane segments which are localized in each TMD unit. This internal cavity comprises mostly hydrophobic and aromatic residues and could accommodate at least two compounds simultaneously. Moreover $\mathrm{P}$-gp is able to distinguish between the stereo-isomers of cyclic peptides, resulting in different binding locations, orientation and stoichiometry. This last one has validated earlier studies, where it was stated that P-gp presents at least four and possibly several overlapping substrate binding sites. Some research teams even suggest that substrate binding sites can be classified as both transport and modulating sites [18] and have the ability to switch between high and low affinity states to accommodate substrates and/or modulators [19]. 


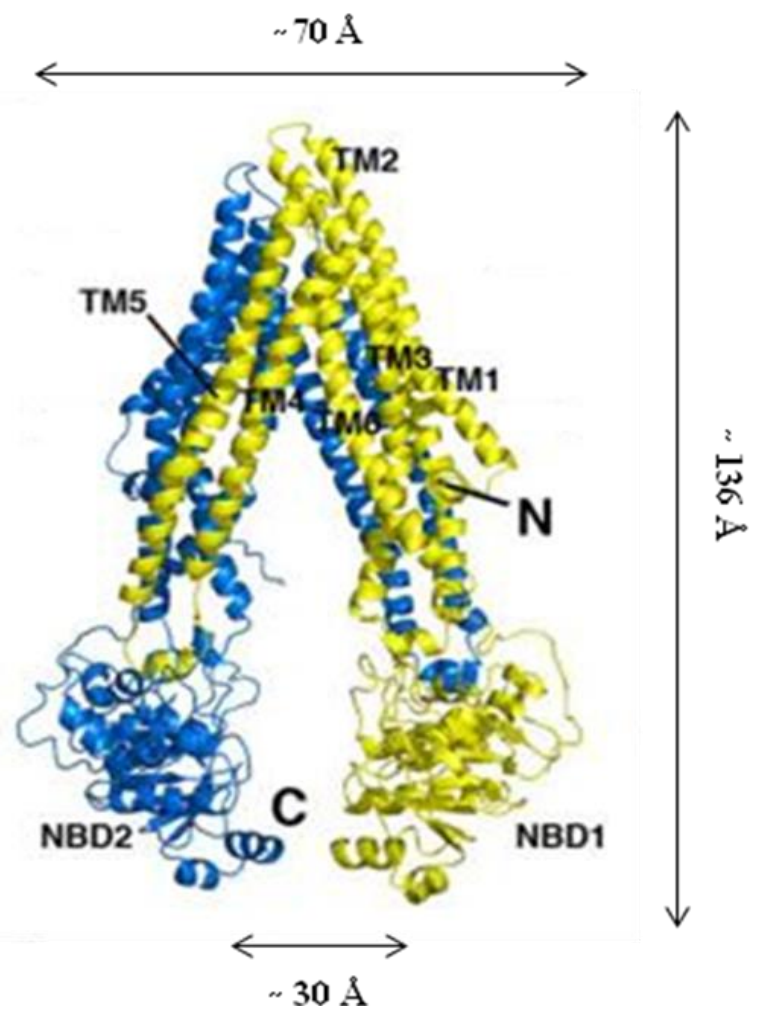

Figure 2. Front cristal structure of P-gp at a $3.8 \AA$ A resolution [17].

\subsubsection{The transport cycle of P-glycoprotein}

Currently, it is well known that the P-gp mediated transport mechanism is saturable, osmotically sensitive and ATP dependent [20]. Nevertheless, insights into how P-gp couples the hydrolysis of ATP to the movement of substrates across the plasma membrane are still controversial. The substrate transport presumes two interconnected cycles. First, the catalytic cycle of ATP hydrolysis which drives the transport and second, the substrates transport cycle, whereby the substrate is moved from the cytoplasmic side to the extracellular side of the membrane. Some models have been proposed to help in the understanding of these two cycles. 


\subsubsection{P-glycoprotein models of the catalytic cycle}

Two potential models have been proposed in order to explain the sequence of events in the catalytic cycle. The most significant difference between these two models is the nature of the power stroke that drives the drug from a high affinity site to a low affinity site.

In the ATP switch model (proposed for all ABC proteins) (Fig. 3), the drug binding to the high affinity binding in the TMDs induces ATP binding and dimerization of the two NBDs. This in turn, results in conformational changes that are communicated to the TMDs. In this new conformation, the substrate binding sites are exposed to the extracellular environment and the substrate is released due to a reduction in the binding affinity. Then, two sequential ATP hydrolysis events provide the energy to break the dimerization, inorganic phosphate and ADP are released and P-gp finally returns to its original conformation [21, 22].

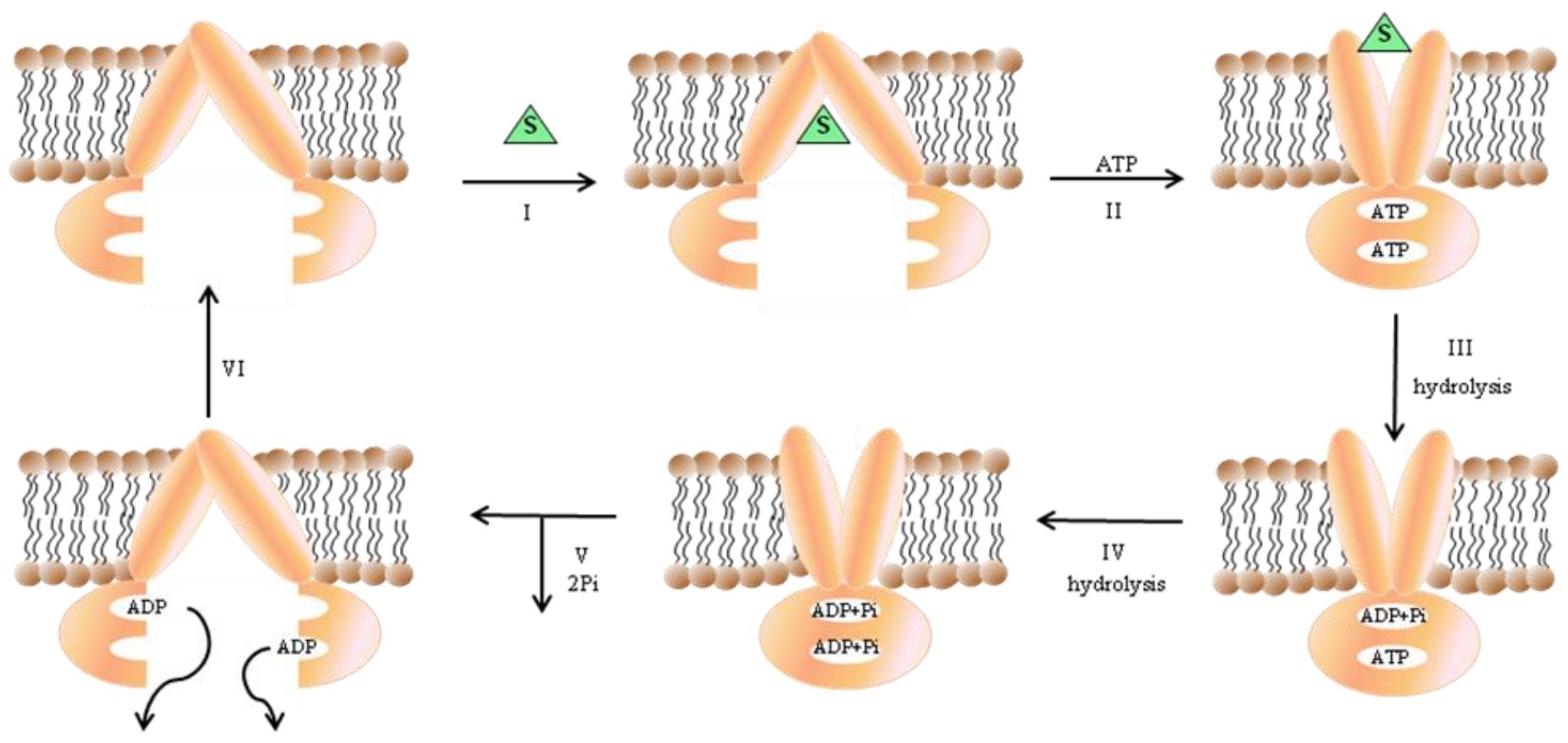

Figure 3. Model proposing the dimerization of the ATP sites as the power stroke. Step I: The substrate binds to a high affinity site in the TDM domain. Step II: Binding of the substrate reduces the activation energy and increases the affinity for ATP. This, results in the dimerization of the two NBD and ATP is tightly bound at the interface. Steps III and IV: Two sequential ATP hydrolysis events provide the energy to break apart the nucleotide dimer-ATP sandwich. Steps V and VI: Inorganic phosphate and two ADPs are released and P-gp is reset to its ground state.

Nonetheless, the data proposed by Al-Shawi et al. and Omote et al. demonstrated that P-gp substrates are not absolutely required for the dimerization of the NBDs and ATP hydrolysis rather than ATP binding causes the conformational changes in the drug binding sites [23, 24]. Then an alternate model was proposed (Fig. 4). In this model, the ATP binding and the substrate binding, which are independent on each other, initiate the cycle. The asymmetric 
occlusion of ATP at site I causes conformational changes that decrease the affinity of the drug binding sites, thus releasing the substrate. The occluded ATP is hydrolyzed and inorganic phosphate and ADP are released but the efflux protein is still in a low affinity state. After the second occlusion and hydrolysis of the second ATP at site II, inorganic phosphate and ADP are once more released and P-gp returns to its initial conformation [25, 26].

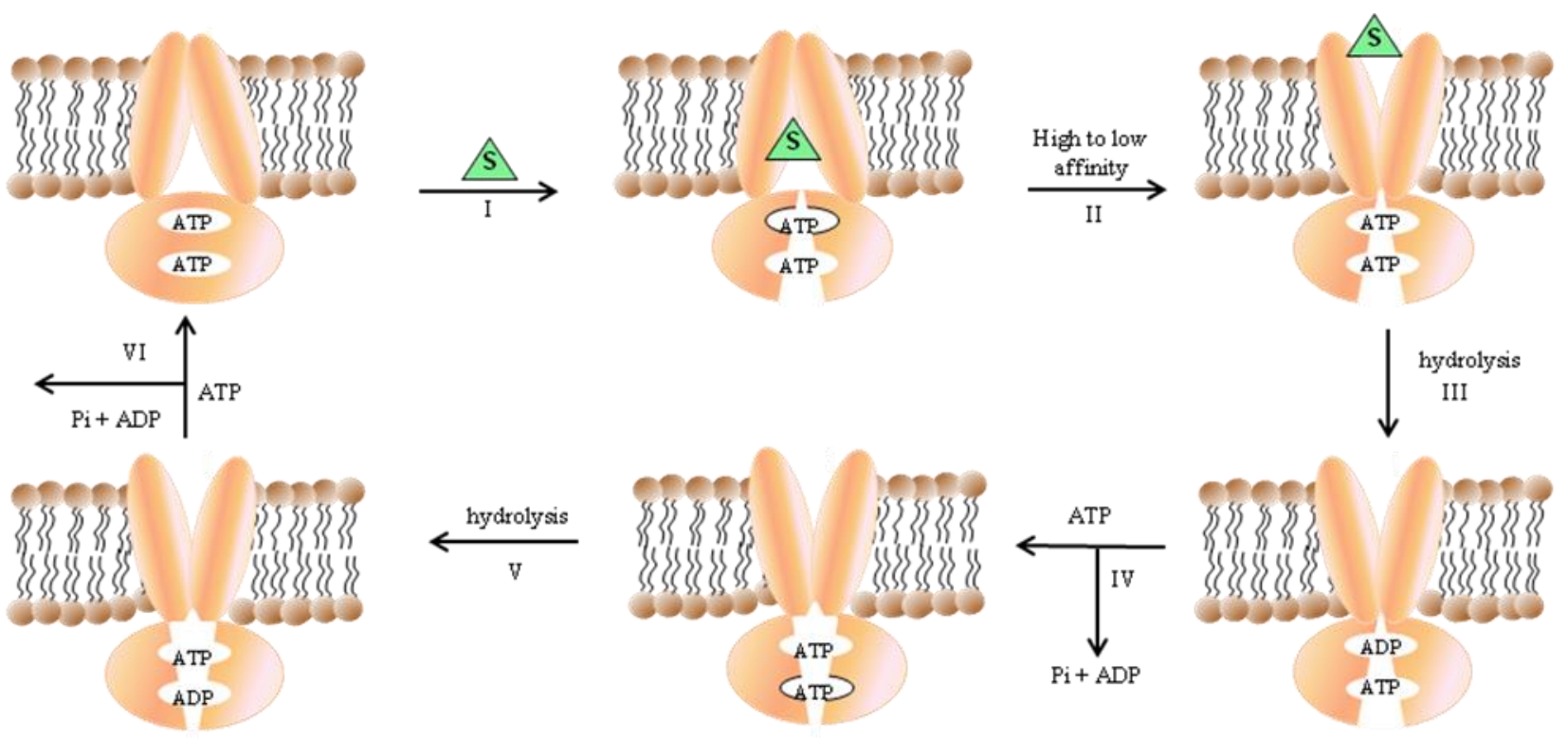

Figure 4. Model proposing the ATP hydrolysis as the power stroke. Step I: Binding of ATP and substrate initiates the cycle. Step II: Occlusion of one ATP at site I of the two NBDs results in the release of the substrate. Step III and IV: Hydrolysis of ATP and the sequential release of inorganic phosphate and ADP make the NBDs accessible to the second ATP but the drug binding sites are still in their low-affinity conformation. Steps V and VI: The binding and hydrolysis of a second ATP at site II result in the release of inorganic phosphate and ADP. This, resets the protein to its ground state, where the P-gp can bind substrates.

Is the binding energy of the nucleotide sandwich that generates the closed dimer or is the ATP hydrolysis? Remaining a challenge, the harmonization of the aforementioned models could help us to understand the coupling between the ATP hydrolysis and drug transport. Further studies using high resolution structures of intact P-gp at different stages of the catalytic cycle could help to increase the understanding of this cycle.

\subsubsection{P-glycoprotein models of substrates transport cycle}

The original model of membrane transport was that of a classic pump which moves its polar substrates from the internal aqueous phase, through its hydrophilic interior directly to the external aqueous phase. However, since hydrophobic compounds were discovered to be P-gp substrates, the hydrophobic vacuum cleaner and flippase models were proposed. Both models assume that the substrate partition into the lipid membrane is prior to the interaction with the 
substrate binding sites. However, given the rapid partitioning of the substrate between the aqueous phase and the membrane, it is difficult to distinguish between these two models [15]. In the hydrophobic vacuum cleaner model (Fig. 5), the hydrophobic substrate is extracted from the inner leaf of the plasma membrane where it is embedded and is then pumped directly to the external aqueous medium [27, 28]. This model supposes that substrates gain their access to their binding sites through gates formed in the TMDs, which becomes evident by the crystal structure of the P-gp at a $3.8 \AA$ resolution [17].

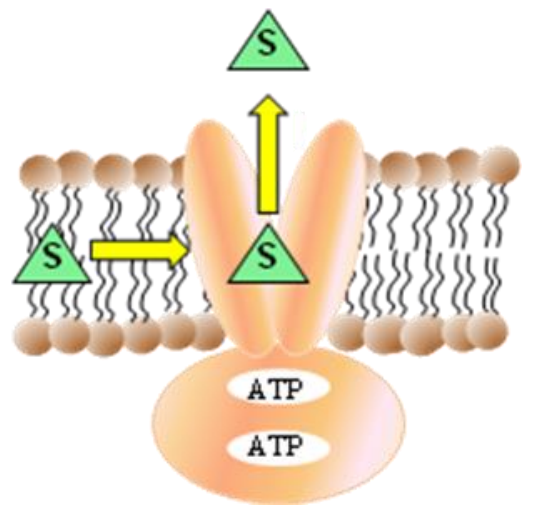

Figure 5. Hydrophobic vacuum cleaner model.

Alternatively, in the flippase model (Fig 6), the lipid-like substrate is extruded from the inner (cytosolic) leaflet to the outer (extracellular) leaflet of the plasma membrane, from where the substrate will diffuse to the external aqueous medium by simple diffusion [29]. This model agrees with some studies where fluorescent lipids such as phosphatidylcholine, phosphatidylethanolamine, phosphatidylserine, and and sphingomyelin are flipped between the inner and the outer leaflets of the lipid membrane [30].

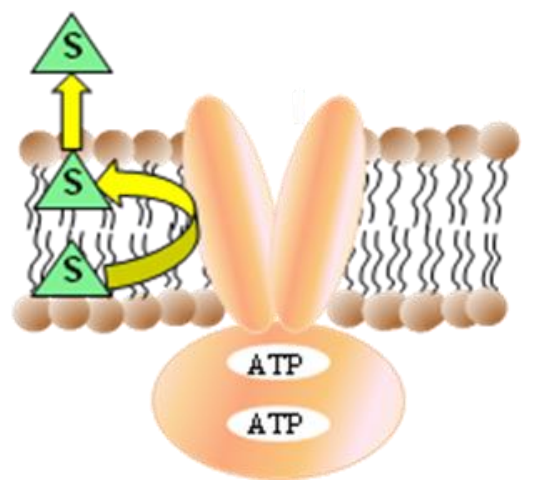

Figure 6. Flippase model 
Although earlier studies favored one or another model, recent data indicates that both models are not exclusive. The partition of the substrate into the plasma membrane and its migration to the extracellular environment exposed by the vacuum cleaner and flippase models strongly confirms that P-gp is a unidirectional efflux pump [17, 31]

\subsubsection{P-glycoprotein substrates}

P-gp substrates are molecules actively transported by the efflux protein and therefore have a higher concentration outside the cell than in the cytosol [32]. As a result of the broad substrate specificity of P-gp, efforts have been made to find similarities among the P-gp substrates. Hence, Didziapetris and co-workers introduced the "rule of fours" which can roughly estimate whether a compound is a P-gp substrate or not. This rule states that if a compound has: (1) a total of at least eight nitrogen and oxygen atoms, (2) a molecular weight (MW) of more than 400 daltons and an acid with a pKa greater than four, it is more likely to be a P-gp substrate. In contrast, if a compound has: (1) a total of no more than four nitrogen and oxygen atoms, (2) a molecular weight less than 400 daltons and a base with a pKa lower than than eight, it is likely to be non-substrate [33].

$$
\begin{aligned}
& (\mathrm{N}+\mathrm{O}) \geq 8, \mathrm{MW}>400 \text { and acid } \mathrm{pKa}>4=\mathrm{P} \text {-gp substrate } \\
& (\mathrm{N}+\mathrm{O}) \leq 4, \mathrm{MW}<400 \text { and base } \mathrm{pKa}<8=\mathrm{P} \text {-gp non-substrate }
\end{aligned}
$$

Recently, several computational models have been developed in order to predict if a compound is a P-gp substrate or not. To date, the most accurate model (accuracy > 90\%) proposed for prediction of P-gp substrates uses a Particle Swarm (PS) algorithm and a Support Vector Machine (SVM) approach. [34]. However, in March 2010 the International Transporter Consortium (ITC) has stated that in general P-gp substrates are organic cations or a neutral molecules, relatively hydrophobic with a molecular mass ranging from 200 to greater than 1000 daltons [8].

In fact, the large list of substrates that undergo P-gp translocation (Table 2) support the hypothesis of the presence of several binding sites [18]. 
Table 2: The most clinically representative P-gp substrates

\begin{tabular}{|c|c|}
\hline Anticancer drugs: & $\begin{array}{l}\text { Doxorubicin, daunorubicin, docetaxel, epirubicin, etoposide, idarubicin, } \\
\text { methotrexate, mitoxantrone, paclitaxel, teniposide, vinblastine and vincristine }\end{array}$ \\
\hline HIV protease inhibitors: & Amprenavir, indinavir, nelfinavir, ritonavir and saquinavir \\
\hline Analgesics: & Fentanyl, morphine and methadone \\
\hline Antibiotics: & Erythromycin, fluoroquinolines, valinomycin and tretracyclines \\
\hline Antiepileptic drugs: & $\begin{array}{l}\text { Carbamazepine, felbamate, gabapentin, lamotrigine, phenytoin, phenobarbital } \\
\text { and topiramate }\end{array}$ \\
\hline Antidepressants: & Amitryptiline, doxepin, nortryptiline, paroxetine and venlafaxine \\
\hline Antidiarrheal agents: & Loperamide \\
\hline Antiemetics: & Domperidone and ondansetron \\
\hline Anthelminthic agents: & Abamectin and ivermectin \\
\hline Antigout agents: & Colchicine \\
\hline Antipsychotic agents: & Amisulpride and olanzapine \\
\hline B-Adrenoceptor antagonists: & Bunitrolol, carvedilol, celiprolol and talinolol \\
\hline Cytokines: & IL-2, IL-4 and IFN-y \\
\hline Corticoids: & $\begin{array}{l}\text { Aldosterone, corticosterone, cortisol, dexamethasone, hydrocortisone and } \\
\text { prednisolone }\end{array}$ \\
\hline $\begin{array}{l}\text { Histamine H1-receptor } \\
\text { antagonists: }\end{array}$ & Cetirizine, fexofenadine and terfenadine \\
\hline $\begin{array}{l}\text { Histamine H2-receptor } \\
\text { antagonists: }\end{array}$ & Cimetidine \\
\hline Immunosuppressive agents: & Cyclosporin A and tacrolimus \\
\hline Lipid-lowering agents: & Atorvastatin, cerivastatin and lovastatin \\
\hline Diagnostic (fluorescent) dyes: & Calcein-AM, Hoechst 33342/33258 and Rhodamine-123 \\
\hline Ref & {$[3]$} \\
\hline
\end{tabular}

\subsubsection{Multidrug resistance (MDR)}

Multidrug resistance is a phenomenon by which tumor cells simultaneously exhibit intrinsic (inherent) or acquired cross-resistance to diverse anticancer drugs, thereby causing cancer treatment failure [11]. Treatment with high doses or multiple cytotoxic drugs with different mechanisms of action (chemotherapy) are not sufficient to overcome MDR. Furthermore, these treatments are often associated with toxic side effects in patients because most 
anticancer drugs do not have specificity towards cancer cells. Different mechanism can mediate the development of MDR. These mechanisms of drug resistance are grouped into (1) increased drug efflux, (2) decreased drug uptake, (3) DNA repair activation, (4) detoxifying systems activation and (5) blockage of drug-induced apoptosis [35].

Some members of the ABC superfamily such as P-gp, MRP1 and BCRP have been implicated in the efflux of anticancer drugs and the subsequent MDR phenomenon [35, 36]. However, the overexpression of P-gp on resistant malignant cells was first recognized in 1976 and is considered to be a major cause of MDR [10]. Because of its association with colchicines permeability it was called P-glycoprotein. In 1981, Tsuruo et al. demonstrated that the calcium-influx blocker, verapamil, could reverse MDR, suggesting thus the possibility of clinically useful reversing agents for MDR [37]. In 1983, Kartner et al. using Western blots indicated for the first time the presence of P-gp in a variety of MDR cell lines [38]. Since then, several studies have led us to confirm that P-gp is a major contributor of the phenomenon of MDR (Table 3).

Table 3: Timeline of important discoveries related to P-gp

\begin{tabular}{|c|c|c|}
\hline Date & Discovery & Ref. \\
\hline 1973 & Demonstration of increased efflux in MDR cell lines causing decreased drug accumulation. & [39] \\
\hline 1976 & Demonstration of P-gp expression in MDR cell lines (Chinese hamster ovary cells). & {$[10]$} \\
\hline 1981 & Demonstration that verapamil could reverse MDR & [37] \\
\hline 1983 & First indication that P-gp is commonly expressed in a variety of MDR cell lines. & {$[38]$} \\
\hline \multirow[t]{2}{*}{1986} & Detection of $A B C B 1$ and $A B C B 2$ genes amplified in human cancer cells. & [40] \\
\hline & Cloning of the first human mdr sequences. & [41] \\
\hline 1989 & Mice expressing MDR1 in bone marrow are drug resistant. & {$[42]$} \\
\hline 1990 & Hormone progesterone regulates expression of $\mathrm{P}-\mathrm{gp}$. & [43] \\
\hline 1993 & Epigenetic induction of MDR1 expression exposure to different chemotherapeutic drugs. & [44] \\
\hline 1997 & P-g is a major factor in reducing the oral availability of amphipathic drugs as Taxol. & {$[45]$} \\
\hline 2001 & $\begin{array}{l}\text { Classical trials showing survival advantage for patients with AML treated with MDR } \\
\text { inhibitors and chemotherapy. }\end{array}$ & [46] \\
\hline 2004 & Global prediction of MDR1 substrates and inhibitors. & [47] \\
\hline
\end{tabular}


To date, $\mathrm{P}$-gp is found to be expressed in acute myelogenous leukemia in $1 / 3$ of the patients at the time of the first diagnosis and in more than $50 \%$ of the patients at the first relapse. The level of expression of P-gp at the presentation of the cancer is sufficient to confer resistance [26]. MDR1 is also expressed at high levels in many other tumors under three different circumstances [26]:

- Cancers derived from epithelial tissues that normally express P-gp including kidney, liver, and colon cancer.

- Cancers in which P-gp levels are low, but after chemotherapy cancers recur and express higher levels of P-gp such as leukemias, lymphomas, and multiple myeloma.

- Cancers in which the development of the tumor appears to be associated with the turning on of expression of P-gp, including chronic myelogenous leukemia in blast crisis and neuroblastoma.

\subsubsection{Location and physiological functions of P-glycoprotein}

The strategic localization of P-gp (Fig. 7), suggests that its main physiological role is to protect sensitive organs and the fetus from a variety of endogenous and exogenous molecules. Consequently, P-gp also plays a prominent role in the absorption, distribution and excretion of clinically administered drugs.

P-gp is highly expressed on the apical surface of the superficial columnar epithelial cells of the ileum and the colon. The expression levels of P-gp are lower in the jejunum, duodenum and stomach. Therefore the P-gp in these locations acts as a first natural line of defense against toxins such as Listeria monocytogenes [48]. However, the extrusion of substrates from the intestinal epithelium into the intestinal lumen limits the oral drug bioavailability [49].

In the liver, P-gp is exclusively localized on the apical (canalicular) membrane of hepatocytes, where it plays a major role in the hepatic excretion of toxins, many drugs and metabolites into the bile. High levels of P-gp are also found on the apical surfaces of epithelial cells of small biliary ductules $[50,51]$. P-gp is observed on the apical surface of epithelial cells of small pancreatic ductules [50]. In the kidney, P-gp is found on the apical surface of epithelial cells of the proximal tubules where the efflux protein is supposed to pump the substrates from the blood into the urine $[50,52]$. In normal human and rat lung tissue, P-gp is localized on the luminal membrane of the alveolar epithelium [53]. 
In addition to the expression of P-gp in human tissues with excretory function, high levels of P-glycoprotein are also found at the blood-tissue barriers, such as the blood-brain barrier, the blood-testis barrier and the placenta, suggesting that it has a generalized barrier function [3, 15]. The function of P-gp in the placenta is the protection of the highly sensitive developing fetus from xenotoxins and drugs present in the maternal circulation by active back transport [52]. The presence of P-gp in hematopoietic progenitor cells protects the bone marrow from the toxicity of chemotherapeutic drugs [54].

As seen, P-gp is one of the major components of a well developed "chemo immunity system" which dynamically protects the body and its more vulnerable structures against the accumulation of foreign chemical agents. Although the size, hydrophobicity, charge or the amphipathic character of a drug may allow a rapid penetration through the membrane lipid layers, P-gp selectively does modulate the entry and exit of the drug through cellular barriers.

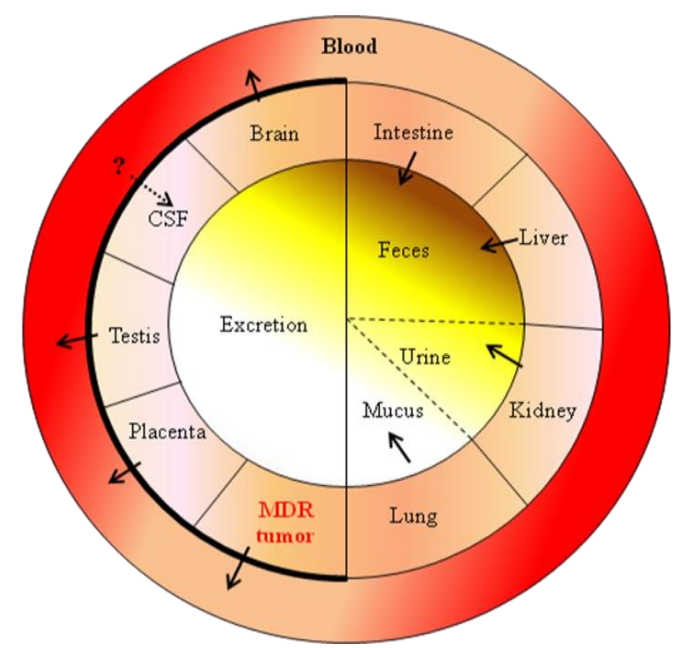

Figure 7. Direction of the P-gp-mediated transport in the human body [55]. The bold solid arrows indicate the known direction of transport and the dotted arrow indicates unclear direction of transport. The thick black line indicates the location of P-gp in the lipid bilayer that forms blood-barriers.

\subsubsection{P-glycoprotein, a critical element of the blood brain barrier}

The blood-brain barrier (BBB) (Fig. 8) is a selective barrier formed by the endothelial cells that line cerebral microvessels. The combined surface area of these microvessels constitutes by far the largest interface for the blood-brain exchange [56]. The BBB endothelial cells differ from the endothelial cells in the rest of the body by the absence of fenestrations, sparse pinocytic vesicular transport and more extensive tight junctions which cover the walls of the vessels as a continuous sheath, leaving no space between cells. In addition to endothelial cells, 
the BBB is also composed by an extracellular matrix (basal membrane), pericytes which are embedded within the basal membrane and astrocyte foot processes $[3,56]$.

As a result of this configuration, most molecular traffic take a transcellular route across the $\mathrm{BBB}$, rather than moving paracellularly through the junctions, as in most endothelia. Small gaseous molecules such as $\mathrm{O}_{2}$ and $\mathrm{CO}_{2}$ can diffuse freely through the lipid membranes, and this is also a route of entry for small lipophilic agents, including drugs such as barbiturates and ethanol [57]. The presence of specific transport systems on the luminal and abluminal membranes regulates the influx or efflux of various essential substrates such as electrolytes, nucleosides, amino acids and glucose [58]. It was originally supposed that these membrane transporters at the $\mathrm{BBB}$ were solely responsible for the transport of such endogenous compounds and that drugs transport across the BBB was dependent on their physicochemical properties such as lipophilicity, molecular weight and ionic state. Nonetheless, it is the presence of drug efflux transporters at the BBB which limit the brain uptake of a variety of therapeutic compounds, including compounds that are relatively lipophilic and would be predicted to permeate the endothealial lining of the brain microvasculature [59].

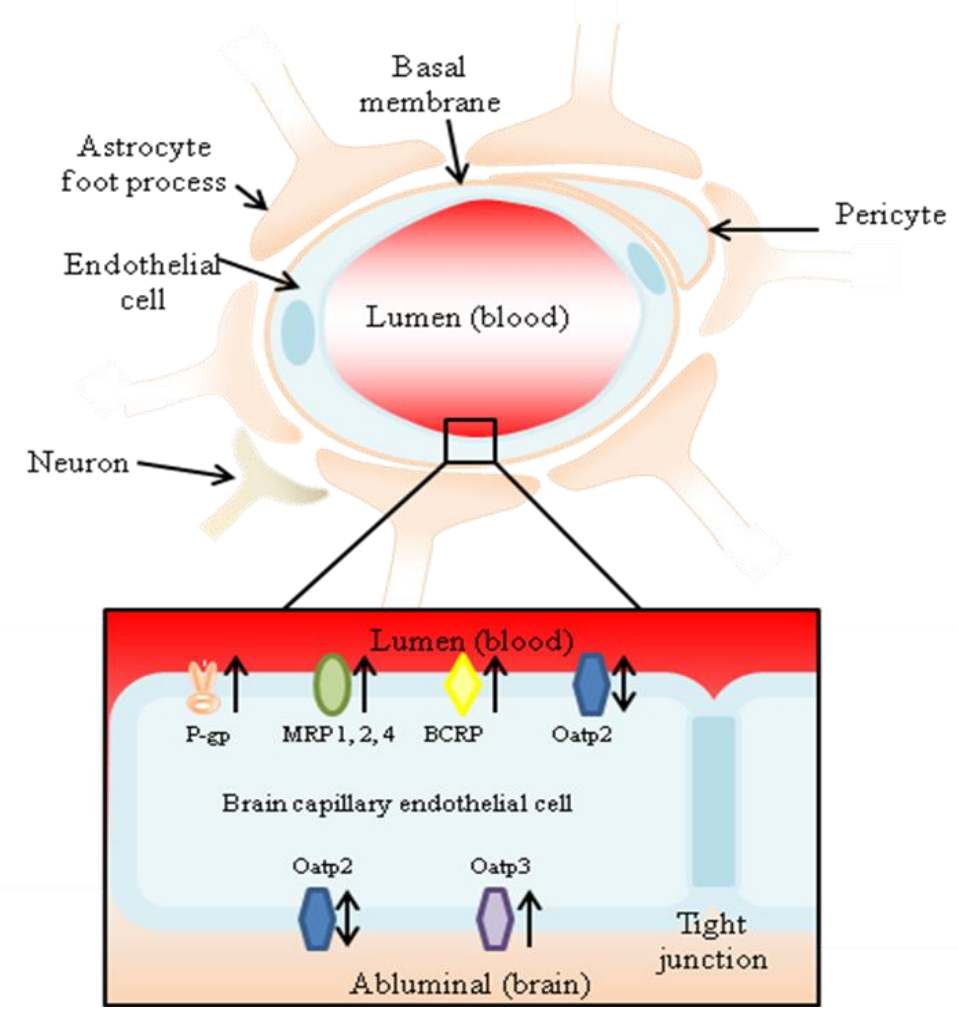

Figure 8. The Blood-Brain barrier 
The presence of various efflux transporters at the BBB acts as a gatekeeper in the entry of many therapeutic drugs into the brain. Based on three critical defining criteria: (1) multispecificity, (2) location and (3) energetic; P-glycoprotein (P-gp) is considered to be the most important efflux transport at the BBB [60]. The expression of P-gp on the endothelial cells at the human BBB was first described in 1989 by Cordon-Cardo et al. and Theibaut et al [61, 62]. Since these studies have been published, P-gp has been found to be localized at the luminal membrane of the endothelial cells lining the capillaries of the brain [56,63], in neurons [64] and in astrocytes [65]. Other studies have demonstrated the presence of P-gp at the apical surfaces of the epithelial cells that constitute the ventricular exposed surface of the human choroid plexus [66]. Consequently, the relevant distribution of P-gp at the BBB offers a mechanism of detoxification to remove harmful endogenous and exogenous compounds from the brain. Thus, the penetration of therapeutic compounds into the brain tissue is equally decreased leading to the failure of various clinical treatments for brain diseases such as epilepsy, depression and brain cancer [3]. Additionally, it is known that Alzheimer's, Parkinson's and Huntington's diseases are related to the expression and function of P-gp at the BBB [3]. The replication of the human immunodeficiency virus (HIV) in its primary stages takes place in the central nervous system (CNS), which causes neurological complications in HIV patients [67]. Unfortunately, many of the anti-HIV drugs are known Pgp substrates, inhibitors, or inducers, which results in toxicity or drug resistance and the subsequent failure of the treatment [68].

The in vivo impact of Pgp at the BBB has been properly illustrated in knockout mice lacking the Pgp isoform mdr1a (mdr1a (-/-) mice) or the isoforms, mdr1a and mdr1b (mdr1a/1b (-/-) mice). The mdrla (-/-) mice were healthy and fertile and appeared phenotypically normal, but they accumulate much higher levels of P-gp substrates in the brain. A clear example was the increased sensitivity to the centrally neurotoxic pesticide ivermectin [69]. Knockout mice treated with ivermectin developed a severe intoxication and nearly all of the animals died because they were 100-fold more sensitive to the neurotoxic adverse effects of this compound. This enhanced sensitivity was due to the 100-higher accumulation of ivermectin in the brain as compared to wildtype mice. Based on this impressive proof, pharmacokinetic studies in knockout mice were rapidly extended to other drugs. The absence of mdr1a led to highly increased levels of vinblastine, digoxin, and cyclosporin A in the brain. Some drugs such as loperamide, domperidone, and ondansetron also demonstrated to be substrates for Pgp, while phenytoin demonstrated to be a relatively weaker substrate. Haloperidol, clozapine, 
and flunitrazepam are transported hardly or not at all by P-gp [70]. Tissue distribution studies demonstrated that the relative brain penetration of radiolabeled ondansetron and loperamide is increased 4- and almost 14-fold, respectively in mdr1a (-/-) mice. Moreover, a pilot toxicity study showed that the oral administration of loperamide gains potent opiate-like activity in the CNS of mdrla (-/-) mice. Oral domperidone also showed neuroleptic-like side effects in mdr1a (-/-) mice [70]. These results have certified the prominent role of P-gp in the clinical use of many drugs that could eventually target the CNS.

\subsubsection{Techniques to measure the drug transport across the blood-brain barrier}

A number of techniques have been developed to study the disposition of drugs in the brain, after P-gp overcoming. The following techniques give evidence of the bi-directional (influx/efflux) transport of the drug across the BBB.

\subsubsection{In vitro models}

Early in vitro models of the BBB used cells from non-cerebral origin such as human umbilical endothelial cells (HUEVCs), epithelial Madin-Darby canine kidney (MDCK) or human colon carcinoma cells (Caco-2) [71, 72]. The high technical skills to isolate HUEVCs and their rapid senescence, made their use quite expensive and time consuming [72]. MDCK and Caco2 are easy to grow up and retain differentiating properties after repetitive passages [72], however their variable P-gp expression promoted the transfection of MDCK with human MDR1 gene and the treatment of Caco-2 with vinblastine to enhance and standardize the P-gp expression [73]. Hence, both cell lines are currently considered useful predictors of the BBB permeability (Table 4).

The isolation of brain capillaries led to the first primary cerebral endothelial cultures and cell lines. One of the best characterized is the rat brain endothelial cell line (RBE4), which is able to retain many $\mathrm{BBB}$ characteristics like high alkaline phosphatase, gamma-glutamyl transpepetidase activity and P-gp expression [71]. The hCMEC/D3 is another reliable human brain endothelial cell line that was proposed as a model system for drug transport investigations given the expression of tight junction proteins and efflux transporters [71]. Due to the presence of other cell types that play important regulatory roles at the BBB, several 
research groups initiated the co-culture of endothelial cells with glial cells or pericytes or even with neurons to mimic the BBB. To cut down the distance between in vitro and in vivo models even more, a triple co-culture system was opportunely proposed. It is based on the culture of endothelial cells, pericytes and astrocytes (Table 4) [71].

Table 4: Correlation coefficient $\left(\mathrm{r}^{2}\right)$ between in vitro and in vivo BBB models

\begin{tabular}{ccc}
\hline & $\begin{array}{c}\text { In vivo mouse brain } \\
\text { distribution model }\end{array}$ & In vivo rat microdialysis \\
\hline MDCK-MDR1 & 0.78 & 0.85 \\
\hline Caco-2 & 0.60 & 0.91 \\
\hline VB-Caco-2 & 0.72 & --- \\
\hline BBMECs & --- & 0.99 \\
\hline Triple culture (BCECs & 0.80 & --- \\
\hline pericytes + astrocytes) & & {$[74]$} \\
\hline Ref & {$[73]$} & \\
\hline
\end{tabular}

Madin-Darby canine kidney (MDCK) transfected with human MDR1 (MDCK-MDR1), human colon carcinoma cells (Caco-2), Vinblastine-treated Caco-2 (VB-Caco-2), bovine brain microvessel endothelial cells (BBMEC) and brain capillary endothelial cells (BCECs)

Mimicking the functional properties of the BBB is critical to succeed the development of novel CNS pharmacotherapies. Hence, in vitro models have to accomplish the following characteristics [73]:

- A low penetrability for paracellular transport of low molecular size tracer.

- A transepithelial electric resistance (TEER) greater or equal to $150-200 \Omega \mathrm{cm}^{2}$.

- The expression and activity of transporters, most importantly that of P-gp

Because in vitro models cannot provide information on drug distribution into the brain once the drug passes the $\mathrm{BBB}$, in vivo $\mathrm{BBB}$ models may predict the clinical fate of drugs more accurately.

\subsubsection{In vivo quantitative models}

The study of the BBB and brain uptake has been expedited by the use of techniques that quantify the influx and efflux of various molecules across the BBB in the living animal. The most common techniques used in the latest studies are described herein. 


\subsection{Intravenous pharmacokinetics and brain distribution studies}

The aim of a pharmacokinetic study is to assess the fraction of the administered dose that is distributed to the brain or is excreted from the body. The intravenous technique remains the reference for brain uptake studies because it represents fully physiological conditions. Additionally, it offers the potentially highest sensitivity, as brain uptake in intravenous experiments can be measured over long periods [75]. In this method, blood (plasma) and brain are sampled at several time points and drug concentrations are measured in both compartments. From these measurements, the area under the concentration-time curve (AUC) can be obtained for blood and brain. Pharmacokinetic models quantify the rate and extent of the distribution by mathematically analyzing these data. Thus, several pharmacokinetic parameters such the peak concentration $\left(\mathrm{C}_{\max }\right)$, time to reach peak concentration $\left(\mathrm{T}_{\max }\right)$, halflife $\left(t_{1 / 2}\right)$ and mean residence time (MRT) can be determined for both, blood and brain. Other organs can be also included in the pharmacokinetic study [76]. It is important to keep in mind that the analytical method to be applied must be validated in order to avoid potential pitfalls.

\subsection{Microdialysis}

The use of microdialysis techniques is gaining popularity in the study of P-gp at the BBB. This technique involves the surgical implantation of a microdialysis probe in the brain of mice or rats. Once the probe is implanted it allows the in vivo measurement of drug transport into specific brain region(s) and monitoring of the time course of drug-drug interactions in freely moving animals. Furthermore, more than one compound can be assessed simultaneously using dual/triple-probe approaches. Sziráki and co-workers used a dual/triple-probe system with simultaneous sampling of blood and brain in mice for testing P-gp modulation by valspodar, a second-generation P-gp modulator using quinidine as P-gp probe substrate [77].

\subsection{External detection}

The non-invasive character of external detection methods make them applicable in humans and allow to measure individually the time course of uptake together with plasma pharmacokinetics. Special resolution of single photon computed tomography (SPECT) is in the centimeter range, whereas positron emission tomography (PET) approaches the 
autoradiographic resolution [75]. Recent efforts were directed to the development of radiotracers to study drug-drug and drug-P-gp interactions at the BBB. The most common radiotracers for P-gp studies are $(\mathrm{R})-\left[{ }^{11} \mathrm{C}\right]$ verapamil and $\left[{ }^{11} \mathrm{C}\right]$ loperamide [78]. However, $\left[{ }^{11} \mathrm{C}\right]$ elacridar and $\left[{ }^{11} \mathrm{C}\right]$ tariquidar are currently available [79].

Each of the previous techniques has its own advantages and disadvantages (Table 5), which should be cautiously considered before starting the experiments. Parameters like expertise, equipments and treatment of the data should be taken into account to ensure the success of the experiment.

\subsubsection{In vivo behavioral models}

Behavioral tests are in general used to reveal the pharmacodynamics of drugs that have the ability to interfere with the brain signaling and induce specific behavioral effects (opioid analgesics) [76]. Early in vivo studies characterized behavioral abnormalities when mice received morphine, an opiate that does enter the CNS. Mice displayed a typical crouched appearance and the Straub reaction, which is characterized by the rigidity and erection in an S-shaped curve of the tail across the back of the animal [80]. In addition animals exhibited a compulsive circling behavior interspersed with periods of immobility [81]. This opiateinduced behavior pattern was used to evaluate the brain uptake of loperamide, a $\mu$-opioid agonist without central effects that could become a drug that produces substantial antinociception in P-gp-deficient animals or after P-gp inhibition in wild-type animals [82, 83].

Behavioral tests of nociception are also widely used to assess the brain uptake of opioids. The term nociceptive refers to the potential of a stimulus to produce a tissue lesion and a reaction (response) from the organism. Among the short-duration stimuli, three basic tests have been developed based on thermal stimuli: The tail-flick test, the paw withdrawal test and the hot plate test. The tests based on long-duration stimuli involve the use of irritant chemical agents as the nociceptive stimulus. The administration of the irritant undergoes intradermal (Formalin test) or intraperitoneal (Writhing test) injections [84]. These tests are convenient because they apply to healthy wild-type mice or rats, requiring no disease induction or transgenic animals. More exhaustive literature and protocols about these methods and some other models of nociception have been properly described by Le Bars et al. [84]. 
Table 5: Comparison between in vitro and in vivo BBB models

\begin{tabular}{|c|c|c|c|}
\hline & & Advantages & Disadvantages \\
\hline \multirow{12}{*}{$\begin{array}{c}\text { In } \\
\text { vitro }\end{array}$} & & \multirow{2}{*}{ Molecular mechanisms } & \multirow{5}{*}{$\begin{array}{l}\text { No brain imaging } \\
\text { No histology } \\
\text { No drug distribution } \\
\text { No drug efficacy and safety } \\
\text { No clinical outcome }\end{array}$} \\
\hline & & & \\
\hline & & \multirow{3}{*}{$\begin{array}{l}\text { Cell isolation } \\
\text { Cell manipulation } \\
\text { Drug permeability }\end{array}$} & \\
\hline & & & \\
\hline & & & \\
\hline & \multirow{3}{*}{$\begin{array}{l}\text { Cells of non-cerebral } \\
\text { origin }\end{array}$} & Not laborious & \multirow{3}{*}{$\begin{array}{l}\text { Differences in tight junction } \\
\text { proteins and transporters compared } \\
\text { to the } \mathrm{BBB}\end{array}$} \\
\hline & & Differentiating properties even after & \\
\hline & & repetitive passages & \\
\hline & $\begin{array}{l}\text { Cerebral endothelial } \\
\text { cells }\end{array}$ & $\begin{array}{l}\text { Expression of tight junction proteins, } \\
\text { transporters and drug-metabolizing } \\
\text { enzymes }\end{array}$ & $\begin{array}{l}\text { Lack of interactions between the } \\
\text { CNS cells }\end{array}$ \\
\hline & \multirow{3}{*}{ Co-culture systems } & \multirow{3}{*}{$\begin{array}{l}\text { Most approximate representation of the } \\
\text { BBB }\end{array}$} & Laborious \\
\hline & & & Variable permeability for repeated \\
\hline & & & tests \\
\hline \multirow{21}{*}{$\begin{array}{c}\text { In } \\
\text { vivo }\end{array}$} & & \multicolumn{2}{|l|}{ Brain imaging } \\
\hline & & \multicolumn{2}{|l|}{ Histology } \\
\hline & & Molecular mechanisms & Laborious cell isolation \\
\hline & & Drug distribution & Limited cell manipulation \\
\hline & & Drug efficacy and safety & Limited drug permeability \\
\hline & & \multicolumn{2}{|l|}{ Physiological conditions } \\
\hline & & \multicolumn{2}{|l|}{ Clinical outcome } \\
\hline & IV pharmacokinetic & Highest sensitivity & Laborious and good analytical tools \\
\hline & and brain distribution & Low technical difficulty & Careful pharmacokinetic analysis \\
\hline & \multirow{3}{*}{ Microdyalisis } & \multirow{3}{*}{$\begin{array}{l}\text { Time-course measurements } \\
\text { Samples well suited for analytical } \\
\text { procedures }\end{array}$} & \multirow{3}{*}{$\begin{array}{l}\text { Probe calibration } \\
\text { Possible damage of the } \mathrm{BBB}\end{array}$} \\
\hline & & & \\
\hline & & & \\
\hline & \multirow{5}{*}{ External detection } & \multirow{5}{*}{$\begin{array}{l}\text { Non-invasive } \\
\text { Applicable in humans } \\
\text { Time-course measurements }\end{array}$} & Expensive equipment and tracers \\
\hline & & & Poor spatial resolution for small \\
\hline & & & animals (SPECT) \\
\hline & & & Availability of labeled tracers \\
\hline & & & $(\mathrm{PET})$ \\
\hline & \multirow{4}{*}{ Behavioral observation } & \multirow{4}{*}{ Rapidity and not laborious } & No quantitative information of the \\
\hline & & & drug uptake \\
\hline & & & Response may be influenced by the \\
\hline & & & animal handling \\
\hline
\end{tabular}


The extent to which a drug in the bloodstream gains access to the CNS needs to be determined to improve existing CNS pharmacotherapies as well as to study drug candidates with primary targets in the CNS. This concern pushed researches to develop various in vitro BBB models. Despite all the progress, there is no an in vitro $\mathrm{BBB}$ model able to replace the in vivo human BBB. Hence, the different available models and methods (Table 5) should complement each other and should be chosen depending on whether we want to obtain (uptake values, visualize the uptake mechanism or test the drug effects). 


\section{References}

[1] I. Cascorbi, Role of pharmacogenetics of ATP-binding cassette transporters in the pharmacokinetics of drugs, Pharmacol Ther, 112 (2006) 457-473.

[2] R. Kerb, Implications of genetic polymorphisms in drug transporters for pharmacotherapy, Cancer Lett, 234 (2006) 4-33.

[3] W. Loscher, H. Potschka, Role of drug efflux transporters in the brain for drug disposition and treatment of brain diseases, Prog Neurobiol, 76 (2005) 22-76.

[4] W.E. Kaminski, A. Piehler, J.J. Wenzel, ABC A-subfamily transporters: structure, function and disease, Biochim Biophys Acta, 1762 (2006) 510-524.

[5] C.F. Higgins, ABC transporters: physiology, structure and mechanism--an overview, Res Microbiol, 152 (2001) 205-210.

[6] D.C. Rees, E. Johnson, O. Lewinson, ABC transporters: the power to change, Nat Rev Mol Cell Biol, 10 (2009) 218-227.

[7] T.W. Loo, D.M. Clarke, Mutational analysis of ABC proteins, Arch Biochem Biophys, 476 (2008) 51-64.

[8] K.M. Giacomini, S.M. Huang, D.J. Tweedie, L.Z. Benet, K.L. Brouwer, X. Chu, A. Dahlin, R. Evers, V. Fischer, K.M. Hillgren, K.A. Hoffmaster, T. Ishikawa, D. Keppler, R.B. Kim, C.A. Lee, M. Niemi, J.W. Polli, Y. Sugiyama, P.W. Swaan, J.A. Ware, S.H. Wright, S.W. Yee, M.J. Zamek-Gliszczynski, L. Zhang, Membrane transporters in drug development, Nat Rev Drug Discov, 9 215-236.

[9] G. Szakacs, A. Varadi, C. Ozvegy-Laczka, B. Sarkadi, The role of ABC transporters in drug absorption, distribution, metabolism, excretion and toxicity (ADME-Tox), Drug Discov Today, 13 (2008) 379-393.

[10] R.L. Juliano, V. Ling, A surface glycoprotein modulating drug permeability in Chinese hamster ovary cell mutants, Biochim Biophys Acta, 455 (1976) 152-162.

[11] S.V. Ambudkar, S. Dey, C.A. Hrycyna, M. Ramachandra, I. Pastan, M.M. Gottesman, Biochemical, cellular, and pharmacological aspects of the multidrug transporter, Annu Rev Pharmacol Toxicol, 39 (1999) 361-398.

[12] A.J. Smith, A. van Helvoort, G. van Meer, K. Szabo, E. Welker, G. Szakacs, A. Varadi, B. Sarkadi, P. Borst, MDR3 P-glycoprotein, a phosphatidylcholine translocase, transports several cytotoxic drugs and directly interacts with drugs as judged by interference with nucleotide trapping, J Biol Chem, 275 (2000) 23530-23539.

[13] S. Ruetz, P. Gros, Phosphatidylcholine translocase: a physiological role for the mdr2 gene, Cell, 77 (1994) 1071-1081.

[14] J. Schricks, J. Fink-Gremmels, Characterization of porcine MDR1 and validation of a lymphocyte model for functional studies., Doctoral thesis Utrecht University Chapter 7, (2006). 
[15] M. Hennessy, J.P. Spiers, A primer on the mechanics of P-glycoprotein the multidrug transporter, Pharmacol Res, 55 (2007) 1-15.

[16] T.W. Loo, D.M. Clarke, Determining the dimensions of the drug-binding domain of human P-glycoprotein using thiol cross-linking compounds as molecular rulers, J Biol Chem, 276 (2001) 36877-36880.

[17] S.G. Aller, J. Yu, A. Ward, Y. Weng, S. Chittaboina, R. Zhuo, P.M. Harrell, Y.T. Trinh, Q. Zhang, I.L. Urbatsch, G. Chang, Structure of P-glycoprotein reveals a molecular basis for poly-specific drug binding, Science, 323 (2009) 1718-1722.

[18] C. Martin, G. Berridge, C.F. Higgins, P. Mistry, P. Charlton, R. Callaghan, Communication between multiple drug binding sites on P-glycoprotein, Mol Pharmacol, 58 (2000) 624-632.

[19] R.B. Wang, C.L. Kuo, L.L. Lien, E.J. Lien, Structure-activity relationship: analyses of pglycoprotein substrates and inhibitors, J Clin Pharm Ther, 28 (2003) 203-228.

[20] F.J. Sharom, X. Yu, C.A. Doige, Functional reconstitution of drug transport and ATPase activity in proteoliposomes containing partially purified P-glycoprotein, J Biol Chem, 268 (1993) 24197-24202.

[21] C.F. Higgins, K.J. Linton, The ATP switch model for ABC transporters, Nat Struct Mol Biol, 11 (2004) 918-926.

[22] K.J. Linton, C.F. Higgins, Structure and function of ABC transporters: the ATP switch provides flexible control, Pflugers Arch, 453 (2007) 555-567.

[23] M.K. Al-Shawi, M.K. Polar, H. Omote, R.A. Figler, Transition state analysis of the coupling of drug transport to ATP hydrolysis by P-glycoprotein, J Biol Chem, 278 (2003) 52629-52640.

[24] H. Omote, R.A. Figler, M.K. Polar, M.K. Al-Shawi, Improved energy coupling of human P-glycoprotein by the glycine 185 to valine mutation, Biochemistry, 43 (2004) 3917-3928.

[25] S.V. Ambudkar, I.W. Kim, Z.E. Sauna, The power of the pump: mechanisms of action of P-glycoprotein (ABCB1), Eur J Pharm Sci, 27 (2006) 392-400.

[26] S.V. Ambudkar, C. Kimchi-Sarfaty, Z.E. Sauna, M.M. Gottesman, P-glycoprotein: from genomics to mechanism, Oncogene, 22 (2003) 7468-7485.

[27] L. Homolya, Z. Hollo, U.A. Germann, I. Pastan, M.M. Gottesman, B. Sarkadi, Fluorescent cellular indicators are extruded by the multidrug resistance protein, J Biol Chem, 268 (1993) 21493-21496.

[28] Y. Raviv, H.B. Pollard, E.P. Bruggemann, I. Pastan, M.M. Gottesman, Photosensitized labeling of a functional multidrug transporter in living drug-resistant tumor cells, J Biol Chem, 265 (1990) 3975-3980.

[29] C.F. Higgins, M.M. Gottesman, Is the multidrug transporter a flippase?, Trends Biochem Sci, 17 (1992) 18-21. 
[30] Y. Romsicki, F.J. Sharom, Phospholipid flippase activity of the reconstituted Pglycoprotein multidrug transporter, Biochemistry, 40 (2001) 6937-6947.

[31] F.E. O'Brien, T.G. Dinan, B.T. Griffin, J.F. Cryan, Interactions between antidepressants and P-glycoprotein at the blood-brain barrier: clinical significance of in vitro and in vivo findings, Br J Pharmacol, 165 (2011) 289-312.

[32] C. Martin, G. Berridge, P. Mistry, C. Higgins, P. Charlton, R. Callaghan, Drug binding sites on P-glycoprotein are altered by ATP binding prior to nucleotide hydrolysis, Biochemistry, 39 (2000) 11901-11906.

[33] R. Didziapetris, P. Japertas, A. Avdeef, A. Petrauskas, Classification analysis of Pglycoprotein substrate specificity, J Drug Target, 11 (2003) 391-406.

[34] J. Huang, G. Ma, I. Muhammad, Y. Cheng, Identifying P-glycoprotein substrates using a support vector machine optimized by a particle swarm, J Chem Inf Model, 47 (2007) 16381647.

[35] J.P. Gillet, M.M. Gottesman, Mechanisms of multidrug resistance in cancer, Methods Mol Biol, 596 47-76.

[36] M.M. Gottesman, T. Fojo, S.E. Bates, Multidrug resistance in cancer: role of ATPdependent transporters, Nat Rev Cancer, 2 (2002) 48-58.

[37] T. Tsuruo, H. Iida, S. Tsukagoshi, Y. Sakurai, Overcoming of vincristine resistance in P388 leukemia in vivo and in vitro through enhanced cytotoxicity of vincristine and vinblastine by verapamil, Cancer Res, 41 (1981) 1967-1972.

[38] N. Kartner, J.R. Riordan, V. Ling, Cell surface P-glycoprotein associated with multidrug resistance in mammalian cell lines, Science, 221 (1983) 1285-1288.

[39] K. Dano, Active outward transport of daunomycin in resistant Ehrlich ascites tumor cells, Biochim Biophys Acta, 323 (1973) 466-483.

[40] I.B. Roninson, J.E. Chin, K.G. Choi, P. Gros, D.E. Housman, A. Fojo, D.W. Shen, M.M. Gottesman, I. Pastan, Isolation of human mdr DNA sequences amplified in multidrugresistant KB carcinoma cells, Proc Natl Acad Sci U S A, 83 (1986) 4538-4542.

[41] A.T. Fojo, D.W. Shen, L.A. Mickley, I. Pastan, M.M. Gottesman, Intrinsic drug resistance in human kidney cancer is associated with expression of a human multidrugresistance gene, J Clin Oncol, 5 (1987) 1922-1927.

[42] H. Galski, M. Sullivan, M.C. Willingham, K.V. Chin, M.M. Gottesman, I. Pastan, G.T. Merlino, Expression of a human multidrug resistance cDNA (MDR1) in the bone marrow of transgenic mice: resistance to daunomycin-induced leukopenia, Mol Cell Biol, 9 (1989) 43574363.

[43] R.J. Arceci, F. Baas, R. Raponi, S.B. Horwitz, D. Housman, J.M. Croop, Multidrug resistance gene expression is controlled by steroid hormones in the secretory epithelium of the uterus, Mol Reprod Dev, 25 (1990) 101-109. 
[44] P.M. Chaudhary, I.B. Roninson, Induction of multidrug resistance in human cells by transient exposure to different chemotherapeutic drugs, J Natl Cancer Inst, 85 (1993) 632-639.

[45] A. Sparreboom, J. van Asperen, U. Mayer, A.H. Schinkel, J.W. Smit, D.K. Meijer, P. Borst, W.J. Nooijen, J.H. Beijnen, O. van Tellingen, Limited oral bioavailability and active epithelial excretion of paclitaxel (Taxol) caused by P-glycoprotein in the intestine, Proc Natl Acad Sci U S A, 94 (1997) 2031-2035.

[46] A.F. List, K.J. Kopecky, C.L. Willman, D.R. Head, D.L. Persons, M.L. Slovak, R. Dorr, C. Karanes, H.E. Hynes, J.H. Doroshow, M. Shurafa, F.R. Appelbaum, Benefit of cyclosporine modulation of drug resistance in patients with poor-risk acute myeloid leukemia: a Southwest Oncology Group study, Blood, 98 (2001) 3212-3220.

[47] G. Szakacs, J.P. Annereau, S. Lababidi, U. Shankavaram, A. Arciello, K.J. Bussey, W. Reinhold, Y. Guo, G.D. Kruh, M. Reimers, J.N. Weinstein, M.M. Gottesman, Predicting drug sensitivity and resistance: profiling $\mathrm{ABC}$ transporter genes in cancer cells, Cancer Cell, 6 (2004) 129-137.

[48] B.L. Neudeck, J.M. Loeb, N.G. Faith, C.J. Czuprynski, Intestinal P glycoprotein acts as a natural defense mechanism against Listeria monocytogenes, Infect Immun, 72 (2004) 38493854.

[49] G.T. Ho, F.M. Moodie, J. Satsangi, Multidrug resistance 1 gene (P-glycoprotein 170): an important determinant in gastrointestinal disease?, Gut, 52 (2003) 759-766.

[50] F. Thiebaut, T. Tsuruo, H. Hamada, M.M. Gottesman, I. Pastan, M.C. Willingham, Cellular localization of the multidrug-resistance gene product P-glycoprotein in normal human tissues, Proc Natl Acad Sci U S A, 84 (1987) 7735-7738.

[51] J.E. Ros, L. Libbrecht, M. Geuken, P.L. Jansen, T.A. Roskams, High expression of MDR1, MRP1, and MRP3 in the hepatic progenitor cell compartment and hepatocytes in severe human liver disease, J Pathol, 200 (2003) 553-560.

[52] A.H. Schinkel, J.W. Jonker, Mammalian drug efflux transporters of the ATP binding cassette (ABC) family: an overview, Adv Drug Deliv Rev, 55 (2003) 3-29.

[53] L. Campbell, A.N. Abulrob, L.E. Kandalaft, S. Plummer, A.J. Hollins, A. Gibbs, M. Gumbleton, Constitutive expression of p-glycoprotein in normal lung alveolar epithelium and functionality in primary alveolar epithelial cultures, J Pharmacol Exp Ther, 304 (2003) 441452.

[54] O. van Tellingen, T. Buckle, J.W. Jonker, M.A. van der Valk, J.H. Beijnen, Pglycoprotein and Mrp1 collectively protect the bone marrow from vincristine-induced toxicity in vivo, Br J Cancer, 89 (2003) 1776-1782.

[55] P. Kannan, C. John, S.S. Zoghbi, C. Halldin, M.M. Gottesman, R.B. Innis, M.D. Hall, Imaging the function of P-glycoprotein with radiotracers: pharmacokinetics and in vivo applications, Clin Pharmacol Ther, 86 (2009) 368-377.

[56] A.H. Schinkel, P-Glycoprotein, a gatekeeper in the blood-brain barrier, Adv Drug Deliv Rev, 36 (1999) 179-194. 
[57] D.J. Begley, M.W. Brightman, Structural and functional aspects of the blood-brain barrier, Prog Drug Res, 61 (2003) 39-78.

[58] G. Lee, S. Dallas, M. Hong, R. Bendayan, Drug transporters in the central nervous system: brain barriers and brain parenchyma considerations, Pharmacol Rev, 53 (2001) 569596.

[59] P.L. Golden, G.M. Pollack, Blood-brain barrier efflux transport, J Pharm Sci, 92 (2003) 1739-1753.

[60] D.S. Miller, B. Bauer, A.M. Hartz, Modulation of P-glycoprotein at the blood-brain barrier: opportunities to improve central nervous system pharmacotherapy, Pharmacol Rev, 60 (2008) 196-209.

[61] C. Cordon-Cardo, J.P. O'Brien, D. Casals, L. Rittman-Grauer, J.L. Biedler, M.R. Melamed, J.R. Bertino, Multidrug-resistance gene (P-glycoprotein) is expressed by endothelial cells at blood-brain barrier sites, Proc Natl Acad Sci U S A, 86 (1989) 695-698.

[62] F. Thiebaut, T. Tsuruo, H. Hamada, M.M. Gottesman, I. Pastan, M.C. Willingham, Immunohistochemical localization in normal tissues of different epitopes in the multidrug transport protein P170: evidence for localization in brain capillaries and crossreactivity of one antibody with a muscle protein, J Histochem Cytochem, 37 (1989) 159-164.

[63] S. Seetharaman, M.A. Barrand, L. Maskell, R.J. Scheper, Multidrug resistance-related transport proteins in isolated human brain microvessels and in cells cultured from these isolates, J Neurochem, 70 (1998) 1151-1159.

[64] H.A. Volk, K. Burkhardt, H. Potschka, J. Chen, A. Becker, W. Loscher, Neuronal expression of the drug efflux transporter P-glycoprotein in the rat hippocampus after limbic seizures, Neuroscience, 123 (2004) 751-759.

[65] S. Spiegl-Kreinecker, J. Buchroithner, L. Elbling, E. Steiner, G. Wurm, A. Bodenteich, J. Fischer, M. Micksche, W. Berger, Expression and functional activity of the ABC-transporter proteins P-glycoprotein and multidrug-resistance protein 1 in human brain tumor cells and astrocytes, J Neurooncol, 57 (2002) 27-36.

[66] V.V. Rao, J.L. Dahlheimer, M.E. Bardgett, A.Z. Snyder, R.A. Finch, A.C. Sartorelli, D. Piwnica-Worms, Choroid plexus epithelial expression of MDR1 P glycoprotein and multidrug resistance-associated protein contribute to the blood-cerebrospinal-fluid drug-permeability barrier, Proc Natl Acad Sci U S A, 96 (1999) 3900-3905.

[67] M. Strazza, V. Pirrone, B. Wigdahl, M.R. Nonnemacher, Breaking down the barrier: the effects of HIV-1 on the blood-brain barrier, Brain Res, 1399 96-115.

[68] C.H. Storch, D. Theile, H. Lindenmaier, W.E. Haefeli, J. Weiss, Comparison of the inhibitory activity of anti-HIV drugs on P-glycoprotein, Biochem Pharmacol, 73 (2007) 15731581 .

[69] A.H. Schinkel, J.J. Smit, O. van Tellingen, J.H. Beijnen, E. Wagenaar, L. van Deemter, C.A. Mol, M.A. van der Valk, E.C. Robanus-Maandag, H.P. te Riele, et al., Disruption of the mouse mdr1a P-glycoprotein gene leads to a deficiency in the blood-brain barrier and to increased sensitivity to drugs, Cell, 77 (1994) 491-502. 
[70] A.H. Schinkel, E. Wagenaar, C.A. Mol, L. van Deemter, P-glycoprotein in the bloodbrain barrier of mice influences the brain penetration and pharmacological activity of many drugs, J Clin Invest, 97 (1996) 2517-2524.

[71] I. Wilhelm, C. Fazakas, I.A. Krizbai, In vitro models of the blood-brain barrier, Acta Neurobiol Exp (Wars), 71 (2011) 113-128.

[72] P. Naik, L. Cucullo, In vitro blood-brain barrier models: current and perspective technologies, J Pharm Sci, 101 (2012) 1337-1354.

[73] E. Hellinger, S. Veszelka, A.E. Toth, F. Walter, A. Kittel, M.L. Bakk, K. Tihanyi, V. Hada, S. Nakagawa, T.D. Duy, M. Niwa, M.A. Deli, M. Vastag, Comparison of brain capillary endothelial cell-based and epithelial (MDCK-MDR1, Caco-2, and VB-Caco-2) cellbased surrogate blood-brain barrier penetration models, Eur J Pharm Biopharm, 82 (2012) $340-351$.

[74] J.J. Hakkarainen, A.J. Jalkanen, T.M. Kaariainen, P. Keski-Rahkonen, T. Venalainen, J. Hokkanen, J. Monkkonen, M. Suhonen, M.M. Forsberg, Comparison of in vitro cell models in predicting in vivo brain entry of drugs, Int J Pharm, 402 (2010) 27-36.

[75] U. Bickel, How to measure drug transport across the blood-brain barrier, NeuroRx, 2 (2005) 15-26.

[76] S.C.-T. Inge van Rooy, Wim E. Hennink, Gert Storm, Raymond M. Schiffelers, and Enrico Mastrobattista, In Vivo Methods to Study Uptake of Nanoparticles into the Brain, Pharm Res, 28 (2011) 456-471.

[77] I. Sziraki, F. Erdo, P. Trampus, M. Sike, P.M. Molnar, Z. Rajnai, J. Molnar, I. Wilhelm, C. Fazakas, E. Kis, I. Krizbai, P. Krajcsi, The use of microdialysis techniques in mice to study P-gp function at the blood-brain barrier, J Biomol Screen, 18 430-440.

[78] S.S. Zoghbi, J.S. Liow, F. Yasuno, J. Hong, E. Tuan, N. Lazarova, R.L. Gladding, V.W. Pike, R.B. Innis, 11C-loperamide and its $\mathrm{N}$-desmethyl radiometabolite are avid substrates for brain permeability-glycoprotein efflux, J Nucl Med, 49 (2008) 649-656.

[79] T. Wanek, C. Kuntner, J.P. Bankstahl, M. Bankstahl, J. Stanek, M. Sauberer, S. Mairinger, S. Strommer, V. Wacheck, W. Loscher, T. Erker, M. Muller, O. Langer, A comparative small-animal PET evaluation of [11C]tariquidar, [11C]elacridar and (R)[11C]verapamil for detection of P-glycoprotein-expressing murine breast cancer, Eur J Nucl Med Mol Imaging, 39 149-159.

[80] D.L. Bilbey, H. Salem, M.H. Grossman, The anatomical basis of the straub phenomenon, Br J Pharmacol Chemother, 15 (1960) 540-543.

[81] C.J. Niemegeers, F.M. Lenaerts, P.A. Janssen, Loperamide (R 18 553), a novel type of antidiarrheal agent. Part 2: in vivo parenteral pharmacology and acute toxicity in mice. Comparison with morphine, codeine and diphenoxylate, Arzneimittelforschung, 24 (1974) 1636-1641.

[82] J.C. Kalvass, C.L. Graff, G.M. Pollack, Use of loperamide as a phenotypic probe of mdr1a status in CF-1 mice, Pharm Res, 21 (2004) 1867-1870. 
[83] M.J. Zamek-Gliszczynski, D.W. Bedwell, J.Q. Bao, J.W. Higgins, Characterization of SAGE Mdrla (P-gp), Bcrp, and Mrp2 knockout rats using loperamide, paclitaxel, sulfasalazine, and carboxydichlorofluorescein pharmacokinetics, Drug Metab Dispos, 40 (2012) 1825-1833.

[84] D. Le Bars, M. Gozariu, S.W. Cadden, Animal models of nociception, Pharmacol Rev, 53 (2001) 597-652. 


\title{
2 DELIVERY OF P-GLYCOPROTEIN SUBSTRATES USING \\ CHEMOSENSITIZERS AND NANOTECHNOLOGY FOR SELECTIVE AND EFFICIENT THERAPEUTIC OUTCOMES
}

\begin{abstract}
As a result of its broad substrate specificity and critical localization in excretory and barrier function tissues, P-glycoprotein (P-gp) plays major roles in the pharmacokinetics, safety and efficacy profiles of numerous drugs. P-gp is often responsible for the failure of many chemical treatments against cancer, immunosuppressive, infectious and neurodegenerative diseases. Among the therapeutic approaches to circumvent P-gp function, advances in the design of new chemical P-gp modulators to interact specifically with P-gp have yielded few clinical successful reports. Members of a class of components that were initially developed as surface active agents showed promising results with regard to the modulation of $\mathrm{P}$-gp. These components include surfactants and amphiphilic co-polymers. Alternatively, colloidal systems were developed to facilitate drug uptake in resistant cells. This approach is based on the encapsulation of drugs, which masks them from the biological environment and prevents their transport by P-gp using the surfactants released from the nanocarrier. Likewise, a novel and synergistic strategy is currently being explored and involves nanocarrier-mediated transport and controlled release of both P-gp substrates and P-gp modulators. In this review, we discuss recent results obtained by direct modulation with chemosensitizers and the available nanotechnology to modulate P-gp function. In this manuscript, we also discuss unexplored pathways for future therapies.
\end{abstract}

Keywords: P-glycoprotein, drug efflux, P-gp modulators, nanocarriers, drug delivery strategies

\section{This chapter was published in:}

R. Nieto Montesinos, A. Beduneau, Y. Pellequer, A. Lamprecht, Delivery of Pglycoprotein substrates using chemosensitizers and nanotechnology for selective and efficient therapeutic outcomes, J Control Release, 161 (2012) 50-61. 


\subsection{Introduction}

Over the last several years, a large body of literature has confirmed that drug efflux transporters play prominent roles in the pharmacological behavior of most clinically used drugs, thereby affecting drug absorption, disposition and elimination. Often this efflux of therapeutic compounds is mediated by the family of ATP-binding cassette (ABC) transporters. Among the ABC transporters, P-glycoprotein (P-gp), multidrug resistanceassociated proteins (MRPs) and breast cancer resistance protein (BCRP) play significant roles in restricting the permeability of several pharmacological agents, including anti-cancer and anti-HIV agents [1,2].

Because P-gp was the first member of the ABC transporter family to be described [3], it is currently the most recognized efflux protein. Two factors make P-gp the most critical efflux transporter: (1) its broad substrate specificity eliciting multidrug resistance (MDR) [4] and (2) the prominent presence of P-gp in most excretory and barrier function tissues [2]. As a result of these aspects, P-gp is a major obstacle for the treatment of cancer and several brain disorders, as well as immunosuppressive and infectious diseases.

Screening studies to identify P-gp substrates indicated that some of the substrates also have the ability to block P-gp efflux, which led to a new strategy to identify successful therapeutic treatments. Unfortunately, the association of these compounds, known as first- and secondgeneration P-gp modulators, with cytotoxic drugs failed in clinical trials due to toxic profiles. These limitations prompted the development of third-generation P-gp modulators that specifically and potently inhibit P-gp function without interfering with other ABC transporters [5].

In addition, members of a diverse group of structurally and functionally excipients, such as surfactants and amphiphilic polymers, which are used for the preparation of drug delivery systems (DDSs), have clearly demonstrated their abilities to modulate the P-gp-mediated efflux mechanisms [6, 7]. DDSs, also known as nanocarriers, range in size from 1 to $200 \mathrm{~nm}$, thus allowing parenteral administration. Their major advantages reside in their ability to mask drugs from the host environment, especially the reticuloendothelial system and in the recognition of target tissues by passive or active pathways. A few promising DDSs, such as doxorubicin-loaded pluronic ${ }^{\circledR}$ micelles (SP1049C), were tested in clinical trials. This micellar nanocarrier has shown promising results in terms of efficiency and safety in a phase II clinical trial in patients with advanced adenocarcinoma of the esophagus and gastroesophageal junction [8]. 
To ensure selective delivery of P-gp substrates and P-gp modulators, a relevant strategy would be to utilize nanocarriers to target both compound types to cells affected by the disease and thereby improving the therapeutic effectiveness and safety profile.

The present review is focused on the emerging strategies to modulate P-gp function. The main results and obstacles obtained by direct modulation of chemosensitizers will be described. We will also outline the characteristics of pharmaceutical excipients, with a focus on the most sophisticated DDSs. Modulation of P-gp is becoming a high imperative for the research medical community and the pharmaceutical industry. Thus, this manuscript will highlight a novel and synergistic strategy that engages the association of chemosensitizers and DDSs to provide unexplored pathways for selective and efficient therapeutic outcomes.

\subsection{Role of P-glycoprotein in efflux mechanisms}

The discovery of efflux transporters has helped to explain why the minimal effective concentrations of certain drugs are not attained and why chemotherapy and the treatment of several brain disorders, immunosuppressive and infectious diseases fail. This mechanism is mediated by a large list of efflux transporters, most of which belong to the $\mathrm{ABC}$ transporter family $[2,9]$.

ABC transporters are transmembrane proteins that use ATP hydrolysis to drive the efflux of endogenous substrates and also xenobiotics. Some members of this family show specificity for one substrate, whereas others can transport a broad variety of structurally unrelated hydrophobic compounds. Previous studies identified 49 human ABC proteins that can be grouped into 7 subclasses or families (ABCA to ABCG) based on the organization of their domains and their amino acid homology [10-12]. 35 years after its discovery, P-gp is still the most-relevant member and serves as a model for the study of all ABC transport proteins (Fig. $1)$.

In humans, $\mathrm{P}-\mathrm{gp}$ is a $170-\mathrm{kDa}$ polypeptide encoded by two multidrug resistance genes, MDR 1 and MDR 2 (also called MDR 3). MDR 1 is associated with a multidrug resistance phenotype, while the MDR 2 isoform inefficiently mediates the efflux of MDR 1 substrates; however, MDR 2 also functions as a phosphatidylcholine translocase [3, 13-15].

Little is known about the complex mechanism by which P-gp recognizes an unlimited number of molecules that differ in chemical structure and pharmacological action. However, it is clear 
that today we dispose of several documents where the P-gp structure and its mechanism of translocation have been properly described [16-18].

The overexpression of P-gp on resistant malignant cells was first recognized in 1976 and is considered to be a major cause of MDR, a phenomenon by which tumor cells simultaneously exhibit intrinsic (inherent) or acquired cross-resistance to diverse anti-cancer drugs, thereby causing cancer treatment failure [16, 19, 20]. Treatment with high doses or combination treatments with anti-cancer drugs (chemotherapy) are not sufficient to inhibit the function of P-gp; furthermore, these treatments are often associated with toxic side effects in patients because most anti-cancer drugs do not have specificity towards cancer cells.

In addition to the expression of P-gp in human tissues with excretory function, such as liver and kidney, P-gp is highly expressed on the apical surfaces of the superficial columnar epithelial cells of the ileum and the colon, which results in limited oral drug bioavailability. The expression levels of P-gp is lower in the jejunum, duodenum and stomach [21].

Moreover, P-gp is highly expressed at the blood-tissue barriers, such as the blood-brain barrier (BBB), the blood-testis barrier and the placenta, suggesting that it has a generalized barrier function $[2,18]$. The expression of P-gp on the endothelial cells at the human BBB was first described in 1989 by Cordon-Cardo et al. and Theibaut et al. [22, 23]. Since these studies have been published, P-gp has been found to be localized at the luminal membrane of the endothelial cells lining the capillaries of the brain $[24,25]$ and in primary brain tumors $[26,27]$ and astrocytes $[27,28]$. Other studies have demonstrated the presence of P-gp at the apical surfaces of the epithelial cells that constitute the ventricular exposed surface of the human choroid plexus [29]. Consequently, the relevant distribution of P-gp at the BBB offers a mechanism of detoxification to remove harmful endogenous and exogenous compounds from the brain. Thus, the penetration of therapeutic compounds into the brain tissue is equally decreased [2], leading to the failure of various clinical treatments for brain diseases, such as epilepsy [2, 30] and depression [31, 32]. Additionally, it is known that Alzheimer's, Parkinson's and Huntington's diseases are related to the expression and function of P-gp at the BBB $[2,33]$. The replication of the human immunodeficiency virus (HIV) in its primary stages takes place in the central nervous system (CNS), which causes neurological complications in HIV patients [34]. Unfortunately, many of the anti-HIV drugs are known Pgp substrates, inhibitors, or inducers, which results in toxicity or drug resistance and the subsequent failure of the treatment $[35,36]$. 


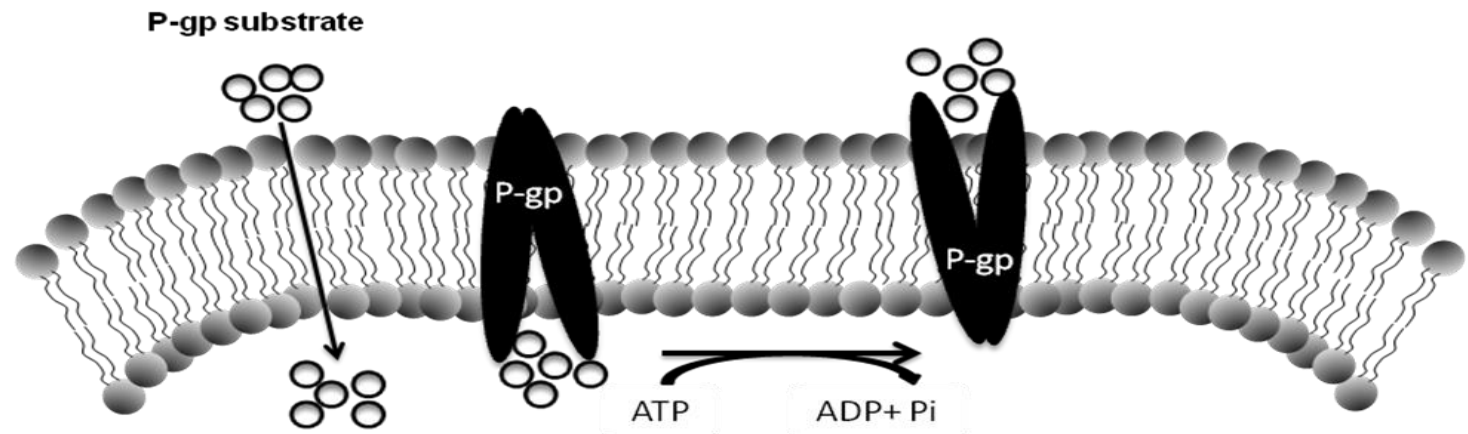

Figure 1. Structural and functional insights into P-glycoprotein, a transmembrane efflux protein that uses ATP hydrolysis to transport drugs out of the cell.

Because of the meaningful role of P-gp, it has become an important target for the successful treatments of various diseases. Some strategies that have been proposed to modulate P-gp include the use of:

- Chemosensitizers to achieve direct modulation of the efflux activity of P-gp.

- Nanocarriers to encapsulate P-gp substrates and therefore overcome the P-gp-mediated efflux system

- Both nanocarriers and chemosensitizers to emphasize P-gp inhibition.

\subsection{Therapeutic approaches using P-gp modulators}

The modulation of P-gp is complex and involves competition at the P-gp substrate-binding sites, as well as the blockage of the ATP hydrolysis necessary for efflux transport function [37]. Over the last two decades, several P-gp modulators have been thoroughly studied to achieve effective inhibition of P-gp with the fewest possible interactions. Early in the 1980s, the calcium channel blocker verapamil was recognized for its ability to module P-gp efflux activity [38]. This property was quickly studied in other pharmacological compounds, from immunosuppressive drugs, such as cyclosporine A [39], to anti-steroidal compounds, such as tamoxifen [40]. Having obtained similar results, these agents were classified as first generation P-gp modulators or chemosensitizers (Table 1). Nevertheless, a few years later, phase I clinical trials showed that these compounds were not specific enough to ensure pharmacological intracellular concentrations of P-gp substrates [41-46]. Because most of these P-gp modulators are also P-gp substrates, the usage of higher doses to compete with cytotoxic drugs resulted in toxic profiles. Additionally, many of these drugs are substrates for 
other efflux proteins and enzymes, which increases the risk of undesirable pharmacokinetic profiles $[4,5]$.

Table 1| P-gp modulators and pharmaceutical excipients with P-gp inhibitory activity

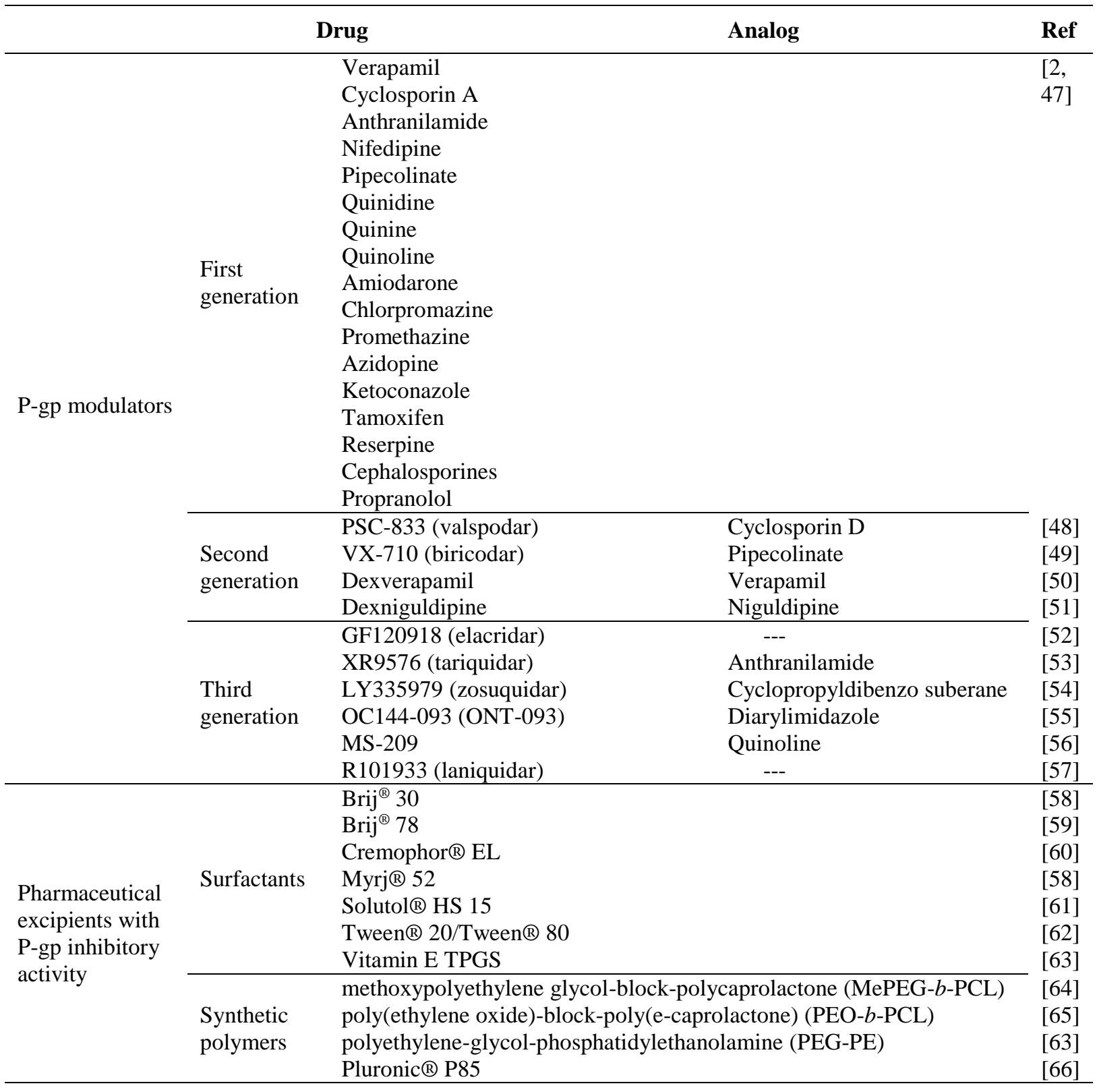

In view of these limitations and based on quantitative structure-activity relationships (SARs) of the first-generation P-gp modulators, a few laboratories have synthesized secondgeneration P-gp modulators [48-50, 67]. Unfortunately, these compounds presented affinity for P-gp and also for cytochrome P450 3A4, thus minimizing the clearance of P-gp substrates, 
such as anti-cancer drugs, until they reached toxic levels. The reduction in P-gp substrate dosages resulted in a reduction in therapeutic efficacy $[68,69]$.

Because of its disappointing level of interaction with P-gp substrates, PSC-833 (valspodar or Amdray $^{\circledR}$ ), a non-immunosuppressive derivative of cyclosporine D and the most-studied second-generation P-gp modulator, was discontinued by Novartis [70]. Later, phase III studies corroborated the hypothesis that valspodar, administered together with vincristine, doxorubicin, dexamethasone, paclitaxel or carboplatin, did not improve treatment outcomes but did increase toxicity $[71,72]$. In spite of these results, Binkhathlan et al. showed in a recent in vivo study that methoxy-poly(ethylene oxide)-block-poly(e-caprolactone) (PEO- $b$ PCL) micelles are a good alternative to improve valspodar solubility and its subsequent intravenous administration. The PEO- $b$-PCL formulation displayed significantly higher plasma area under the curve (AUC) and lower volume of distribution $\left(\mathrm{Vd}_{\mathrm{ss}}\right)$ and clearance (CL) than a formulation similar to the earlier clinical product, Amdray ${ }^{\circledR}$ [65]. The composition of Amdray ${ }^{\circledR}$ included ethanol and Cremophor ${ }^{\circledR}$ EL [65]. This latter excipient could increase pharmacokinetics interactions of valspodar due to its ability to inhibit P-gp by itself [60]. Moreover, Cremophor ${ }^{\circledR}$ EL has also been associated with acute hypersensitivity reactions and neurological toxicity, depending on the dosage used [73]. Hence, the study of Binkhathlan et al. suggests that the association of a DDS and a P-gp modulator could significantly improve the pharmacokinetics of the P-gp modulator and reduce the pharmacokinetic interactions with P-gp substrates and possible toxic profiles caused by Cremophor ${ }^{\circledR}$ EL.

Although no interactions between VX-710 (biricodar) and cytochrome P450 3A4 were reported, clinical studies with this second-generation P-gp modulator were not successful [74, 75].

To avoid the limitations of the first- and second-generation P-gp modulators, third-generation P-gp modulators have been developed using the power of combinational chemistry and SARs. These compounds are non-competitive inhibitors that induce changes in protein conformation, thereby modulating the transport of P-gp substrates [52-56].

GlaxoSmithKline developed GF120918 (elacridar), an acridonecarboxamide derivative, which has high affinity for P-gp [52]. Interestingly, their assays have shown that elacridar mediates the efflux of several P-gp substrates in various in vitro and in vivo models [76-78] and these data led to the assessment of this P-gp modulator in cancer patients. Oral administration of elacridar allowed the appropriate plasma concentrations of doxorubicin and paclitaxel to reverse MDR without the harmful pharmacokinetic interactions [79-81]. Other 
studies, including a phase I trial, reported that elacridar is a modulator of breast cancer resistance protein $(\mathrm{BCRP})[82,83]$.

In agreement with earlier assays [84, 85], recent clinical studies examining XR9576 (tariquidar), an anthranilic acid derivative, demonstrated that it is a well-tolerated and selective P-gp modulator with fewer pharmacokinetic interactions and a high duration of inhibition but without significant systemic side effects [86, 87]. In contrast, intravenous tariquidar in $5 \%$ dextrose failed to produce significant central nervous effects caused by loperamide in humans [88]. The authors justified this finding in a previous in vivo study, in which high doses of tariquidar in propylene glycol, 5\% dextrose and ethanol (4:5:1) were needed to inhibit P-gp function at the BBB [89].

LY335979 (zosuquidar), is another third-generation modulator that, similar to tariquidar, is not a P-gp substrate and according to clinical trials does not significantly affect the pharmacokinetics of true P-gp substrates [90-92]. In addition, zosuquidar achieved P-gp inhibition in patients with acute myeloid leukemia in clinical trials [93, 94]. Unfortunately, in vivo model studies reported that $\mathrm{P}$-gp at the $\mathrm{BBB}$ is only partially inhibited by zosuquidar, in spite of the presence of mannitol (inducer of BBB disruption) in the sterile saline vehicle [95, 96].

Other third-generation P-gp modulators include R101933 (laniquidar) and OC144-093 (ONT093), which in combination with anti-cancer drugs result in good safety profiles [57, 97, 98].

The development of P-gp modulating agents and SAR studies were well described by Colabufo et al. and McDevitt et al [37, 99].

As reviewed above, much remains to be clarified. Phases II and III clinical trials are still ongoing to assess the lack of pharmacokinetic interaction between third-generation P-gp modulators and anti-cancer drugs, as well as the inhibition of P-gp in malignant cancer cells to elicit a better clinical prognosis. Inhibition of P-gp at the BBB requires higher doses of Pgp modulators. However, these doses might approach the maximum tolerated doses in patients, thus limiting the use of these agents. Another relevant factor that strongly influences the bioavailability and therefore the efficacy of third-generation P-gp modulators is their limited solubility in aqueous solutions. As demonstrated in the study of Binkhathlan et al., the association between a P-gp modulator or a P-gp substrate with a DDS could reduce the effective doses and improve the solubility and the consequent release and bioavailability of these agents at the pharmacological sites of action. Moreover, this strategy would utilize the properties of certain colloidal systems to bypass and modulate the P-gp efflux system. 


\subsection{Therapeutic approaches with drug-loaded nanocarriers}

Many studies emphasize the promising potential of nanocarriers to overcome drug efflux mechanisms [7]. These colloidal systems include polymeric micelles [100], nanoparticles (NPs) [101], lipid nanocapsules (LNCs) [102], liposomes [103] and microemulsions [104]. These DDSs have many advantages. First, they promote the partial solubilization of hydrophobic drugs. Second, the presence of high molecular weight hydrophilic polymers, including polyethylene glycol (PEG) or dextran, on the surface confers stealth properties by drastically reducing mononuclear phagocyte system uptake. This prolongs the vascular residence time of the encapsulated drug [105]. Third, various DDSs have clearly demonstrated their ability to modulate the P-gp efflux pump. The $\mathrm{IC}_{50}$ of doxorubicin-loaded lipid NPs was 8-fold lower in a P-gp-overexpressing human melanoma cell line compared with free doxorubicin [59]. In contrast, the nanocarriers had no effects on the sensitive cells, demonstrating a selective interaction with the MDR system. Colloidal systems facilitate the accumulation of P-gp substrates in drug-resistant cells by modulating both their physicochemical properties and their compositions. After encapsulation, the biological fates of the drugs are dependent on the nanocarrier properties, not on the structures of the drugs. Additionally, some additives, such as surfactants or certain polymers located in the nanocarrier structure, could be responsible for P-gp inhibition, especially if they have amphiphilic properties. P-gp modulation strategies based on the use of surfactants and amphiphilic copolymers will be described further, as well as the mechanisms involved. Active targeting strategies will be also mentioned. These approaches involve the conjugation of ligands onto the nanocarrier surface, which promotes the recognition of specific receptors overexpressed on drug-resistant cells. The aim of these approaches is to facilitate drug uptake by receptor-mediated endocytosis. An alternative strategy was reported with doxorubicinladen polyalkylcyanoacrylate (PACA) NPs. De Verdière et al. showed that the enhanced uptake of doxorubicin in resistant murine leukemia (P388/ADR) cell lines using PACA NPs was due to the degradation products of the polymer, in particular polyalkylcyanoacrylic acid. Intracellular diffusion of the drug was then facilitated by the accumulation of doxorubicinpolyalkylcyanoacrylic acid ion pairs formed during the degradation step [106]. 


\subsubsection{Surfactant-based strategies}

Surfactants are required for both the preparation and stabilization of NPs. Due to their interfacial activity, they facilitate the emulsification step [107] or allow the formation of microemulsion precursors $[108,109]$. They are located at the surface of colloidal systems and govern the surface properties. Due to their nature, they can confer to the NPs steric and/or electrostatic barriers. Numerous authors have shown that the efficiency of surfactants as P-gp inhibitors is dependent on their chemical structure. Most of the MDR-reversing surfactants, such as Solutol ${ }^{\circledR}$ HS15, Cremophor ${ }^{\circledR}$ EL and Tween ${ }^{\circledR}$ 80, contain PEG in their hydrophilic portion [110]. Lo et al. showed that intracellular accumulation of epirubicin in human colorectal adenocarcinoma (Caco-2) cells was enhanced after pre-treatment with surfactants composed of PEG and fatty acids or fatty alcohols. Additionally, the authors reported a relevant relationship between the hydrophilic-lipophilic balance (HLB) values of surfactants and drug uptake in resistant cells. Optimal values ranged from 10 to 17 [62]. Tween ${ }^{\circledR} 20$, Tween $^{\circledR} 80$, Myrj $^{\circledR} 52$ and Brij ${ }^{\circledR} 30$ decreased the apical efflux of epirubicin across Caco-2 monolayers in the same range as verapamil. Similar results were observed with surfactantcoated colloidal systems. De Juan et al. showed that Tween ${ }^{\circledR} 80$ significantly enhanced the cytotoxic effects of doxorubicin-loaded polybutylcyanoacrylate NPs in rat glioma cell lines [58]. Recently, Dong et al. showed that doxorubicin uptake was 7-fold higher than free doxorubicin in resistant human ovarian carcinoma (NCI/ADR-RES) cell lines that were pretreated with blank lipid NPs [59]. Lipid nanocarriers were obtained from a warm microemulsion composed of emulsifying wax, D-alpha-tocopheryl polyethylene glycol succinate (Vitamin E TPGS). Additionally, the same uptake enhancement was obtained by pre-treatment with Brij ${ }^{\circledR} 78$, thus confirming the role of surfactants as P-gp modulators. Furthermore, promising results were also obtained with an anionic surfactant, dioctylsodium sulfosuccinate (AOT). AOT was used for the preparation of alginate NPs [111]. Blank AOTalginate NPs facilitated the accumulation of the P-gp substrate rhodamine 123 in drugresistant cells [112], whereas no effect was observed with fluorescein, a non-P-gp substrate. The efficiency of the NPs was in the same range as Verapamil. However, this strategy can be limited by the potential toxicity of the surfactants. Lamprecht et al. showed that toxicity levels were dependent on both the chemical structure of the surfactants and their surface activities. Due to their amphiphilic structure, surfactants insert themselves into the lipid bilayer, thereby altering cellular viability. This effect was inversely proportional to the length of the hydrophilic chain [113]. 


\subsubsection{Amphiphilic copolymer-based strategy}

Similar to low-molecular weight surfactants, amphiphilic polymers have shown promising potential for the inhibition of the P-gp efflux system. One of the most well-known polymers is Pluronic ${ }^{\circledR}$ P85 (P85), a poloxamer composed of a central hydrophobic chain (polypropylene glycol) and two hydrophilic chains of PEG [114]. Other polymers are more seldom used, including methoxypolyethylene glycol-block-polycaprolactone (MePEG-b-PCL) [64] and polyethylene-glycol-phosphatidylethanolamine (PEG-PE) [63]. The polymers are organized in micelles from a threshold concentration termed the critical micelle concentration (CMC). The micellar structure allows the entrapment of poorly soluble drugs within a hydrophobic core. Kabanov et al. have shown that the internalization of P-gp substrates in resistant cells was drastically increased with Pluronic ${ }^{\circledR}$ copolymers [66]. This enhancement correlated with the level of P-gp expression, while Pluronic ${ }^{\circledR}$ had no effect on sensitive cells. P-gp substrates solubilized in mixed PEG-PE/vitamin E TPGS were successfully internalized in Caco-2 resistant cells [63]. Recently, the uptake of doxorubicin in P-gp-overexpressing breast cancer cells was greatly enhanced by PEG-PE micelles compared with free drug [115].

\subsubsection{Mechanisms of P-gp modulation using amphiphilic excipients and/or nanocarriers}

Amphiphilic structure appears to be a preponderant condition for the modulation of the P-gp efflux pump. The components are then able to insert themselves into the lipid bilayers of cells, leading to a fluidization of the lipid membrane [116]. This mechanism is closely linked to the interfacial activity of amphiphilic structures and therefore the HLB. The fluidity modulation of the lipid bilayer is generally evaluated by measuring the 1,6-diphenyl-1,3,5-hexatriene (DPH) fluorescent anisotropy. Numerous authors have hypothesized that the fluidization of lipid membrane directly correlates with P-gp inhibition [110, 117, 118]. However, this correlation has not been clearly demonstrated and was not supported by the study of Rege et al. [119]. These authors showed that the vitamin E TPGS was able to inhibit rhodamine 123 efflux across a Caco-2 monolayer and to rigidify the lipid bilayer. Additionally, cholesterol and benzylalcohol, which are well-known membrane modulators, do not modify the efflux transport of rhodamine 123 across a Caco 2 monolayer. Thus, other mechanisms are hypothesized to be involved in P-gp inhibition that could then interact in a synergistic manner. P-gp inhibition by Cremophor ${ }^{\circledR}$ EL was demonstrated to be specific. Cremophor ${ }^{\circledR}$ EL binds to 
the hydrophobic sites of the efflux protein, leading to a modification of the conformation of Pgp and subsequently a reduction in the efflux activity [60] .

Another mechanism involves the ATP-dependent transport mediated by P-gp. P85, after internalization in MDR cells, reaches the mitochondria and alters the respiratory chain [120]. This leads to the inhibition of the ATPase and subsequently to ATP depletion. Then, the efflux activity of P-gp is tremendously reduced. Verapamil-stimulated P-gp ATPase activity was also partially inhibited by polyoxyethylene (40) stearate [118].

All the mechanisms described above are significant for free surfactants or for unimers. When surfactants are used for the preparation of nanocarriers, they are immobilized on the nanoparticle surface. To solubilize hydrophobic drugs, amphiphilic polymers self-assemble into micelles. These arrangements can drastically limit the interaction between hydrophilic and hydrophobic groups and thus the ability of the surfactants to inhibit P-gp [62]. Koziara et al. showed that lipid nanoparticles (LNPs) prepared with Brij ${ }^{\circledR} 78$ facilitated paclitaxel delivery to the brain and drug uptake in resistant human colon adenocarcinoma cells (HCT15). After comparison with Taxol, a commercial formulation of paclitaxel and Cremophor ${ }^{\circledR}$ EL, the authors suggested that the efficiency of the NPs was not due to the presence of Brij ${ }^{\circledR}$ 78, despite its ability to inhibit P-gp. The study showed that the cytotoxic effects of paclitaxelloaded NPs were much higher than the toxicity from Taxol ${ }^{\circledR}$ alone [108]. These results do not support the P-gp inhibition mechanism mediated by $\mathrm{Brij}^{\circledR} 78$ considering both the high potential of Cremophor ${ }^{\circledR}$ EL to circumvent P-gp [110] and the 2-fold lower concentration of Brij $^{\circledR} 78$. Additionally, a high proportion of Brij ${ }^{\circledR} 78$ is embedded in the nanoparticle structure due to the preparation process using warm microemulsion precursors, whereas a high amount of Cremophor ${ }^{\circledR}$ EL is free. The authors suggested that the encapsulation of the drug strongly reduces the interactions between the drug and P-gp. After encapsulation, the fate of the drug is mainly dependent on the physicochemical properties of the carrier. A similar study was performed with paclitaxel-loaded LNPs [59]. The $\mathrm{IC}_{50}$ value of paclitaxel-NP was 9-fold higher than that of Taxol ${ }^{\circledR}$ in resistant cells. In contrast with the study of Koziara et al. [108], the authors demonstrated that lipid NPs were able to inhibit P-gp due to the presence of Brij ${ }^{\circledR}$ 78, which was used for the preparation of microemulsion precursors [109]. A transient and reversible depletion of ATP was observed with blank NPs and free Brij ${ }^{\circledR} 78$. Thus, the high accumulation of P-gp substrates was explained by a synergistic combination of NP with Brij ${ }^{\circledR}$ 78. NPs increase drug uptake by partially bypassing P-gp and the drug efflux is limited by the release of Brij ${ }^{\circledR} 78$ from NPs (Fig. 2). 


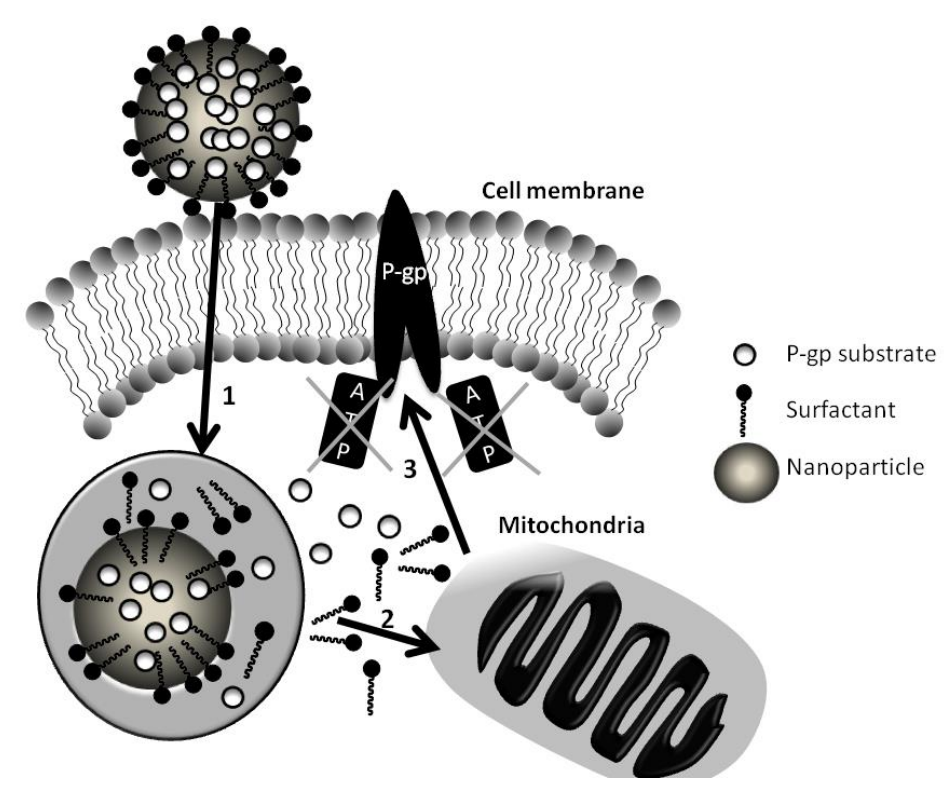

Figure 2. Fate of nanocarriers after uptake in resistant cells. 1: intracellular uptake of nanocarriers; 2: surfactant release and migration to mitochondria; 3: ATP depletion and P-gp modulation.

This mechanism was also supported by the study by Lamprecht et al. [61]. Etoposide-laden lipid nanocapsules (LNCs) were taken up by glioma cell lines and then the Solutol ${ }^{\circledR}$ HS15 surfactant was released from the LNCs, leading to P-gp inhibition (Fig. 3).

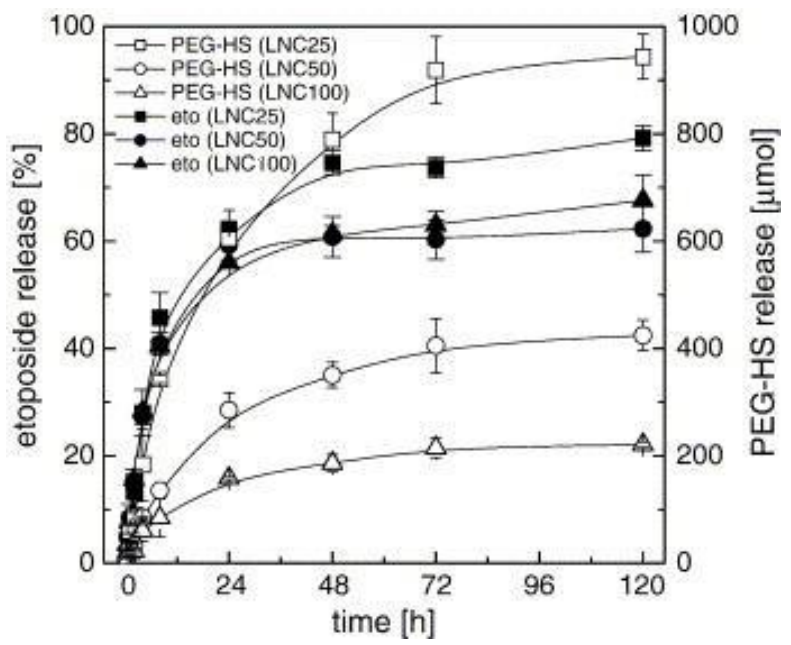

Figure 3. Release profiles of different etoposide-loaded LNC formulations in a phosphate buffer release medium at $\mathrm{pH} 7.4$ and $37^{\circ} \mathrm{C}$ where etoposide release is given in percent of the entrapped drug and PEG-HS as total amount released. The percentages of PEG-HS released after $120 \mathrm{~h}$ versus total surfactant amount used for the LNC preparation were similar for all preparations LNC25: $37.8 \pm 1.8 \%$; LNC50: $38.9 \pm 2.6 \%$; LNC100: $35.1 \pm$ $0.8 \%$.

Reprinted from Journal of Control Release 112, Lamprecht, A. and J.P. Benoit, Etoposide nanocarriers suppress glioma cell growth by intracellular drug delivery and simultaneous P-glycoprotein inhibition, p. 208-213 (2006) with permission from Elsevier. 
Batrakova et al. studied the effects of P85 on drug transport across Caco-2 or bovine brain microvessel endothelial cell (BBMEC) monolayers. The authors showed that drugs encapsulated in micelles utilize a different transport route compared with unimers [121]. Whereas P-gp inhibition is involved in the drug permeability with P85 unimers, drug-loaded micelles are endocytosed and subsequently, the drug is shuttled out of the cells. Similarly, polyoxyethylene (40) stearate unimers exhibited a concentration-dependent inhibition of P-gp up to the CMC value; however, the effect was not observed for high concentrations above the CMC [118]. Generally, the inhibition of P-gp induced by unimers was much more efficient than the micelle-mediated transport, which allows a transient accumulation of the drug. Drug permeability or cellular uptake generally reaches levels close to controls for high concentrations above the CMC [122-124]. The internalization of drug-loaded mixed PEGPE/Vitamin E TPGS micelles in Caco-2 cells was not influenced by verapamil hydrochloride, thus confirming a P-gp independent transport process [63]. In contrast to the NPs mechanism, it appears that micelle internalization does not subsequently lead to a release of unimers, which are responsible for P-gp inhibition. The cellular concentration of amphiphilic molecules likely stays above the CMC, thereby preserving the micellar structure. However, the work of Zastre et al. [64] was not in agreement with these findings. The authors reported that accumulation of a P-gp substrate in Caco-2 cells was enhanced with MePEG-b-PCL for concentrations above the CMC. Only a small effect was noted for concentrations below the CMC [64]. Despite the presence of micelles, the drugs were transported by P-gp and not via an endocytic process [125]. It was hypothesized that below the CMC, MePEG- $b$-PCL could not modulate P-gp due to its low surface properties. Above the CMC, the micelles could act as "depots" for free unimers, thereby maintaining a high concentration of the unimers in equilibrium with the micelles. Surprisingly, membrane fluidization and significant increases in ATPase activity were not observed as P-gp was inhibited [126].

In addition to the passive nanocarriers previously described, several DDSs actively target the resistant cells using recognition ligands located on the nanocarrier surface. Promising results were obtained with these surface-modified systems. The cytotoxicity of transferrin receptortargeted liposomal doxorubicin was 3.5-fold higher than free doxorubicin in the resistant human small cell lung cancer cells SBC3/ADM [127]. The effect was only observed with targeted liposomes with a fluid bilayer, which allows a rapid release of the drug. Additionally, folate conjugated to liposomes allowed increased doxorubicin uptake in multidrug-resistant tumor cells compared with free drug [128]. The cytotoxic effect of folate-liposomes was 10fold higher than untargeted liposomes. The enhanced accumulation observed with folate and 
transferrin-conjugated liposomes was explained by an overexpression of transferrin and folate receptors on cancer cells [127-129]. Moreover, the transport of rhodamine 123 in insulinconjugated P85 micelles across a BBMEC monolayer was increased by 2- to 3-fold compared with insulin-free micelles or micelles incubated with unconjugated insulin. This effect was inhibited after the addition of free insulin and was not observed using a Caco-2 monolayer, thus confirming the specific interaction with insulin receptors overexpressed on BBMECs [121].

\subsection{Synergistic combination of P-gp modulators with nanocarriers}

As previously discussed, DDSs may overcome MDR in many tumor types. However, effective therapeutic P-gp modulation is often limited to cells with high resistance levels [130]. Additionally, some nanocarriers that allow high drug loading can exhibit a reduced ability to modulate P-gp due to the type of surfactant used, the surfactant concentration and the amount of anchorage on the surface. Thus, an alternative approach is to associate nanocarriers with chemosensitizers to benefit from both of the following strategies: P-gp bypassing and P-gp modulation. With such strategy, pharmacokinetic interactions either between chemosensitizers and P-gp substrates or between chemosensitizers and other protein efflux transporters or enzymes could be avoided while improving the selectivity and efficacy of P-gp modulation. Additionally, the solubility, bioavailability and half-lives of encapsulated compounds could further be improved. This promising approach has been explored over the last few years; however, the studies showed a non-uniformity of the strategy.

In one example, the P-gp modulator was encapsulated in nanocarriers. Lo et al. demonstrated that cyclosporin A and valspodar loaded in liposomes, compared with intralipid $(\mathrm{o} / \mathrm{W}$ emulsion) and free valspodar could further achieve the highest level of epirubicin uptake at all studied concentrations in Caco-2 cells. In line with these results, the highest absorption of epirubicin in the everted sacs of a rat jejunum and ileum model was obtained using cyclosporine and valspodar liposomes [131, 132].

In contrast, Krishna et al. showed in several publications that the encapsulation of P-gp substrates and the subsequent use with the free form of the P-gp modulator was also effective. First, in BDF1 mice bearing lymphocytic leukemia solid tumors (P388/ADR), no significant effect on tumor growth was observed when free doxorubicin was administered with or without free valspodar. In contrast, the addition of free valspodar to 1,2 distearoyl-sn-glycero3-phosphocholine/cholesterol (DSPC/Chol) liposomal doxorubicin provided complete 
chemosensitization, thereby inhibiting tumor growth. Furthermore, using pharmacokinetic and biodistribution studies in the same tumor model, liposomal doxorubicin exhibited similar pharmacokinetic profiles in the presence and absence of valspodar, while decreased plasma elimination rates and altered tissue distribution was observed for free doxorubicin in the presence of valspodar [133]. All of these results were supported by a rat model with implanted jugular vein and bile duct catheters. The co-administration of valspodar with free doxorubicin caused significant decreases in renal and biliary clearance, while negligible changes were observed for egg phosphatidylcholine/cholesterol (EPC/Chol) liposomal doxorubicin and no effects were observed for doxorubicin excretion after administration of polyethylene glycol 2000-distearoylglycerophosphatidylethanolamine/1,2-distearoyl-snglycero-3-phosphocholine/cholesterol ( $\mathrm{PEG}_{2000}$-DSPE/DSPC/Chol) liposomal doxorubicin. Hence, these previous results suggest that the use of a nanocarrier and its composition play major roles in the pharmacokinetic properties of the encapsulated drug. Besides the minimal pharmacokinetic interactions between PEGylated liposomal doxorubicin and valspodar, this liposomal sterically stabilized formulation displayed superiority at suppressing tumor growth, particularly in the presence of valspodar $[134,135]$.

As a result of the above in vivo data, a phase I clinical study in patients with resistant or recurrent malignancies evaluated the effects of valspodar on liposomal doxorubicin (Doxil ${ }^{\circledR}$ ) toxicity and pharmacokinetics. PEGylated liposomal doxorubicin at a maximal dose of 25 $\mathrm{mg} / \mathrm{m}^{2}$ every two weeks co-administered with valspodar was safely administered by intravenous infusion. In agreement with all previous reports in animals, valspodar moderately increased the plasma levels and half-life of doxorubicin and decreased the clearance of total doxorubicin, indicating that there is a weak interaction between PEGylated liposomal doxorubicin $\left(\right.$ Doxil $\left.^{\circledR}\right)$ and valspodar [136].

As cited by Song et al., many questions arose with the advance of this synergistic strategy. It remained unclear which agent should be encapsulated and what is the optimal sequence of administration to obtain the highest P-gp inhibition, fewest pharmacokinetic interactions and lowest normal tissue toxicity [137]. Subsequent investigations were not limited to the encapsulation of a P-gp substrate or P-gp modulator; in fact, they went further and coencapsulated both compounds. 


\subsubsection{Co-encapsulation of P-gp substrates and P-gp modulators in liposomes and liposomal derivatives}

Based on the information presented above and to enhance the reversion efflux of doxorubicin, J. C. Wang et al. tested the in vitro cytotoxicity of a series of doxorubicin formulations in the multidrug-resistant rat prostate adenocarcinoma Mat-LyLu-B2 (MLLB2) cell line, in which the most prodigious formulation was a stealth liposomal co-encapsulation of doxorubicin and verapamil (DARSLs). The $\mathrm{IC}_{50}$ of DARSLs was $0.079 \mu \mathrm{M}$, which was slightly lower than the value obtained with a mixture of liposomal doxorubicin and liposomal verapamil $(0.099 \mu \mathrm{M})$ but 13-fold lower than the $\mathrm{IC}_{50}$ of a mixture of liposomal doxorubicin and free verapamil $(0.96 \mu \mathrm{M})$. Furthermore, the authors reported that the most significant finding was that stealth liposomes encapsulating doxorubicin alone was not sufficient to reverse doxorubicin resistance in two resistant cell lines, MLLB2 and doxorubicin-resistant human uterus sarcoma (MES-SA/Dx5) cells [130]. Additionally, the same research team explored the in vivo pharmacokinetics and cardiotoxicity of all previous formulations administered intravenously in order to discard reported toxicity of free doxorubicin and free verapamil co-administered in neoplastic patients. In accordance with previous reports, verapamil interferes with the pharmacokinetics of doxorubicin when both molecules are administered in their nonencapsulated form. Encapsulation of doxorubicin and its co-administration with verapamil, whether free or co-encapsulated, has a major impact on reducing the clearance of doxorubicin, resulting in a significant increase of its AUC. This fact could be due to the P-gp inhibition, which results in a reduction in doxorubicin transport across the biliary canaliculi. Moreover, the co-encapsulation of doxorubicin and verapamil in DARSLs decreased bradycardia produced by free verapamil and resulted in the lowest doxorubicin distribution in the heart, as well as in other organs, such as the liver, kidneys and lungs [138].

One of the most recent studies aimed to develop a system to co-encapsulate a third-generation P-gp modulator, tariquidar and paclitaxel in long circulating liposomes. This formulation caused high cytotoxicity of a paclitaxel-resistant human ovarian adenocarcinoma (SK-OV3TR) cell line at a dose that was ineffective in the absence of tariquidar. Co-loaded long circulating liposomes resulted in a about 100 -fold lower $\mathrm{IC}_{50}$ than paclitaxel long circulating liposomes [139].

Another approach combined doxorubicin and verapamil co-encapsulated in liposomes actively targeted with transferrin (Tf-L-DOX/VER). Human transferrin is an iron-binding glycoprotein with high affinity for the Tf receptor, which is overexpressed in tumor and 
chronic human leukemia (K562) cells. Through cytotoxicity studies in doxorubicin-resistant K562/DOX cells, Tf-L-DOX/VER displayed a 3-fold lower $\mathrm{IC}_{50}$ than the value obtained with transferrin liposomes loaded with doxorubicin alone (Tf-L-DOX) $(4.18 \mu \mathrm{M}$ vs $11.4 \mu \mathrm{M})$. These values suggest that the presence of verapamil in the formulation results in a stronger reversal of drug resistance in K562 cells [140].

Based on its active targeting mechanism of receptor-mediated endocytosis and its high affinity for the cerebral capillary endothelium, wheat germ agglutinin (WGA) has been shown to be a good candidate for drug carrier targeting. WGA conjugated to the surface could help transfer topotecan-tamoxifen-loaded liposomes across the BBB and then target brain tumors. Among the four types of topotecan liposomes with or without the P-gp modulator tamoxifen and/or WGA, the one modified with tamoxifen and WGA exhibited the strongest cytotoxic effect against murine glial tumor (C6) cells. Likewise, this formulation achieved the highest inhibitory effect against C6 cells after crossing an in vitro BBB (brain microvascular endothelial cells/rat astrocytes) model, with only a $65.8 \%$ survival rate. The percent survival for topotecan liposomes with WGA was $75.6 \%$, for topotecan liposomes with tamoxifen it was $76.1 \%$, for topotecan liposomes it was $86.5 \%$ and for free topotecan it was $88.0 \%$. In addition, after one week of treatment with the different formulations, the mean survival time of an in vivo brain C6 glioma-bearing model was 26 days for topotecan liposomes modified with tamoxifen and WGA, 20 days for topotecan liposomes, 19 days for free topotecan and 15 days for saline. A mean survival time of 31 days was achieved with two weeks of treatment with topotecan liposomes modified with tamoxifen and WGA [141].

Synthetic liposomes, or polymersomes, were recently developed from amphiphilic polymers. Because of their similar properties to self-assembled phospholipids, polymersomes are being engineered to improve their performance as DDSs [142]. Taking this information into account, Pang et al. have recently worked on the formulation of biodegradable polymersomes as carriers for the simultaneous co-administration of doxorubicin and tetrandrine (PODox/Tet). Additionally, these vesicles were actively targeted with lactoferrin (Lf-PODox/Tet). Tetrandrine is a bis-benzylisoquinoline alkaloid isolated from the roots of Radix stephania tetrandrae. In vitro and in vivo studies showed that tetrandrine is not a $\mathrm{P}$-gp substrate, but through direct binding, it acts as a P-gp modulator. A clear example is the enhancement of doxorubicin plasma levels by co-administration of tetrandrine, with no apparent effects on doxorubicin pharmacokinetics [143, 144]. Lactoferrin is a multifunctional glycoprotein with high potential to overcome the $\mathrm{BBB}$ and to increase the targeting interactions with glioma cells. As predicted after the active targeting, a cytotoxicity evaluation 
against a murine $\mathrm{C} 6$ glioma cell line showed that the $\mathrm{IC}_{50}$ of Lf-PO-Dox/Tet was about 2-fold lower than the $\mathrm{IC}_{50}$ of PO-Dox/Tet and about 4-fold lower than the $\mathrm{IC}_{50}$ of polymersomes containing doxorubicin alone (PO-Dox). Moreover, in an in vivo brain C6 glioma-bearing model, treatment with Lf-PO-Dox/Tet resulted in significantly smaller tumor volumes and longer median survival time compared with animals treated with Lf-PO-Dox [145].

\subsubsection{Co-encapsulation of P-gp substrates and P-gp modulators in nanoparticles}

Early doxorubicin-targeting strategies included NPs co-loaded with doxorubicin and a chemosensitizer compound. A clear example was co-encapsulation of doxorubicin with cyclosporine A in polyalkylcyanoacrylate (PACA) NPs. As expected, using cytotoxicity assays in a doxorubicin-resistant murine leukemia (P388/ADR) cell line, co-encapsulation of both compounds proved to be significantly more efficient than doxorubicin PACA NPs with or without free cyclosporine A [146].

Y. Patil and co-workers have been studying simultaneous encapsulation and targeted delivery of paclitaxel with the P-gp inhibitor, tariquidar, in poly-(lactic-co-glycolic acid) (PLGA) NPs. The two P-gp-overexpressing cell lines used in their cytotoxic study were murine mammary adenocarcinoma (JC) and human ovarian adenocarcinoma (NCI/ADR-RES) cells, both of which are resistant to different anti-cancer drugs. Paclitaxel in solution or encapsulated in NPs did not significantly alter the viability of these cells; however, the addition of tariquidar restored the cytotoxicity. These results are supported by the amount of paclitaxel accumulated in each cell line. Dual-agent NPs displayed almost a 2-fold higher paclitaxel accumulation than a mixture of the anti-cancer drug and the P-gp modulator in solution and almost an 8-fold higher accumulation than paclitaxel alone in NPs or in solution. Because previous studies have shown that cancer cells overexpress biotin receptors and with the purpose of treating a JC tumor-bearing animal model, paclitaxel-tariquidar PLGA NPs were functionalized with biotin. This formulation led to a significant increase in tumor cell accumulation of NPs and the slowest tumor growth, as well as the least ulceration and tumor-induced mortality. In contrast, paclitaxel, either encapsulated in NPs or in solution, was not effective and the inclusion of tariquidar only showed slightly better tumor growth inhibition [147].

The co-encapsulation of doxorubicin and the chemosensitizer elacridar using polymer-lipid hybrid nanoparticles (PLNs) was reported for the first time by H.L. Wong et al. This new 
lipid-based system is a modification of the previously described solid lipid NPs by incorporation of anionic polymers to complex cationic drugs, thereby increasing its partition in lipids. Among the different formulations, co-encapsulation of doxorubicin and elacridar in PLNs resulted in the highest uptake of doxorubicin and the strongest anti-cancer effect in a Pgp-overexpressing human breast carcinoma (MDA435/LCC6/MDR1) cell line. The IC $_{50}$ obtained by this co-encapsulation was 3 -fold lower than the value obtained by single doxorubicin PLNs and 2-fold lower than the value obtained by doxorubicin PLNs with free elacridar [148].

In Adriamycin ${ }^{\circledR}$-resistant human leukemic (K562/A02) cells, treatment with tetrandrine coloaded with Adriamycin in $\mathrm{Fe}_{3} \mathrm{O}_{4}$ magnetic NPs using a polymerization process resulted in the highest growth inhibition among all the polymerized conjugations or single drug forms. These results were corroborated by measuring fluorescence intensity of intracellular Adriamycin [149].

In line with previous results, other research teams showed that the simultaneous administration of a P-gp substrate and a P-gp modulator co-loaded in nanocarriers achieved the highest reversal efficacy and caused minimal tissue drug toxicity and dramatically fewer drug-drug interactions (Table 2).

Promising early preclinical studies certified that P-gp modulation by this synergistic and novel strategy is feasible and the results from these studies are encouraging. Among all the examples using this approach, the dual-loaded drug delivery system always resulted in the highest acute cytotoxicity and uptake of the P-gp substrate by P-gp-overexpressing cell lines. Additionally, these co-loaded formulations always achieved the most improved pharmacokinetic profiles and the highest long-term suppression of cancerous tumors. More encouraging results were only obtained with the actively targeted forms of the co-loaded nanocarriers. 
Table 2: Characteristics and results of in vitro and in vivo studies using the novel combination of nanocarriers and P-gp modulators

\begin{tabular}{|c|c|c|c|c|c|c|c|}
\hline Year & $\begin{array}{c}\text { P-gp } \\
\text { modulator }\end{array}$ & $\begin{array}{c}\text { P-gp } \\
\text { substrate }\end{array}$ & DDS & In vitro model & In vivo model & Results & Refs \\
\hline 1999 & $\begin{array}{c}\text { Cyclosporin } \\
\text { A }\end{array}$ & Doxorubicin & $\begin{array}{l}\text { Polyalkylcyanoa- } \\
\text { crylate (PACA) } \\
\text { nanoparticles } \\
\end{array}$ & $\begin{array}{c}\text { Doxorubicin-resistant } \\
\text { leukemia } \\
\text { (P388/ADR) cells }\end{array}$ & --- & $\begin{array}{l}\text { Improved } \\
\text { cytotoxicity }\end{array}$ & [146] \\
\hline \multirow[t]{2}{*}{2005} & Verapamil & Doxorubicin & Stealth liposomes & $\begin{array}{l}\text { Multidrug-resistant } \\
\text { rat prostate } \\
\text { adenocarcinoma Mat- } \\
\text { LyLu-B2 (MLLB2) } \\
\text { cells }\end{array}$ & --- & $\begin{array}{l}\text { Improved } \\
\text { cytotoxicity }\end{array}$ & [130] \\
\hline & & & & & $\begin{array}{c}\text { Pharmacokinetics } \\
\text { in Sprague } \\
\text { Dawley rats } \\
\end{array}$ & $\begin{array}{c}\text { Improved } \\
\text { pharmacokinetic } \\
\text { profile } \\
\end{array}$ & [138] \\
\hline 2006 & Elacridar & Doxorubicin & $\begin{array}{l}\text { Polymer-lipid } \\
\text { hybrid } \\
\text { nanoparticles } \\
\text { (PLN) }\end{array}$ & $\begin{array}{c}\text { Human breast } \\
\text { carcinoma } \\
\text { (MDA435/LCC6/M } \\
\text { DR1) cells } \\
\text { Clonogenic assay in } \\
\text { MDA435/LCC6/MD } \\
\text { R1 cells } \\
\end{array}$ & --- & $\begin{array}{l}\text { Improved } \\
\text { doxorubicin } \\
\text { uptake } \\
\text { Long-term } \\
\text { cancer growth } \\
\text { suppression } \\
\end{array}$ & [148] \\
\hline 2007 & Verapamil & Doxorubicin & $\begin{array}{l}\text { Transferrin- } \\
\text { conjugated } \\
\text { liposomes }\end{array}$ & $\begin{array}{c}\text { Chronic } \\
\text { myelogenous } \\
\text { leukemia } \\
(\mathrm{K} 562 / \mathrm{DOX}) \text { cells } \\
\end{array}$ & --- & $\begin{array}{l}\text { Improved } \\
\text { cytotoxicity }\end{array}$ & [140] \\
\hline \multirow[t]{2}{*}{2009} & Tamoxifen & Topotecan & $\begin{array}{l}\text { Wheat germ } \\
\text { agglutinin- } \\
\text { conjugated } \\
\text { liposomes }\end{array}$ & $\begin{array}{l}\text { Murine glial tumor } \\
\text { (C6) cells } \\
\text { Transport across } \\
\text { BBB (brain } \\
\text { microvascular } \\
\text { endothelial cells / rat } \\
\text { astrocytes) - } \\
\text { (BMVECs/RAs) }\end{array}$ & & $\begin{array}{l}\text { Improved } \\
\text { cytotoxicity } \\
\text { Improved } \\
\text { transport and } \\
\text { targeting of C6 } \\
\text { cells }\end{array}$ & [141] \\
\hline & & & & & $\begin{array}{c}\text { C6 tumor-bearing } \\
\text { Sprague Dawley } \\
\text { rats }\end{array}$ & $\begin{array}{l}\text { Longer survival } \\
\text { of animals }\end{array}$ & \\
\hline \multirow[t]{2}{*}{2009} & Tariquidar & Paclitaxel & $\begin{array}{l}\text { Poly(D,L-lactide- } \\
\text { co-glycolide acid) } \\
\text { (PLGA) } \\
\text { nanoparticles }\end{array}$ & $\begin{array}{c}\text { Murine mammary } \\
\text { adenocarcinoma (JC) } \\
\text { and human ovarian } \\
\text { adenocarcinoma } \\
\text { (NCI/ADR-RES) } \\
\text { cells }\end{array}$ & & $\begin{array}{l}\text { Improved } \\
\text { cytotoxicity }\end{array}$ & [147] \\
\hline & & & $\begin{array}{l}\text { Biotin- poly(D,L- } \\
\text { lactide-co- } \\
\text { glycolide acid) } \\
\text { (PLGA) } \\
\text { nanoparticles } \\
\end{array}$ & & $\begin{array}{l}\text { JC tumor-bearing } \\
\text { female BALB/c } \\
\text { mice }\end{array}$ & $\begin{array}{l}\text { Improved tumor } \\
\text { growth } \\
\text { inhibition }\end{array}$ & \\
\hline 2009 & Verapamil & Vincristine & $\begin{array}{c}\text { Poly(D,L-lactide- } \\
\text { co-glycolide acid) } \\
\text { (PLGA) } \\
\text { nanoparticles }\end{array}$ & $\begin{array}{l}\text { Human breast cancer } \\
\text { (MCF-7/ADR) cells }\end{array}$ & --- & $\begin{array}{l}\text { Improved } \\
\text { cytotoxicity }\end{array}$ & [137] \\
\hline 2010 & & & & $\begin{array}{c}\text { Human } \\
\text { hepatocellular } \\
\text { carcinoma } \\
\text { (BEL7402/5-FU) } \\
\text { cells }\end{array}$ & --- & $\begin{array}{l}\text { Improved } \\
\text { cytotoxicity }\end{array}$ & [150] \\
\hline 2011 & Tariquidar & Paclitaxel & Stealth liposomes & $\begin{array}{c}\text { Paclitaxel-resistant } \\
\text { human ovarian } \\
\text { adenocarcinoma (SK- } \\
\text { OV-3TR) cells }\end{array}$ & --- & $\begin{array}{l}\text { Improved } \\
\text { cytotoxicity }\end{array}$ & [139] \\
\hline
\end{tabular}




\subsection{Conclusion}

In spite of exponential improvements and progress with the various strategies to circumvent P-gp, the efficacy and safety of these strategies in clinical trials are still a challenge for drug development programs. The attainment of the ideal modulator is not yet a reality. Although third-generation modulators have demonstrated high selectivity and efficacy in preclinical studies, the clinical trial results were more conflicting. The poor solubility of chemosensitizers and sometimes their short half-lives could limit their use as P-gp modulators. These drawbacks can be reduced by the use of DDSs that additionally exhibit a high potential to bypass and/or to modulate the P-gp efflux protein. The mechanisms of nanocarriers involved in P-gp modulation have not yet been clearly demonstrated. Nevertheless, an enhanced intracellular uptake compared with free drug followed by a simultaneous release of P-gp substrate and amphiphilic excipients was hypothesized.

Rather than develop other strategies, some laboratories suggest a synergistic association between the unique properties of DDSs and the selectivity and potency of P-gp modulators. In this manuscript, we have highlighted a dual strategy where a prominent number of nanocarriers containing both $\mathrm{P}$-gp substrates and P-gp modulators are currently being explored. In general, the first results in this direction were already obtained with in vitro and in vivo studies. To our knowledge, most of these studies succeeded in their goal opening outcoming windows to clinical trials. These examples apply to cytotoxic drugs but many other P-gp substrates with different therapeutic activities remain to be studied. Particular attention should be given to P-gp substrates, such as HIV protease inhibitors, anti-epileptic or antidepressants drugs, which are not able to reach the brain due to the overexpression of P-gp at the BBB. First-generation P-gp modulators have been tested most frequently in the studies mentioned above. However, the usage of the latest generation of modulators is a factor that independently predicts the further decrease of any residual interaction with other $\mathrm{ABC}$ transporters or enzymes and thereby improves the safety profiles. Among nanocarriers, liposomes and nanoparticles have been extensively used for such combinations; however, other nanocarriers such as polymersomes or niosomes would also be suitable for this aim. The data suggest that future challenges involve taking advantage of the modified, stealth or actively targeted nanocarriers and also exploiting the best combinations. Although this approach is still probably some years away from the marketplace, more detailed in vivo pharmacodynamics, safety pharmacology, pharmacokinetic and toxicology studies could maximize the efficacy of this synergistic strategy for the success of future clinical trials. 
Moreover, some important aspects should be considered when working in vitro models. Numerous in vitro models to study P-gp modulation utilize immortalized cells with a different phenotype compared to normal primary cells. These phenotypic variations could alter cell internalization routes and induce a higher membrane turnover. In addition, culture conditions such as the composition of culture media could also result in a poor representation of uptake pathways in cells found in intact tissues and thus explaining significant differences observed between in vitro and preclinical studies. 


\section{REFERENCES}

[1] K.M. Giacomini, S.M. Huang, D.J. Tweedie, L.Z. Benet, K.L. Brouwer, X. Chu, A. Dahlin, R. Evers, V. Fischer, K.M. Hillgren, K.A. Hoffmaster, T. Ishikawa, D. Keppler, R.B. Kim, C.A. Lee, M. Niemi, J.W. Polli, Y. Sugiyama, P.W. Swaan, J.A. Ware, S.H. Wright, S.W. Yee, M.J. Zamek-Gliszczynski, L. Zhang, Membrane transporters in drug development, Nat Rev Drug Discov, 9 215-236.

[2] W. Loscher, H. Potschka, Role of drug efflux transporters in the brain for drug disposition and treatment of brain diseases, Prog Neurobiol, 76 (2005) 22-76.

[3] R.L. Juliano, V. Ling, A surface glycoprotein modulating drug permeability in Chinese hamster ovary cell mutants, Biochim Biophys Acta, 455 (1976) 152-162.

[4] S.V. Ambudkar, S. Dey, C.A. Hrycyna, M. Ramachandra, I. Pastan, M.M. Gottesman, Biochemical, cellular, and pharmacological aspects of the multidrug transporter, Annu Rev Pharmacol Toxicol, 39 (1999) 361-398.

[5] R. Krishna, L.D. Mayer, Multidrug resistance (MDR) in cancer. Mechanisms, reversal using modulators of MDR and the role of MDR modulators in influencing the pharmacokinetics of anticancer drugs, Eur J Pharm Sci, 11 (2000) 265-283.

[6] N. Akhtar, A. Ahad, R.K. Khar, M. Jaggi, M. Aqil, Z. Iqbal, F.J. Ahmad, S. Talegaonkar, The emerging role of P-glycoprotein inhibitors in drug delivery: a patent review, Expert Opin Ther Pat, 21 (2011) 561-576.

[7] T. Bansal, N. Akhtar, M. Jaggi, R.K. Khar, S. Talegaonkar, Novel formulation approaches for optimising delivery of anticancer drugs based on P-glycoprotein modulation, Drug Discov Today, 14 (2009) 1067-1074.

[8] J. Valle, A. Armstrong, C. Newman, V. Alakhov, G. Pietrzynski, J. Brewer, S. Campbell, P. Corrie, E. Rowinsky, M. Ranson, A phase 2 study of SP1049C, doxorubicin in Pglycoprotein-targeting pluronics, in patients with advanced adenocarcinoma of the esophagus and gastroesophageal junction, Investigational New Drugs, 29 (2011) 1029-1037.

[9] R. Kerb, Implications of genetic polymorphisms in drug transporters for pharmacotherapy, Cancer Lett, 234 (2006) 4-33.

[10] W.E. Kaminski, A. Piehler, J.J. Wenzel, ABC A-subfamily transporters: structure, function and disease, Biochim Biophys Acta, 1762 (2006) 510-524.

[11] T.W. Loo, D.M. Clarke, Mutational analysis of ABC proteins, Arch Biochem Biophys, 476 (2008) 51-64.

[12] I.L. Aye, A.T. Singh, J.A. Keelan, Transport of lipids by ABC proteins: interactions and implications for cellular toxicity, viability and function, Chem Biol Interact, 180 (2009) 327339.

[13] A.J. Smith, A. van Helvoort, G. van Meer, K. Szabo, E. Welker, G. Szakacs, A. Varadi, B. Sarkadi, P. Borst, MDR3 P-glycoprotein, a phosphatidylcholine translocase, transports several cytotoxic drugs and directly interacts with drugs as judged by interference with nucleotide trapping, J Biol Chem, 275 (2000) 23530-23539. 
[14] S. Ruetz, P. Gros, Phosphatidylcholine translocase: a physiological role for the mdr2 gene, Cell, 77 (1994) 1071-1081.

[15] J.J. Smit, A.H. Schinkel, R.P. Oude Elferink, A.K. Groen, E. Wagenaar, L. van Deemter, C.A. Mol, R. Ottenhoff, N.M. van der Lugt, M.A. van Roon, et al., Homozygous disruption of the murine mdr2 P-glycoprotein gene leads to a complete absence of phospholipid from bile and to liver disease, Cell, 75 (1993) 451-462.

[16] S.V. Ambudkar, I.W. Kim, Z.E. Sauna, The power of the pump: mechanisms of action of P-glycoprotein (ABCB1), Eur J Pharm Sci, 27 (2006) 392-400.

[17] R. Callaghan, R.C. Ford, I.D. Kerr, The translocation mechanism of P-glycoprotein, FEBS Lett, 580 (2006) 1056-1063.

[18] M. Hennessy, J.P. Spiers, A primer on the mechanics of P-glycoprotein the multidrug transporter, Pharmacol Res, 55 (2007) 1-15.

[19] M.M. Gottesman, T. Fojo, S.E. Bates, Multidrug resistance in cancer: role of ATPdependent transporters, Nat Rev Cancer, 2 (2002) 48-58.

[20] E. Yague, A. Arance, L. Kubitza, M. O'Hare, P. Jat, C.M. Ogilvie, I.R. Hart, C.F. Higgins, S. Raguz, Ability to acquire drug resistance arises early during the tumorigenesis process, Cancer Res, 67 (2007) 1130-1137.

[21] G.T. Ho, F.M. Moodie, J. Satsangi, Multidrug resistance 1 gene (P-glycoprotein 170): an important determinant in gastrointestinal disease?, Gut, 52 (2003) 759-766.

[22] C. Cordon-Cardo, J.P. O'Brien, D. Casals, L. Rittman-Grauer, J.L. Biedler, M.R. Melamed, J.R. Bertino, Multidrug-resistance gene (P-glycoprotein) is expressed by endothelial cells at blood-brain barrier sites, Proc Natl Acad Sci U S A, 86 (1989) 695-698.

[23] F. Thiebaut, T. Tsuruo, H. Hamada, M.M. Gottesman, I. Pastan, M.C. Willingham, Immunohistochemical localization in normal tissues of different epitopes in the multidrug transport protein P170: evidence for localization in brain capillaries and crossreactivity of one antibody with a muscle protein, J Histochem Cytochem, 37 (1989) 159-164.

[24] A.H. Schinkel, P-Glycoprotein, a gatekeeper in the blood-brain barrier, Adv Drug Deliv Rev, 36 (1999) 179-194.

[25] S. Seetharaman, M.A. Barrand, L. Maskell, R.J. Scheper, Multidrug resistance-related transport proteins in isolated human brain microvessels and in cells cultured from these isolates, J Neurochem, 70 (1998) 1151-1159.

[26] M. Demeule, D. Shedid, E. Beaulieu, R.F. Del Maestro, A. Moghrabi, P.B. Ghosn, R. Moumdjian, F. Berthelet, R. Beliveau, Expression of multidrug-resistance P-glycoprotein (MDR1) in human brain tumors, Int J Cancer, 93 (2001) 62-66.

[27] S. Spiegl-Kreinecker, J. Buchroithner, L. Elbling, E. Steiner, G. Wurm, A. Bodenteich, J. Fischer, M. Micksche, W. Berger, Expression and functional activity of the ABC-transporter proteins P-glycoprotein and multidrug-resistance protein 1 in human brain tumor cells and astrocytes, J Neurooncol, 57 (2002) 27-36. 
[28] K. Dietzmann, P.V. Bossanyi, D.S. Franke, [Expression of P-glycoprotein as a multidrug resistance gene product in human reactive astrocytes and astrocytoma], Zentralbl Pathol, 140 (1994) 149-153.

[29] V.V. Rao, J.L. Dahlheimer, M.E. Bardgett, A.Z. Snyder, R.A. Finch, A.C. Sartorelli, D. Piwnica-Worms, Choroid plexus epithelial expression of MDR1 P glycoprotein and multidrug resistance-associated protein contribute to the blood-cerebrospinal-fluid drug-permeability barrier, Proc Natl Acad Sci U S A, 96 (1999) 3900-3905.

[30] G.D. Anderson, D.D. Shen, Where is the evidence that p-glycoprotein limits brain uptake of antiepileptic drug and contributes to drug resistance in epilepsy?, Epilepsia, 48 (2007) $2372-2374$

[31] O.L. de Klerk, A.T. Willemsen, M. Roosink, A.L. Bartels, N.H. Hendrikse, F.J. Bosker, J.A. den Boer, Locally increased P-glycoprotein function in major depression: a PET study with [11C]verapamil as a probe for P-glycoprotein function in the blood-brain barrier, Int $\mathbf{J}$ Neuropsychopharmacol, 12 (2009) 895-904.

[32] M. Uhr, T. Steckler, A. Yassouridis, F. Holsboer, Penetration of amitriptyline, but not of fluoxetine, into brain is enhanced in mice with blood-brain barrier deficiency due to mdrla Pglycoprotein gene disruption, Neuropsychopharmacology, 22 (2000) 380-387.

[33] S. Rapposelli, M. Digiacomo, A. Balsamo, P-gp transporter and its role in neurodegenerative diseases, Curr Top Med Chem, 9 (2009) 209-217.

[34] M. Strazza, V. Pirrone, B. Wigdahl, M.R. Nonnemacher, Breaking down the barrier: The effects of HIV-1 on the blood-brain barrier, Brain Res, 1399 96-115.

[35] C.H. Storch, D. Theile, H. Lindenmaier, W.E. Haefeli, J. Weiss, Comparison of the inhibitory activity of anti-HIV drugs on P-glycoprotein, Biochem Pharmacol, 73 (2007) 15731581.

[36] L. Varatharajan, S.A. Thomas, The transport of anti-HIV drugs across blood-CNS interfaces: summary of current knowledge and recommendations for further research, Antiviral Res, 82 (2009) A99-109.

[37] N.A. Colabufo, F. Berardi, M. Cantore, M. Contino, C. Inglese, M. Niso, R. Perrone, Perspectives of $\mathrm{P}$-glycoprotein modulating agents in oncology and neurodegenerative diseases: pharmaceutical, biological, and diagnostic potentials, J Med Chem, 53 1883-1897.

[38] T. Tsuruo, H. Iida, S. Tsukagoshi, Y. Sakurai, Overcoming of vincristine resistance in P388 leukemia in vivo and in vitro through enhanced cytotoxicity of vincristine and vinblastine by verapamil, Cancer Res, 41 (1981) 1967-1972.

[39] H. Goldberg, V. Ling, P.Y. Wong, K. Skorecki, Reduced cyclosporin accumulation in multidrug-resistant cells, Biochem Biophys Res Commun, 152 (1988) 552-558.

[40] A. Ramu, D. Glaubiger, Z. Fuks, Reversal of acquired resistance to doxorubicin in P388 murine leukemia cells by tamoxifen and other triparanol analogues, Cancer Res, 44 (1984) 4392-4395. 
[41] A.B. Benson, 3rd, D.L. Trump, J.M. Koeller, M.I. Egorin, E.A. Olman, R.S. Witte, T.E. Davis, D.C. Tormey, Phase I study of vinblastine and verapamil given by concurrent iv infusion, Cancer Treat Rep, 69 (1985) 795-799.

[42] M.S. Cairo, S. Siegel, N. Anas, L. Sender, Clinical trial of continuous infusion verapamil, bolus vinblastine, and continuous infusion VP-16 in drug-resistant pediatric tumors, Cancer Res, 49 (1989) 1063-1066.

[43] L. Saltz, B. Murphy, N. Kemeny, J. Bertino, W. Tong, D. Keefe, Y. Tzy-Jun, Y. Tao, D. Kelsen, J.P. O'Brien, A phase I trial of intrahepatic verapamil and doxorubicin. Regional therapy to overcome multidrug resistance, Cancer, 74 (1994) 2757-2764.

[44] J. Verweij, H. Herweijer, R. Oosterom, M.E. van der Burg, A.S. Planting, C. Seynaeve, G. Stoter, K. Nooter, A phase II study of epidoxorubicin in colorectal cancer and the use of cyclosporin-A in an attempt to reverse multidrug resistance, Br J Cancer, 64 (1991) 361-364.

[45] N.L. Bartlett, B.L. Lum, G.A. Fisher, N.A. Brophy, M.N. Ehsan, J. Halsey, B.I. Sikic, Phase I trial of doxorubicin with cyclosporine as a modulator of multidrug resistance, J Clin Oncol, 12 (1994) 835-842.

[46] E. Berman, M. McBride, S. Lin, C. Menedez-Botet, W. Tong, Phase I trial of high-dose tamoxifen as a modulator of drug resistance in combination with daunorubicin in patients with relapsed or refractory acute leukemia, Leukemia, 9 (1995) 1631-1637.

[47] T. Ozben, Mechanisms and strategies to overcome multiple drug resistance in cancer, FEBS Lett, 580 (2006) 2903-2909.

[48] P.R. Twentyman, N.M. Bleehen, Resistance modification by PSC-833, a novel nonimmunosuppressive cyclosporin [corrected], Eur J Cancer, 27 (1991) 1639-1642.

[49] U.A. Germann, D. Shlyakhter, V.S. Mason, R.E. Zelle, J.P. Duffy, V. Galullo, D.M. Armistead, J.O. Saunders, J. Boger, M.W. Harding, Cellular and biochemical characterization of VX-710 as a chemosensitizer: reversal of P-glycoprotein-mediated multidrug resistance in vitro, Anticancer Drugs, 8 (1997) 125-140.

[50] V. Hollt, M. Kouba, M. Dietel, G. Vogt, Stereoisomers of calcium antagonists which differ markedly in their potencies as calcium blockers are equally effective in modulating drug transport by P-glycoprotein, Biochem Pharmacol, 43 (1992) 2601-2608.

[51] M. Dietel, H. Boss, A. Reymann, S. Pest, A. Seidel, In vivo reversibility of multidrug resistance by the MDR-modulator dexniguldipine (niguldipine derivative B859-35) and by verapamil, J Exp Ther Oncol, 1 (1996) 23-29.

[52] F. Hyafil, C. Vergely, P. Du Vignaud, T. Grand-Perret, In vitro and in vivo reversal of multidrug resistance by GF120918, an acridonecarboxamide derivative, Cancer Res, 53 (1993) 4595-4602.

[53] M. Roe, A. Folkes, P. Ashworth, J. Brumwell, L. Chima, S. Hunjan, I. Pretswell, W. Dangerfield, H. Ryder, P. Charlton, Reversal of P-glycoprotein mediated multidrug resistance by novel anthranilamide derivatives, Bioorg Med Chem Lett, 9 (1999) 595-600. 
[54] D.L. Slate, N.A. Bruno, S.M. Casey, N. Zutshi, L.J. Garvin, H. Wu, J.R. Pfister, RS33295-198: a novel, potent modulator of P-glycoprotein-mediated multidrug resistance, Anticancer Res, 15 (1995) 811-814.

[55] M.J. Newman, J.C. Rodarte, K.D. Benbatoul, S.J. Romano, C. Zhang, S. Krane, E.J. Moran, R.T. Uyeda, R. Dixon, E.S. Guns, L.D. Mayer, Discovery and characterization of OC144-093, a novel inhibitor of P-glycoprotein-mediated multidrug resistance, Cancer Res, 60 (2000) 2964-2972.

[56] F. Narasaki, M. Oka, M. Fukuda, R. Nakano, K. Ikeda, H. Takatani, K. Terashi, H. Soda, O. Yano, T. Nakamura, L.A. Doyle, T. Tsuruo, S. Kohno, A novel quinoline derivative, MS209, overcomes drug resistance of human lung cancer cells expressing the multidrug resistance-associated protein (MRP) gene, Cancer Chemother Pharmacol, 40 (1997) 425-432.

[57] L. van Zuylen, A. Sparreboom, A. van der Gaast, M.E. van der Burg, V. van Beurden, C.J. Bol, R. Woestenborghs, P.A. Palmer, J. Verweij, The orally administered P-glycoprotein inhibitor R101933 does not alter the plasma pharmacokinetics of docetaxel, Clin Cancer Res, 6 (2000) 1365-1371.

[58] B.S. De Juan, H. Von Briesen, S.E. Gelperina, J. Kreuter, Cytotoxicity of doxorubicin bound to poly(butyl cyanoacrylate) nanoparticles in rat glioma cell lines using different assays, J Drug Target, 14 (2006) 614-622.

[59] X. Dong, C.A. Mattingly, M.T. Tseng, M.J. Cho, Y. Liu, V.R. Adams, R.J. Mumper, Doxorubicin and paclitaxel-loaded lipid-based nanoparticles overcome multidrug resistance by inhibiting P-glycoprotein and depleting ATP, Cancer Res, 69 (2009) 3918-3926.

[60] Y. Shono, H. Nishihara, Y. Matsuda, S. Furukawa, N. Okada, T. Fujita, A. Yamamoto, Modulation of intestinal P-glycoprotein function by cremophor EL and other surfactants by an in vitro diffusion chamber method using the isolated rat intestinal membranes, J Pharm Sci, 93 (2004) 877-885.

[61] A. Lamprecht, J.P. Benoit, Etoposide nanocarriers suppress glioma cell growth by intracellular drug delivery and simultaneous P-glycoprotein inhibition, J Control Release, 112 (2006) 208-213.

[62] Y.L. Lo, Relationships between the hydrophilic-lipophilic balance values of pharmaceutical excipients and their multidrug resistance modulating effect in Caco-2 cells and rat intestines, J Control Release, 90 (2003) 37-48.

[63] R.D. Dabholkar, R.M. Sawant, D.A. Mongayt, P.V. Devarajan, V.P. Torchilin, Polyethylene glycol-phosphatidylethanolamine conjugate (PEG-PE)-based mixed micelles: some properties, loading with paclitaxel, and modulation of P-glycoprotein-mediated efflux, Int J Pharm, 315 (2006) 148-157.

[64] J. Zastre, J. Jackson, M. Bajwa, R. Liggins, F. Iqbal, H. Burt, Enhanced cellular accumulation of a P-glycoprotein substrate, rhodamine-123, by Caco-2 cells using low molecular weight methoxypolyethylene glycol-block-polycaprolactone diblock copolymers, Eur J Pharm Biopharm, 54 (2002) 299-309. 
[65] Z. Binkhathlan, D.A. Hamdy, D.R. Brocks, A. Lavasanifar, Development of a polymeric micellar formulation for valspodar and assessment of its pharmacokinetics in rat, Eur J Pharm Biopharm, 75 90-95.

[66] A.V. Kabanov, E.V. Batrakova, V.Y. Alakhov, Pluronic block copolymers as novel polymer therapeutics for drug and gene delivery, J Control Release, 82 (2002) 189-212.

[67] J.P. Jaffrezou, J.M. Herbert, T. Levade, M.N. Gau, P. Chatelain, G. Laurent, Reversal of multidrug resistance by calcium channel blocker SR33557 without photoaffinity labeling of P-glycoprotein, J Biol Chem, 266 (1991) 19858-19864.

[68] V.J. Wacher, C.Y. Wu, L.Z. Benet, Overlapping substrate specificities and tissue distribution of cytochrome P450 3A and P-glycoprotein: implications for drug delivery and activity in cancer chemotherapy, Mol Carcinog, 13 (1995) 129-134.

[69] V. Fischer, A. Rodriguez-Gascon, F. Heitz, R. Tynes, C. Hauck, D. Cohen, A.E. Vickers, The multidrug resistance modulator valspodar (PSC 833) is metabolized by human cytochrome P450 3A. Implications for drug-drug interactions and pharmacological activity of the main metabolite, Drug Metab Dispos, 26 (1998) 802-811.

[70] M. Liscovitch, Y. Lavie, Cancer multidrug resistance: a review of recent drug discovery research, IDrugs, 5 (2002) 349-355.

[71] C. Lhomme, F. Joly, J.L. Walker, A.A. Lissoni, M.O. Nicoletto, G.M. Manikhas, M.M. Baekelandt, A.N. Gordon, P.M. Fracasso, W.L. Mietlowski, G.J. Jones, M.H. Dugan, Phase III study of valspodar (PSC 833) combined with paclitaxel and carboplatin compared with paclitaxel and carboplatin alone in patients with stage IV or suboptimally debulked stage III epithelial ovarian cancer or primary peritoneal cancer, J Clin Oncol, 26 (2008) 2674-2682.

[72] W.R. Friedenberg, M. Rue, E.A. Blood, W.S. Dalton, C. Shustik, R.A. Larson, P. Sonneveld, P.R. Greipp, Phase III study of PSC-833 (valspodar) in combination with vincristine, doxorubicin, and dexamethasone (valspodar/VAD) versus VAD alone in patients with recurring or refractory multiple myeloma (E1A95): a trial of the Eastern Cooperative Oncology Group, Cancer, 106 (2006) 830-838.

[73] H. Gelderblom, J. Verweij, K. Nooter, A. Sparreboom, Cremophor EL: the drawbacks and advantages of vehicle selection for drug formulation, Eur J Cancer, 37 (2001) 1590-1598.

[74] R.P. Rago, A. Einstein, Jr., R. Lush, T.M. Beer, Y.J. Ko, W.D. Henner, G. Bubley, E.A. Merica, V. Garg, E. Ette, M.W. Harding, W.S. Dalton, Safety and efficacy of the MDR inhibitor Incel (biricodar, VX-710) in combination with mitoxantrone and prednisone in hormone-refractory prostate cancer, Cancer Chemother Pharmacol, 51 (2003) 297-305.

[75] M.V. Seiden, K.D. Swenerton, U. Matulonis, S. Campos, P. Rose, G. Batist, E. Ette, V. Garg, A. Fuller, M.W. Harding, D. Charpentier, A phase II study of the MDR inhibitor biricodar (INCEL, VX-710) and paclitaxel in women with advanced ovarian cancer refractory to paclitaxel therapy, Gynecol Oncol, 86 (2002) 302-310.

[76] D. den Ouden, M. van den Heuvel, M. Schoester, G. van Rens, P. Sonneveld, In vitro effect of GF120918, a novel reversal agent of multidrug resistance, on acute leukemia and multiple myeloma cells, Leukemia, 10 (1996) 1930-1936. 
[77] S.P. Letrent, G.M. Pollack, K.R. Brouwer, K.L. Brouwer, Effect of GF120918, a potent P-glycoprotein inhibitor, on morphine pharmacokinetics and pharmacodynamics in the rat, Pharm Res, 15 (1998) 599-605.

[78] M.S. Myer, G. Joone, M.R. Chasen, C.E. van Rensburg, The chemosensitizing potential of GF120918 is independent of the magnitude of P-glycoprotein-mediated resistance to conventional chemotherapeutic agents in a small cell lung cancer line, Oncol Rep, 6 (1999) 217-218.

[79] A. Sparreboom, A.S. Planting, R.C. Jewell, M.E. van der Burg, A. van der Gaast, P. de Bruijn, W.J. Loos, K. Nooter, L.H. Chandler, E.M. Paul, P.S. Wissel, J. Verweij, Clinical pharmacokinetics of doxorubicin in combination with GF120918, a potent inhibitor of MDR1 P-glycoprotein, Anticancer Drugs, 10 (1999) 719-728.

[80] M.M. Malingre, J.H. Beijnen, H. Rosing, F.J. Koopman, R.C. Jewell, E.M. Paul, W.W. Ten Bokkel Huinink, J.H. Schellens, Co-administration of GF120918 significantly increases the systemic exposure to oral paclitaxel in cancer patients, Br J Cancer, 84 (2001) 42-47.

[81] A.S. Planting, P. Sonneveld, A. van der Gaast, A. Sparreboom, M.E. van der Burg, G.P. Luyten, K. de Leeuw, M. de Boer-Dennert, P.S. Wissel, R.C. Jewell, E.M. Paul, N.B. Purvis, Jr., J. Verweij, A phase I and pharmacologic study of the MDR converter GF120918 in combination with doxorubicin in patients with advanced solid tumors, Cancer Chemother Pharmacol, 55 (2005) 91-99.

[82] I.E. Kuppens, E.O. Witteveen, R.C. Jewell, S.A. Radema, E.M. Paul, S.G. Mangum, J.H. Beijnen, E.E. Voest, J.H. Schellens, A phase I, randomized, open-label, parallel-cohort, dosefinding study of elacridar (GF120918) and oral topotecan in cancer patients, Clin Cancer Res, 13 (2007) 3276-3285.

[83] C.M. Kruijtzer, J.H. Beijnen, H. Rosing, W.W. ten Bokkel Huinink, M. Schot, R.C. Jewell, E.M. Paul, J.H. Schellens, Increased oral bioavailability of topotecan in combination with the breast cancer resistance protein and P-glycoprotein inhibitor GF120918, J Clin Oncol, 20 (2002) 2943-2950.

[84] B. Antonsson, F. Conti, A. Ciavatta, S. Montessuit, S. Lewis, I. Martinou, L. Bernasconi, A. Bernard, J.J. Mermod, G. Mazzei, K. Maundrell, F. Gambale, R. Sadoul, J.C. Martinou, Inhibition of Bax channel-forming activity by Bcl-2, Science, 277 (1997) 370-372.

[85] P. Mistry, A.J. Stewart, W. Dangerfield, S. Okiji, C. Liddle, D. Bootle, J.A. Plumb, D. Templeton, P. Charlton, In vitro and in vivo reversal of P-glycoprotein-mediated multidrug resistance by a novel potent modulator, XR9576, Cancer Res, 61 (2001) 749-758.

[86] J. Abraham, M. Edgerly, R. Wilson, C. Chen, A. Rutt, S. Bakke, R. Robey, A. Dwyer, B. Goldspiel, F. Balis, O. Van Tellingen, S.E. Bates, T. Fojo, A phase I study of the Pglycoprotein antagonist tariquidar in combination with vinorelbine, Clin Cancer Res, 15 (2009) 3574-3582.

[87] R.J. Kelly, D. Draper, C.C. Chen, R.W. Robey, W.D. Figg, R.L. Piekarz, X. Chen, E.R. Gardner, F.M. Balis, A.M. Venkatesan, S.M. Steinberg, T. Fojo, S.E. Bates, A pharmacodynamic study of docetaxel in combination with the P-glycoprotein antagonist tariquidar (XR9576) in patients with lung, ovarian, and cervical cancer, Clin Cancer Res, 17 569-580. 
[88] D. Kurnik, G.G. Sofowora, J.P. Donahue, U.B. Nair, G.R. Wilkinson, A.J. Wood, M. Muszkat, Tariquidar, a selective P-glycoprotein inhibitor, does not potentiate loperamide's opioid brain effects in humans despite full inhibition of lymphocyte P-glycoprotein, Anesthesiology, 109 (2008) 1092-1099.

[89] E.F. Choo, D. Kurnik, M. Muszkat, T. Ohkubo, S.D. Shay, J.N. Higginbotham, H. Glaeser, R.B. Kim, A.J. Wood, G.R. Wilkinson, Differential in vivo sensitivity to inhibition of P-glycoprotein located in lymphocytes, testes, and the blood-brain barrier, J Pharmacol Exp Ther, 317 (2006) 1012-1018.

[90] F. Morschhauser, P.L. Zinzani, M. Burgess, L. Sloots, F. Bouafia, C. Dumontet, Phase I/II trial of a P-glycoprotein inhibitor, Zosuquidar.3HCl trihydrochloride (LY335979), given orally in combination with the CHOP regimen in patients with non-Hodgkin's lymphoma, Leuk Lymphoma, 48 (2007) 708-715.

[91] A. Sandler, M. Gordon, D.P. De Alwis, I. Pouliquen, L. Green, P. Marder, A. Chaudhary, K. Fife, L. Battiato, C. Sweeney, C. Jordan, M. Burgess, C.A. Slapak, A Phase I trial of a potent P-glycoprotein inhibitor, zosuquidar trihydrochloride (LY335979), administered intravenously in combination with doxorubicin in patients with advanced malignancy, Clin Cancer Res, 10 (2004) 3265-3272.

[92] P.M. Fracasso, L.J. Goldstein, D.P. de Alwis, J.S. Rader, M.A. Arquette, S.A. Goodner, L.P. Wright, C.L. Fears, R.J. Gazak, V.A. Andre, M.F. Burgess, C.A. Slapak, J.H. Schellens, Phase I study of docetaxel in combination with the P-glycoprotein inhibitor, zosuquidar, in resistant malignancies, Clin Cancer Res, 10 (2004) 7220-7228.

[93] J.F. Marcelletti, P.S. Multani, J.E. Lancet, M.R. Baer, B.I. Sikic, Leukemic blast and natural killer cell P-glycoprotein function and inhibition in a clinical trial of zosuquidar infusion in acute myeloid leukemia, Leuk Res, 33 (2009) 769-774.

[94] J.E. Lancet, M.R. Baer, G.E. Duran, A.F. List, R. Fielding, J.F. Marcelletti, P.S. Multani, B.I. Sikic, A phase I trial of continuous infusion of the multidrug resistance inhibitor zosuquidar with daunorubicin and cytarabine in acute myeloid leukemia, Leuk Res, 33 (2009) 1055-1061.

[95] E.M. Kemper, C. Cleypool, W. Boogerd, J.H. Beijnen, O. van Tellingen, The influence of the P-glycoprotein inhibitor zosuquidar trihydrochloride (LY335979) on the brain penetration of paclitaxel in mice, Cancer Chemother Pharmacol, 53 (2004) 173-178.

[96] B.D. Anderson, M.J. May, S. Jordan, L. Song, M.J. Roberts, M. Leggas, Dependence of nelfinavir brain uptake on dose and tissue concentrations of the selective P-glycoprotein inhibitor zosuquidar in rats, Drug Metab Dispos, 34 (2006) 653-659.

[97] L. van Zuylen, A. Sparreboom, A. van der Gaast, K. Nooter, F.A. Eskens, E. Brouwer, C.J. Bol, R. de Vries, P.A. Palmer, J. Verweij, Disposition of docetaxel in the presence of Pglycoprotein inhibition by intravenous administration of R101933, Eur J Cancer, 38 (2002) 1090-1099.

[98] K.N. Chi, S.K. Chia, R. Dixon, M.J. Newman, V.J. Wacher, B. Sikic, K.A. Gelmon, A phase I pharmacokinetic study of the P-glycoprotein inhibitor, ONT-093, in combination with paclitaxel in patients with advanced cancer, Invest New Drugs, 23 (2005) 311-315. 
[99] C.A. McDevitt, R. Callaghan, How can we best use structural information on Pglycoprotein to design inhibitors?, Pharmacol Ther, 113 (2007) 429-441.

[100] E.V. Batrakova, S. Li, Y. Li, V.Y. Alakhov, A.V. Kabanov, Effect of pluronic P85 on ATPase activity of drug efflux transporters, Pharm Res, 21 (2004) 2226-2233.

[101] Z. Zhang, S.S. Feng, The drug encapsulation efficiency, in vitro drug release, cellular uptake and cytotoxicity of paclitaxel-loaded poly(lactide)-tocopheryl polyethylene glycol succinate nanoparticles, Biomaterials, 27 (2006) 4025-4033.

[102] E. Garcion, A. Lamprecht, B. Heurtault, A. Paillard, A. Aubert-Pouessel, B. Denizot, P. Menei, J.P. Benoit, A new generation of anticancer, drug-loaded, colloidal vectors reverses multidrug resistance in glioma and reduces tumor progression in rats, Mol Cancer Ther, 5 (2006) 1710-1722.

[103] M.L. Immordino, P. Brusa, F. Rocco, S. Arpicco, M. Ceruti, L. Cattel, Preparation, characterization, cytotoxicity and pharmacokinetics of liposomes containing lipophilic gemcitabine prodrugs, J Control Release, 100 (2004) 331-346.

[104] A.O. Nornoo, D.W. Osborne, D.S. Chow, Cremophor-free intravenous microemulsions for paclitaxel I: formulation, cytotoxicity and hemolysis, Int J Pharm, 349 (2008) 108-116.

[105] S.M. Moghimi, J. Szebeni, Stealth liposomes and long circulating nanoparticles: critical issues in pharmacokinetics, opsonization and protein-binding properties, Prog Lipid Res, 42 (2003) 463-478.

[106] A.C. de Verdiere, C. Dubernet, F. Nemati, E. Soma, M. Appel, J. Ferte, S. Bernard, F. Puisieux, P. Couvreur, Reversion of multidrug resistance with polyalkylcyanoacrylate nanoparticles: towards a mechanism of action, Br J Cancer, 76 (1997) 198-205.

[107] B. Heurtault, P. Saulnier, B. Pech, J.E. Proust, J.P. Benoit, A novel phase inversionbased process for the preparation of lipid nanocarriers, Pharm Res, 19 (2002) 875-880.

[108] J.M. Koziara, P.R. Lockman, D.D. Allen, R.J. Mumper, Paclitaxel nanoparticles for the potential treatment of brain tumors, J Control Release, 99 (2004) 259-269.

[109] P. Ma, X. Dong, C.L. Swadley, A. Gupte, M. Leggas, H.C. Ledebur, R.J. Mumper, Development of idarubicin and doxorubicin solid lipid nanoparticles to overcome Pgpmediated multiple drug resistance in leukemia, J Biomed Nanotechnol, 5 (2009) 151-161.

[110] D.M. Woodcock, M.E. Linsenmeyer, G. Chojnowski, A.B. Kriegler, V. Nink, L.K. Webster, W.H. Sawyer, Reversal of multidrug resistance by surfactants, Br J Cancer, 66 (1992) 62-68.

[111] M.D. Chavanpatil, A. Khdair, B. Gerard, C. Bachmeier, D.W. Miller, M.P. Shekhar, J. Panyam, Surfactant-polymer nanoparticles overcome P-glycoprotein-mediated drug efflux, Mol Pharm, 4 (2007) 730-738.

[112] V. Munic, Z. Kelneric, L. Mikac, V. Erakovic Haber, Differences in assessment of macrolide interaction with human MDR1 (ABCB1, P-gp) using rhodamine-123 efflux, ATPase activity and cellular accumulation assays, Eur J Pharm Sci, 41 (2010) 86-95. 
[113] C. Maupas, B. Moulari, A. Beduneau, A. Lamprecht, Y. Pellequer, Surfactant dependent toxicity of lipid nanocapsules in HaCaT cells, Int J Pharm, 411 (2011) 136-141.

[114] A.V. Kabanov, V.I. Slepnev, L.E. Kuznetsova, E.V. Batrakova, V. Alakhov, N.S. Melik-Nubarov, P.G. Sveshnikov, V.A. Kabanov, Pluronic micelles as a tool for lowmolecular compound vector delivery into a cell: effect of Staphylococcus aureus enterotoxin B on cell loading with micelle incorporated fluorescent dye, Biochem Int, 26 (1992) 10351042 .

[115] T. Wang, V.A. Petrenko, V.P. Torchilin, Paclitaxel-loaded polymeric micelles modified with MCF-7 cell-specific phage protein: enhanced binding to target cancer cells and increased cytotoxicity, Mol Pharm, 7 (2010) 1007-1014.

[116] P.K. Dudeja, K.M. Anderson, J.S. Harris, L. Buckingham, J.S. Coon, Reversal of multidrug resistance phenotype by surfactants: relationship to membrane lipid fluidity, Arch Biochem Biophys, 319 (1995) 309-315.

[117] E.V. Batrakova, S. Li, S.V. Vinogradov, V.Y. Alakhov, D.W. Miller, A.V. Kabanov, Mechanism of pluronic effect on P-glycoprotein efflux system in blood-brain barrier: contributions of energy depletion and membrane fluidization, J Pharmacol Exp Ther, 299 (2001) 483-493.

[118] S. Zhu, R. Huang, M. Hong, Y. Jiang, Z. Hu, C. Liu, Y. Pei, Effects of polyoxyethylene (40) stearate on the activity of P-glycoprotein and cytochrome P450, Eur J Pharm Sci, 37 (2009) 573-580.

[119] B.D. Rege, J.P. Kao, J.E. Polli, Effects of nonionic surfactants on membrane transporters in Caco-2 cell monolayers, Eur J Pharm Sci, 16 (2002) 237-246.

[120] D.Y. Alakhova, N.Y. Rapoport, E.V. Batrakova, A.A. Timoshin, S. Li, D. Nicholls, V.Y. Alakhov, A.V. Kabanov, Differential metabolic responses to pluronic in MDR and nonMDR cells: a novel pathway for chemosensitization of drug resistant cancers, J Control Release, 142 (2011) 89-100.

[121] E.V. Batrakova, H.Y. Han, D.W. Miller, A.V. Kabanov, Effects of pluronic P85 unimers and micelles on drug permeability in polarized BBMEC and Caco-2 cells, Pharm Res, 15 (1998) 1525-1532.

[122] V. Alakhov, E. Klinski, P. Lemieux, G. Pietrzynski, A. Kabanov, Block copolymeric biotransport carriers as versatile vehicles for drug delivery, Expert Opin Biol Ther, 1 (2001) 583-602.

[123] D.W. Miller, E.V. Batrakova, T.O. Waltner, V. Alakhov, A.V. Kabanov, Interactions of pluronic block copolymers with brain microvessel endothelial cells: evidence of two potential pathways for drug absorption, Bioconjug Chem, 8 (1997) 649-657.

[124] X. Zhu, M. Sui, W. Fan, In vitro and in vivo characterizations of tetrandrine on the reversal of P-glycoprotein-mediated drug resistance to paclitaxel, Anticancer Res, 25 (2005) 1953-1962. 
[125] J. Zastre, J. Jackson, H. Burt, Evidence for modulation of P-glycoprotein-mediated efflux by methoxypolyethylene glycol-block-Polycaprolactone amphiphilic diblock copolymers, Pharm Res, 21 (2004) 1489-1497.

[126] J. Zastre, J.K. Jackson, W. Wong, H.M. Burt, Methoxypolyethylene glycol-blockpolycaprolactone diblock copolymers reduce P-glycoprotein efflux in the absence of a membrane fluidization effect while stimulating P-glycoprotein ATPase activity, J Pharm Sci, 96 (2007) 864-875.

[127] T. Kobayashi, T. Ishida, Y. Okada, S. Ise, H. Harashima, H. Kiwada, Effect of transferrin receptor-targeted liposomal doxorubicin in P-glycoprotein-mediated drug resistant tumor cells, Int J Pharm, 329 (2007) 94-102.

[128] D. Goren, A.T. Horowitz, D. Tzemach, M. Tarshish, S. Zalipsky, A. Gabizon, Nuclear delivery of doxorubicin via folate-targeted liposomes with bypass of multidrug-resistance efflux pump, Clin Cancer Res, 6 (2000) 1949-1957.

[129] X. Wang, J. Li, Y. Wang, L. Koenig, A. Gjyrezi, P. Giannakakou, E.H. Shin, M. Tighiouart, Z.G. Chen, S. Nie, D.M. Shin, A folate receptor-targeting nanoparticle minimizes drug resistance in a human cancer model, ACS Nano, 5 (2011) 6184-6194.

[130] J. Wang, B. Goh, W. Lu, Q. Zhang, A. Chang, X.Y. Liu, T.M. Tan, H. Lee, In vitro cytotoxicity of Stealth liposomes co-encapsulating doxorubicin and verapamil on doxorubicin-resistant tumor cells, Biol Pharm Bull, 28 (2005) 822-828.

[131] Y. Lo, F. Liu, J. Cherng, Effect of PSC 833 liposomes and Intralipid on the transport of epirubicin in Caco-2 cells and rat intestines, J Control Release, 76 (2001) 1-10.

[132] Y.L. Lo, F.I. Liu, J.M. Yang, J.Y. Cherng, Reversal of multidrug resistance to epirubicin by cyclosporin A in liposomes or intralipid, Anticancer Res, 21 (2001) 445-450.

[133] R. Krishna, L.D. Mayer, Liposomal doxorubicin circumvents PSC 833-free drug interactions, resulting in effective therapy of multidrug-resistant solid tumors, Cancer Res, 57 (1997) 5246-5253.

[134] R. Krishna, N. McIntosh, K.W. Riggs, L.D. Mayer, Doxorubicin encapsulated in sterically stabilized liposomes exhibits renal and biliary clearance properties that are independent of valspodar (PSC 833) under conditions that significantly inhibit nonencapsulated drug excretion, Clin Cancer Res, 5 (1999) 2939-2947.

[135] R. Krishna, M. St-Louis, L.D. Mayer, Increased intracellular drug accumulation and complete chemosensitization achieved in multidrug-resistant solid tumors by co-administering valspodar (PSC 833) with sterically stabilized liposomal doxorubicin, Int J Cancer, 85 (2000) 131-141.

[136] P.M. Fracasso, K.A. Blum, M.K. Ma, B.R. Tan, L.P. Wright, S.A. Goodner, C.L. Fears, W. Hou, M.A. Arquette, J. Picus, A. Denes, J.E. Mortimer, L. Ratner, S.P. Ivy, H.L. McLeod, Phase I study of pegylated liposomal doxorubicin and the multidrug-resistance modulator, valspodar, Br J Cancer, 93 (2005) 46-53. 
[137] X.R. Song, Z. Cai, Y. Zheng, G. He, F.Y. Cui, D.Q. Gong, S.X. Hou, S.J. Xiong, X.J. Lei, Y.Q. Wei, Reversion of multidrug resistance by co-encapsulation of vincristine and verapamil in PLGA nanoparticles, Eur J Pharm Sci, 37 (2009) 300-305.

[138] J.C. Wang, X.Y. Liu, W.L. Lu, A. Chang, Q. Zhang, B.C. Goh, H.S. Lee, Pharmacokinetics of intravenously administered stealth liposomal doxorubicin modulated with verapamil in rats, Eur J Pharm Biopharm, 62 (2006) 44-51.

[139] N.R. Patel, A. Rathi, D. Mongayt, V.P. Torchilin, Reversal of multidrug resistance by co-delivery of tariquidar (XR9576) and paclitaxel using long-circulating liposomes, Int J Pharm, (2011).

[140] J. Wu, Y. Lu, A. Lee, X. Pan, X. Yang, X. Zhao, R.J. Lee, Reversal of multidrug resistance by transferrin-conjugated liposomes co-encapsulating doxorubicin and verapamil, $\mathrm{J}$ Pharm Pharm Sci, 10 (2007) 350-357.

[141] J. Du, W.L. Lu, X. Ying, Y. Liu, P. Du, W. Tian, Y. Men, J. Guo, Y. Zhang, R.J. Li, J. Zhou, J.N. Lou, J.C. Wang, X. Zhang, Q. Zhang, Dual-targeting topotecan liposomes modified with tamoxifen and wheat germ agglutinin significantly improve drug transport across the blood-brain barrier and survival of brain tumor-bearing animals, Mol Pharm, 6 (2009) 905-917.

[142] D.H. Levine, P.P. Ghoroghchian, J. Freudenberg, G. Zhang, M.J. Therien, M.I. Greene, D.A. Hammer, R. Murali, Polymersomes: a new multi-functional tool for cancer diagnosis and therapy, Methods, 46 (2008) 25-32.

[143] C.L. Dai, H.Y. Xiong, L.F. Tang, X. Zhang, Y.J. Liang, M.S. Zeng, L.M. Chen, X.H. Wang, L.W. Fu, Tetrandrine achieved plasma concentrations capable of reversing MDR in vitro and had no apparent effect on doxorubicin pharmacokinetics in mice, Cancer Chemother Pharmacol, 60 (2007) 741-750.

[144] L. Fu, Y. Liang, L. Deng, Y. Ding, L. Chen, Y. Ye, X. Yang, Q. Pan, Characterization of tetrandrine, a potent inhibitor of P-glycoprotein-mediated multidrug resistance, Cancer Chemother Pharmacol, 53 (2004) 349-356.

[145] Z. Pang, L. Feng, R. Hua, J. Chen, H. Gao, S. Pan, X. Jiang, P. Zhang, Lactoferrinconjugated biodegradable polymersome holding Doxorubicin and tetrandrine for chemotherapy of glioma rats, Mol Pharm, 7 (2010) 1995-2005.

[146] C.E. Soma, C. Dubernet, D. Bentolila, S. Benita, P. Couvreur, Reversion of multidrug resistance by co-encapsulation of doxorubicin and cyclosporin A in polyalkylcyanoacrylate nanoparticles, Biomaterials, 21 (2000) 1-7.

[147] Y. Patil, T. Sadhukha, L. Ma, J. Panyam, Nanoparticle-mediated simultaneous and targeted delivery of paclitaxel and tariquidar overcomes tumor drug resistance, J Control Release, 136 (2009) 21-29.

[148] H.L. Wong, R. Bendayan, A.M. Rauth, X.Y. Wu, Simultaneous delivery of doxorubicin and GG918 (Elacridar) by new polymer-lipid hybrid nanoparticles (PLN) for enhanced treatment of multidrug-resistant breast cancer, J Control Release, 116 (2006) 275-284. 
[149] B. Chen, Q. Sun, X. Wang, F. Gao, Y. Dai, Y. Yin, J. Ding, C. Gao, J. Cheng, J. Li, X. Sun, N. Chen, W. Xu, H. Shen, D. Liu, Reversal in multidrug resistance by magnetic nanoparticle of $\mathrm{Fe} 3 \mathrm{O} 4$ loaded with adriamycin and tetrandrine in K562/A02 leukemic cells, Int J Nanomedicine, 3 (2008) 277-286.

[150] X.R. Song, Y. Zheng, G. He, L. Yang, Y.F. Luo, Z.Y. He, S.Z. Li, J.M. Li, S. Yu, X. Luo, S.X. Hou, Y.Q. Wei, Development of PLGA nanoparticles simultaneously loaded with vincristine and verapamil for treatment of hepatocellular carcinoma, J Pharm Sci, 99 (2010) 4874-4879. 


\section{OBJECTIVES OF THE WORK}

Although P-gp represents an obstacle to tackle in order to succeed several central nervous system pharmacotherapies, it is irrefutable that the main role of P-gp is to protect the brain from intoxication by endogenous and exogenous harmful lipophilic compounds that otherwise could penetrate the BBB by simple diffusion. Therefore, any modulation of the efflux transporter has to consider the potential neurotoxicity of such modulation.

Elacridar and tariquidar are two potent third-generation P-gp modulators that proved to increase the distribution of several P-gp substrates into the brain in various in vivo studies. Unfortunately, elacridar also demonstrated a high plasma protein binding in rat and human species, which means that high doses of elacridar are required to saturate the protein binding and modulate the P-gp-mediated efflux at the BBB. However, at relative high doses, elacridar not only increases the P-gp substrates levels in the brain but also in other vital organs, such as the liver. Moreover, the bound portion of elacridar may act as a depot from which the P-gp modulator would be slowly released, lengthening its pharmacological effects. Similarly, because tariquidar failed to produce significant central nervous effects caused by loperamide, recent studies suggest the use of high doses of this P-gp modulator to efficiently modulate the P-gp at the BBB. Nevertheless, when co-administered with P-gp substrates, these high doses may be associated with pharmacokinetic interactions and toxic profiles, thus limiting the use of these compounds.

The general aim of this thesis was then to engineer a different strategy to attain a transient but efficient modulation of the P-gp-mediated efflux at the BBB using elacridar and tariquidar but avoiding the use of large doses of these compounds. As seen in various diseases, the use of multiple drugs with different binding sites or targets increases the efficacy of the therapy via synergistic effects, while enables dose reduction and avoids drug resistance and toxicity. A specific goal was hence to evaluate the concomitant administration of low but therapeutic doses of elacridar and tariquidar and its impact on the pharmacokinetics and brain distribution of a P-gp substrate probe, loperamide. For this purpose an analytical method for the appropriate measurement of these three compounds in biological fluids was firstly required. Immunocarriers have been widely recognized as a promising tool for specific delivery across the BBB due to their increased permeability against the brain. Therefore another specific goal was to develop an immunonanocarrier to improve the pharmacokinetics and brain distribution 
of elacridar and tariquidar and consequently enhance the brain uptake of loperamide. Although the aforementioned strategies represent steps forward to improve the efficacy of central nervous system pharmacotherapies, they do not counteract the possible neurotoxicity caused by large doses of elacridar and tariquidar to modulate the P-gp at the BBB. The administration of empty nanocarriers that can extract the P-gp modulators from the circulation and brain could avoid a long exposure and a long-lasting P-gp modulation. To this extent the goal was to investigate the potential of nanocarriers as bio-detoxifying agents for elacridar and tariquidar. 


\title{
4 SIMULTANEOUS DETERMINATION OF LOPERAMIDE, ELACRIDAR AND $\begin{array}{llllllll}\text { TARIQUIDAR IN RAT } & \text { PLASMA AND } & \text { TISSUES } & \text { BY LIQUID }\end{array}$ CHROMATOGRAPHY-MASS SPECTROMETRY: DEVELOPMENT AND VALIDATION
}

\begin{abstract}
A rapid, sensitive, precise and accurate liquid chromatography-mass spectrometry (LC-MS) method was developed and validated for the simultaneous determination of loperamide, elacridar and tariquidar in rat plasma, brain, liver and kidneys. The sample preparation method used acetonitrile and tert-butyl methyl ether. Ketoconazole was used as internal standard for loperamide and chlorpromazine for elacridar and tariquidar. Analytes were separated on a Zorbax Eclipse XDB-C18 column with isocratic elution of ammonium acetate $(\mathrm{pH} 5.5 ; 10 \mathrm{mM})$-methanol-acetonitrile $(37.5: 40.0: 22.5 \mathrm{v} / \mathrm{v} / \mathrm{v})$ at $0.4 \mathrm{~mL} / \mathrm{min}$. Detection was performed using positive electrospray ionization in an octapole quadrupole mass spectrometer operating in single ion monitoring mode. The developed LC-MS method presented a run time of 12 minutes and was used to construct linear calibration curves over the concentration range $5.0 \mathrm{ng} / \mathrm{mL}-1000 \mathrm{ng} / \mathrm{mL}$ for loperamide, elacridar and tariquidar $\left(\mathrm{r}^{2} \geq 0.9990\right)$. Using $100 \mu \mathrm{L}$ of rat plasma or tissue homogenate, the validated lower limit of quantification (LLOQ) for each compound was the lowest concentration of standard on the calibration curves, 5.0 $\mathrm{ng} / \mathrm{mL}$. Intra- and inter-day accuracy and precision were within $15 \%$ for the three analytes. The specificity of the method was confirmed by the absence of interferences from endogenous compounds. The applicability of the current method was assessed utilizing plasma and tissues samples obtained during the pharmacokinetic and tissue distribution studies of loperamide, elacridar and tariquidar in Sprague Dawley rats.
\end{abstract}

Keywords: Loperamide, elacridar, tariquidar, LC-MS, rat plasma, rat tissues and validation. 


\subsection{Introduction}

The presence of various efflux transporters at the blood-brain barrier (BBB) acts as a gatekeeper in the entry of many therapeutic drugs into the brain. Based on three critical defining criteria (multi-specificity, location and energetics), P-glycoprotein (P-gp) is considered to be the most important efflux transport at the BBB [1].

Clinical studies have revealed that over-expression of P-gp at the human BBB can exert a profound effect on the ability of HIV protease inhibitors, anticancer drugs, opioids, some psychotropics and other drugs leading to the failure of various clinical treatments for brain diseases [2-4]. The inhibition of P-gp could enhance the distribution of these substrates into the brain and therefore improve central nervous system (CNS) pharmacotherapies.

Interesting studies have demonstrated that elacridar and tariquidar are able to mediate the efflux of numerous P-gp substrates in different BBB in vitro and in vivo models $[5,6]$. These third-generation P-gp modulators are non-competitive, well-tolerated, without significant side effects and much less pharmacokinetics interactions. Based on an anti-nociceptive response model, Choo et al. showed that loperamide, a $\mu$-opioid agonist without central effects could become a drug that produces substantial anti-nociception in the presence of elacridar or tariquidar [7].

To further investigate the pre-clinical pharmacokinetic interaction after concurrent intravenous administration of loperamide and elacridar and/or tariquidar, a simultaneous determination of the three molecules is therefore highly desirable. Liquid chromatography methods using ultraviolet, fluorescence or tandem mass spectrometric detection for the separately determination of loperamide [8-12], elacridar [13, 14] and tariquidar [15] in biological fluids have been fully described. Nevertheless, an extensive literature survey revealed a lack of methods for the simultaneous estimation of these three compounds.

The present study aims to develop a new LC-MS method using electrospray ionization for the simultaneous quantitation of loperamide, elacridar and tariquidar in small volumes of rat plasma and brain, liver and kidneys homogenates. The present method has been fully validated for specificity, lower limit of quantification (LLOQ), calibration curve, accuracy, precision, recovery and stability according to the FDA guidance for bioanalytical method validation [16]. Matrix factor and dilution integrity were also assessed. In the case of plasma, the influence of hemolyzed plasma was also investigated. The applicability of the bioanalytical method was evaluated by monitoring pharmacokinetic and biodistribution data 
after intravenous administration of loperamide alone or concurrently administered with elacridar and/or tariquidar to Sprague Dawley rats.

\subsection{Materials and methods}

\subsubsection{Chemicals and reagents}

Loperamide hydrochloride, ketoconazole and chlorpromazine hydrochloride were obtained from Sigma Aldrich (France). Elacridar was synthesized at the Laboratory of Pharmaceutical Chemistry, University of Bonn (Germany) and tariquidar was purchased from API Services Inc. (USA). tert-Butyl methyl ether was obtained from Sigma Aldrich (France) and polyethylene glycol 600 (PEG 600) from Interchimie (France).

HPLC grade methanol and acetonitrile were purchased from Carlo Erba (France). Analytical grade ammonium acetate and glacial acetic acid were purchased from Sigma Aldrich (France). Ultrapure water was freshly obtained before use from a Purelab Prima 7/15/20 Purelab Ultra Mk 2 from Elga (France). Drug-free plasma or tissues homogenates were obtained from healthy Sprague Dawley rats $(230$ - $280 \mathrm{~g}$ weight $)$ provided by Janvier (France). Trisodium citrate solution was purchased from BD Vacutainer ${ }^{\circledR}$.

\subsubsection{Stock solutions, calibration standards (CS), quality control samples (QCS) and internal standards (IS)}

Stock solutions of loperamide, elacridar and tariquidar for CS and QCS were prepared separately in the mobile phase at a concentration of $1000 \mu \mathrm{g} / \mathrm{mL}$ on each validation day. Intermediate solutions were prepared by successive dilutions of the stock solutions in the mobile phase. Six calibration standards were prepared by spiking the intermediate solutions containing loperamide, elacridar and tariquidar into rat plasma or tissue homogenate to yield final concentrations of $1000,500,100,50,10$ and $5 \mathrm{ng} / \mathrm{mL}$. QCS were prepared at concentrations of 800,80 and $8 \mathrm{ng} / \mathrm{mL}$.

On each day of validation, stock solutions of IS, ketoconazole and chlorpromazine hydrochloride were prepared in the mobile phase at $1000 \mu \mathrm{g} / \mathrm{mL}$ and successively diluted in a mixture of acetonitrile and tert-butyl methyl ether (1:1). 


\subsubsection{Sample preparation}

Prior to chromatographic analysis, $25 \mu \mathrm{L}$ of the IS solution containing ketoconazole and chlorpromazine hydrochloride was added to $100 \mu \mathrm{L}$ of each plasma or tissue sample. After deproteinization with the addition of $800 \mu \mathrm{L}$ of a mixture of acetonitrile and tert-butyl methyl ether (1:1), samples were vortexed for 3 minutes and centrifuged at $5000 \mathrm{~g}$ for 10 minutes. The upper organic layer was decanted and evaporated to dryness and the residue was reconstituted in $100 \mu \mathrm{L}$ of mobile phase. A volume of $20 \mu \mathrm{L}$ was injected onto the analytical column. The final concentrations of ketoconazole and chlorpromazine hydrochloride were $100 \mathrm{ng} / \mathrm{mL}$ and $25 \mathrm{ng} / \mathrm{mL}$, respectively. All CS, QCS and samples from the pharmacokinetic and tissue distribution studies were processed following this same procedure.

\subsubsection{Instrumentation: Chromatographic and mass spectrometer conditions}

Chromatographic analyses were carried out on a Shimadzu High Performance Liquid Chromatography/Mass Spectrometer (LCMS-2010EV) equipped with a LC-20AD solvent delivery system. Analytes were well separated on a Zorbax Eclipse XDB-C18 (2.1 x 150 mm, $5.0 \mu \mathrm{m}$ ) column from Agilent Technologies at $50^{\circ} \mathrm{C}$ using a Millipore Waters oven. The mobile phase consisting of ammonium acetate $(\mathrm{pH} 5.5 ; 10 \mathrm{mM})$-methanol-acetonitrile $(37.5: 40.0: 22.5 \mathrm{v} / \mathrm{v} / \mathrm{v})$ was delivered in isocratic mode at $0.4 \mathrm{~mL} / \mathrm{min}$. An autosampler 360 from Kontrons Instruments was set to deliver $20 \mu \mathrm{L}$.

Compounds were quantitated using positive electrospray ionization (ESI) in an octapole quadrupole mass analyzer with single ion monitoring (SIM) mode at m/z 477 for loperamide, $\mathrm{m} / \mathrm{z} 531$ for ketoconazole, m/z 564 for elacridar, m/z 647 for tariquidar and m/z 319 for chlorpromazine. Nitrogen was used as the nebulizing gas at $1.5 \mathrm{~L} / \mathrm{min}$. The curved desolvation line $(\mathrm{CDL})$ and heat block temperatures were set at $250^{\circ} \mathrm{C}$ and $300^{\circ} \mathrm{C}$, respectively. The detector voltage was $1.5 \mathrm{kV}$, the interface voltage was $-3.5 \mathrm{kV}$ and the CDL voltage was $15.0 \mathrm{~V}$. 


\subsubsection{Validation procedure}

The current analytical method was validated according to the Guidance for Industry, Bioanalytical Method Validation, Food and Drug Administration (FDA) 2001 [16]. Selectivity, lower limit of quantification (LLOQ), calibration curve, intra- and inter-day accuracy and precision as well as absolute recovery, stability, matrix effects and dilution integrity of loperamide, elacridar and tariquidar were evaluated. The influence of hemolyzed plasma was also investigated.

\subsubsection{Selectivity}

The selectivity of the method was determined by analyzing six different batches of rat blank plasma or tissue homogenates. Samples were prepared as previously described with and without addition of both IS. Absence of interference and selectivity should be ensured at the LLOQ of loperamide, elacridar and tariquidar and at the working concentrations of each IS.

\subsubsection{Lower limit of quantification (LLOQ) and calibration curve}

To determine the linearity of the assay, six-point calibration curves, a blank sample (whether plasma or tissue homogenates), which was not used for linear regression and three sets of QCS were analyzed on each of the three validation days. The calibration curves were evaluated by linear regression based on the peak area ratio (analyte peak area/IS peak area) ( $y$ ) versus the nominal concentration $(x)$ of each CS. The slopes, intercepts and correlation coefficients of the corresponding individual curves were then calculated. The acceptance criterion for each back-calculated standard concentration was $\pm 15 \%$ from the nominal concentration except for the lowest concentration, where the deviation should not exceed $20 \%$.

The LLOQ was defined as the lowest concentration of standard on the calibration curve where the analyte peak should be reproducible with both an accuracy and a precision less or equal to $20 \%$. 


\subsubsection{Accuracy and precision}

The intra- and inter-day accuracy and precision were evaluated by determining the concentrations of loperamide, elacridar and tariquidar in five replicates of each QCS. The accuracy was calculated as the ratio of the experimental and the nominal concentrations: Accuracy $(\%)=($ experimental concentration/nominal concentration $) \times 100$. Precision was calculated as the coefficient of variation $(\mathrm{CV})$ of the experimental concentrations: $\mathrm{CV}(\%)=$ (standard deviation/mean) x 100. The criteria for acceptability of the data included accuracy within $\pm 15 \%$ from the nominal values and precision within $\pm 15 \%$, except for the LLOQ where the accuracy and precision should not exceed $20 \%$.

\subsubsection{Absolute recovery}

Absolute recovery of loperamide, elacridar and tariquidar through the sample preparation procedures was investigated by comparing the responses of spiked extracted samples with post-extracted spiked samples. Absolute recovery $(\%)=$ mean peak area of the analyte in spiked and extracted rat sample/mean peak area of the analyte added to post-extracted blank rat sample) x 100. Absolute recovery of loperamide, elacridar and tariquidar was evaluated in six replicates at three different concentrations and the recovery of IS was determined in a similar way except that it was evaluated only at the working concentrations. A $100 \%$ recovery of each analyte and IS was not required, but the recovery should be consistent, precise and reproducible.

\subsubsection{Stability studies}

The stability of loperamide, elacridar and tariquidar and the stability of their IS in rat plasma or tissue homogenates was assessed by analyzing five QCS at two concentrations (low and high) exposed to different storage times and temperatures. The results were then compared with those of freshly prepared QCS. The freeze-thaw stability was assessed after three freezethaw cycles; in each cycle, the samples were frozen at $-20^{\circ} \mathrm{C}$ for 24 hours and thawed to room temperature. The short-term stability was determined after incubation of the samples at room temperature for 8 hours. The long-term stability was evaluated after storage of the samples at $-20^{\circ} \mathrm{C}$ for 2 and 40 days. The post-preparative stability was investigated after storage at $20^{\circ} \mathrm{C}$ 
(autosampler temperature) for 24 and 48 hours. The stability of the stock solutions of loperamide, elacridar, tariquidar and their respective IS was evaluated after storage at room temperature for 6 hours.

\subsubsection{Matrix effect}

The assessment of the absolute matrix effect of loperamide, elacridar and tariquidar and their IS was carried out according to the method proposed by Matuszewski [17]. The responses of post-extracted spiked samples were compared to the responses of the same concentrations of analytes in the mobile phase. Matrix factor $=$ peak area ratio of the analyte added to postextracted blank rat sample/peak area ratio of the analyte in the mobile phase. The matrix effect was evaluated in six replicates at three different concentrations. A matrix factor greater than 1 suggests analyte ion enhancement and a value lower than 1 indicates ion suppression due to matrix components. A value equal to 1 suggests no matrix effects. The variability of the matrix factor as measured by the CV should be less than $15 \%$.

\subsubsection{Influence of hemolyzed plasma}

The influence of hemolyzed plasma on the quantification of loperamide, elacridar and tariquidar was determined by measuring five replicates of spiked QCS at 8 and $800 \mathrm{ng} / \mathrm{mL}$ in hemolyzed rat plasma. These five replicates were analyzed in the same run with QCS at 8 and $800 \mathrm{ng} / \mathrm{mL}$ in non-hemolyzed rat plasma. The hemolyzed rat plasma was processed as previously described for non-hemolyzed rat plasma. Accuracy should be within $\pm 15 \%$ of the nominal values and precision should be less than or equal to $15 \%$.

\subsubsection{Applicability of the analytical method}

The applicability of the previously described method was tested for the quantitation of loperamide, elacridar and tariquidar during the pharmacokinetic and tissue studies. Briefly, Sprague Dawley male rats were randomized into nine groups of twelve animals each. The different groups received intravenous loperamide alone at $0.5 \mathrm{mg} / \mathrm{kg}$ or in co-administration with intravenous elacridar and/or tariquidar. Elacridar and tariquidar were studied as free 
drugs at 0.5 and $1.0 \mathrm{mg} / \mathrm{kg}$ and co-encapsulated in four types of liposomes at a total dose of $1.0 \mathrm{mg} / \mathrm{kg}$ of P-gp modulators.

In the pharmacokinetic study, blood was collected from rat tail vein 1, 6, 12 and 24 hours after every administration. Plasma was obtained by centrifugation of the blood at $2500 \mathrm{~g}$ for 5 min and stored frozen at $-20^{\circ} \mathrm{C}$ until analysis Three rats were used at each time point $(n=3)$. In the tissue distribution study, animals were sacrificed at 1, 6, 12 and 24 hours after deep anesthesia with sodium pentobarbital $(50 \mathrm{mg} / \mathrm{kg}$; intraperitoneal $)$, cardiac perfusion with saline and exsanguination. After sacrifice, the whole brain, liver and kidneys were immediately frozen at $-20^{\circ} \mathrm{C}$ until analysis analysis. Three rats were used at each time point $(n=3)$. See chapter 5 .

\subsection{Results and discussion}

\subsubsection{Method development}

Based on structural similarities, solubility, recovery efficiency and previous successful data $[11,13]$, ketoconazole showed satisfactory results as IS for loperamide, as did chlorpromazine for elacridar and tariquidar (Fig. 1 and 2).

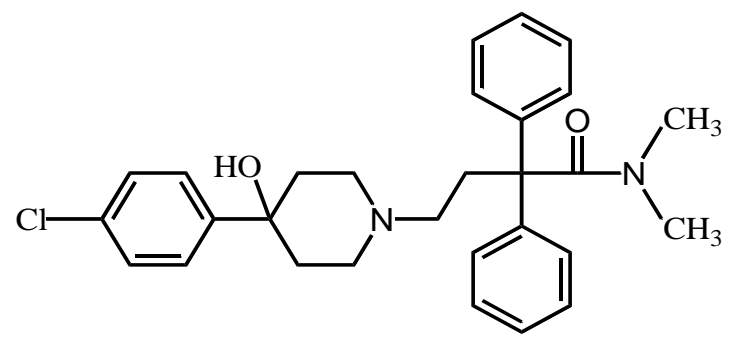

Loperamide $\mathrm{C}_{29} \mathrm{H}_{33} \mathrm{ClN}_{2} \mathrm{O}_{2}(477.05)$

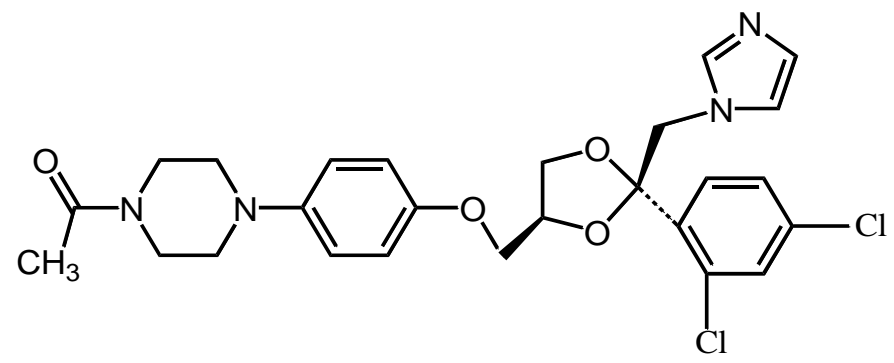

Ketoconazole $\mathrm{C}_{26} \mathrm{H}_{28} \mathrm{Cl}_{2} \mathrm{~N}_{4} \mathrm{O}_{4}$ (531.44)

Figure 1. Chemical structures of loperamide and ketoconazole (IS). 


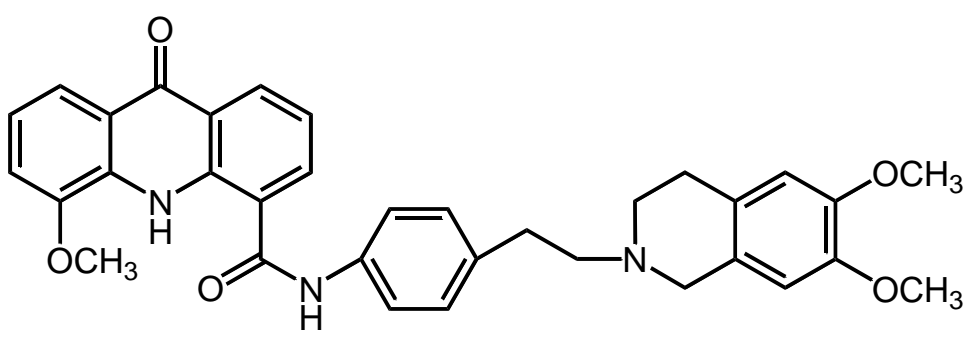

Elacridar

$\mathrm{C}_{34} \mathrm{H}_{33} \mathrm{~N}_{3} \mathrm{O}_{5}(563.64)$<smiles>COc1cc2c(cc1OC)CN(CCc1ccc(NC(=O)c3cc(OC)c(OC)cc3NC(=O)c3cnc4ccccc4c3)cc1)CC2</smiles><smiles>CN(C)CCCN1c2ccccc2Sc2ccc(Cl)cc21</smiles>

Tariquidar

$\mathrm{C}_{38} \mathrm{H}_{38} \mathrm{~N}_{4} \mathrm{O}_{6}(646.73)$

Figure 2. Chemical structures of elacridar, tariquidar and chlorpromazine (IS).

The main challenge during the method development was the chromatographic separation of loperamide, elacridar, tariquidar and their respective IS. Among the various common C18 columns tested, the Zorbax Eclipse XDB-C18 $(2.1 \times 150 \mathrm{~mm}, 5.0 \mu \mathrm{m})$ at $50^{\circ} \mathrm{C}$ was the stationary phase with the best sensitivity and resolution. To achieve complete chromatographic resolution for each compound, several elution conditions using acetonitrile, methanol, buffers with a $\mathrm{pH}$ range between 4.0 and 6.0 and a flow rate between 0.2 and 0.5 $\mathrm{mL} / \mathrm{min}$ were tested. Moreover, varying the $\mathrm{pH}$ of the ammonium acetate buffer was the most critical factor because lower $\mathrm{pH}(4.0-5.0)$ worsened the resolution. Isocratic elution of ammonium acetate $(\mathrm{pH} 5.5 ; 10 \mathrm{mM})$-methanol-acetonitrile $(37.5: 40.0: 22.5 \mathrm{v} / \mathrm{v} / \mathrm{v})$ at 0.4 $\mathrm{mL} / \mathrm{min}$ was the most suitable mobile phase for the best resolution and least peak tailing of each compound.

To optimize ESI conditions for loperamide, elacridar, tariquidar and for their IS, full scans were carried out in both positive and negative SIM modes. Positive mode was chosen over negative mode because of its improved signal to noise ratio $(\mathrm{S} / \mathrm{N})$ for extracted samples. 


\subsubsection{Validation procedure}

\subsubsection{Selectivity}

Six samples of plasma, brain, liver and kidneys from six healthy rats receiving no medication were extracted and analyzed to discard potential interference from endogenous substances. Based on the analysis of drug-free rat plasma, brain, liver and kidneys, endogenous matrix components did not interfere with the analytes or with their IS at their respective retention times and over the concentration range described herein. Figure 3 shows representative chromatograms obtained from rat blank plasma (A), and rat plasma obtained $6 \mathrm{~h}$ after simultaneous administration of loperamide, elacridar, and tariquidar, at $0.5 \mathrm{mg} / \mathrm{kg}$, each (B).
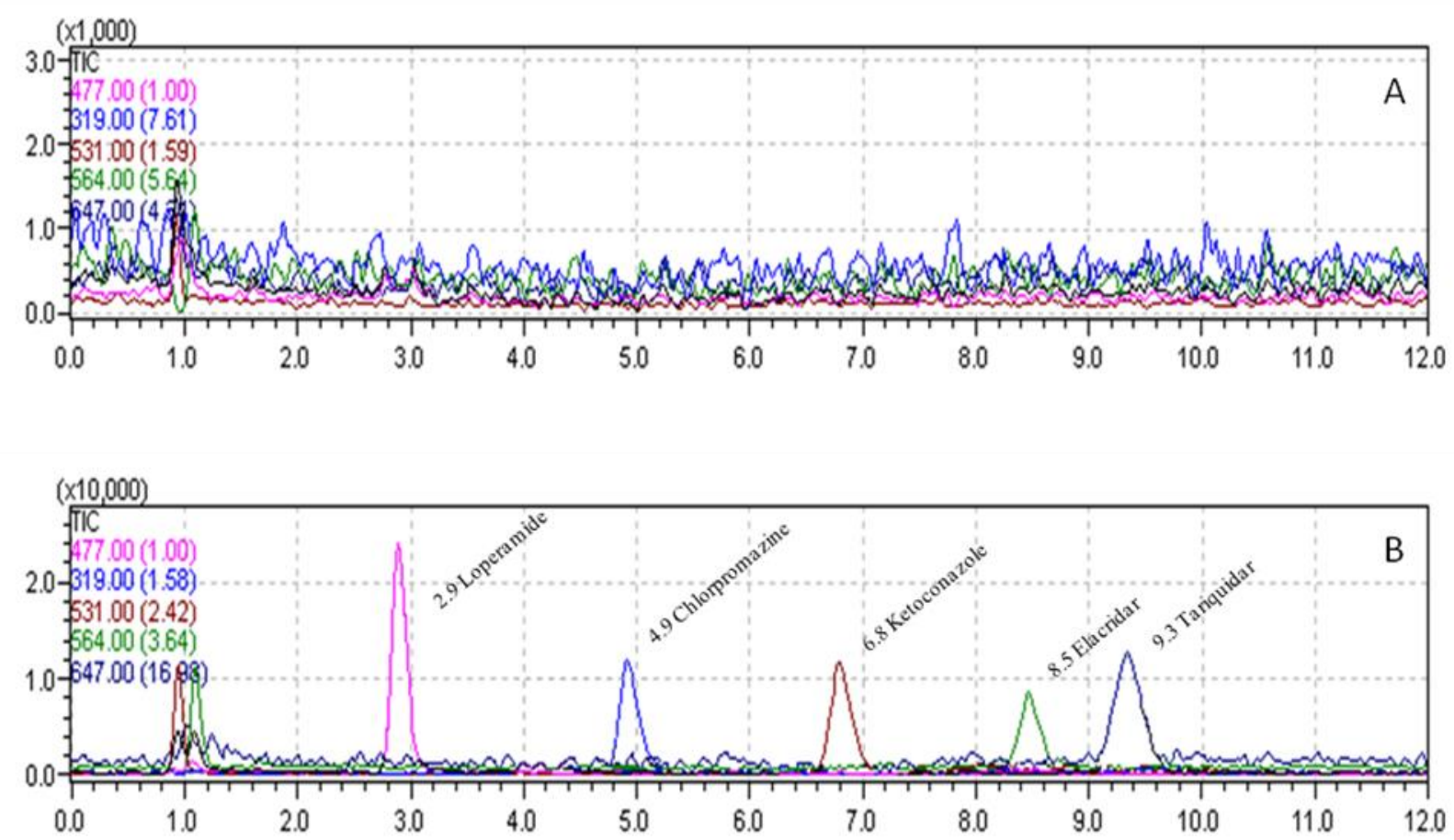

Figure 3. Representative chromatograms for rat blank plasma (A) and plasma sample from a rat obtained $6 \mathrm{~h}$ after simultaneous administration of loperamide, elacridar and tariquidar at $0.5 \mathrm{mg} / \mathrm{kg}$, each (B).

\subsubsection{Lower limit of quantification (LLOQ) and calibration curve}

Linear regression of the peak area ratios versus concentrations was fitted over the concentration range of $5.0 \mathrm{ng} / \mathrm{mL}-1000 \mathrm{ng} / \mathrm{mL}$ for loperamide, elacridar and tariquidar in plasma and tissues. The mean linear regression equation of the calibration curves and the correlation coefficients generated during the validation are summarized in table 1 . 
Table 1: Loperamide, elacridar and tariquidar calibration curve parameters $(n=3)$.

\begin{tabular}{|c|c|c|c|c|}
\hline Tissue & Analyte & Slope & Intercept & $r^{2}$ \\
\hline \multirow{3}{*}{ Plasma } & Loperamide & $0.0306 \pm 0.0028$ & $0.0162 \pm 0.0023$ & \multirow{3}{*}{$\geq 0.9990$} \\
\hline & Elacridar & $0.0105 \pm 0.0005$ & $0.0062 \pm 0.0014$ & \\
\hline & Tariquidar & $0.0065 \pm 0.0011$ & $0.0031 \pm 0.0013$ & \\
\hline \multirow{3}{*}{ Brain } & Loperamide & $0.0267 \pm 0.0015$ & $0.0206 \pm 0.0056$ & \multirow{3}{*}{$\geq 0.9990$} \\
\hline & Elacridar & $0.0108 \pm 0.0004$ & $0.0020 \pm 0.0009$ & \\
\hline & Tariquidar & $0.0066 \pm 0.0018$ & $0.0028 \pm 0.0013$ & \\
\hline \multirow{3}{*}{ Liver } & Loperamide & $0.0307 \pm 0.0046$ & $0.0123 \pm 0.0027$ & \multirow{3}{*}{$\geq 0.9990$} \\
\hline & Elacridar & $0.0129 \pm 0.0014$ & $0.0078 \pm 0.0025$ & \\
\hline & Tariquidar & $0.0077 \pm 0.0018$ & $0.0033 \pm 0.0004$ & \\
\hline \multirow{3}{*}{ Kidney } & Loperamide & $0.0312 \pm 0.0029$ & $0.0069 \pm 0.0027$ & \multirow{3}{*}{$\geq 0.9990$} \\
\hline & Elacridar & $0.0108 \pm 0.0002$ & $0.0050 \pm 0.0015$ & \\
\hline & Tariquidar & $0.0085 \pm 0.0013$ & $0.0037 \pm 0.0018$ & \\
\hline
\end{tabular}

The inter-day accuracy of the back-calculated calibration standards in plasma and tissues ranged from $93.87 \%$ to $102.39 \%$ for loperamide, from $94.51 \%$ to $105.57 \%$ for elacridar and from $96.29 \%$ to $104.41 \%$ for tariquidar. The inter-day precision in plasma and tissues ranged from $0.33 \%$ to $8.53 \%$ for loperamide, from $0.24 \%$ to $5.37 \%$ for elacridar and from $0.22 \%$ to $7.24 \%$ for tariquidar. These results met the acceptance criteria of no more than $15 \%$ deviation of standards from nominal concentrations.

Using $100 \mu \mathrm{L}$ of rat plasma or tissue homogenates, the LLOQ defined as the lowest concentration of standard on the calibration curves, was $5.0 \mathrm{ng} / \mathrm{mL}$ for loperamide, elacridar and tariquidar in plasma, brain, liver and kidneys, which were adequate for the pharmacokinetic and tissue distribution studies. The inter-day accuracy and precision obtained at the LLOQ are shown in table 2. In all the cases, these values were were within the acceptance criteria of no more than $20 \%$ deviation for concentrations at the LLOQ. 
Table 2: Inter-day accuracy and precision for loperamide, elacridar and tariquidar at their LLOQ in rat plasma, brain, liver and kidneys $(\mathrm{n}=3)$.

\begin{tabular}{ccccccc}
\hline \multirow{2}{*}{ Tissue } & \multicolumn{2}{c}{ Loperamide } & \multicolumn{2}{c}{ Elacridar } & \multicolumn{2}{c}{ Tariquidar } \\
\cline { 2 - 6 } & $\begin{array}{c}\text { Accuracy } \\
(\%)\end{array}$ & $\begin{array}{c}\text { Precision } \\
(\%)\end{array}$ & $\begin{array}{c}\text { Accuracy } \\
(\%)\end{array}$ & $\begin{array}{c}\text { Precision } \\
(\%)\end{array}$ & $\begin{array}{c}\text { Accuracy } \\
(\%)\end{array}$ & $\begin{array}{c}\text { Precision } \\
(\%)\end{array}$ \\
\hline Plasma & 95.64 & 3.32 & 95.32 & 4.16 & 99.88 & 3.30 \\
\hline Brain & 93.87 & 4.39 & 95.46 & 3.47 & 103.98 & 7.24 \\
\hline Liver & 102.39 & 4.05 & 97.26 & 4.89 & 102.44 & 4.20 \\
\hline Kidney & 98.61 & 5.97 & 105.57 & 4.16 & 101.51 & 2.68 \\
\hline
\end{tabular}

Numerous methods for quantitation of loperamide in human plasma and biological homogenates were developed and have approached the $\mathrm{pg} / \mathrm{mL}$ scale for the LLOQ, unfortunately these LC-MS and LC-MS/MS methods used a volume of at least $500 \mu \mathrm{L}$ [9-12]. The same disadvantage was met with the method of Kemper et al. for the quantitation of elacridar using HPLC with fluorescence detection. In that study, the LLOQ was $5.7 \mathrm{ng} / \mathrm{mL}$ for $200 \mu \mathrm{L}$ of human plasma and $23.0 \mathrm{ng} / \mathrm{mL}$ for $50 \mu \mathrm{L}$ of murine plasma [13]. Hence, the method proposed in this paper was amenable to the preclinical and simultaneous pharmacokinetic and biodistribution studies of loperamide, elacridar and tariquidar because only small volumes of blood can be collected in murine models.

\subsubsection{Accuracy and precision}

Intra- and inter-day accuracy and precision for loperamide, elacridar and tariquidar were assessed by extracting and analyzing five replicates of each of the three QCS in each of the three validation days. Tables 3 and 4 summarize intra- and inter-day accuracy and precision for loperamide and elacridar. These values were within the acceptance criteria of no more than $\pm 15 \%$ deviation for concentrations above the LLOQ. 
Table 3: Intra-day precision and accuracy for loperamide, elacridar and tariquidar quantitation in rat plasma, brain, liver and kidneys $(\mathrm{n}=5)$.

\begin{tabular}{|c|c|c|c|c|c|c|c|c|}
\hline \multirow[b]{2}{*}{ Tissue } & \multirow{2}{*}{$\begin{array}{l}\text { Nominal } \\
\text { concentration } \\
(\mathrm{ng} / \mathrm{mL})\end{array}$} & \multirow[b]{2}{*}{ Day } & \multicolumn{2}{|c|}{ Loperamide } & \multicolumn{2}{|c|}{ Elacridar } & \multicolumn{2}{|c|}{ Tariquidar } \\
\hline & & & $\begin{array}{c}\text { Accuracy } \\
(\%)\end{array}$ & $\begin{array}{c}\text { Precision } \\
(\%)\end{array}$ & $\begin{array}{c}\text { Accuracy } \\
(\%)\end{array}$ & $\begin{array}{c}\text { Precision } \\
(\%)\end{array}$ & $\begin{array}{c}\text { Accuracy } \\
(\%)\end{array}$ & $\begin{array}{c}\text { Precision } \\
(\%)\end{array}$ \\
\hline \multirow{9}{*}{ Plasma } & \multirow{3}{*}{8} & Day 1 & 100.98 & 3.98 & 99.31 & 2.93 & 104.55 & 5.25 \\
\hline & & Day 2 & 101.83 & 1.01 & 104.22 & 4.13 & 100.12 & 4.21 \\
\hline & & Day 3 & 104.33 & 1.72 & 100.45 & 5.29 & 102.76 & 3.79 \\
\hline & \multirow{3}{*}{80} & Day 1 & 101.99 & 3.42 & 101.92 & 2.50 & 103.10 & 2.46 \\
\hline & & Day 2 & 103.23 & 2.04 & 99.87 & 3.68 & 100.90 & 3.24 \\
\hline & & Day 3 & 100.52 & 2.23 & 100.02 & 3.92 & 102.24 & 4.06 \\
\hline & \multirow{3}{*}{800} & Day 1 & 103.25 & 4.89 & 99.90 & 2.88 & 100.97 & 2.04 \\
\hline & & Day 2 & 100.95 & 1.42 & 99.58 & 2.80 & 99.89 & 4.51 \\
\hline & & Day 3 & 99.08 & 1.63 & 100.95 & 2.38 & 101.47 & 1.68 \\
\hline \multirow{9}{*}{ Brain } & \multirow{3}{*}{8} & Day 1 & 99.26 & 6.46 & 108.03 & 2.27 & 100.00 & 3.70 \\
\hline & & Day 2 & 107.81 & 8.28 & 99.43 & 3.93 & 111.92 & 4.77 \\
\hline & & Day 3 & 102.29 & 2.25 & 102.29 & 4.60 & 100.76 & 6.78 \\
\hline & \multirow{3}{*}{80} & Day 1 & 102.88 & 4.83 & 105.47 & 2.48 & 101.58 & 3.15 \\
\hline & & Day 2 & 102.10 & 2.88 & 91.11 & 3.66 & 100.83 & 2.85 \\
\hline & & Day 3 & 101.80 & 1.80 & 99.75 & 2.73 & 99.18 & 2.28 \\
\hline & \multirow{3}{*}{800} & Day 1 & 103.36 & 5.03 & 102.87 & 2.87 & 99.66 & 4.49 \\
\hline & & Day 2 & 102.66 & 3.35 & 90.41 & 2.80 & 102.41 & 2.73 \\
\hline & & Day 3 & 101.74 & 1.71 & 99.56 & 0.39 & 97.07 & 1.56 \\
\hline \multirow{9}{*}{ Liver } & \multirow{3}{*}{8} & Day 1 & 99.66 & 5.85 & 99.65 & 1.67 & 98.03 & 2.38 \\
\hline & & Day 2 & 101.21 & 2.42 & 100.78 & 5.73 & 106.62 & 2.08 \\
\hline & & Day 3 & 99.23 & 5.94 & 94.73 & 4.33 & 103.88 & 7.39 \\
\hline & \multirow{3}{*}{80} & Day 1 & 100.88 & 4.28 & 96.20 & 2.64 & 101.41 & 3.04 \\
\hline & & Day 2 & 98.31 & 3.85 & 98.99 & 3.38 & 103.05 & 3.49 \\
\hline & & Day 3 & 97.81 & 6.69 & 96.33 & 6.70 & 103.79 & 5.07 \\
\hline & \multirow{3}{*}{800} & Day 1 & 97.55 & 2.57 & 96.89 & 1.32 & 100.69 & 3.53 \\
\hline & & Day 2 & 99.00 & 2.92 & 96.35 & 4.14 & 99.05 & 1.23 \\
\hline & & Day 3 & 99.56 & 1.90 & 98.09 & 4.00 & 100.97 & 5.51 \\
\hline \multirow{9}{*}{ Kidney } & \multirow{3}{*}{8} & Day 1 & 98.51 & 8.74 & 102.64 & 6.51 & 101.45 & 5.19 \\
\hline & & Day 2 & 103.05 & 5.07 & 101.76 & 3.51 & 108.62 & 2.53 \\
\hline & & Day 3 & 102.35 & 1.63 & 101.63 & 3.08 & 100.05 & 4.98 \\
\hline & \multirow{3}{*}{80} & Day 1 & 101.38 & 4.15 & 99.95 & 5.75 & 100.82 & 4.71 \\
\hline & & Day 2 & 102.26 & 2.45 & 100.50 & 1.82 & 105.51 & 2.84 \\
\hline & & Day 3 & 101.00 & 3.48 & 103.02 & 0.72 & 103.96 & 3.43 \\
\hline & \multirow{3}{*}{800} & Day 1 & 101.71 & 3.68 & 95.46 & 2.87 & 100.30 & 1.55 \\
\hline & & Day 2 & 101.71 & 1.79 & 99.35 & 2.40 & 102.94 & 3.34 \\
\hline & & Day 3 & 99.84 & 4.33 & 105.59 & 1.71 & 102.44 & 5.29 \\
\hline
\end{tabular}


Table 4: Inter-day precision and accuracy for loperamide, elacridar and tariquidar quantitation in rat plasma, brain, liver and kidneys $(\mathrm{n}=15)$.

\begin{tabular}{|c|c|c|c|c|c|c|c|}
\hline \multirow[b]{2}{*}{ Tissue } & \multirow{2}{*}{$\begin{array}{l}\text { Nominal } \\
\text { concentration } \\
(\mathrm{ng} / \mathrm{mL})\end{array}$} & \multicolumn{2}{|c|}{ Loperamide } & \multicolumn{2}{|c|}{ Elacridar } & \multicolumn{2}{|c|}{ Tariquidar } \\
\hline & & $\begin{array}{c}\text { Accuracy } \\
(\%)\end{array}$ & $\begin{array}{c}\text { Precision } \\
(\%)\end{array}$ & $\begin{array}{c}\text { Accuracy } \\
(\%)\end{array}$ & $\begin{array}{c}\text { Precision } \\
(\%)\end{array}$ & $\begin{array}{c}\text { Accuracy } \\
(\%)\end{array}$ & $\begin{array}{c}\text { Precision } \\
(\%)\end{array}$ \\
\hline \multirow{3}{*}{ Plasma } & 8 & 102.38 & 2.24 & 101.33 & 4.11 & 102.48 & 4.42 \\
\hline & 80 & 101.91 & 2.56 & 100.60 & 3.36 & 102.08 & 3.25 \\
\hline & 800 & 101.10 & 2.65 & 100.15 & 2.69 & 100.78 & 2.74 \\
\hline \multirow{3}{*}{ Brain } & 8 & 103.12 & 5.66 & 103.25 & 3.76 & 104.23 & 5.08 \\
\hline & 80 & 102.26 & 3.17 & 98.78 & 2.96 & 100.53 & 2.76 \\
\hline & 800 & 102.58 & 3.33 & 97.61 & 2.02 & 99.71 & 2.93 \\
\hline \multirow{3}{*}{ Liver } & 8 & 100.03 & 4.74 & 98.39 & 3.91 & 102.84 & 3.95 \\
\hline & 80 & 99.00 & 4.94 & 97.17 & 4.24 & 102.75 & 3.87 \\
\hline & 800 & 98.70 & 2.46 & 97.11 & 3.15 & 100.24 & 3.42 \\
\hline \multirow{3}{*}{ Kidney } & 8 & 101.30 & 5.15 & 102.01 & 4.37 & 103.37 & 4.23 \\
\hline & 80 & 101.55 & 3.36 & 101.16 & 2.77 & 103.43 & 3.66 \\
\hline & 800 & 101.09 & 3.27 & 100.13 & 2.33 & 101.89 & 3.39 \\
\hline
\end{tabular}

\subsubsection{Absolute recovery}

In our study, the use of tert-butyl methyl ether alone for the recovery of elacridar and chlorpromazine suggested by Kemper et al. [13] yielded poor recovery values for chlorpromazine (chapter 4). However, a mixture of tert-butyl methyl ether and acetonitrile, one of the most effective protein precipitants [18], resulted in satisfactory recovery values not only for chlorpromazine but also for the other analytes. The mean absolute recovery values for each analyte are shown in table 5.

Table 5: Absolute recovery for loperamide, elacridar, tariquidar and their IS in rat plasma, brain, liver and kidneys $(\mathrm{n}=15)$.

\begin{tabular}{cccccc}
\hline Tissue & Loperamide & Ketoconazole & Elacridar & Tariquidar & Chlorpromazine \\
\hline Plasma & $93.19 \pm 1.92$ & $92.54 \pm 1.47$ & $93.35 \pm 3.10$ & $91.64 \pm 4.70$ & $91.89 \pm 5.20$ \\
\hline Brain & $91.07 \pm 2.10$ & $90.16 \pm 3.71$ & $91.51 \pm 0.92$ & $92.41 \pm 7.39$ & $92.87 \pm 3.45$ \\
\hline Liver & $86.43 \pm 2.61$ & $88.57 \pm 4.23$ & $88.65 \pm 3.66$ & $89.28 \pm 4.70$ & $87.67 \pm 1.26$ \\
\hline Kidney & $87.05 \pm 4.47$ & $90.97 \pm 4.00$ & $85.43 \pm 4.03$ & $89.26 \pm 3.12$ & $90.38 \pm 6.04$ \\
\hline
\end{tabular}


Previously, $\mathrm{Yu}$ et al. reported extraction recovery values for plasma loperamide and ketoconazole of $88.4 \%$ and $85.6 \%$, respectively, when tert-butyl methyl ether alone was used. In addition, Kemper et al. reported extraction recovery values for plasma elacridar and chlorpromazine of $86.0 \%$ and $91.0 \%$, respectively, when tert-butyl methyl ether alone was again used [11, 13]. In this study sample preparation procedure using acetonitrile and tertbutyl methyl ether (1:1) demonstrated satisfactory and similar recovery values for the analytes not only in rat plasma but also in brain, liver and kidneys.

\subsubsection{Stability studies}

The results of the stability tests (Table 6) proved that the analytes of interest were stable during sample storage, sample preparation and chromatographic analysis. Furthermore, loperamide, elacridar, tariquidar and IS stock solutions proved to be stable at room temperature for up to 6 hours. 
Table 6: Stability of loperamide, elacridar and tariquidar in rat plasma, brain, liver and kidneys $(n=5)$.

\begin{tabular}{|c|c|c|c|c|c|c|}
\hline \multirow{2}{*}{ Tissue } & \multirow{2}{*}{\multicolumn{2}{|c|}{$\begin{array}{l}\text { Loperamide } \\
\text { Stability test }\end{array}$}} & \multicolumn{2}{|c|}{ LQCS } & \multicolumn{2}{|c|}{ HQCS } \\
\hline & & & Accuracy (\%) & Precision $(\%)$ & Accuracy (\%) & Precision (\%) \\
\hline \multirow{4}{*}{ Plasma } & Freeze-thaw & 3 cycles & 103.62 & 5.32 & 102.35 & 3.42 \\
\hline & Short-term & 12 hours & 99.59 & 3.21 & 97.96 & 2.01 \\
\hline & Long-term & 40 days & 100.28 & 5.01 & 100.25 & 1.05 \\
\hline & Post-preparative & 24 hours & 104.01 & 2.26 & 101.99 & 3.24 \\
\hline \multirow{4}{*}{ Brain } & Freeze-thaw & 3 cycles & 100.25 & 7.31 & 97.63 & 4.14 \\
\hline & Short-term & 12 hours & 101.67 & 2.07 & 100.86 & 4.40 \\
\hline & Long-term & 40 days & 98.62 & 5.39 & 101.35 & 3.65 \\
\hline & Post-preparative & 24 hours & 104.26 & 6.04 & 99.00 & 2.11 \\
\hline \multirow{4}{*}{ Liver } & Freeze-thaw & 3 cycles & 102.36 & 5.25 & 99.48 & 2.69 \\
\hline & Short-term & 12 hours & 103.58 & 4.83 & 98.30 & 3.01 \\
\hline & Long-term & 40 days & 100.84 & 4.00 & 100.14 & 3.55 \\
\hline & Post-preparative & 24 hours & 105.25 & 5.32 & 101.27 & 2.36 \\
\hline \multirow{4}{*}{ Kidney } & Freeze-thaw & 3 cycles & 101.52 & 6.36 & 97.25 & 2.07 \\
\hline & Short-term & 12 hours & 100.20 & 5.12 & 99.43 & 3.76 \\
\hline & Long-term & 40 days & 102.28 & 4.23 & 99.28 & 2.88 \\
\hline & Post-preparative & 24 hours & 104.89 & 4.86 & 101.21 & 3.11 \\
\hline & ck sol. & 6 hours & 105.51 & 2.18 & 102.39 & 3.23 \\
\hline \multirow{2}{*}{ Tissue } & \multirow{2}{*}{\multicolumn{2}{|c|}{$\begin{array}{c}\text { Elacridar } \\
\text { Stability test }\end{array}$}} & \multicolumn{2}{|c|}{ LQCS } & \multicolumn{2}{|c|}{ HQCS } \\
\hline & & & Accuracy (\%) & Precision $(\%)$ & Accuracy (\%) & Precision (\%) \\
\hline \multirow{4}{*}{ Plasma } & Freeze-thaw & 3 cycles & 100.26 & 5.29 & 101.29 & 2.56 \\
\hline & Short-term & 12 hours & 101.54 & 4.63 & 102.64 & 6.01 \\
\hline & Long-term & 40 days & 99.86 & 4.16 & 100.23 & 3.28 \\
\hline & Post-preparative & 24 hours & 102.31 & 2.36 & 103.68 & 4.67 \\
\hline \multirow{4}{*}{ Brain } & Freeze-thaw & 3 cycles & 107.22 & 3.45 & 105.24 & 3.53 \\
\hline & Short-term & 12 hours & 104.06 & 2.69 & 102.15 & 5.94 \\
\hline & Long-term & 40 days & 102.97 & 6.95 & 99.68 & 2.31 \\
\hline & Post-preparative & 24 hours & 108.93 & 4.21 & 103.15 & 1.98 \\
\hline \multirow{4}{*}{ Liver } & Freeze-thaw & 3 cycles & 99.58 & 7.28 & 100.26 & 1.21 \\
\hline & Short-term & 12 hours & 95.32 & 3.25 & 99.21 & 3.64 \\
\hline & Long-term & 40 days & 100.52 & 4.84 & 94.02 & 4.09 \\
\hline & Post-preparative & 24 hours & 102.33 & 5.30 & 101.56 & 0.84 \\
\hline \multirow{4}{*}{ Kidney } & Freeze-thaw & 3 cycles & 99.48 & 3.97 & 100.28 & 2.86 \\
\hline & Short-term & 12 hours & 100.01 & 4.28 & 99.63 & 2.03 \\
\hline & Long-term & 40 days & 97.10 & 6.24 & 96.34 & 0.42 \\
\hline & Post-preparative & 24 hours & 101.26 & 3.64 & 102.59 & 2.17 \\
\hline & ck sol. & 6 hours & 107.53 & 1.02 & 103.54 & 0.31 \\
\hline \multirow{2}{*}{ Tissue } & \multirow{2}{*}{\multicolumn{2}{|c|}{$\begin{array}{c}\text { Tariquidar } \\
\text { Stability test }\end{array}$}} & & & $\overline{\mathrm{HQ}}$ & \\
\hline & & & Accuracy (\%) & Precision $(\%)$ & Accuracy (\%) & Precision (\%) \\
\hline & Freeze-thaw & 3 cycles & 102.36 & 5.61 & 100.59 & 3.01 \\
\hline & Short-term & 12 hours & 100.65 & 2.36 & 101.63 & 2.51 \\
\hline Plasma & Long-term & 40 days & 101.89 & 4.97 & 100.88 & 0.84 \\
\hline & Post-preparative & 24 hours & 103.57 & 5.30 & 103.42 & 0.62 \\
\hline & Freeze-thaw & 3 cycles & 104.56 & 8.01 & 97.59 & 2.62 \\
\hline Prain & Short-term & 12 hours & 103.27 & 5.69 & 101.73 & 4.86 \\
\hline Brain & Long-term & 40 days & 100.51 & 6.24 & 99.08 & 2.07 \\
\hline & Post-preparative & 24 hours & 106.35 & 2.85 & 102.51 & 0.11 \\
\hline & Freeze-thaw & 3 cycles & 106.68 & 3.64 & 100.83 & 2.04 \\
\hline I iver & Short-term & 12 hours & 100.37 & 4.59 & 99.65 & 1.86 \\
\hline Liver & Long-term & 40 days & 97.64 & 5.66 & 99.57 & 3.15 \\
\hline & Post-preparative & 24 hours & 108.29 & 5.42 & 105.24 & 2.98 \\
\hline & Freeze-thaw & 3 cycles & 104.21 & 5.04 & 101.00 & 2.36 \\
\hline & Short-term & 12 hours & 102.62 & 2.39 & 99.53 & 4.85 \\
\hline Kidney & Long-term & 40 days & 103.73 & 5.43 & 100.48 & 3.49 \\
\hline & Post-preparative & 24 hours & 107.40 & 4.00 & 103.69 & 0.88 \\
\hline
\end{tabular}




\subsubsection{Matrix effect}

Using the method proposed by Matuszewski [17], the matrix factors obtained for loperamide, elacridar and tariquidar are shown in table 7. These values indicated the absence of matrix effects is surely due to favorable protein precipitation by acetonitrile [18] and the ability of tert-butyl methyl ether to exclude phospholipids found in the matrices [19]. This synergism has already been exploited and approved by Bristol-Myers Squibb [20]. In this last document the ratio of acetonitrile to tert-butyl methyl ether was 1:3 to ensure elimination of irregular emulsions between aqueous and organic interfaces and to modulate the polarity of the extraction solvents. In our study, an adjustment of the ratio to 1:1 was made to achieve desired recovery values.

Table 7: Matrix effects evaluation for loperamide, elacridar and tariquidar in rat plasma, brain, liver and kidneys $(n=18)$.

\begin{tabular}{cccc}
\hline Tissue & Loperamide & Elacridar & Tariquidar \\
\hline Plasma & 104.25 & 104.31 & 103.36 \\
\hline Brain & 108.35 & 102.60 & 106.52 \\
\hline Liver & 96.73 & 91.45 & 94.90 \\
\hline Kidney & 97.83 & 95.43 & 92.52 \\
\hline
\end{tabular}

\subsubsection{Influence of hemolyzed plasma}

As depicted in table 8, no influence of hemolyzed rat plasma on the accuracy and precision of the method was observed.

Table 8: Influence of hemolyzed plasma on the quantitation of loperamide, elacridar and tariquidar $(n=3)$.

\begin{tabular}{ccccccc}
\hline \multirow{2}{*}{$\begin{array}{c}\text { Nominal } \\
\text { concentration } \\
(\mathrm{ng} / \mathrm{mL})\end{array}$} & $\begin{array}{c}\text { Accuracy } \\
(\%)\end{array}$ & $\begin{array}{c}\text { Precision } \\
(\%)\end{array}$ & $\begin{array}{c}\text { Accuracy } \\
(\%)\end{array}$ & $\begin{array}{c}\text { Precision } \\
(\%)\end{array}$ & $\begin{array}{c}\text { Accuracy } \\
(\%)\end{array}$ & $\begin{array}{c}\text { Precision } \\
(\%)\end{array}$ \\
\hline 8 & 94.54 & 1.95 & 95.6 & 0.75 & 99.78 & 2.04 \\
\hline 800 & 97.98 & 0.92 & 101.4 & 2.34 & 101.76 & 0.99 \\
\hline
\end{tabular}




\subsubsection{Applicability of the analytical method}

The aforementioned method was successfully applied to the pharmacokinetic and tissue distribution studies of loperamide, elacridar and tariquidar (see: Co-administration of P-gp modulators on loperamide pharmacokinetics and brain distribution). The samples which were initially above the upper limit of quantification (ULOQ), were analyzed after dilution along with QCS treated with the same dilution factor.

\subsection{Conclusion}

To date, no published method is available for the simultaneous determination of loperamide, elacridar and tariquidar in a biological matrix. Therefore, a sensitive, accurate and precise LCMS method for the simultaneous determination of the three analytes in rat plasma, brain, liver and kidneys using structurally close IS was developed and validated. The method involved sample preparation using acetonitrile and tert-butyl methyl ether (1:1), which allowed quantitation of loperamide, elacridar and tariquidar with high absolute recovery and without interference of matrix components. The advantages of this method include easy sample preparation, small sample volumes, high selectivity and a fast run time. This method represents a meaningful tool for in vivo pharmacokinetic and tissue distribution studies. 


\section{References}

[1] D.S. Miller, B. Bauer, A.M. Hartz, Modulation of P-glycoprotein at the blood-brain barrier: opportunities to improve central nervous system pharmacotherapy, Pharmacol Rev, 60 (2008) 196-209.

[2] W. Loscher, H. Potschka, Role of drug efflux transporters in the brain for drug disposition and treatment of brain diseases, Prog Neurobiol, 76 (2005) 22-76.

[3] K. Linnet, T.B. Ejsing, A review on the impact of P-glycoprotein on the penetration of drugs into the brain. Focus on psychotropic drugs, Eur Neuropsychopharmacol, 18 (2008) 157-169.

[4] L. Varatharajan, S.A. Thomas, The transport of anti-HIV drugs across blood-CNS interfaces: summary of current knowledge and recommendations for further research, Antiviral Res, 82 (2009) A99-109.

[5] C. Kuntner, J.P. Bankstahl, M. Bankstahl, J. Stanek, T. Wanek, G. Stundner, R. Karch, R. Brauner, M. Meier, X. Ding, M. Muller, W. Loscher, O. Langer, Dose-response assessment of tariquidar and elacridar and regional quantification of P-glycoprotein inhibition at the rat blood-brain barrier using (R)-[(11)C]verapamil PET, Eur J Nucl Med Mol Imaging, 37 942953.

[6] M. Hubensack, C. Muller, P. Hocherl, S. Fellner, T. Spruss, G. Bernhardt, A. Buschauer, Effect of the ABCB1 modulators elacridar and tariquidar on the distribution of paclitaxel in nude mice, J Cancer Res Clin Oncol, 134 (2008) 597-607.

[7] E.F. Choo, D. Kurnik, M. Muszkat, T. Ohkubo, S.D. Shay, J.N. Higginbotham, H. Glaeser, R.B. Kim, A.J. Wood, G.R. Wilkinson, Differential in vivo sensitivity to inhibition of P-glycoprotein located in lymphocytes, testes, and the blood-brain barrier, J Pharmacol Exp Ther, 317 (2006) 1012-1018.

[8] H. Chen, F. Gaul, D. Guo, A. Maycock, Determination of loperamide in rat plasma and bovine serum albumin by LC, J Pharm Biomed Anal, 22 (2000) 555-561.

[9] H. He, A. Sadeque, J.C. Erve, A.J. Wood, D.L. Hachey, Quantitation of loperamide and $\mathrm{N}$-demethyl-loperamide in human plasma using electrospray ionization with selected reaction ion monitoring liquid chromatography-mass spectrometry, J Chromatogr B Biomed Sci Appl, 744 (2000) 323-331.

[10] B. Streel, A. Ceccato, R. Klinkenberg, P. Hubert, Validation of a liquid chromatographictandem mass spectrometric method for the determination of loperamide in human plasma, $\mathrm{J}$ Chromatogr B Analyt Technol Biomed Life Sci, 814 (2005) 263-273. 
[11] J.H. Yu, H.J. Kim, S. Lee, S.J. Hwang, W. Kim, C.J. Moon, LC-MS determination and bioavailability study of loperamide hydrochloride after oral administration of loperamide capsule in human volunteers, J Pharm Biomed Anal, 36 (2004) 421-427.

[12] S.S. Johansen, J.L. Jensen, Liquid chromatography-tandem mass spectrometry determination of loperamide and its main metabolite desmethylloperamide in biological specimens and application to forensic cases, J Chromatogr B Analyt Technol Biomed Life Sci, 811 (2004) 31-36.

[13] E.M. Kemper, B. Jansen, K.R. Brouwer, J.H. Schellens, J.H. Beijnen, O. van Tellingen, Bioanalysis and preliminary pharmacokinetics of the acridonecarboxamide derivative GF120918 in plasma of mice and humans by ion-pairing reversed-phase high-performance liquid chromatography with fluorescence detection, J Chromatogr B Biomed Sci Appl, 759 (2001) 135-143.

[14] E. Stokvis, H. Rosing, R.C. Causon, J.H. Schellens, J.H. Beijnen, Quantitative analysis of the P-glycoprotein inhibitor Elacridar (GF120918) in human and dog plasma using liquid chromatography with tandem mass spectrometric detection, J Mass Spectrom, 39 (2004) 1122-1130.

[15] C.C. Wagner, M. Bauer, R. Karch, T. Feurstein, S. Kopp, P. Chiba, K. Kletter, W. Loscher, M. Muller, M. Zeitlinger, O. Langer, A pilot study to assess the efficacy of tariquidar to inhibit P-glycoprotein at the human blood-brain barrier with (R)-11C-verapamil and PET, J Nucl Med, 50 (2009) 1954-1961.

[16] F.a.D.A. U.S. Departement of Health and Human Services, Guidance for Industry: Bioanalytical Method Validation, (2001).

[17] B.K. Matuszewski, M.L. Constanzer, C.M. Chavez-Eng, Strategies for the assessment of matrix effect in quantitative bioanalytical methods based on HPLC-MS/MS, Anal Chem, 75 (2003) 3019-3030.

[18] S. Souverain, S. Rudaz, J.L. Veuthey, Protein precipitation for the analysis of a drug cocktail in plasma by LC-ESI-MS, J Pharm Biomed Anal, 35 (2004) 913-920.

[19] E. Chambers, D.M. Wagrowski-Diehl, Z. Lu, J.R. Mazzeo, Systematic and comprehensive strategy for reducing matrix effects in LC/MS/MS analyses, J Chromatogr B Analyt Technol Biomed Life Sci, 852 (2007) 22-34.

[20] Y.J. Xue, J. Pursley, M.E. Arnold, A simple 96-well liquid-liquid extraction with a mixture of acetonitrile and methyl t-butyl ether for the determination of a drug in human plasma by high-performance liquid chromatography with tandem mass spectrometry, J Pharm Biomed Anal, 34 (2004) 369-378. 


\title{
5 CO-ADMINISTRATION OF P-GLYCOPROTEIN MODULATORS ON LOPERAMIDE PHARMACOKINETICS AND BRAIN DISTRIBUTION
}

\begin{abstract}
The efflux transporter P-glycoprotein, expressed at high levels at the blood-brain barrier, exerts a profound effect on the disposition of various therapeutic compounds in the brain. A rapid and efficient modulation of this efflux transporter could enhance the distribution of its substrates and thereby improve central nervous system pharmacotherapies. This study explored the impact of the intravenous co-administration of two P-glycoprotein modulators, tariquidar and elacridar, on the pharmacokinetics and brain distribution of loperamide, a Pglycoprotein substrate probe, in rats. After one hour post-dosing, tariquidar and elacridar, both at a dose of $1.0 \mathrm{mg} / \mathrm{kg}$, increased loperamide levels in the brain by 2.3 - and 3.5 -fold, respectively. However, the concurrent administration of both P-glycoprotein modulators, each at a dose of $0.5 \mathrm{mg} / \mathrm{kg}$, increased loperamide levels in the brain by 5.8 -fold and resulted in the most pronounced opioid-induced clinical signs. This phenomenon may be the result of a combined non-competitive modulation by tariquidar and elacridar. Besides, the simultaneous administration of elacridar and tariquidar did not significantly modify the pharmacokinetic parameters of loperamide. This observation potentially allows the concurrent use of low but therapeutic doses of P-gp modulators to achieve full inhibitory effects.
\end{abstract}

Keywords: P-glycoprotein, blood-brain barrier, P-gp modulators, co-administration, synergy.

This chapter was published in:

R. Nieto Montesinos, B. Moulari, J. Gromand, A. Beduneau, A. Lamprecht, Y. Pellequer, Co-administration of P-glycoprotein modulators on loperamide pharmacokinetics and brain distribution, Drug Metabolism and Disposition. Ref: DMD/2013/055566. 


\subsection{Introduction}

Since its discovery in 1976 [1], P-glycoprotein (P-gp) has been the most extensively studied ATP-binding cassette (ABC)-dependent efflux transporter. This protein is often regarded as a model to understand the biochemical mechanism of some $\mathrm{ABC}$ transport proteins. Two factors make P-gp the most critical efflux transporter: (1) its broad substrate specificity which results in multidrug resistance (MDR) [2] and (2) the prominent expression of P-gp in most excretory and barrier-function tissues [3]. The relevant expression of P-gp at the blood brain barrier (BBB) exerts a profound effect on the brain distribution of HIV protease inhibitors, anticancer drugs, opioids, some psychotropics and other drugs, which leads to the failure of various clinical treatments for brain diseases [3-5]. The inhibition of P-gp-mediated efflux could enhance the distribution of these substrates into the brain and therefore improve central nervous system (CNS) pharmacotherapies.

The identification of some P-gp substrates that also had the ability to block the P-gp-mediated efflux led to the synthesis of their analogs in order to minimize effects not related to their inhibition of P-gp-mediated efflux. Unfortunately, these compounds, known as first- and second-generation P-gp modulators, caused undesirable pharmacokinetic profiles due to their non-specificity towards the P-gp [6]. With the purpose of avoiding these limitations, thirdgeneration P-gp modulators have been developed. To be therapeutically effective, these compounds should be non-competitive and sufficiently potent to achieve inhibitory effects at non-toxic plasma concentrations and sufficiently selective for P-gp to minimize effects on overall drug pharmacokinetics [7]. In vivo studies demonstrated that elacridar and tariquidar, third-generation P-gp modulators, significantly increased the brain distribution of several P-gp substrates without pharmacokinetic interactions $[8,9]$. In contrast, recent studies promote the use of significantly high doses of these P-gp modulators to efficiently modulate the P-gpmediated efflux at the BBB [10]. However, when co-administered with P-gp substrates, these doses may be associated with pharmacokinetic interactions and toxic profiles, thus limiting the use of these agents. This escalating doses approach could reflect the same drawbacks of the first- and second-generation P-gp modulators.

Unnecessary exposure to P-gp modulators could be minimized and potential drug-related side effects might be reduced if, instead of using one P-gp modulator at a high dose, a combination of P-gp modulators with different drug binding sites were used at lower and safe doses. Martin et al. described the presence of at least four distinct interaction sites on P-gp and the 
binding of tariquidar to site II (a transport and regulatory site) and elacridar to site IV (an exclusive regulatory site) [11]. In the presence of a P-gp substrate, elacridar and tariquidar, complex allosteric communication between the binding sites may result in synergistic interactions, thus improving the pharmacokinetics and pharmacodynamics of the P-gp substrate. The goal of this work was to evaluate the concomitant administration of tariquidar and elacridar and the subsequent impact on the pharmacokinetics and brain distribution of loperamide in rats after simultaneous intravenous (I.V) administration of the three compounds. After effective modulation of the P-gp activity by elacridar and/or tariquidar, loperamide, a $\mu$-opioid agonist without central effects, can become a drug that produces substantial antinociception.

\subsection{Materials and Methods}

\subsubsection{Materials}

Loperamide hydrochloride and tetraglycol were obtained from Sigma Aldrich (France), elacridar was synthesized by the Laboratory of Pharmaceutical Chemistry at the University of Bonn in Germany and tariquidar was purchased from API Services Inc. (USA). Polyethylene glycol 600 (PEG600) was obtained from Interchimie (France). Trisodium citrate solution was purchased from BD Vacutainer®80.

Ketoconazole (internal standard for loperamide) and chlorpromazine hydrochloride (internal standard for elacridar and tariquidar), tert-Butyl methyl ether ( $t$-BME), analytical grade ammonium acetate and glacial acetic acid were obtained from Sigma Aldrich (France). HPLC grade methanol $(\mathrm{MeOH})$ and acetonitrile $(\mathrm{ACN})$ were purchased from Carlo Erba (France). Ultrapure water was freshly obtained before use from a Purelab Prima 7/15/20 - Purelab Ultra Mk 2 from Elga (France).

\subsubsection{Animals}

Behavioral observation, pharmacokinetic and brain distribution studies were conducted in male Sprague Dawley rats (Janvier, France). All animal experiments were carried out in accordance with the recommendations in the Guide for the Care and Use of Laboratory Animals (Institute of Laboratory Animal Resources, National Research Council, National 
Academy of Sciences, USA). All the animals were allowed to acclimate for one week and were seven weeks old $(230-280 \mathrm{~g})$ at the time of the experiment. The animals were maintained under a 12-h light/dark cycle and a temperature-controlled environment. Food and water were provided ad libitum. The studies were approved by the Institutional Animal Care and Use Committee of the University of Franche-Comte.

\subsubsection{Drug solutions}

The drug solutions were prepared on the day of the experiment. Elacridar was dissolved in tetraglycol at an initial concentration of $20 \mathrm{mg} / \mathrm{mL}$. Loperamide and tariquidar were dissolved separately in a mixture of saline and $\mathrm{PEG}_{600}(3: 1)$ at concentrations of $2 \mathrm{mg} / \mathrm{mL}$. For each treatment, loperamide, elacridar and tariquidar solutions were diluted with saline and $\mathrm{PEG}_{600}$ (3:1). All the solutions were completely transparent indicating the full solubility of loperamide and both P-gp modulators in the vehicle (Appendices 1 and 2).

\subsubsection{Study design}

This study was carried out using a rat model, which is a promising model to predict P-gpbased drug-drug interactions at the human BBB [12]. The choice of loperamide as a P-gp substrate and its dose was based on its opiate-like behavior, which provides an efficient means with which to ascertain the blockage of the P-gp [13]. Because the reported half-maximum effective dose $\left(\mathrm{ED}_{50}\right)$ for tariquidar and elacridar in rats [14] were lethal in co-administration with loperamide in our pilot study, the doses of the P-gp modulators were reduced to 0.5 or $1.0 \mathrm{mg} / \mathrm{kg}$.

The animals were randomly divided into five experimental groups, each of which received loperamide at a dose of $0.5 \mathrm{mg} / \mathrm{kg}$. The co-administration of P-gp modulators was carried out as follows: Group I, elacridar $1.0 \mathrm{mg} / \mathrm{kg}$; group II, tariquidar $1.0 \mathrm{mg} / \mathrm{kg}$; group III, elacridar $1.0 \mathrm{mg} / \mathrm{kg}$ plus tariquidar $1.0 \mathrm{mg} / \mathrm{kg}$; group IV, elacridar $0.5 \mathrm{mg} / \mathrm{kg}$ plus tariquidar $0.5 \mathrm{mg} / \mathrm{kg}$ and group V (control group), no P-gp modulator. The different treatments were administered via the jugular vein by a single I.V bolus. Groups I, II and III were used to study the influence of the co-administration of elacridar and tariquidar on their own plasma and brain distribution. Groups I, II, IV and V were used to evaluate the influence of the concurrent administration of elacridar and tariquidar on the pharmacokinetics and brain distribution of loperamide. 
Prior to the pharmacokinetic and tissue distribution studies, all the animals were observed for one hour to determine the clinical signs induced by central opiate effects of loperamide. Observations were limited to two to three rats at a time to maximize visibility $(n=12)$. The clinical signs were established according to previous data $[15,16]$ and our pilot study. The degrees of the clinical signs were scored on a 0 to 3 scale according to the intensity of each clinical sign, where $0=$ none, $1=$ mild, $2=$ moderate and $3=$ severe (Table 3 ). Rats that displayed a score of 1 or higher on three or more signs were considered to display opioidinduced behavior.

In the pharmacokinetic study, blood $(-0.25 \mathrm{~mL})$ was serially sampled from the tail vein at 1,6 , 12 and 24 hours after administration of the different treatments. The blood was collected in tubes containing trisodium citrate solution. The plasma was obtained by centrifugation of the blood at $2500 \mathrm{x} g$ for 5 minutes and stored frozen at $-20^{\circ} \mathrm{C}$ until analysis. Three rats were used at each time point $(n=3)$.

In the tissue distribution study, animals were sacrificed at 1, 6, 12 and 24 hours after administration of the different treatments, following deep anesthesia with sodium pentobarbital (50 mg/kg; intraperitoneal), cardiac perfusion with saline and exsanguination. After sacrifice, the whole brain was immediately frozen at $-20^{\circ} \mathrm{C}$ until analysis. Three rats were used at each time point $(n=3)$.

The blood and brains were first sampled at 1 hour post-dosing because according to the literature, loperamide reaches a pseudoequilibrium between the brain and the plasma at this time [12]. The subsequent time points up to 24 hours were selected to determine possible drug-drug interactions and a possible extension of the P-gp modulation at the BBB.

\subsubsection{Analysis of loperamide, elacridar and tariquidar by Liquid Chromatography-Mass Spectrometry (LC-MS)}

Loperamide, elacridar and tariquidar in plasma and brain samples were determined by an LCMS method that has been validated for specificity, calibration curve, lower limit of quantification (LLOQ), accuracy, precision, and recovery according to the FDA guidance for bioanalytical method validation [17]. Ketoconazole was used as internal standard for loperamide and chlorpromazine for elacridar and tariquidar.

The chromatographic analyses were carried out on a Shimadzu High Performance Liquid Chromatography/Mass Spectrometer LCMS-2010EV equipped with a LC-20AD solvent delivery system. The analytes were well separated on a Zorbax Eclipse XDB-C18 2.1 x 150 
$\mathrm{mm}, 5.0-\mu \mathrm{m}$ column from Agilent Technologies at $50^{\circ} \mathrm{C}$ using a Millipore Waters oven. The mobile phase, consisting of $10 \mathrm{mM}$ ammonium acetate (pH 5.5):MeOH:ACN (37.5:40:22.5 $\mathrm{v} / \mathrm{v} / \mathrm{v})$, was delivered in isocratic mode at $0.4 \mathrm{~mL} / \mathrm{min}$. An autosampler 360 from Kontrons Instruments was set at $20 \mu \mathrm{L}$. The compounds were quantitated using positive electrospray ionization (ESI) in an octupole quadrupole mass analyzer with single ion monitoring (SIM) mode at m/z 477 for loperamide, m/z 531 for ketoconazole, m/z 564 for elacridar, m/z 647 for tariquidar and m/z 319 for chlorpromazine. Nitrogen was used as the nebulizing gas at 1.5 $\mathrm{L} / \mathrm{min}$. The curved desolvation line (CDL) and heat block temperatures were set at $250^{\circ} \mathrm{C}$ and $300^{\circ} \mathrm{C}$, respectively. The detector voltage was $1.5 \mathrm{KV}$, the interface voltage was $-3.5 \mathrm{KV}$ and the CDL voltage was $15.0 \mathrm{~V}$.

Frozen brain samples were thawed and homogenized with one volume of water using a Janke \& Kunkel T45 Ultra-turrax and a Fischer Scientific Vibra-cell homogenizer. Prior to chromatographic analysis, $25 \mu \mathrm{L}$ of the internal standard solution containing ketoconazole and chlorpromazine hydrochloride were added to $100 \mu \mathrm{L}$ of each plasma or homogenate sample to yield final concentrations of $100 \mathrm{ng} / \mathrm{mL}$ and $25 \mathrm{ng} / \mathrm{mL}$, respectively. After deproteinization by addition of $800 \mu \mathrm{L}$ of a mixture of ACN and $t$-BME (1:1), the samples were vortexed for 3 minutes and centrifuged at $5000 \mathrm{x} g$ for 10 minutes. The upper organic layer was decanted and evaporated to dryness and the residue was reconstituted in $100 \mu \mathrm{L}$ of mobile phase. A volume of $20 \mu \mathrm{L}$ was injected onto the analytical column.

\subsubsection{Pharmacokinetic calculations}

The pharmacokinetic parameters were calculated by non-compartmental analysis using Kinetica $^{\mathrm{TM}}$ version 4.0 (Inna Phase Corp., 2001). The area under the concentration-time curves (AUC) values was determined using the trapezoidal rule. The half-lives of elimination $\left(t_{1 / 2}\right)$ were calculated as $\ln (2) / \mathrm{K}$, where $\mathrm{K}$ represents the terminal elimination rate constant obtained from the slopes of the semilogarithmic plots of the concentration-time profile. The mean residence time (MRT) was estimated from AUMC/AUC, where AUMC is the partial area under the moment curve. The plasma clearance (CL) was calculated as dose/AUC $C_{\text {inf }}$, where $\mathrm{AUC}_{\mathrm{inf}}$ is the AUC from time zero to infinity. The apparent volume of the plasma compartment $\left(\mathrm{Vd}_{\mathrm{ss}}\right)$ was calculated from dose $\mathrm{x} \mathrm{MRT} / \mathrm{AUC} \mathrm{C}_{\text {inf. }}$ The brain-to-plasma partition coefficient $(K \mathrm{p})$ was calculated as $\mathrm{AUC}_{\text {inf-brain }} / \mathrm{AUC}_{\text {inf-plasma. }}$ 


\subsubsection{Statistical Analysis}

The statistical analysis was carried out using SigmaStat 3.5 software. Analyses of statistical significance between two groups were examined by Student's t-test and between many groups by one-way analysis of variance (ANOVA) with the Holm-Sidak post-hoc test. A $P<0.05$ was considered to be significant. Moreover, the variance of the $\mathrm{AUC}_{\mathrm{inf}}$ in each treatment group was estimated according to the Bailer method [18, 19], which is based on the variability of the concentrations at each sampling time. A Z-test was used for pairwise comparison of AUCs. A $P<0.05$ was considered to be significant.

\subsection{Results}

\subsubsection{Analysis of loperamide, elacridar and tariquidar by Liquid Chromatography-Mass Spectrometry (LC-MS)}

Based on structural similarities, solubility, recovery efficiency and previous successful data $[20,21]$, ketoconazole was a satisfactory internal standard for loperamide, as chlorpromazine was for elacridar and tariquidar. The developed LC-MS method described in this manuscript was linear over the concentration range $5.0 \mathrm{ng} / \mathrm{mL}-1000 \mathrm{ng} / \mathrm{mL}$ for all the three analytes, loperamide, elacridar and tariquidar $\left(\mathrm{r}^{2} \geq 0.9990\right)$. Using $100 \mu \mathrm{L}$ of rat plasma or tissue homogenate, the validated lower limit of quantification (LLOQ) for each compound was the lowest concentration of standard on the calibration curves, $5.0 \mathrm{ng} / \mathrm{mL}$. Intra- and inter-day accuracy and precision were within $15 \%$ for the three analytes. The specificity of the method was confirmed by the absence of interferences from endogenous compounds. In this study, the sample preparation procedure using $\mathrm{ACN}$ and $t$-BME (1:1) demonstrated absolute recovery values from rat plasma and brain samples higher than $90 \%$, for loperamide, ketoconazole, elacridar, tariquidar and chlorpromazine. Furthermore, stability tests demonstrated that the analytes were stable under the storage conditions. The current validated method (chapter 4) was then used for the simultaneous quantitation of loperamide, elacridar and tariquidar in plasma and brain samples. 


\subsubsection{Influence of the co-administration of elacridar and tariquidar on their plasma and brain levels}

At a first stage, the groups which received elacridar at $1.0 \mathrm{mg} / \mathrm{kg}$ and/or tariquidar at 1.0 $\mathrm{mg} / \mathrm{kg}$ (groups I, II and III) were used to compare whether the concurrent administration of both P-gp modulators influenced their own plasma and brain distributions (Fig 1 and 2).

No modification in the plasma $\mathrm{AUC}_{\text {inf }}$ of elacridar alone or co-administered with tariquidar $(31.9 \pm 2.7$ vs $32.2 \pm 3.4 \mathrm{nmol} . \mathrm{h} / \mathrm{mL})$ and in the plasma $\mathrm{AUC}_{\mathrm{inf}}$ of tariquidar alone or coadministered with elacridar $(37.8 \pm 1.9$ vs $37.0 \pm 2.8 \mathrm{nmol} . \mathrm{h} / \mathrm{mL})$ were observed (Table 1$)$. These values indicate that the co-administration of these P-gp modulators at $1.0 \mathrm{mg} / \mathrm{kg}$ each had no observable effects on each other plasma concentrations.

The elacridar $\mathrm{AUC}_{\mathrm{inf}}$ for the brain remained unchanged after concurrent administration with tariquidar $(3.1 \pm 0.1$ vs $3.6 \pm 0.4 \mathrm{nmol} . \mathrm{h} / \mathrm{g})$. Vice versa, the tariquidar $\mathrm{AUC}_{\mathrm{inf}}$ for the brain increased from $0.8 \pm 0.1$ to $1.6 \pm 0.1 \mathrm{nmol} . \mathrm{h} / \mathrm{g}$ (2.0-fold) in the presence of elacridar (Table 1). This increase was associated with a 2 -fold higher $K \mathrm{p}$ for tariquidar. These findings suggest that when both P-gp modulators are co-administered, elacridar could interfere with the active transport of tariquidar at the BBB.

Table1. Area under the concentration-time curves $\left(\mathrm{AUC}_{\mathrm{inf}}\right)$ and $K \mathrm{p}$ of elacridar and tariquidar

\begin{tabular}{ccccccccc}
\hline \multirow{2}{*}{$\begin{array}{c}\text { Pharmacokinetic } \\
\text { parameters }\end{array}$} & \multicolumn{2}{c}{$\begin{array}{c}\text { Elacridar } 1.0 \mathrm{mg} / \mathrm{kg} \\
(1773.05 \mathrm{nmol} / \mathrm{kg})\end{array}$} & \multicolumn{2}{c}{$\begin{array}{c}\text { Elacridar } 1.0 \mathrm{mg} / \mathrm{kg} \\
(+ \text { Tariquidar } 1.0 \mathrm{mg} / \mathrm{kg})\end{array}$} & \multicolumn{2}{c}{$\begin{array}{c}\text { Tariquidar } 1.0 \mathrm{mg} / \mathrm{kg} \\
(1545.60 \mathrm{nmol} / \mathrm{kg})\end{array}$} & \multicolumn{2}{c}{$\begin{array}{c}\text { Tariquidar } 1.0 \mathrm{mg} / \mathrm{kg} \\
\text { (+ Elacridar } 1.0 \mathrm{mg} / \mathrm{kg})\end{array}$} \\
\cline { 2 - 9 } & Mean & S.D. & Mean & S.D. & Mean & S.D. & Mean & S.D. \\
\hline $\begin{array}{c}\mathrm{AUC}_{\text {inf-plasma }} \\
(\mathrm{nmol.h} / \mathrm{mL})\end{array}$ & 31.9 & 2.7 & 32.2 & 3.4 & 37.8 & 1.9 & 37.0 & 2.8 \\
$\begin{array}{c}\mathrm{AUC} \text { inf-brain } \\
(\mathrm{nmol.h} / \mathrm{g})\end{array}$ & 3.1 & 0.1 & 3.6 & 0.4 & 0.8 & 0.1 & $1.6^{*}$ & 0.1 \\
$\mathrm{Kp}$ & 0.098 & 0.011 & 0.115 & 0.021 & 0.022 & 0.003 & $0.043^{\#}$ & 0.007 \\
\hline
\end{tabular}

* Bailler method: Significantly different compared to the group which only received one P-gp modulator, whether elacridar at $1.0 \mathrm{mg} / \mathrm{kg}$ or tariquidar at $1.0 \mathrm{mg} / \mathrm{kg}$

\# Student's t-test: Significantly different compared to the group which only received one P-gp modulator, whether elacridar at $1.0 \mathrm{mg} / \mathrm{kg}$ or tariquidar at $1.0 \mathrm{mg} / \mathrm{kg}$ 


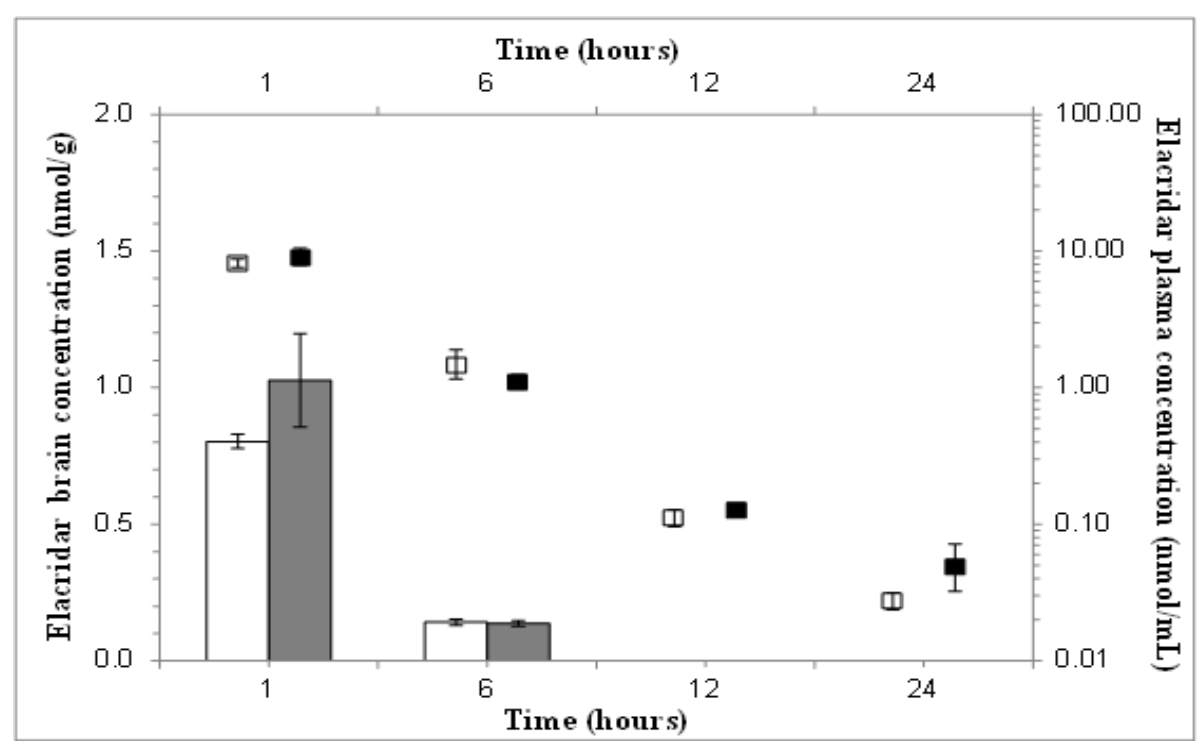

Figure 1: Brain concentrations (left axis) and plasma concentrations (right axis) of elacridar after intravenous administration of elacridar alone at $1.0 \mathrm{mg} / \mathrm{kg}$ (white bars/empty squares) or concurrently administered with tariquidar at $1.0 \mathrm{mg} / \mathrm{kg}$ (gray bars/full squares). Concentrations are expressed as mean \pm standard deviation. Concentrations are expressed as mean \pm standard deviation. Bars represent the standard deviation. $\mathrm{n}=3$.

\# Student's t-test: Significantly different compared to the group which received elacridar at $1.0 \mathrm{mg} / \mathrm{kg}$ alone.

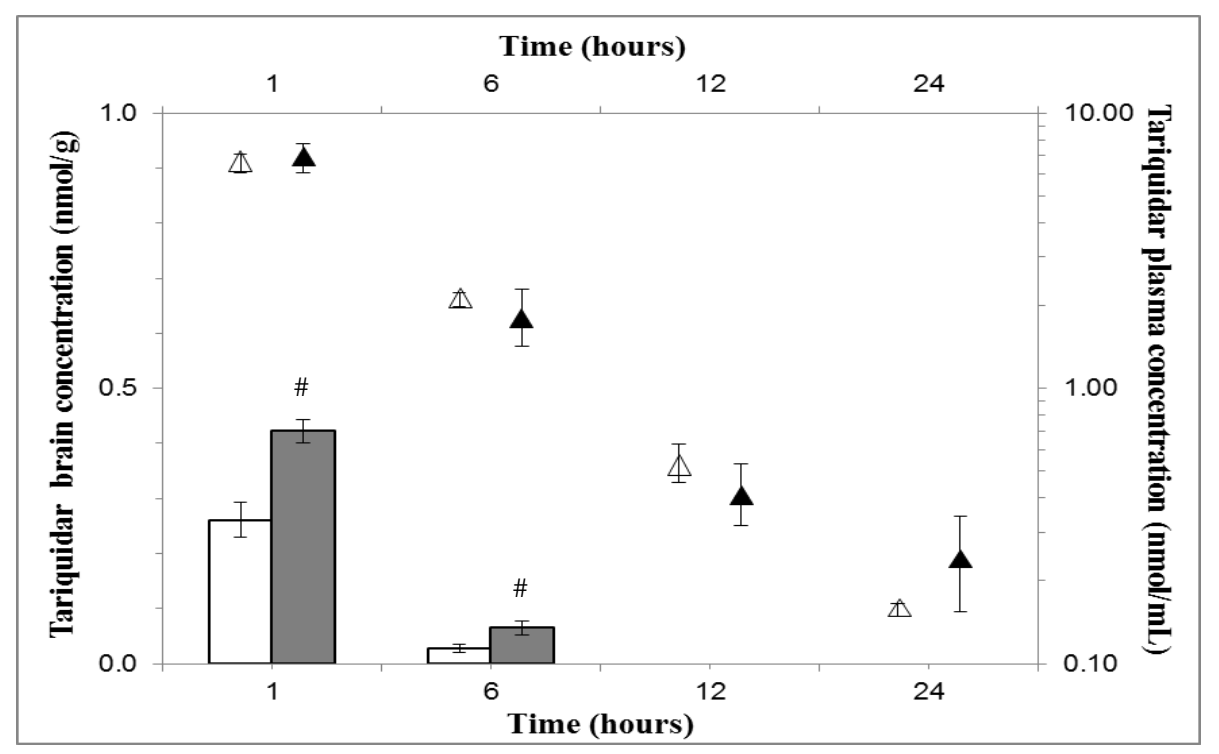

Figure 2: Brain concentrations (left axis) and plasma concentrations (right axis) of tariquidar after intravenous administration of tariquidar alone at $1.0 \mathrm{mg} / \mathrm{kg}$ (white bars/empty triangles) or concurrently administered with elacridar at $1.0 \mathrm{mg} / \mathrm{kg}$ (gray bars/full triangles). Concentrations are expressed as mean \pm standard deviation. Bars represent the standard deviation. $\mathrm{n}=3$.

\# Student's t-test: Significantly different compared to the group which received tariquidar at $1.0 \mathrm{mg} / \mathrm{kg}$ alone. 


\subsubsection{Influence of the co-administration of elacridar and tariquidar on loperamide plasma levels}

To evaluate the effects of the co-administration of both P-gp modulators on loperamide pharmacokinetics, the groups which received a total dose of $1.0 \mathrm{mg} / \mathrm{kg}$ of P-gp modulators (groups I, II, and IV) were compared. Group V served as a control.

In rats receiving $0.5 \mathrm{mg} / \mathrm{kg}$ loperamide alone, the concentration of loperamide in plasma $\left(\mathrm{C}_{\max }\right)$ after 1 hour $\left(\mathrm{T}_{\max }\right)$ was approximately $4.0 \% / \mathrm{mL}$ of the administered dose, which reflects a rapid metabolism of loperamide during this first hour (Fig. 3, Table 2). The mean elimination half-life of a single loperamide administration in this study was $3.6 \pm 0.3$ hours and it was not significantly altered in presence of elacridar and/or tariquidar. Likewise, the AUC, MRT, CL and $\mathrm{Vd}_{\mathrm{ss}}$ were not significantly different in any of the treatments using one or two P-gp modulators. These results confirmed that neither elacridar nor tariquidar altered the pharmacokinetic parameters of loperamide.

Table 2. Pharmacokinetic parameter of loperamide

\begin{tabular}{ccccccccc}
\hline \multirow{2}{*}{$\begin{array}{c}\text { Pharmacokinetic } \\
\text { parameters }\end{array}$} & \multicolumn{2}{c}{ No P-gp modulator } & \multicolumn{2}{c}{ Tariquidar $1.0 \mathrm{mg} / \mathrm{kg}$} & \multicolumn{2}{c}{ Elacridar $1.0 \mathrm{mg} / \mathrm{kg}$} & \multicolumn{2}{c}{$\begin{array}{c}\text { Elacridar 0.5 mg/kg }+ \\
\text { Tariquidar 0.5 mg/kg }\end{array}$} \\
\cline { 2 - 8 } & Mean & S.D. & Mean & S.D. & Mean & S.D. & Mean & S.D. \\
\hline $\mathrm{T}_{\max }(\mathrm{h})$ & 1.0 & --- & 1.0 & --- & 1.0 & -- & 1.0 & --- \\
$\begin{array}{c}\mathrm{C}_{\max } \\
(\mathrm{ng} / \mathrm{mL})\end{array}$ & 5052 & 800 & 5371 & 660 & 5855 & 626 & 5756 & 252 \\
$\begin{array}{c}\mathrm{AUC} \text { inf } \\
(\mathrm{ng} . \mathrm{h} / \mathrm{mL})\end{array}$ & 28900 & 4554 & 34365 & 4800 & 34409 & 4306 & 30627 & 3492 \\
$\mathrm{t}_{1 / 2}(\mathrm{~h})$ & 3.6 & 0.3 & 3.9 & 0.5 & 4.9 & 0.7 & 4.2 & 0.2 \\
$\mathrm{MRT}(\mathrm{h})$ & 5.0 & 0.4 & 5.5 & 0.3 & 5.9 & 0.8 & 5.0 & 0.5 \\
$\begin{array}{c}\mathrm{Cl} \\
(\mathrm{mL} / \mathrm{h} / \mathrm{Kg})\end{array}$ & 4.4 & 0.7 & 3.7 & 0.5 & 3.4 & 0.5 & 4.2 & 0.5 \\
$\begin{array}{c}\mathrm{Vd} \\
(\mathrm{mL} / \mathrm{Kg})\end{array}$ & 22.1 & 2.6 & 20.6 & 3.5 & 21.7 & 3.7 & 20.8 & 1.0 \\
\hline
\end{tabular}

\# ANOVA: Significantly different compared to the group which received no P-gp modulator.

\#\# ANOVA: Significantly different compared to the group which received elacridar or tariquidar at $1.0 \mathrm{mg} / \mathrm{kg}$. 


\subsubsection{Influence of the co-administration of elacridar and tariquidar on loperamide concentrations in the CNS}

To evaluate the effects of the co-administration of both P-gp modulators on the brain distribution of loperamide, the groups which received a total dose of $1.0 \mathrm{mg} / \mathrm{kg}$ of P-gp modulators (groups I, II, and IV) were compared. Group V served as a control.

Previous studies $[13,22]$ showed that low doses of P-gp modulators and loperamide were taken up into the brain. In agreement with these results, in the present study, these doses demonstrated sufficient degree of P-gp inhibition at the BBB (Table 3). Immediately after administration, a few animals from the loperamide-treated groups which received tariquidar at $1.0 \mathrm{mg} / \mathrm{kg}$ or elacridar at $1.0 \mathrm{mg} / \mathrm{kg}$ showed lethargy, piloerection and shallow breathing. However, these animals were able to respond if handled, and by 15 minutes post-treatment they recovered normal activity. According to our clinical score, $1.0 \mathrm{mg} / \mathrm{kg}$ of tariquidar (total score $=13$ ) and $1.0 \mathrm{mg} / \mathrm{kg}$ of elacridar (total score $=26$ ) slightly promoted the central effects of loperamide. More than $50 \%$ of the animals from the group that received loperamide coadministered with elacridar and tariquidar, each at $0.5 \mathrm{mg} / \mathrm{kg}$ not only immediately exhibited the same clinical signs but also demonstrated whole body tetany and eye protrusion. In addition, two of the 12 animals of this group showed the Straub reaction which is characterized by the rigidity of the tail, held in an S-shaped curve across the back of the animal [23]. These animals recovered normal activity approximately 30 minutes later. These clinical signs indicate that the co-administration of the two P-gp modulators (total score = 102) at a total dose of $1.0 \mathrm{mg} / \mathrm{kg}$ significantly potentiated the opioid brain effects of loperamide. 
Table 3. Opioid-induced clinical signs

\begin{tabular}{|c|c|c|c|c|c|c|c|c|}
\hline \multirow{2}{*}{$\begin{array}{c}\text { Clinical signs } \\
\text { (1 hour post-dose) }\end{array}$} & \multicolumn{2}{|c|}{ No P-gp modulator } & \multicolumn{2}{|c|}{ Elacridar $1.0 \mathrm{mg} / \mathrm{kg}$} & \multicolumn{2}{|c|}{ Tariquidar $1.0 \mathrm{mg} / \mathrm{kg}$} & \multicolumn{2}{|c|}{$\begin{array}{l}\text { Elacridar } 0.5 \mathrm{mg} / \mathrm{kg}+ \\
\text { Tariquidar } 0.5 \mathrm{mg} / \mathrm{kg}\end{array}$} \\
\hline & $\mathrm{N} / \mathrm{n}$ & degree & $\mathrm{N} / \mathrm{n}$ & degree & $\mathrm{N} / \mathrm{n}$ & degree & $\mathrm{N} / \mathrm{n}$ & degree \\
\hline \multicolumn{9}{|l|}{ CNS : } \\
\hline Lethargy & $0 / 12$ & 0 & $6 / 12$ & 2 & $4 / 12$ & 2 & $9 / 12$ & 3 \\
\hline Whole body tetany & $0 / 12$ & 0 & $0 / 12$ & 0 & $0 / 12$ & 0 & $9 / 12$ & 2 \\
\hline Straub tail & $0 / 12$ & 0 & $0 / 12$ & 0 & $0 / 12$ & 0 & $2 / 12$ & 3 \\
\hline Piloerection & $0 / 12$ & 0 & $4 / 12$ & 1 & $3 / 12$ & 1 & $7 / 12$ & 2 \\
\hline \multicolumn{9}{|l|}{ Pulmonary : } \\
\hline Shallow breathing & $0 / 12$ & 0 & $5 / 12$ & 2 & $2 / 12$ & 1 & $9 / 12$ & 3 \\
\hline \multicolumn{9}{|l|}{ Eyes : } \\
\hline Eye protrusion & $0 / 12$ & 0 & $0 / 12$ & 0 & $0 / 12$ & 0 & $5 / 12$ & 2 \\
\hline Total score & \multicolumn{2}{|c|}{0} & \multicolumn{2}{|c|}{26} & \multicolumn{2}{|c|}{13} & \multicolumn{2}{|c|}{102} \\
\hline
\end{tabular}

$\mathrm{N} / \mathrm{n}=$ number of rats displaying these clinical signs/number of rats per group. $(n=12)$.

The degrees of the clinical signs are scored as $0=$ none, $1=$ mild, $2=$ moderate and $3=$ severe.

Values shown in the degree columns are the mean degree score for each symptom.

Total score $=$ total sum of $\mathrm{N} x$ degree

Rats that displayed a score of 1 or higher on 3 or more signs were considered to display opioid-induced behavior. 
The administration of loperamide alone resulted in very low levels $(10.53 \pm 0.51 \mathrm{ng} / \mathrm{g})$ in the brain after 1 hour (Fig. 3). However, the co-administration of the P-gp modulators significantly increased the concentration of loperamide in the brain at this time point. Tariquidar and elacridar, each at $1.0 \mathrm{mg} / \mathrm{kg}$ increased loperamide levels in the brain by 2$(22.48 \pm 2.93 \mathrm{ng} / \mathrm{g})$ and 3 -fold $(33.84 \pm 3.95 \mathrm{ng} / \mathrm{g})$, respectively. However, the concurrent administration of both P-gp modulators at half doses increased the concentration of loperamide in the brain by 5 -fold $(47.26 \pm 6.09 \mathrm{ng} / \mathrm{g})$. After 6 hours, loperamide was undetectable in brains from animals that had not received either P-gp modulator and close to $10.0 \mathrm{ng} / \mathrm{g}$ in the other three groups. After 12 and 24 hours, loperamide was not detectable in any group. The differences in the loperamide $\mathrm{AUC}_{\mathrm{inf}}$ for the brains and the $\mathrm{Kp}$ values were even more marked than the effects at the individual times (Table 4). All these results suggest a greater inhibition of the P-gp-mediated efflux by elacridar than by tariquidar and a possible synergistic effect of both P-gp modulators when they are co-administered.

Table 4. Brain distribution of loperamide

\begin{tabular}{|c|c|c|c|c|c|c|c|c|}
\hline \multirow{2}{*}{$\begin{array}{c}\text { Pharmacokinetic } \\
\text { parameters }\end{array}$} & \multicolumn{2}{|c|}{ No P-gp modulator } & \multicolumn{2}{|c|}{ Tariquidar $1.0 \mathrm{mg} / \mathrm{kg}$} & \multicolumn{2}{|c|}{ Elacridar $1.0 \mathrm{mg} / \mathrm{kg}$} & \multicolumn{2}{|c|}{$\begin{array}{l}\text { Elacridar } 0.5 \mathrm{mg} / \mathrm{kg}+ \\
\text { Tariquidar } 0.5 \mathrm{mg} / \mathrm{kg}\end{array}$} \\
\hline & Mean & S.D. & Mean & S.D. & Mean & S.D. & Mean & S.D. \\
\hline $\begin{array}{l}\mathrm{AUC}_{\text {inf }} \\
\text { (ng.h/g) }\end{array}$ & 10.5 & 0.5 & $124.5^{*}$ & 20.1 & $142.3^{*}$ & 15.8 & $\begin{array}{c}160.5^{*} \\
* *\end{array}$ & 16.2 \\
\hline$K \mathrm{p}$ & 0.0004 & 0.0001 & $0.0037^{\#}$ & 0.0009 & $0.0042^{\#}$ & 0.0004 & $\begin{array}{c}0.0061^{\#} \\
\# \#\end{array}$ & 0.0002 \\
\hline
\end{tabular}

*Bailer method: Significantly different compared to the group which received no P-gp modulator.

**Bailer method: Significantly different compared the group which received elacridar or tariquidar at $1.0 \mathrm{mg} / \mathrm{kg}$.

\#ANOVA: Significantly different compared to the group which received no P-gp modulator.

\#\#ANOVA: Significantly different compared to the group which received elacridar or tariquidar at $1.0 \mathrm{mg} / \mathrm{kg}$. 


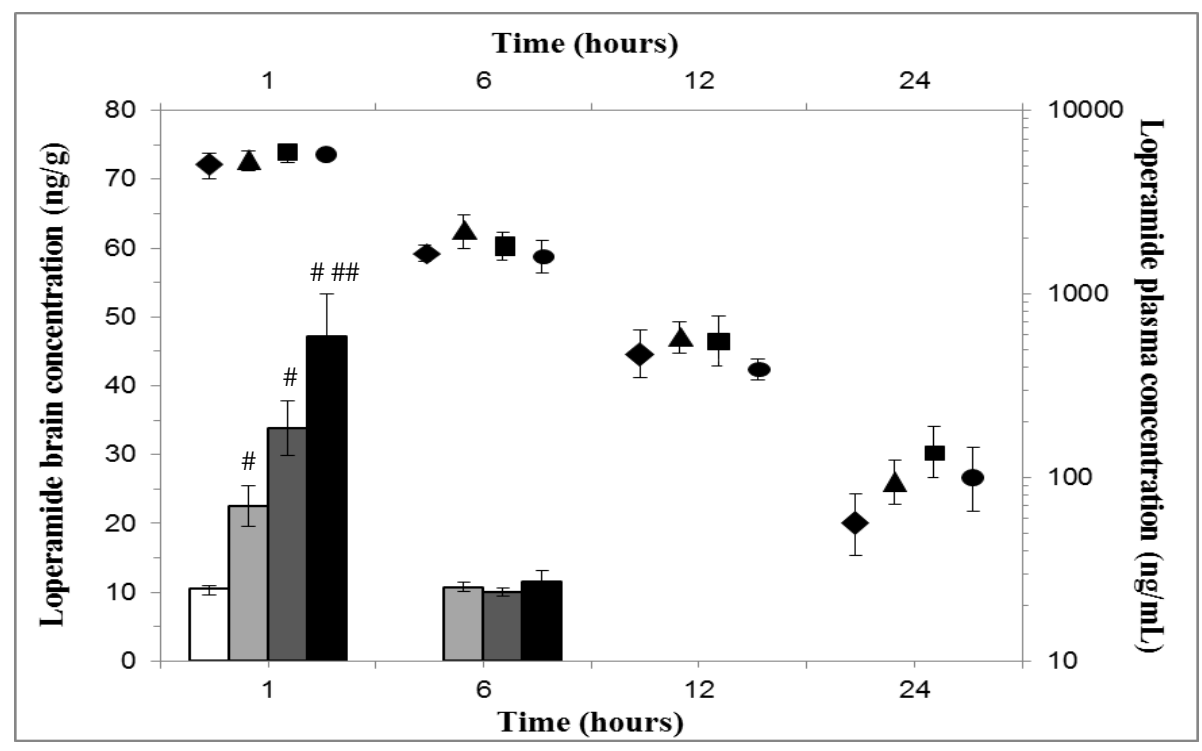

Figure 3 : Brain concentrations (left axis) and plasma concentrations (right axis) of loperamide after intravenous administration of loperamide alone at $0.5 \mathrm{mg} / \mathrm{kg}$ (white bars/rhombus) or concurrently administered with tariquidar at $1.0 \mathrm{mg} / \mathrm{kg}$ (light gray bars/triangles), or with elacridar at $1.0 \mathrm{mg} / \mathrm{kg}$ (dark gray bars/squares) or with tariquidar at $0.5 \mathrm{mg} / \mathrm{kg}$ plus elacridar at $0.5 \mathrm{mg} / \mathrm{kg}$ (black bars/circles). Bars represent the standard deviation. $\mathrm{n}$ $=3$.

\#ANOVA: Significantly different compared to the concentration of loperamide in the brain (ng/g) from the group which received no P-gp modulator.

\#\#ANOVA: Significantly different compared to the concentration of loperamide in the brain (ng/g) from the group which received elacridar or tariquidar at $1.0 \mathrm{mg} / \mathrm{kg}$.

\subsection{Discussion}

Given that the use of relatively high doses of the third-generation P-gp modulators [24] may be limited by the same drawbacks of the first- and second-generation P-gp modulators, this study evaluated the potential of combining the administration of two P-gp modulators to see the influence on the efflux activity of the P-gp at the BBB.

The co-administration of elacridar and tariquidar did not significantly increase the plasma concentrations of each agent relative to the values obtained for administration of the single agents. Their respective AUCs suggest that at the doses used in the current work, neither P-gp modulator interferes with the elimination pathway of the other. The $K \mathrm{p}$ obtained for individual doses of elacridar and tariquidar are low due to the low concentrations of either Pgp modulator in the brain. These results contrast with prior studies that showed that the levels of tariquidar and elacridar were much higher in the brain than in the plasma [14, 25], but those experiments utilized between 3.0- and 15-fold higher doses of P-gp modulators compared to 
the current study. These differences were properly explained before [22, 26], where murine models revealed that at higher doses of elacridar, a higher distribution of the P-gp modulator was attained in the brain. For instance, at 1 hour post-injection, the $\mathrm{B} / \mathrm{P}$ ratio of elacridar increased from $\sim 0.4$ at $0.5 \mathrm{mg} / \mathrm{kg}$ to $\sim 5.2$ at $2.5 \mathrm{mg} / \mathrm{kg}$ [26]. This dose-dependent distribution relationship was also observed for tariquidar [27]. A supplementary explanation for the low brain distribution of elacridar and tariquidar in this study is based on the pharmacokinetic behavior of these compounds at low doses. At nanomolar doses, both P-gp modulators are actively transported not only by the P-gp but also by the breast cancer resistance protein (BCRP) at the BBB [27]. Thus, the amount transported by these two proteins would be higher than the amount that arrives to the brain by passive diffusion, resulting in increased plasma concentrations and decreased brain concentrations of these compounds. Nevertheless, when the two compounds are co-administered, elacridar may reduce or delay the active transport of tariquidar by both proteins [28], thus significantly increasing the $K \mathrm{p}$ of tariquidar. An important issue to consider when comparing the distribution of low doses of P-gp modulators in the brain is the species differences in P-gp transport activity, which appear to be substratedependent [29]. It was found that several chemical entities which were P-gp substrates in mice were also P-gp substrates in rats, but the brain distribution of these compounds is not always the same in both species. In one clear example, while the $K \mathrm{p}$ of $N$-desmethyl-venlafaxine was the same in mice and rats, the $K \mathrm{p}$ of risperidone was 2.36-fold higher in mice than in rats [30]. These data can also account for the higher brain distribution of relative low doses of P-gp modulators in mice compared to our rat model.

To evaluate the effects of the co-administration of both P-gp modulators at a total dose of 1.0 $\mathrm{mg} / \mathrm{kg}$ on P-gp activity, loperamide was chosen as a P-gp substrate probe. The mean half-life of loperamide was $3.6 \pm 0.3 \mathrm{~h}$, which is different from a previous study [15], where less than $1.0 \% / \mathrm{mL}$ of the intravenous administered dose of loperamide was monitored at 5 minutes post-dosing. This difference can be attributed to the low solubility of loperamide in the vehicle used in that study. However, our $K \mathrm{p}$ values of loperamide are more in agreement with another study, where the $K \mathrm{p}_{(0-1 \mathrm{~h})}$ of the $\mu$-opioid agonist was 0.006 [13]. In the current investigation, the half-life as well as the $\mathrm{AUC}, \mathrm{MRT}, \mathrm{CL}$ and $\mathrm{Vd}_{\mathrm{ss}}$ were not significantly modified when loperamide was co-administered with elacridar or tariquidar or both P-gp modulators at a total dose of $1.0 \mathrm{mg} / \mathrm{kg}$. The lack of alterations in the pharmacokinetic parameters of loperamide in the different groups confirms the minimal modulation on the cytochrome P4503A4 by elacridar and tariquidar [9]. This cytochrome plays a predominant role in the metabolism of loperamide [31,32]. Previously, different models showed that even 
higher doses of tariquidar and elacridar did not significantly change the pharmacokinetics of the P-gp substrates $[8,9]$.

Therefore, the increase of loperamide levels in the brain could not be explained by the modest increase of loperamide in plasma. Instead, it was likely due to the efficient modulation of the P-gp at the BBB by tariquidar and elacridar. The clinical signs noticed in the observation phase are in line with the opiate effects [23] when loperamide at an oral dose of $10 \mathrm{mg} / \mathrm{kg}$ was administered to Mdr1a knockout rats (SAGE Mdr1a) [15], a standard for the complete blockage of the P-gp at the BBB. These observations suggest an important and extremely rapid distribution of the P-gp modulators in the brain and an immediate modulation of the P$\mathrm{gp}$ at the BBB. After one hour of administration, tariquidar or elacridar, each at $1.0 \mathrm{mg} / \mathrm{kg}$, increased loperamide levels in the brain by 2.3- and 3.5-fold, respectively, thus showing that even at relatively low doses, elacridar is more potent than tariquidar. These results are consistent with precedent studies [9, 14], where the authors used BBB mice and rat models to show that the $\mathrm{ED}_{50}$ of elacridar is between 2- and 3-fold lower than the $\mathrm{ED}_{50}$ of tariquidar. Nevertheless, the most significant finding in this investigation was that the concurrent administration of both P-gp modulators at half doses increased the concentration of loperamide in the brain by 5 -fold. A suitable explanation for this lies on the non-competitive activity of tariquidar and elacridar towards the P-gp, which means that both P-gp modulators can independently and simultaneously bind the P-gp on distinct drug binding sites [11]. Equilibrium and kinetic radioligand binding assays allowed to determine the presence of at least four distinct drug interaction sites on P-gp. Sites I, II and III were classified as sites for transport because they interacted with P-gp substrates such as vinblastine, paclitaxel, rhodamine 123 and Hoechst 33342. Site II could also interact with some P-gp modulators such as tariquidar. In contrast, site IV was classified as a regulatory site because only P-gp modulators such as elacridar could interact with this site [11]. Although site IV could allosterically communicate in a negative heterotropic manner with the site II, the dissociation rate of $[3 \mathrm{H}] \mathrm{XR} 9576$, an analog of tariquidar, was significantly slower than that of the P-gp substrate [3H]vinblastine [33]. Thus, despite the active transport, it appears that both P-gp modulators were able to bind the P-gp at their corresponding drug binding sites and the complex allosteric communication resulted in a possible synergistic interaction. Nevertheless, the dose-limiting opioid effects of loperamide preclude assessing this strategy with higher doses of loperamide co-administered with higher doses of the P-gp modulators. Taking into account that synergism can be different at different dose levels [34]; these preliminary synergistic effects should be further confirmed using radiolabelled [3H or 14C] loperamide 
associated to higher doses of P-gp modulators. Moreover, many other P-gp substrates with different therapeutic effects and several doses of elacridar and tariquidar remain to be explored and extrapolated to different species to define the synergistic interaction between both P-gp modulators. The synergistic phenomenon observed herein resulted in strong pharmacodynamic effects by loperamide, a potent CNS agent. However, this approach could be restricted in infectious or cancer diseases, where high brain concentrations of the therapeutic agents are needed and a synergism at high effect levels is more relevant than at low effect levels [34]. Other P-gp modulators can also be used for these studies, provided that the steric hindrance of one does not affect the binding of the other.

Since this preliminary study support the synergistic modulation of P-gp using low doses of elacridar and tariquidar, this approach may represent a potential step forward to avoid the use of high, nearly toxic doses of P-gp modulators without significant pharmacokinetics interactions. Furthermore, because the distribution and the permanence of these P-gp modulators in the brain are dose-dependent, the rapid decrease of the P-gp modulators in the brain as observed in this work represents an advantage. Our approach could avoid the entry of harmful compounds after a long-lasting P-gp inhibition at the BBB. 


\section{References}

[1] R.L. Juliano, V. Ling, A surface glycoprotein modulating drug permeability in Chinese hamster ovary cell mutants, Biochim Biophys Acta, 455 (1976) 152-162.

[2] S.V. Ambudkar, S. Dey, C.A. Hrycyna, M. Ramachandra, I. Pastan, M.M. Gottesman, Biochemical, cellular, and pharmacological aspects of the multidrug transporter, Annu Rev Pharmacol Toxicol, 39 (1999) 361-398.

[3] W. Loscher, H. Potschka, Role of drug efflux transporters in the brain for drug disposition and treatment of brain diseases, Prog Neurobiol, 76 (2005) 22-76.

[4] K. Linnet, T.B. Ejsing, A review on the impact of P-glycoprotein on the penetration of drugs into the brain. Focus on psychotropic drugs, Eur Neuropsychopharmacol, 18 (2008) 157-169.

[5] L. Varatharajan, S.A. Thomas, The transport of anti-HIV drugs across blood-CNS interfaces: summary of current knowledge and recommendations for further research, Antiviral Res, 82 (2009) A99-109.

[6] G. Ecker, P. Chiba, Structure-activity-relationship studies on modulators of the multidrug transporter P-glycoprotein--an overview, Wien Klin Wochenschr, 107 (1995) 681-686.

[7] B.D. Anderson, M.J. May, S. Jordan, L. Song, M.J. Roberts, M. Leggas, Dependence of nelfinavir brain uptake on dose and tissue concentrations of the selective P-glycoprotein inhibitor zosuquidar in rats, Drug Metab Dispos, 34 (2006) 653-659.

[8] M. Hubensack, C. Muller, P. Hocherl, S. Fellner, T. Spruss, G. Bernhardt, A. Buschauer, Effect of the ABCB1 modulators elacridar and tariquidar on the distribution of paclitaxel in nude mice, J Cancer Res Clin Oncol, 134 (2008) 597-607.

[9] E.F. Choo, D. Kurnik, M. Muszkat, T. Ohkubo, S.D. Shay, J.N. Higginbotham, H. Glaeser, R.B. Kim, A.J. Wood, G.R. Wilkinson, Differential in vivo sensitivity to inhibition of P-glycoprotein located in lymphocytes, testes, and the blood-brain barrier, J Pharmacol Exp Ther, 317 (2006) 1012-1018.

[10] M. Bauer, M. Zeitlinger, D. Todorut, M. Bohmdorfer, M. Muller, O. Langer, W. Jager, Pharmacokinetics of Single Ascending Doses of the P-Glycoprotein Inhibitor Tariquidar in Healthy Subjects, Pharmacology, 91 (2013) 12-19.

[11] C. Martin, G. Berridge, C.F. Higgins, P. Mistry, P. Charlton, R. Callaghan, Communication between multiple drug binding sites on P-glycoprotein, Mol Pharmacol, 58 (2000) 624-632. 
[12] P. Hsiao, J.D. Unadkat, P-glycoprotein-based loperamide-cyclosporine drug interaction at the rat blood-brain barrier: prediction from in vitro studies and extrapolation to humans, Mol Pharm, 9 (2012) 629-633.

[13] I.A. Elkiweri, Y.L. Zhang, U. Christians, K.Y. Ng, M.C. Tissot van Patot, T.K. Henthorn, Competitive substrates for P-glycoprotein and organic anion protein transporters differentially reduce blood organ transport of fentanyl and loperamide: pharmacokinetics and pharmacodynamics in Sprague-Dawley rats, Anesth Analg, 108 (2009) 149-159.

[14] C. Kuntner, J.P. Bankstahl, M. Bankstahl, J. Stanek, T. Wanek, G. Stundner, R. Karch, R. Brauner, M. Meier, X. Ding, M. Muller, W. Loscher, O. Langer, Dose-response assessment of tariquidar and elacridar and regional quantification of P-glycoprotein inhibition at the rat blood-brain barrier using (R)-[(11)C]verapamil PET, Eur J Nucl Med Mol Imaging, 37 (2010) 942-953.

[15] M.J. Zamek-Gliszczynski, D.W. Bedwell, J.Q. Bao, J.W. Higgins, Characterization of SAGE Mdr1a (P-gp), Bcrp, and Mrp2 knockout rats using loperamide, paclitaxel, sulfasalazine, and carboxydichlorofluorescein pharmacokinetics, Drug Metab Dispos, 40 (2012) 1825-1833.

[16] A. Pinelli, S. Trivulzio, Quantitative evaluation of opioid withdrawal signs in rats repeatedly treated with morphine and injected with naloxone, in the absence or presence of the antiabstinence agent clonidine, J Pharmacol Toxicol Methods, 38 (1997) 117-131.

[17] F.D.A.U.S.D.o.H.a.H. Services., Guidance for Industry: Bioanalytical Method Validation, (2001).

[18] A.J. Bailer, Testing for the equality of area under the curves when using destructive measurement techniques, J Pharmacokinet Biopharm, 16 (1988) 303-309.

[19] J. Yuan, Estimation of variance for AUC in animal studies, J Pharm Sci, 82 (1993) 761763.

[20] J.H. Yu, H.J. Kim, S. Lee, S.J. Hwang, W. Kim, C.J. Moon, LC-MS determination and bioavailability study of loperamide hydrochloride after oral administration of loperamide capsule in human volunteers, J Pharm Biomed Anal, 36 (2004) 421-427.

[21] E.M. Kemper, B. Jansen, K.R. Brouwer, J.H. Schellens, J.H. Beijnen, O. van Tellingen, Bioanalysis and preliminary pharmacokinetics of the acridonecarboxamide derivative GF120918 in plasma of mice and humans by ion-pairing reversed-phase high-performance liquid chromatography with fluorescence detection, J Chromatogr B Biomed Sci Appl, 759 (2001) 135-143.

[22] K. Kawamura, T. Yamasaki, F. Konno, J. Yui, A. Hatori, K. Yanamoto, H. Wakizaka, M. Takei, Y. Kimura, T. Fukumura, M.R. Zhang, Evaluation of limiting brain penetration related to P-glycoprotein and breast cancer resistance protein using [(11)C]GF120918 by PET in mice, Mol Imaging Biol, 13 (2011) 152-160. 
[23] D.L. Bilbey, H. Salem, M.H. Grossman, The anatomical basis of the straub phenomenon, Br J Pharmacol Chemother, 15 (1960) 540-543.

[24] N.N. Salama, E.J. Kelly, T. Bui, R.J. Ho, The impact of pharmacologic and genetic knockout of P-glycoprotein on nelfinavir levels in the brain and other tissues in mice, J Pharm Sci, 94 (2005) 1216-1225.

[25] J.P. Bankstahl, C. Kuntner, A. Abrahim, R. Karch, J. Stanek, T. Wanek, W. Wadsak, K. Kletter, M. Muller, W. Loscher, O. Langer, Tariquidar-induced P-glycoprotein inhibition at the rat blood-brain barrier studied with (R)-11C-verapamil and PET, J Nucl Med, 49 (2008) 1328-1335.

[26] R. Sane, S. Agarwal, R.K. Mittapalli, W.F. Elmquist, Saturable active efflux by pglycoprotein and breast cancer resistance protein at the blood-brain barrier leads to nonlinear distribution of elacridar to the central nervous system, J Pharmacol Exp Ther, 345 (2013) 111 124.

[27] J.P. Bankstahl, M. Bankstahl, K. Romermann, T. Wanek, J. Stanek, A.D. Windhorst, M. Fedrowitz, T. Erker, M. Muller, W. Loscher, O. Langer, C. Kuntner, Tariquidar and elacridar are dose-dependently transported by P-glycoprotein and Bcrp at the blood-brain barrier: a small-animal positron emission tomography and in vitro study, Drug Metab Dispos, 41 (2013) 754-762.

[28] P. Kannan, K.R. Brimacombe, W.C. Kreisl, J.S. Liow, S.S. Zoghbi, S. Telu, Y. Zhang, V.W. Pike, C. Halldin, M.M. Gottesman, R.B. Innis, M.D. Hall, Lysosomal trapping of a radiolabeled substrate of P-glycoprotein as a mechanism for signal amplification in PET, Proc Natl Acad Sci U S A, 108 (2011) 2593-2598.

[29] J.H. Lin, M. Yamazaki, Role of P-glycoprotein in pharmacokinetics: clinical implications, Clin Pharmacokinet, 42 (2003) 59-98.

[30] C. Bundgaard, C.J. Jensen, M. Garmer, Species comparison of in vivo P-glycoproteinmediated brain efflux using mdr1a-deficient rats and mice, Drug Metab Dispos, 40 (2011) 461-466.

[31] K.A. Kim, J. Chung, D.H. Jung, J.Y. Park, Identification of cytochrome P450 isoforms involved in the metabolism of loperamide in human liver microsomes, Eur J Clin Pharmacol, 60 (2004) 575-581.

[32] A.S. Kalgutkar, H.T. Nguyen, Identification of an N-methyl-4-phenylpyridinium-like metabolite of the antidiarrheal agent loperamide in human liver microsomes: underlying reason(s) for the lack of neurotoxicity despite the bioactivation event, Drug Metab Dispos, 32 (2004) 943-952.

[33] C. Martin, G. Berridge, P. Mistry, C. Higgins, P. Charlton, R. Callaghan, The molecular interaction of the high affinity reversal agent XR9576 with P-glycoprotein, Br J Pharmacol, 128 (1999) 403-411. 
[34] T.C. Chou, Theoretical basis, experimental design, and computerized simulation of synergism and antagonism in drug combination studies, Pharmacol Rev, 58 (2006) 621-681. 


\title{
6 LIPOSOMES CO-LOADED WITH ELACRIDAR AND TARIQUIDAR TO MODULATE THE P-GLYCOPROTEIN AT THE BLOOD-BRAIN BARRIER
}

\begin{abstract}
The present study aimed to prepare four liposomal formulations co-loaded with elacridar and tariquidar to overcome the P-glycoprotein-mediated efflux at the blood-brain barrier. Their pharmacokinetics and brain distribution as well as their impact on the P-glycoprotein substrate, loperamide, were compared to the co-administration of free elacridar plus free tariquidar. After intravenous administration in rats, elacridar and tariquidar in conventional and poly(ethylene glycol)-COOH-coated liposomes were rapidly cleared from the bloodstream. Their low levels in the brain did not improve the brain distribution of loperamide. Elacridar and tariquidar in poly(ethylene glycol)- $\mathrm{OCH}_{3}$-coated liposomes exhibited 4.1 and 1.9 longer half-lives and 4.8- and 6.1-fold higher brain distribution than free elacridar and free tariquidar, respectively. This resulted in 2.1-fold higher levels of loperamide in the brain. The conjugation of $\mathrm{OX} 26 \mathrm{~F}\left(\mathrm{ab}^{\prime}\right)_{2}$ fragments to poly(ethylene glycol)$\mathrm{OCH}_{3}$-coated liposomes increased the brain uptake of elacridar and tariquidar by $9.8-$ and 11.8-fold respectively. Consequently, the brain levels of loperamide increased by 4.4-fold. Moreover, the pharmacokinetic parameters and the tissue distribution of loperamide were not modified by the OX26 $\mathrm{F}\left(\mathrm{ab}^{\prime}\right)_{2}$ immunoliposomes. Thus, this formulation represents a promising tool to modulate the P-glycoprotein-mediated efflux at the blood-brain barrier and improve the brain uptake of any P-glycoprotein substrate which is intended to treat central nervous system diseases.
\end{abstract}

Keywords: P-glycoprotein, blood-brain barrier, immunoliposomes, co-encapsulation, Pglycoprotein modulators. 


\subsection{Introduction}

Drug uptake into the brain depends on a variety of factors, including the blood-brain barrier (BBB) and the expression of drug efflux transporters at this barrier. These transporters, specially the P-glycoprotein (P-gp), efficiently removes various drugs from the central nervous system (CNS), limiting their brain uptake $[1,2]$. Therefore the overcoming of the P$\mathrm{gp}$ at the $\mathrm{BBB}$ has become an imperative for the treatment of brain diseases.

The development of third-generation P-gp modulators, which directly inhibit the transport of P-gp substrates, has been a promising approach to circumvent the P-gp activity [3]. Recent studies based on two third-generation P-gp modulators, elacridar and tariquidar [4, 5], suggest high doses of these compounds to efficiently modulate the P-gp at the BBB [6]. However, when co-administered with P-gp substrates, these high doses may be associated with pharmacokinetic interactions and toxic profiles, thus limiting the use of these compounds. Another non-invasive strategy emphasizes the potential of drug delivery systems (DDSs). This approach is based on the encapsulation of drugs, which masks them from the biological environment and avoid a direct interaction with the P-gp [7]. Among them, liposomes have been the most studied due to their composition, which makes them biocompatible, biodegradable and less toxic [8]. The incorporation of PEG-lipid derivatives within the bilayer of conventional liposomes prolongs considerably the liposomal half-life by steric stabilization and reduces the reticuloendothelial system (RES) uptake [9]. Nevertheless, an increased liposomal drug accumulation in the brain could be achieved with targeted liposomes. This involves the coupling of targeting moieties such as monoclonal antibodies (MAb) or their fragments (Fab', F(ab') 2 ) at the distal ends of the PEG chains [10]. These immunoliposomes are then able to target the brain using the biochemical transport systems at the BBB; among them the transferrin transcytosis system [11]. The transferrin receptor (TfR) is over-expressed on the brain capillary endothealial cells (BCECs) and is widely used for drug targeting to the BBB [12]. The most successful studied TfR-targeted monoclonal antibody is OX26 [13, 14], which does not bind the TfR on the transferrin binding site but uses another epitope [15]. Since the whole OX26 antibody activates the Fc receptor-mediated phagocytosis and the classical pathway of the complement system [16], the coupling of the Fab' fragments instead of the whole antibody was used as an alternative to prolong the vascular residence time of the DDSs [17]. However, at the same density, the targeting across the BBB using OX26 nanocarriers demonstrated to be more efficient than that achieved with OX26 Fab'nanocarriers [17]. We hypothesize that by maintaining the two binding sites of the 
antibody, $\mathrm{F}(\mathrm{ab})_{2}$ fragments, the brain targeting might be in the same rate that the observed with the whole antibody but avoiding the activation of the immune system.

In this light, we aimed to develop OX26 F(ab') $)_{2}$ immunoliposomes to simultaneously increase the delivery of elacridar and tariquidar across the BBB. For this purpose, it was necessary to find the right balance between the vascular stability of the DDS and an effective but transient modulation of the P-gp at the BBB. To select the formulation that fits better the aforementioned properties for further development of immunoliposomes, three types of liposomes co-loaded with elacridar and tariquidar were assessed: Conventional, PEGylated with DSPE-PEG $2000-\mathrm{COOH}$ and PEGylated with DSPE- $\mathrm{PEG}_{2000}-\mathrm{OCH}_{3}$ liposomes. The rapid opsonization of conventional liposomes led to their destabilization and the leakage of elacridar and tariquidar which was not enough to modulate the P-gp at the BBB. It was expected that in DSPE-PEG $2000-\mathrm{COOH}$ liposomes, the negative surface charge of the carboxylic acid could counterbalanced the long circulating properties conferred by PEG to facilitate an effective but short P-gp modulation. However, the low brain uptake of elacridar and tariquidar indicated that these negatively charged liposomes were cleared from the bloodstream before than they could release both P-gp modulators. In contrast, DSPE-PEG $2000-$ $\mathrm{OCH}_{3}$ liposomes significantly increased the plasma concentrations of elacridar and tariquidar as well as their brain distribution in comparison to the free form of both P-gp modulators. Hence immunoliposomal development was carried out with DSPE-PEG $2000-\mathrm{OCH}_{3}$. As steric hindrance of the PEG chains may interfere with the antibody moieties recognition by the targeted tissue, we proposed the functionalization of liposomes with two PEG chain lengths, DSPE-PEG $2000-\mathrm{OCH}_{3}$ and DSPE-PEG $5000-\mathrm{COOH}$. While DSPE-PEG $2000-\mathrm{OCH}_{3}$ confers long circulating properties, DSPE-PEG5000-COOH was used as linker to graft the OX26 moieties. The brain distribution of free loperamide concurrently administered with these DDSs was determined, as an in vivo probe of full blockage of the P-gp the BBB. Results were compared with the concurrent administration of both free P-gp modulators associated with free loperamide.

\subsection{Materials and Methods}

\subsubsection{Materials}

Loperamide hydrochloride was obtained from Sigma Aldrich (France), elacridar was synthesized by the Laboratory of Pharmaceutical Chemistry, University of Bonn, Germany 
and tariquidar was purchased from API Services Inc. (USA). 1,2-dimyristoyl-sn-glycero-3phosphocholine (DMPC), 1,2-distearoyl-sn-glycero-3-phosphoethanolamine-N[methoxy(polyethyleneglycol)-2000] (ammonium salt) (DSPE-PEG 2000 ), 1,2-distearoyl-snglycero-3-phosphoethanolamine-N-[carboxy(polyethyleneglycol)-2000] (ammonium salt) (DSPE-PEG $2000-\mathrm{COOH}), \quad$ and 1,2-distearoyl-sn-glycero-3-phosphoethanolamine-N[carboxy(polyethyleneglycol)-5000] (ammonium salt) (DSPE-PEG5000-COOH) were supplied by Coger (France). OX26 and the micro $\mathrm{BCA}^{\mathrm{TM}}$ protein assay kit were purchased from Fischer Thermo Scientific (France). N-(3-dimethylaminopropyl)-N'ethyl-carbodiimide hydrochloride (EDC), N-hydroxysulfosuccinimide (sulfo-NHS) and 2-(Nmorpholino)ethanesulfonic acid (MES), ketoconazole (internal standard for loperamide) and chlorpromazine hydrochloride (internal standard for elacridar and tariquidar), tert-Butyl methyl ether (t-BME), analytical grade ammonium acetate and glacial acetic acid were obtained from Sigma Aldrich (France). Glycine was purchased from Fluka (France) and Trisodium citrate solution was from BD Vacutainer ${ }^{\circledR} 80$. Polyethylene glycol 600 (PEG 600$)$ was obtained from Interchimie (France). HPLC grade methanol and acetonitrile were purchased from Carlo Erba (France). Ultrapure water was freshly obtained before use from a Purelab Prima 7/15/20 - Purelab Ultra Mk 2 from Elga (France). All the other reagents were purchased from Sigma Aldrich (France).

\subsubsection{Preparation of $\mathrm{OX} 26 \mathrm{~F}\left(\mathrm{ab}^{\prime}\right)_{2}$ fragments}

$\mathrm{OX} 26 \mathrm{~F}(\mathrm{ab})_{2}$ fragments generation and subsequent purification was carried out using the Thermo Scientific Pierce F(ab')2 preparation kit according to the manufacturer procedure. Briefly, $2.75 \mathrm{~mL}$ of the antibody at a concentration of $1 \mathrm{mg} / \mathrm{mL}$ in $20 \mathrm{mM}$ sodium acetate, $\mathrm{pH}$ 4.4 was added to the equilibrated immobilized pepsin. The mixture was incubated at $37^{\circ} \mathrm{C}$ for 4 hours with gentle shaking. The $\mathrm{F}\left(\mathrm{ab}{ }^{\prime}\right)_{2}$ fragments were then separated from undigested antibody and Fc fragments by affinity chromatography with immobilized protein A column with the manufacturer IgG elution buffer, $\mathrm{pH} 2.8$. Finally, centrifugation at $1000 \times \mathrm{x} g$ using Ultra $30 \mathrm{~K}$ centrifugal filters was performed to remove the small $\mathrm{Fc}$ fragments. 


\subsubsection{Preparation of liposomes}

In this study, four types of liposomes co-loaded with elacridar and tariquidar were prepared: Conventional liposomes (EL-TAR-CL), PEGylated with DSPE-PEG $2000-\mathrm{COOH}$ (EL-TARCOOHL), PEGylated with DSPE-PEG $2000-\mathrm{OCH}_{3}$ long circulating liposomes (EL-TAR-LCL) and OX26 $\mathrm{F}\left(\mathrm{ab}^{\prime}\right)_{2}$ immunoliposomes (EL-TAR-IL). The four types of liposomes were prepared by thin film hydration method followed by sonication [18]. Briefly, DMPC alone or along with DSPE-PEG $2000 \mathrm{COOH}$, or DSPE-PEG $2000-\mathrm{OCH}_{3}$ or DSPE-PEG $2000-\mathrm{OCH}_{3}$ and DSPE-PEG5000-COOH (Table 1) were weighted and dissolved in chloroform. In all the cases, tariquidar and elacridar were added to chloroform along with lipids. Combined amount of equimolar quantities of tariquidar and elacridar was kept at $10.0 \%(\mathrm{w} / \mathrm{w})$ final lipids. The organic solvent was removed under a nitrogen stream to form a thin film, which was subjected to freeze-drying (Heto Lyolab 3000) overnight to remove any trace of the organic phase. The dried lipid film was then hydrated at $40^{\circ} \mathrm{C}$ with phosphate buffer solution (PBS) $\mathrm{pH} 7.4$, or with MES buffer in the case of immunoliposomes, to obtain a final phospholipid concentration of $10 \mu \mathrm{mol} / \mathrm{mL}$. The hydration was followed by a 15 minutes bath sonication above $40^{\circ} \mathrm{C}$ to produce multilamellar vesicles (MLV). After a rest of 10 minutes to overcome any structural defects, the MLV suspension was sized by sonication at $40^{\circ} \mathrm{C}$ for 15 minutes using a $13 \mathrm{~mm}$ diameter probe sonicator (Bandelin Sonoplus) at 150 watts. The resulting small unilamellar vesicles (SUV) were finally centrifuged for 10 minutes at $10000 \mathrm{x} g$ to remove the titanium particles originating from the probe.

Immunoliposomes were prepared by coupling OX26 $\mathrm{F}\left(\mathrm{ab}^{\prime}\right)_{2}$ fragments at the distal carboxylic groups of the linker lipid, DSPE-PEG ${ }_{5000} \mathrm{COOH}$. The coupling procedure involved a carbodiimide reaction [19]. Briefly, $50 \mathrm{mM}$ EDC and $100 \mathrm{mM}$ Sulfo-NHS were mixed with 8 $\mathrm{mL}$ of liposomes at $10 \mu \mathrm{mol} / \mathrm{mL}$ in $100 \mathrm{mM}$ MES buffer, $\mathrm{pH}$ 5.2. The mixture was incubated with gentle shaking and then dialyzed (100 kDa cut-off) for 15 minutes against PBS pH 7.4 at room temperature to remove the reagents in excess and free DSPE-PEG ${ }_{5000} \mathrm{COOH}$. This last step was repeated three times more to complete one hour of dialysis. After dialysis, the $\mathrm{pH}$ of activated liposomes was adjusted to 7.4 with a sodium hydroxide solution. Then, $1.38 \mathrm{mg}$ of the $\mathrm{OX} 26 \mathrm{~F}\left(\mathrm{ab}^{\prime}\right)_{2}$ fragments were added to activated liposomes which were incubated at room temperature for two hours and thereafter at $4^{\circ} \mathrm{C}$ overnight. The reaction was stopped by addition of glycine $50 \mathrm{mM}$ followed by 30 min-incubation. The immunoliposomes were then stored in the dark at $4^{\circ} \mathrm{C}$ and used within $24 \mathrm{hrs}$. 


\subsubsection{Characterization of liposomes}

\subsubsection{Liposomes size and zeta potential}

The size of diluted $1 / 10$ (with PBS $\mathrm{pH}$ 7.4) liposomes was measured by dynamic light scattering using the NanoZS (Malvern Instrument, France). Zeta potential was measured by the same instrument.

\subsubsection{Drugs loading efficiency}

$150 \mu \mathrm{L}$ of each liposome formulation was sampled and lysed with $450 \mu \mathrm{L}$ of acetonitrile. The mixture was centrifugated at $10000 \times \mathrm{g}$ for 5 minutes to precipitate acetonitrile insoluble compounds. The supernatant containing elacridar and tariquidar was diluted with the mobile phase to determine the drug loading efficiency (DLE) of liposomes. The analytical method is described in "Analysis of loperamide, elacridar and tariquidar by Liquid ChromatographyMass Spectrometry (LS-MS)". At these conditions a calibration curve was constructed for tariquidar and elacridar using five calibrations standards of $0.5,0.75,1.0,2.5$ and $5.0 \mu \mathrm{g} / \mathrm{mL}$. DLE $(\%)=$ (amount of drug in liposomes/amount of drug initially added) $\mathrm{x} 100$.

\subsubsection{Animals}

Pharmacokinetic and tissue distribution studies were conducted in male Sprague Dawley rats (Janvier, France). All animal experiments were carried out in accordance with the recommendations in the Guide for the Care and Use of Laboratory Animals (Institute of Laboratory Animal Resources, National Research Council, National Academy of Sciences, USA). All the animals were allowed to acclimate for one week and were seven weeks old $(230-280 \mathrm{~g})$ at the time of the experiment. The animals were maintained under a 12-h light/dark cycle and a temperature-controlled environment. Food and water were provided ad libitum. The studies were approved by the Institutional Animal Care and Use Committee of the University of Franche-Comte. 


\subsubsection{Study design}

The animals were randomly divided into four experimental groups. The different treatments were administered via the jugular vein by IV bolus. Each group received first a liposomal formulation whether EL-TAR-CL, EL-TAR-COOHL, EL-TAR-LCL or EL-TAR-IL. In all the groups the total administered dose of combined P-gp modulators was $1.0 \mathrm{mg} / \mathrm{kg}$. Given the drugs loading efficiencies, the ratio of tariquidar:elacridar was 1:1 for the first three groups and 2:1 for the group receiving EL-TAR-IL. After one minute, all the groups received free loperamide at a dose of $0.5 \mathrm{mg} / \mathrm{kg}$, previously dissolved and diluted in a mixture of saline and PEG $_{600}$ (3:1). Prior to the pharmacokinetic and tissue distribution studies, all the animals were observed for one hour to determine the clinical signs induced by central opiate effects of loperamide. Observations were limited to two or three rats at a time to maximize visibility $(\mathrm{n}=12)$. The CNS (lethargy, whole body tetany, Straub tail and piloerection), respiratory (shallow breathing) and ocular (eye protrusion) clinical signs were established according to our previous study. The degrees of the clinical signs were scored as $0=$ none, $1=$ mild, $2=$ moderate and $3=$ severe. The degree score for the CNS, respiratory or ocular clinical signs was calculated as: $\mathrm{N} \times \mathrm{D}$, where $\mathrm{N}$ is the number of rats displaying the clinical signs and $\mathrm{D}$ is the degree score for each symptom. The total score (TS) was calculated as: $\Sigma(\mathrm{N} \times \mathrm{D})$.

In the pharmacokinetic study, blood was serially sampled from the tail vein at 1, 6, 12 and 24 hours after the administration of the different treatments. The blood was collected in tubes containing trisodium citrate solution. The plasma was obtained by centrifugation of the blood at $2500 \mathrm{~g}$ for $5 \mathrm{~min}$ and stored frozen at $-20^{\circ} \mathrm{C}$ until analysis. Three rats were used at each time point $(n=3)$.

In the tissue distribution study, animals were sacrificed at 1, 6, 12 and 24 hours after administration of the different treatments, following deep anesthesia with sodium pentobarbital (50 mg/kg; intraperitoneal), exsanguination and cardiac perfusion with saline. At sacrifice, the whole brain, liver and kidneys were immediately frozen at $-20^{\circ} \mathrm{C}$ until analysis. Three rats were used at each time point $(n=3)$.

The results from our previously published study, where animals underwent free loperamide at $0.5 \mathrm{mg} / \mathrm{kg}$ concurrently with free elacridar at $0.5 \mathrm{mg} / \mathrm{kg}$ plus free tariquidar at $0.5 \mathrm{mg} / \mathrm{kg}$ (Free EL-TAR) were used for comparison in the pharmacokinetics and tissue distribution studies. 


\subsubsection{Analysis of loperamide, elacridar and tariquidar by Liquid Chromatography-Mass Spectrometry (LS-MS)}

Loperamide, elacridar and tariquidar in plasma, brain, kidney and liver samples were determined by a LC-MS method that has been validated for specificity, calibration curve, lower limit of quantification (LLOQ), accuracy, precision, and recovery according to the FDA guidance for bioanalytical method validation [20].

The chromatographic analyses were carried out on a Shimadzu High Performance Liquid Chromatography/Mass Spectrometer LCMS-2010EV, equipped with a LC-20AD solvent delivery system. The analytes were well separated on a Zorbax Eclipse XDB-C18 2.1 x 150 $\mathrm{mm}, 5.0 \mu \mathrm{m}$ column from Agilent Technologies at $50^{\circ} \mathrm{C}$ using a Millipore Waters oven. The mobile phase consisting of $10 \mathrm{mM}$ ammonium acetate $\mathrm{pH}$ 5.5:MeOH:ACN (37.5:40:22.5 $\mathrm{v} / \mathrm{v} / \mathrm{v}$ ) was delivered in isocratic mode at $0.4 \mathrm{~mL} / \mathrm{min}$. An autosampler 360 from Kontrons Instruments was set at $20 \mu \mathrm{L}$. The compounds were quantitated using positive electrospray ionization (ESI) in an octapole quadrupole mass analyzer with single ion monitoring (SIM) mode at m/z 477 for loperamide, m/z 531 for ketoconazole, m/z 564 for elacridar, m/z 647 for tariquidar and m/z 319 for chlorpromazine. Nitrogen was used as the nebulizing gas at 1.5 $\mathrm{L} / \mathrm{min}$. The curved desolvation line (CDL) and heat block temperatures were set at $250^{\circ} \mathrm{C}$ and $300^{\circ} \mathrm{C}$, respectively. The detector voltage was $1.5 \mathrm{KV}$, the interface voltage was $-3.5 \mathrm{KV}$ and the CDL voltage was $15.0 \mathrm{~V}$.

Frozen brain, liver and kidney samples were thawed and homogenized with one volume of water using a Janke \& Kunkel T45 Ultra-turrax and a Fischer Scientific Vibra-cell homogenizer. Stability tests demonstrated that the analytes were stable under the storage conditions, during the extraction process, and for at least three freeze/thaw cycles. Prior to chromatographic analysis, $25 \mu \mathrm{L}$ of the internal standard solution containing ketoconazole and chlorpromazine hydrochloride were added to $100 \mu \mathrm{L}$ of each plasma or homogenate samples to yield final concentrations of $100 \mathrm{ng} / \mathrm{mL}$ and $25 \mathrm{ng} / \mathrm{mL}$ respectively. After deproteinization by addition of $800 \mu \mathrm{L}$ of a mixture of acetonitrile and tert-butyl methyl ether (1:1), the samples were vortexed for 3 minutes and centrifuged at $5000 \mathrm{x} g$ for 10 minutes. The upper organic layer was decanted and evaporated to dryness and the residue was reconstituted in $100 \mu \mathrm{L}$ of mobile phase. A volume of $20 \mu \mathrm{L}$ was injected onto the analytical column. 


\subsubsection{Pharmacokinetic calculations}

The pharmacokinetic parameters were calculated by non-compartmental analysis using Kinetica $^{\mathrm{TM}}$ version 4.0 (Inna Phase Corp., 2001). The area under the concentration-time curves (AUC) values was determined using the trapezoidal rule. The half-lives of elimination $\left(t_{1 / 2}\right)$ were calculated as $\ln (2) / \mathrm{K}$, where $\mathrm{K}$ represents the terminal elimination rate constant obtained from the slopes of the semilogarithmic plots of the concentration-time profile. The plasma clearance (CL) was calculated as dose/AUC $\mathrm{Anf}_{\text {, whe }} \mathrm{AUC}_{\mathrm{inf}}$ is the $\mathrm{AUC}$ from time zero to infinity. The brain-to-plasma partition coefficient $(K \mathrm{p})$ was calculated as $\mathrm{AUC}_{\text {inf- }}$ brain/AUC inf-plasma.

\subsubsection{Statistical Analysis}

The statistical analysis was carried out using SigmaStat 3.5 software. Analyses of statistical significance between two groups were examined by Student's t-test and between many groups by one-way analysis of variance (ANOVA) with the Holm-Sidak post-hoc test. A $P<0.05$ was considered to be significant. Moreover, the variance of the $\mathrm{AUC}_{\mathrm{inf}}$ in each treatment group was estimated according to the Bailer method [21,22], which is based on the variability of the concentrations at each sampling time. A Z-test was used for pairwise comparison of AUCs. A $P<0.05$ was considered to be significant.

\subsection{Results}

\subsubsection{Characterization of liposomal formulations}

The average particle diameters of the liposomal formulations vary from $102.6 \pm 2.3$ to $135.8 \pm$ $0.8 \mathrm{~nm}$ (Table 1). The size increase of EL-TAR-COOHL and EL-TAR-LCL compared to ELTAR-CL liposomes is due to the inclusion of DSPE-PEG $2000-\mathrm{COOH}$ and DSPE-PEG 2000 $\mathrm{OCH}_{3}$, respectively, which is in accordance with the $5 \mathrm{~nm}$ thickness of $\mathrm{PEG}_{2000}$ and its possible extension up to $15 \mathrm{~nm}$ [10]. The highest size of EL-TAR-IL is surely caused by the presence of DSPE-PEG $5000-\mathrm{COOH}$ and $\mathrm{OX} 26 \mathrm{~F}\left(\mathrm{ab}^{\prime}\right)_{2}$ fragments. This value is consistent with the size increase of $8 \mathrm{~nm}$ that DSPE-PEG 5000 shows over DSPE-PEG 2000 [23] and with the size increase between 7 and $20 \mathrm{~nm}$ caused by the OX26 F(ab') $)_{2}$ coupling [24]. 
The zeta potential of EL-TAR-CL, EL-TAR-LCL and EL-TAR-IL (after OX26 F(ab') coupling) was nearly neutral but the presence of DSPE-PEG ${ }_{2000}-\mathrm{COOH}$ in EL-TAR-COOHL or DSPE-PEG ${ }_{5000}-\mathrm{COOH}$ in EL-TAR-IL (before OX26 F(ab') 2 coupling) switched to a negative surface charge.

Table 1. Composition, size and zeta potential of elacridar-tariquidar liposomal formulations $(\mathrm{n}=3)$

\begin{tabular}{lcccc}
\hline \multicolumn{1}{c}{$\begin{array}{c}\text { Liposomal } \\
\text { formulation }\end{array}$} & Composition & Molar ratio & $\begin{array}{c}\text { Mean particle } \\
\text { diameter (nm) }\end{array}$ & $\begin{array}{c}\text { Zeta potential } \\
(\mathrm{mV})\end{array}$ \\
\hline EL-TAR-CL & DMPC & 100 & $102.6 \pm 2.3$ & $1.7 \pm 0.8$ \\
EL-TAR-COOHL & DPMC:DSPE-PEG $2000-C O O H$ & $100: 7.5$ & $111.7 \pm 3.9$ & $-9.3 \pm 1.6$ \\
EL-TAR-LCL & DMPC:DSPE-PEG $_{2000}-\mathrm{OCH}_{3}$ & $100: 7.5$ & $109.4 \pm 4.7$ & $1.9 \pm 1.2$ \\
$\begin{array}{l}\text { EL-TAR-IL before OX26 } \\
\text { F(ab') })_{2} \text { coupling }\end{array}$ & DMPC:DSPE-PEG $_{2000}-\mathrm{OCH}_{3}: \mathrm{DSPE}_{2} \mathrm{PEG}_{5000}-\mathrm{COOH}$ & $100: 6.25: 1.25$ & $124.5 \pm 0.7$ & $-4.4 \pm 0.4$ \\
$\begin{array}{l}\text { EL-TAR-IL after } \\
\text { OX26 F(ab') }\end{array}$ coupling & DMPC:DSPE-PEG $_{2000}-\mathrm{OCH}_{3}: \mathrm{DSPE}_{2} \mathrm{PEG}_{5000}-\mathrm{COOH}$ & $100: 6.25: 1.25$ & $135.8 \pm 0.8$ & $-1.2 \pm 0.1$ \\
\hline
\end{tabular}

\subsubsection{Drugs loading and antibody-liposomes coupling efficiencies}

The average loading for both, elacridar and tariquidar, was largely higher than $60.0 \%$ in the EL-TAR-CL, EL-TAR-COOHL and EL-TAR-LCL formulations (Table 2). The use of MES buffer $\mathrm{pH} 5.2$ in the hydration step for the preparation of EL-TAR-IL boosted a high elacridar loading which reached $81.3 \pm 4.3 \%$. However, decreased loading efficiencies were observed for elacridar and tariquidar after the dialysis step, $72.7 \pm 3.6 \%$ and $34.7 \pm 1.9 \%$, respectively.

Table 2. Drugs loading efficiencies $(n=3)$

\begin{tabular}{lcc}
\hline \multicolumn{1}{c}{$\begin{array}{c}\text { Liposomal } \\
\text { formulation }\end{array}$} & $\begin{array}{c}\text { Elacridar loading } \\
\text { efficiency }(\%)\end{array}$ & $\begin{array}{c}\text { Tariquidar loading } \\
\text { efficiency }(\%)\end{array}$ \\
\hline EL-TAR-CL & $64.3 \pm 3.3$ & $62.2 \pm 0.9$ \\
EL-TAR-COOHL & $69.9 \pm 3.2$ & $71.5 \pm 4.0$ \\
EL-TAR-LCL & $63.6 \pm 0.5$ & $67.6 \pm 1.5$ \\
EL-TAR-IL (before OX26 & $81.3 \pm 4.3$ & $55.6 \pm 5.0$ \\
$\begin{array}{l}\text { F(ab') })_{2} \text { coupling) } \\
\text { EL-TAR-IL (after OX26 }\end{array}$ & $72.7 \pm 3.6$ & $34.7 \pm 1.9$ \\
F(ab') $)_{2}$ coupling) & & \\
\hline
\end{tabular}




\subsubsection{Pharmacokinetics of elacridar and tariquidar co-loaded in different types of liposomes}

Both, elacridar and tariquidar, as free drugs were rapidly eliminated from the plasma. Their half-lives were $3.1 \pm 0.2$ and $5.8 \pm 0.7 \mathrm{~h}$, respectively (Table 3). Even though these values were not modified when both compounds were co-loaded in EL-TAR-CL and EL-TARCOOHL, the $\mathrm{AUC}_{\mathrm{inf}}$ were importantly decreased and the clearance values increased. ELTAR-LCL significantly increased the plasma concentrations of elacridar and tariquidar up to 12 hours. Hence, the half-lives of elacridar and tariquidar increased to $12.6 \pm 2.8$ and $11.0 \pm$ 1.8 hours, respectively. These values indicate longer retention of these liposomes in the blood stream as well as an adequate retention of these two compounds in the liposomes. The effect of PEG-conjugation was partially reversed by conjugation to OX26 F(ab') ${ }_{2}$ fragments. Hence, the $\mathrm{AUC}_{\mathrm{inf}}$ of elacridar and tariquidar in EL-TAR-IL were reduced by 1.6- and 1.5-fold, respectively, in comparison with the values obtained in EL-TAR-LCL.

Table 3. Pharmacokinetic parameters of elacridar and tariquidar

\begin{tabular}{|c|c|c|c|c|c|c|c|c|c|c|c|c|}
\hline \multirow{3}{*}{ Formulation } & \multicolumn{6}{|c|}{ Elacridar } & \multicolumn{6}{|c|}{ Tariquidar } \\
\hline & \multicolumn{2}{|c|}{$\begin{array}{l}\mathrm{AUC}_{\mathrm{inf}}(\% \\
\text { dose.h/mL) }\end{array}$} & \multicolumn{2}{|c|}{$\mathrm{t}_{1 / 2}(\mathrm{~h})$} & \multicolumn{2}{|c|}{$\begin{array}{c}\mathrm{CL} \\
(\mathrm{mL} / \mathrm{h} / \mathrm{Kg}) \\
\end{array}$} & \multicolumn{2}{|c|}{$\begin{array}{l}\mathrm{AUC}_{\text {inf }}(\% \\
\text { dose.h/mL) }\end{array}$} & \multicolumn{2}{|c|}{$\mathrm{t}_{1 / 2}(\mathrm{~h})$} & \multicolumn{2}{|c|}{$\begin{array}{c}\mathrm{CL} \\
(\mathrm{mL} / \mathrm{h} / \mathrm{Kg})\end{array}$} \\
\hline & Mean & S.D. & Mean & S.D. & Mean & S.D. & Mean & S.D. & Mean & S.D. & Mean & S.D. \\
\hline Free EL-TAR & 9.8 & 0.7 & 3.1 & 0.2 & 10.3 & 0.7 & 11.9 & 1.7 & 5.8 & 0.7 & 8.6 & 1.2 \\
\hline EL-TAR-CL & $4.5^{\#}$ & 0.4 & 3.7 & 0.1 & $22.4^{\#}$ & 1.9 & $6.0^{\#}$ & 0.7 & 5.5 & 0.3 & $16.8^{\#}$ & 1.9 \\
\hline EL-TAR-COOHL & 6.5 & 0.7 & 3.9 & 0.5 & $15.6^{\#}$ & 1.8 & $4.0^{\#}$ & 0.6 & 6.3 & 1.1 & $25.2^{\#}$ & 3.3 \\
\hline EL-TAR-LCL & $43.5^{\#}$ & 1.6 & $12.6^{\#}$ & 2.8 & $2.3^{\#}$ & 0.1 & $39.0^{\#}$ & 6.1 & $11.0^{\#}$ & 1.8 & $2.6^{\#}$ & 0.4 \\
\hline EL-TAR-IL & $27.9^{\# \# \#}$ & 4.8 & $10.7^{\#}$ & 1.2 & $3.7^{\# \# \#}$ & 0.7 & $26.5^{\# \# \#}$ & 1.2 & $9.3^{\#}$ & 2.2 & $3.8^{\# \# \#}$ & 0.2 \\
\hline
\end{tabular}

\# ANOVA: Significantly different compared to the group which received free elacridar plus free tariquidar

\#\# ANOVA: Significantly different compared to the group which received EL-TAR-LCL 


\subsubsection{Brain distribution of elacridar and tariquidar co-loaded in different types of liposomes}

Figures 1 and 2 show a pronounced difference in the brain distribution of both P-gp modulators after their IV administration as free drugs and co-loaded in liposomal formulations. At 1 hour post-dosing, only $0.24 \pm 0.06 \%$ of the injected dose (ID)/g of free elacridar was monitored in the brain. While EL-TAR-CL did not improve the brain uptake of elacridar, EL-TAR-COOHL decreased by 4 -fold $(0.06 \pm 0.01 \% \mathrm{ID} / \mathrm{g})$ the brain distribution of the P-gp modulator. However, when elacridar was co-loaded in EL-TAR-LCL and ELTAR-IL, its distribution increased by $4.8-(1.14 \pm 0.42 \% \mathrm{ID} / \mathrm{g})$ and 9.6 -fold $(2.30 \pm 0.22 \%$ ID/g), respectively. At 6 hours post-dosing, elacridar in COOHL was not detected but still significant high concentrations of the P-gp modulator co-loaded in EL-TAR-LCL $(0.13 \pm 0.03$ $\% \mathrm{ID} / \mathrm{g})$ and EL-TAR-IL $(0.26 \pm 0.10 \% \mathrm{ID} / \mathrm{g})$ were achieved in comparison to free elacridar $(0.03 \pm 0.01 \% \mathrm{ID} / \mathrm{g})$. At 12 hours, elacridar, as a free compound and in EL-TAR-CL was not detectable but approximately $0.08 \% \mathrm{ID} / \mathrm{g}$ could be detected for elacridar in EL-TAR-LCL and in EL-TAR-IL. Free tariquidar also showed low brain uptake, only $0.09 \pm 0.01 \% \mathrm{ID} / \mathrm{g}$ at 1 hour. Its distribution was not improved with EL-TAR-CL and decreased by 3.0-fold (0.03 \pm $0.06 \% \mathrm{ID} / \mathrm{g}$ ) with EL-TAR-COOHL. Nevertheless, the brain uptake of tariquidar increased by 6.1 - $(0.55 \pm 0.06 \% \mathrm{ID} / \mathrm{g})$ and 11.8 -fold $(1.11 \pm 0.19 \% \mathrm{ID} / \mathrm{g})$ when it was co-loaded in ELTAR-LCL and EL-TAR-IL, respectively. At 6 hours post-dosing, tariquidar in COOHL was not detected but still significant high concentrations of the P-gp inhibitor co-loaded in ELTAR-LCL $(0.06 \pm 0.01 \% \mathrm{ID} / \mathrm{g})$ and EL-TAR-IL $(0.13 \pm 0.04 \% \mathrm{ID} / \mathrm{g})$ were observed in comparison to free tariquidar $(0.09 \pm 0.01 \% \mathrm{ID} / \mathrm{g})$. Unlike elacridar, tariquidar co-loaded in EL-TAR-LCL and EL-TAR-IL could not be detectable at the brain at 12 hours post-dosing. These observations are also reflected in the $\mathrm{AUC}_{\mathrm{inf}}$ for the brain of each P-gp modulator (Table 4). However, the Kp values (Table 4) suggest that a significant higher exposure to both P-gp modulators was only achieved with EL-TAR-IL. This is in agreement with the brain uptake of elacridar and tariquidar in EL-TAR-IL at 6 hours post-dosing, which is in the same range that the one obtained for free elacridar plus free tariquidar at 1 hour post-dosing. The significant higher $K \mathrm{p}$ values obtained with EL-TAR-CL in comparison with the free form of the P-gp modulators are merely due to the low plasma concentrations of these compounds. 




Figure 1: Brain concentrations of elacridar (mean \pm S.D.) after intravenous administration of free elacridar (plus free tariquidar) (white), in ELA-TAR-CL (light grey), in ELA-TAR-COOHL (dark grey), in ELA-TAR-LCL (black), or in ELA-TAR-IL (striped). In all the cases the treatments were concurrently administered with loperamide at $0.5 \mathrm{mg} / \mathrm{kg}$. Bars represent the standard deviation. $\mathrm{n}=3$.

\# ANOVA: Significantly different compared to the group which received free elacridar.

\#\# Student's t-test: Significantly different compared to the group which received EL-TAR-LCL

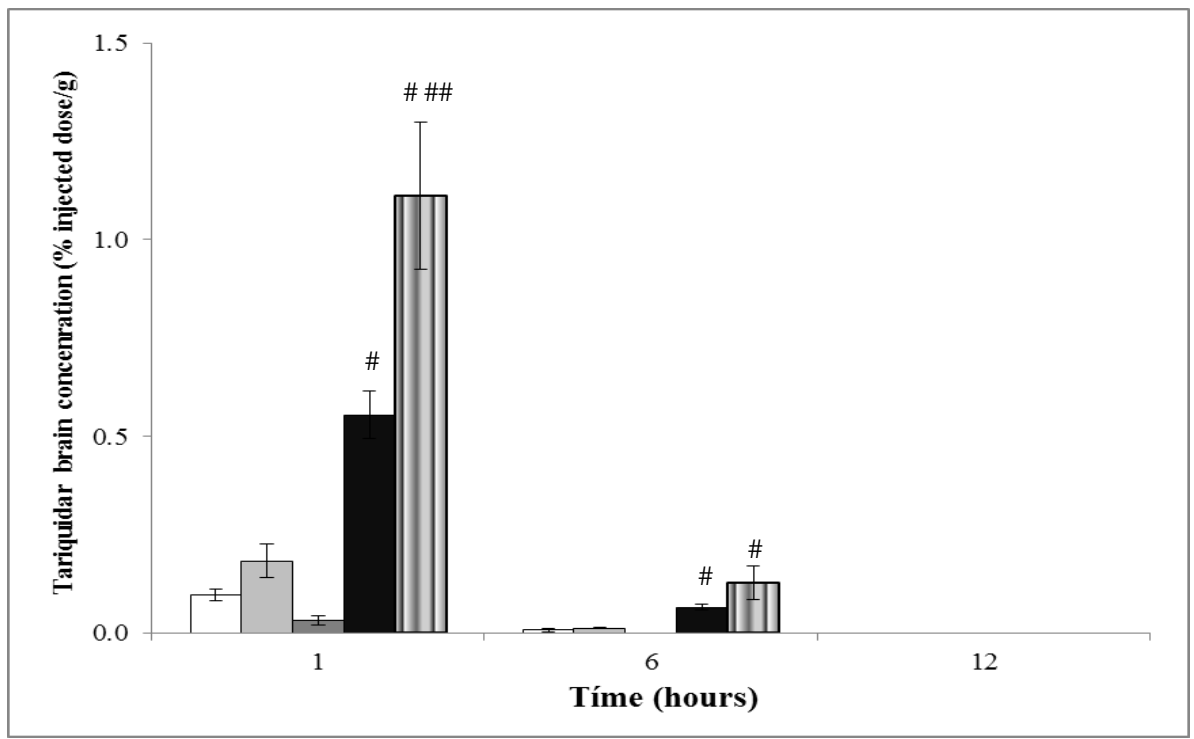

Figure 2: Brain concentrations of tariquidar (mean \pm S.D.) after intravenous administration of free tariquidar (plus free elacridar) (white), in ELA-TAR-CL (light grey), in ELA-TAR-COOHL (dark grey), in ELA-TARLCL (black), or in ELA-TAR-IL (striped). In all the cases the treatments were concurrently administered with loperamide at $0.5 \mathrm{mg} / \mathrm{kg}$. Bars represent the standard deviation. $\mathrm{n}=3$.

\# ANOVA: Significantly different compared to the group which received free elacridar.

\#\#\# Student's t-test: Significantly different compared to the group which received EL-TAR-LCL. 
Table 4. Brain distribution of elacridar and tariquidar

\begin{tabular}{cccccccccc}
\hline & \multicolumn{4}{c}{ Elacridar } & \multicolumn{5}{c}{ Tariquidar } \\
\cline { 2 - 10 } & $\mathrm{AUC}_{\text {inf }}(\%$ dose.h/g $)$ & \multicolumn{2}{c}{$K \mathrm{p}$} & & $\mathrm{AUC}_{\text {inf }}(\%$ dose.h/g $)$ & \multicolumn{2}{c}{$K \mathrm{p}$} \\
\cline { 2 - 10 } & Mean & S.D. & Mean & S.D. & Mean & S.D. & Mean & S.D. \\
\cline { 2 - 10 } Free EL-TAR & 0.79 & 0.12 & 0.08 & 0.02 & 0.29 & 0.06 & 0.03 & 0.01 \\
EL-TAR-CL & 1.18 & 0.28 & $0.26^{\#}$ & 0.05 & 0.50 & 0.09 & $0.09^{\#}$ & 0.02 \\
EL-TAR-COOHL & 0.06 & 0.01 & $0.01^{\#}$ & 0.002 & 0.03 & 0.01 & 0.01 & 0.001 \\
EL-TAR-LCL & $4.15^{*}$ & 0.72 & 0.10 & 0.02 & $1.83^{*}$ & 0.14 & 0.05 & 0.01 \\
EL-TAR-IL & $8.16^{* * *}$ & 0.93 & $0.30^{\# \# \#}$ & 0.05 & $3.70^{* * *}$ & 0.81 & $0.14^{\# \# \#}$ & 0.03 \\
\hline
\end{tabular}

* Bailler method: Significantly different to the group which received free elacridar plus free tariquidar.

** Bailler method: Significantly different compared to the group which received EL-TAR-LCL.

\# ANOVA: Significantly different compared to the group which received free elacridar plus free tariquidar.

\#\# ANOVA: Significantly different compared to the group which received EL-TAR-LCL.

\subsubsection{Tissues distribution of elacridar and tariquidar co-loaded in different types of liposomes}

Liver and kidneys distribution of elacridar and tariquidar are shown in Table 5. In liver, the $\mathrm{AUC}_{\text {inf }}$ of elacridar and tariquidar co-loaded in EL-TAR-CL and EL-TAR-COOHL confirmed that these formulations were rapidly removed from the circulation by the RES and significantly accumulated in this organ. In agreement with their extended half-lives, elacridar and tariquidar in EL-TAR-LCL showed 2.4- and 1.6-fold lower $\mathrm{AUC}_{\text {inf }}$ values compared to the free form of each P-gp modulators, respectively. As the conjugation of OX26 F(ab') fragments to long circulating liposomes partially reversed the stealth effects, a partial increase in $\mathrm{AUC}_{\mathrm{inf}}$ of elacridar and tariquidar co-loaded in EL-TAR-IL were found in relation to ELTAR-LCL. However, these values were still lower compared to the values obtained with free elacridar and free tariquidar.

In kidneys, the distribution of both P-gp modulators in EL-TAR-CL, EL-TAR-LCL and ELTAR-IL was similar to the distribution of the free drugs. Surprisingly, the distribution of elacridar in EL-TAR-COOHL was 1.8-fold lower than the value obtained with free elacridar. 
Table 5. Area under the concentration time curves $\left(\mathrm{AUC}_{\mathrm{inf}}\right)$ (mean $\left.\pm \mathrm{S} . \mathrm{D}\right)$ of elacridar and tariquidar $(\%$ dose.h/g)

\begin{tabular}{ccccccccc}
\hline & \multicolumn{3}{c}{ Elacridar } & \multicolumn{3}{c}{ Tariquidar } \\
\hline & \multicolumn{2}{c}{ Liver } & \multicolumn{2}{c}{ Kidney } & \multicolumn{2}{c}{ Liver } & \multicolumn{2}{c}{ Kidney } \\
\hline & Mean & S.D. & Mean & S.D. & Mean & S.D. & Mean & S.D. \\
\hline Free EL-TAR & 15.2 & 1.0 & 4.1 & 0.4 & 7.8 & 0.3 & 3.1 & 0.1 \\
EL-TAR-CL & $25.0^{\#}$ & 2.8 & 4.2 & 0.2 & $24.4^{\#}$ & 4.6 & 3.9 & 0.2 \\
EL-TAR-COOHL & $21.4^{\#}$ & 3.1 & $2.3^{\#}$ & 0.1 & $29.0^{\#}$ & 9.3 & 3.2 & 0.3 \\
EL-TAR-LCL & $6.4^{\#}$ & 1.1 & 3.4 & 0.3 & 4.9 & 0.5 & 2.5 & 0.5 \\
EL-TAR-IL & $9.5^{\# \# \#}$ & 1.1 & 4.8 & 0.5 & 6.2 & 1.4 & 3.6 & 0.4 \\
\hline
\end{tabular}

\# ANOVA: Significantly different compared to the group which received free elacridar plus free tariquidar ${ }^{\#}$ ANOVA: Significantly different compared to the group which received EL-TAR-LCL

\subsubsection{Effects of elacridar and tariquidar co-loaded in different types of liposomes on the brain distribution of free loperamide}

Elacridar and tariquidar under their free or liposomal form potentiated the opioid-like behavior produced by loperamide. The animals presented mainly lethargy, piloerection and shallow breathing. Only few animals from the groups treated with Free-EL-TAR and ELTAR-IL showed whole body tetany, the Straub reaction [25] and eyes protrusion. However there were significant differences in the latency, intensity and duration of these clinical signs (Fig 3). While the animals treated with Free-EL-TAR (TS = 102), EL-TAR-CL (TS = 11) and EL-TAR-COOHL (TS $=5$ ) showed the aforementioned clinical signs immediately or 5 minutes after treatment, the animals which received EL-TAR-LCL $(\mathrm{TS}=22)$ and EL-TAR-IL (TS $=90)$ did it only 30 minutes post-dosing. In contrast, the persistence of the opioid-like behavior for Free-EL-TAR, EL-TAR-LCL and EL-TAR-IL was the same (30 minutes) and longer than those for EL-TAR-CL (10 minutes) and EL-TAR-COOHL (5 minutes). 


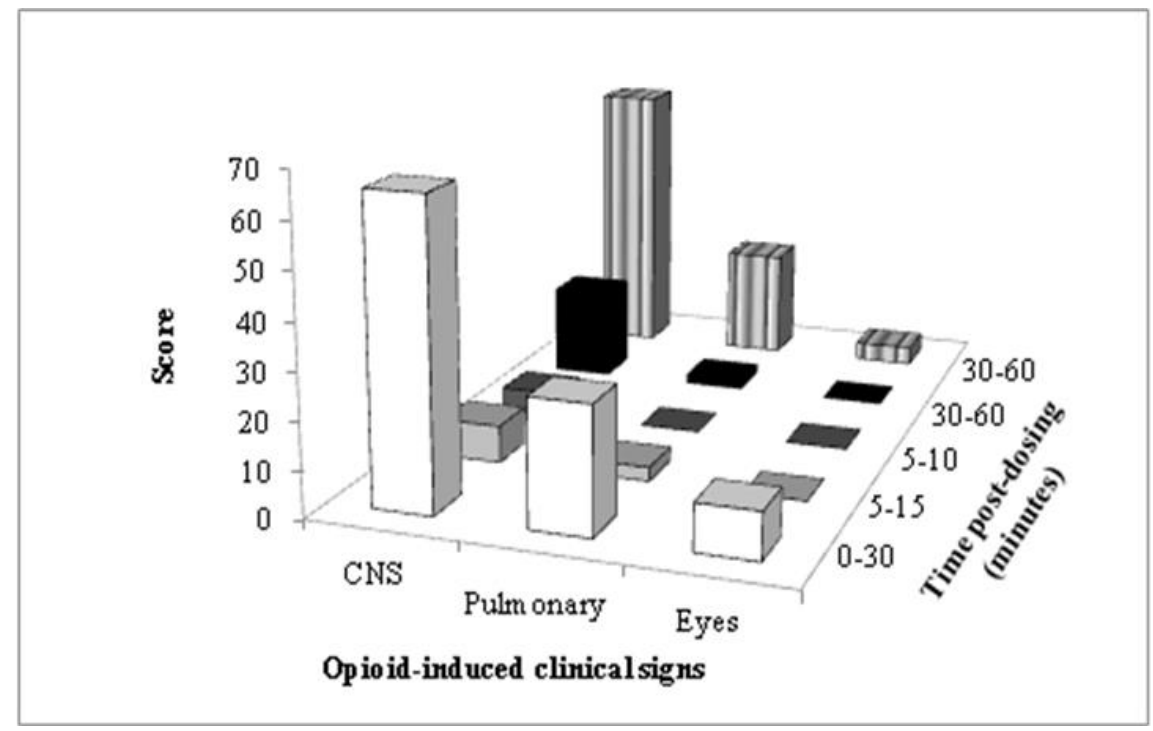

Figure 3: Mean degree score for CNS, respiratory and ocular clinical signs induced by loperamide after concurrent intravenous with free elacridar plus free tariquidar (white), ELA-TAR-CL (light grey), ELA-TARCOOHL (dark grey), ELA-TAR-LCL (black), or ELA-TAR-IL (striped). $\mathrm{n}=12$.

Despite the concurrent administration of free elacridar plus free tariquidar, at 1 hour postdosing, loperamide only reached a brain uptake of $0.038 \pm 0.005 \% \mathrm{ID} / \mathrm{g}$ (Fig. 4). Whereas the simultaneous administration of EL-TAR-CL and EL-TAR-COOHL did not improve the brain uptake of loperamide; EL-TAR-LCL and EL-TAR-IL at 1 hour increased the loperamide brain distribution by $2.1-(0.077 \pm 0.006 \% \mathrm{ID} / \mathrm{g})$ and 4.4 -fold $(0.162 \pm 0.010 \% \mathrm{ID} / \mathrm{g})$, respectively. EL-TAR-LCL and EL-TAR-IL significantly succeed in avoiding the P-gpmediated efflux of loperamide also at 6 hours. At this time point, EL-TAR-LCL and ELTAR-IL increased the loperamide brain uptake by $2.1(0.015 \pm 0.004 \% \mathrm{ID} / \mathrm{g})$ and 6.0 -fold $(0.042 \pm 0.003 \% \mathrm{ID} / \mathrm{g})$, respectively as compared to that with free elacridar plus free tariquidar $(0.007 \pm 0.001 \% \mathrm{ID} / \mathrm{g})$. Importantly, the brain uptake of loperamide achieved with EL-TAR-IL at 6 hours post-dosing is in the same range that the value obtained with free elacridar plus free tariquidar at 1 hour post-dosing. After 12 hours post-dosing, loperamide was not detected in any of the different groups. The differences in the loperamide $\mathrm{AUC}_{\mathrm{inf}}$ for the brains and the $K \mathrm{p}$ values were even more marked than the effects at the individual times (Table 6). 


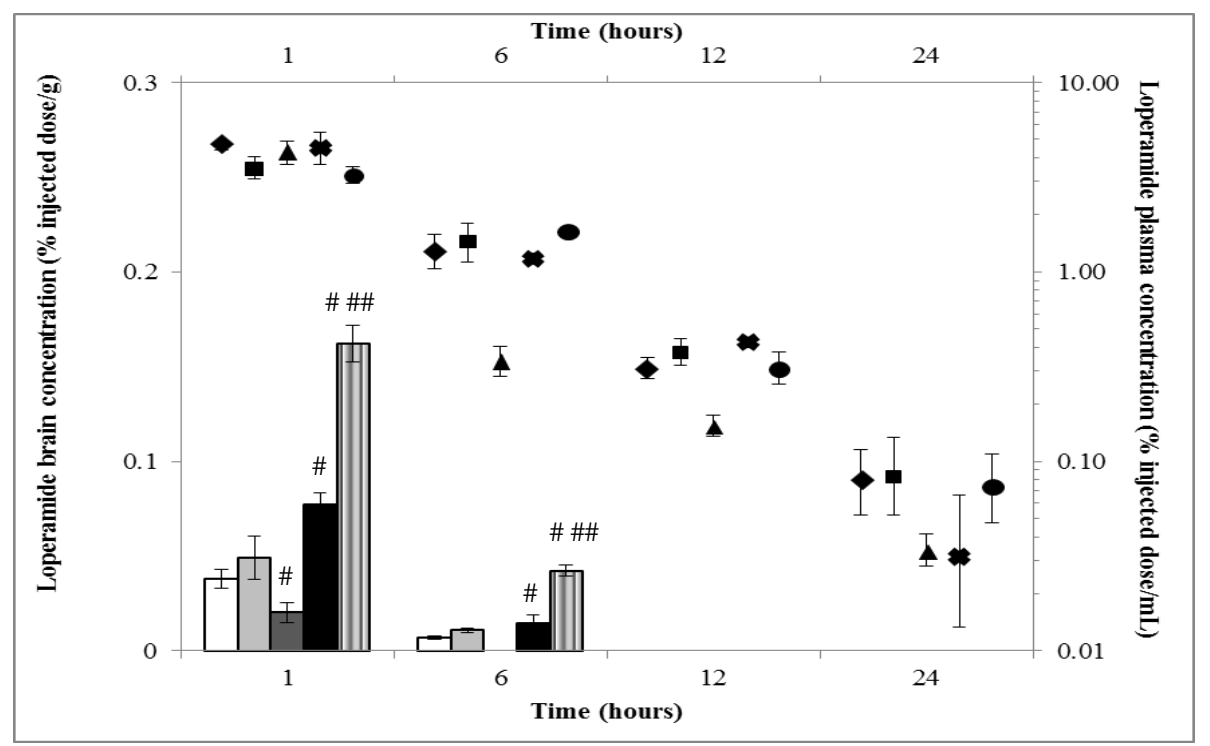

Figure 4: Brain concentrations (left axis) and plasma concentrations (right axis) of loperamide (mean \pm S.D.) after intravenous co-administration with free elacridar plus free tariquidar (white/ rhombus), ELA-TAR-CL (light grey/square), ELA-TAR-COOHL (dark grey/triangle), ELA-TAR-LCL (black/cross), or ELA-TAR-IL (striped/circle). Bars represent the standard deviation. $\mathrm{n}=3$.

\# ANOVA: Significantly different compared to the group which received loperamide at $0.5 \mathrm{mg} / \mathrm{kg}$ concurrently with free elacridar plus free tariquidar.

\#\# Student's t-test: Significantly different compared to the group which received loperamide at $0.5 \mathrm{mg} / \mathrm{kg}$ concurrently with EL-TAR-LCL.

Table 6. Brain distribution of loperamide in co-administration with free and liposomal elacridar plus tariquidar

\begin{tabular}{ccccc}
\hline & \multicolumn{2}{c}{$\mathrm{AUC}_{\text {inf }}(\%$ dose.h/g $)$} & \multicolumn{2}{c}{$K \mathrm{p}$} \\
\cline { 2 - 5 } & Mean & S.D. & Mean & S.D. \\
\cline { 2 - 5 } Free EL-TAR & 0.15 & 0.01 & 0.006 & 0.0003 \\
EL-TAR-CL & $0.21 *$ & 0.02 & 0.009 & 0.0014 \\
EL-TAR-COOHL & $0.02 *$ & 0.01 & $0.001^{\#}$ & 0.0005 \\
EL-TAR-LCL & $0.31 *$ & 0.04 & $0.013^{\#}$ & 0.0023 \\
EL-TAR-IL & $0.77 * * *$ & 0.04 & $0.035^{\# \# \#}$ & 0.0039 \\
\hline
\end{tabular}

\footnotetext{
* Bailler method: Significantly different to the group which received free loperamide concurrently with free elacridar plus free tariquidar

** Bailler method: Significantly different compared to the group which received free loperamide concurrently with EL-TAR-LCL.

\# ANOVA: Significantly different compared to the group which received free loperamide concurrently with free elacridar plus free tariquidar

\#\# ANOVA: Significantly different compared to the group which received free loperamide concurrently with ELTAR-LCL
} 


\subsubsection{Effects of elacridar and tariquidar co-loaded in different types of liposomes on the pharmacokinetics, liver and kidneys distribution of free loperamide}

Previously, we have shown that the pharmacokinetics of loperamide alone at a dose of 0.5 $\mathrm{mg} / \mathrm{kg}$ was not significantly modified when it was concurrently administered with free elacridar plus free tariquidar at a total dose of $1.0 \mathrm{mg} / \mathrm{kg}$. The present study reveals that both P-gp inhibitors at the same total dose co-loaded in EL-TAR-CL, EL-TAR-LCL and EL-TARIL neither changed the pharmacokinetics of loperamide (Fig. 4). Nonetheless, compared to the concurrent administration of both free P-gp inhibitors, the simultaneous administration of ELTAR-COOHL significantly decreased the $\mathrm{AUC}_{\text {inf }}(24.32 \pm 2.94$ to $14.80 \pm 1.77 \%$ dose.h $)$ and increased the clearance $(4.17 \pm 0.47$ to $6.85 \pm 0.77 \mathrm{~mL} / \mathrm{h} / \mathrm{kg})$ of loperamide. Besides, related to the co-administration of free P-gp modulators, EL-TAR-COOHL significantly decreased the loperamide $\mathrm{AUC}_{\mathrm{inf}}$ for the liver $(2.55 \pm 0.26$ to $1.79 \pm 0.20 \% \mathrm{dose} / \mathrm{h})$.

\subsection{Discussion}

Recently, we have shown that while tariquidar and elacridar, both at $1.0 \mathrm{mg} / \mathrm{kg}$, increased loperamide levels in the brain by 2.3- and 3.5-fold respectively, the concurrent administration of both P-gp modulators at a total dose of $1.0 \mathrm{mg} / \mathrm{kg}$, increased loperamide levels in the brain by 5.8 -fold. Hence, this study aims to assess the pharmacokinetics and brain distribution of the same total dose of elacridar and tariquidar co-loaded in $\mathrm{OX} 26 \mathrm{~F}\left(\mathrm{ab}{ }^{\prime}\right)_{2}$ immunoliposomes. To select the framework for immunoliposomal development, conventional, PEGylated $\mathrm{COOH}$ and $\mathrm{PEGylated} \mathrm{OCH}_{3}$ liposomes were previously evaluated. A special emphasis was given to the brain uptake of loperamide, as an in vivo probe of full and simultaneous blockage of the Pgp by both, elacridar and tariquidar.

There were big differences in the pharmacokinetics and tissue distribution of elacridar and tariquidar co-loaded in liposomal formulations compared to the free form of both P-gp modulators. Elacridar and tariquidar in conventional liposomes did preferentially accumulate to a high degree in liver. This behavior is well known and is a consequence of their clearance by macrophages of the RES which can occur when the DDS is directly injected into the blood circulation [26]. The coating of liposomes by a PEG shell is probably one of the most efficient ways to avoid this detrimental liver and/or non-specific accumulation [9]. The most accepted hypothesis for this phenomenon is the ability of PEG to create a hydrophilic protective layer that repel the adsorption of plasma proteins onto the surface of liposomes (opsonization) via 
steric repulsion, thereby avoiding the consequent uptake by the macrophages of the RES [9, 27]. However, this ability depends on the PEG chain length and density [9]. DSPE-PEG 2000 at a density up to $10 \mathrm{~mol} \%$ incorporated into various DDSs demonstrated to efficiently prevent the aggregation and enhance the permanence of various DDSs in the bloodstream [28, 29]. However, the effect of DSPE-PEG 2000 on the pharmacokinetics and biodistribution of the DDSs can be also counterbalanced by the charge of the particle since negatively charged liposomes showed increased RES uptake [30]. In our study, two types of PEG molecules were used, DSPE-PEG $2000-\mathrm{COOH}$ for PEGylated-COOH liposomes and DSPE-PEG $2000-\mathrm{OCH}_{3}$ for PEGylated- $\mathrm{OCH}_{3}$ long circulating liposomes. As expected by their zeta potential, the influence of each PEG on the liposomes distribution was different. PEGylated-COOH liposomes did not improve the permanence of the P-gp modulators in the bloodstream and accumulated in the liver in the same rate than conventional liposomes. In contrast, PEGylated$\mathrm{OCH}_{3}$ long circulating liposomes significantly increased the plasma concentrations of elacridar and tariquidar, lengthening their half-lives in comparison to the free drugs, conventional or PEGylated-COOH liposomes. Simultaneously, the clearance values as well as the liver accumulation of both P-gp modulators decreased using $\mathrm{PEGylated-}^{-\mathrm{OCH}_{3}}$ long circulating liposomes. These results confirm that negatively charged liposomes have shorter half-lives in the blood than do neutral liposomes [9]. Previous studies showed that the fast clearance of $200 \mathrm{~nm}$ negatively-charged phosphatidic acid liposomes can be reversed by PE-

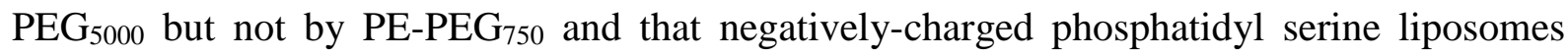
cannot be reversed by either PE-PEG5000 or PE-PEG750 [30]. In contrast, the functionalization of $8 \mathrm{~nm}$ particles with $\mathrm{PEG}_{2000}-\mathrm{COOH}$ prevented their accumulation in the liver, spleen and lungs [31]. Given the above points, we confirm then that the harmoniously tune of size, surface charge and surface chemistry will determine the fate and behavior of these nanocarriers in vivo. In general, a size of around $100 \mathrm{~nm}$, a neutral surface charge and steric stabilization reduce the RES clearance, improve the pharmacokinetics and augur an increase in the targeted tissue uptake [5, 9]. Moreover, if PEGylation is required to ensure the stay of the nanocarriers in the bloodstream, their distribution not only depends on the PEG chain length and density but also on the nature of its end group. The selection of this end group could be also determining when co-administering PEGylated liposomes with a free drug. As observed herein, an alteration in loperamide distribution was caused by the $\mathrm{COOH}$ terminal groups of the negatively charged liposomes. Although, in our study the placement of OX26 $\mathrm{F}(\mathrm{ab})_{2}$ at the distal end of PEG partially reversed the effect of PEGylation, the vascular 
residence time achieved with the immunoliposomes was sufficient for contact with the target tissue.

The brain uptake of both P-gp modulators co-loaded in conventional liposomes may arise from the brain uptake of free elacridar and free tariquidar released to the bloodstream after dissolution of these liposomes in peripheral tissues. A similar pattern was observed for negatively charged $\mathrm{COOH}$ liposomes. In fact, the rapid clearance and the lowest brain uptake of elacridar and tariquidar indicate that these nanocarriers activated the complement system via the classical pathway [9] before than they could release both P-gp modulators. Conversely, PEGylation with $\mathrm{OCH}_{3}$ end groups had a positive impact on the therapeutic delivery of elacridar and tariquidar to the brain. Early investigations demonstrated that PEG coated neutral charged nanocarriers had no effect on the brain uptake of encapsulated drugs [32]. However, since neutral PEG slows down the first-pass metabolism, it may increase the chance of around $150 \mathrm{~nm}$ sized nanocarriers to deliver the encapsulated drugs across the BBB [33]. In the same way, it was demonstrated that nanoparticles coated with PEG were able to penetrate the $\mathrm{BBB}$ and reach the maximum in brain at 1 hour post-injection [34]. Additionally, nanocarriers as large as $114 \mathrm{~nm}$ in diameter and densely coated with PEG are able to spread rapidly within the brain tissue [35]. Thus, the limited contribution of passive targeting seen with our PEGylated- $\mathrm{OCH}_{3}$ long circulating liposomes could be further improved if they are coated with a high density of a longer PEG molecule, for example with DSPE-PEG $5000-\mathrm{OCH}_{3}$. These data favored then further development of long circulating immunoliposomes. These DDSs were armed with an approximately $100 \mathrm{~nm}$ size, neutral zeta potential and sterically stabilized properties, prolonging thus their systemic circulation. Moreover, these immunoliposomes were provided of an elevated permeability to the brain through the conjugation of $\mathrm{OX} 26 \mathrm{~F}(\mathrm{ab})_{2}$ fragments. OX26 is an appropriate vector that previously exhibited specific brain targeting using liposomes [13], lipid [17] and polymer nanoparticles [36]. Therefore, the greatest brain uptake of immunoliposomal elacridar and tariquidar is well explained by the Pardridge pharmacokinetic rule. This rule states that the brain uptake of a drug is a dual function of the plasma AUC of the drug and the permeability of the same drug against brain tissue [37]. Lately, a microemulsion containing elacridar was also prepared to improve the bioavailability and brain distribution of the P-gp modulator [38]. In spite of the 3.0-fold higher $K \mathrm{p}$ value obtained with this DDS in comparison to free elacridar [38], its elimination half-life was not improved, thus limiting the brain uptake of elacridar according to the Pardridge pharmacokinetic rule. 
Even though the brain distribution of both free P-gp modulators is dose-dependent [38, 39], herein the low doses of free elacridar plus free tariquidar caused an important and extremely rapid modulation of the P-gp at the BBB. This phenomenon could be unmanageable leading to toxic profiles with lethal results. Nevertheless, the opioid-induced behavior and the 4.4- (at 1 hour) and 6.1-fold (at 6 hours) higher brain uptake of loperamide achieved by the immunoliposomes indicates that the brain distribution of both P-gp modulators could be delayed and prolonged up to 6 hours. This could avoid an abrupt entry of the P-gp substrate into the brain and subsequent acute toxicities. However the increase in the brain uptake of loperamide was not in the same range than the brain uptake of both immunoliposomal P-gp modulators. This phenomenon could be the result of the minimal interaction of these immunoliposomes with the pharmacokinetics of loperamide and the consequent rapid elimination of the $\mu$-opioid agonist from the bloodstream. Although tariquidar loading efficiency remains to be improved, this immunoliposomal formulation represent a promising tool to modulate the P-gp at the BBB and allow the brain uptake of loperamide or any other Pgp substrate without major pharmacokinetic interactions.

In brief, by integrating two P-gp overcoming strategies, namely, P-gp direct modulation with elacridar and tariquidar and the use of an advanced DDS, an efficient modulation of the P-gp at the BBB can be obtained. Particular attention should be given to the development of the nanocarrier. As seen, the size, the surface charge as well as the length and the end group of the PEG chain should be carefully tuned to successfully modulate the pharmacokinetics and tissue distribution of the encapsulated drugs. Moreover, the coupling of an appropriate targeting vector such as $\mathrm{OX} 26 \mathrm{~F}\left(\mathrm{ab}^{\prime}\right)_{2}$ fragments and its number density are factors that could ensure an effective transport of the encapsulated drugs across the BBB. More detailed in vivo pharmacokinetics, biodistribution, pharmacodynamics, and toxicology studies could maximize the efficacy of this approach. 


\section{References}

[1] W. Loscher, H. Potschka, Role of drug efflux transporters in the brain for drug disposition and treatment of brain diseases, Prog Neurobiol, 76 (2005) 22-76.

[2] K. Linnet, T.B. Ejsing, A review on the impact of P-glycoprotein on the penetration of drugs into the brain. Focus on psychotropic drugs, Eur Neuropsychopharmacol, 18 (2008) $157-169$.

[3] C.A. McDevitt, R. Callaghan, How can we best use structural information on Pglycoprotein to design inhibitors?, Pharmacol Ther, 113 (2007) 429-441.

[4] M. Hubensack, C. Muller, P. Hocherl, S. Fellner, T. Spruss, G. Bernhardt, A. Buschauer, Effect of the ABCB1 modulators elacridar and tariquidar on the distribution of paclitaxel in nude mice, J Cancer Res Clin Oncol, 134 (2008) 597-607.

[5] D.C. Drummond, O. Meyer, K. Hong, D.B. Kirpotin, D. Papahadjopoulos, Optimizing liposomes for delivery of chemotherapeutic agents to solid tumors, Pharmacol Rev, 51 (1999) 691-743.

[6] M. Bauer, M. Zeitlinger, D. Todorut, M. Bohmdorfer, M. Muller, O. Langer, W. Jager, Pharmacokinetics of single ascending doses of the P-glycoprotein inhibitor tariquidar in healthy subjects, Pharmacology, 91 (2013) 12-19.

[7] R. Nieto Montesinos, A. Beduneau, Y. Pellequer, A. Lamprecht, Delivery of Pglycoprotein substrates using chemosensitizers and nanotechnology for selective and efficient therapeutic outcomes, J Control Release, 161 (2012) 50-61.

[8] M. Gulati, M. Grover, S. Singh, M. Singh, Lipophilic drug derivatives in liposomes, International Journal of Pharmaceutics 165 (1998) 129-168.

[9] M.L. Immordino, F. Dosio, L. Cattel, Stealth liposomes: review of the basic science, rationale, and clinical applications, existing and potential, Int J Nanomedicine, 1 (2006) 297 315.

[10] A. Schnyder, J. Huwyler, Drug transport to brain with targeted liposomes, NeuroRx, 2 (2005) 99-107.

[11] J. Kreuter, Nanoparticulate systems for brain delivery of drugs, Adv Drug Deliv Rev, 47 (2001) 65-81.

[12] W.A. Jefferies, M.R. Brandon, S.V. Hunt, A.F. Williams, K.C. Gatter, D.Y. Mason, Transferrin receptor on endothelium of brain capillaries, Nature, 312 (1984) 162-163. 
[13] A. Schnyder, S. Krahenbuhl, J. Drewe, J. Huwyler, Targeting of daunomycin using biotinylated immunoliposomes: pharmacokinetics, tissue distribution and in vitro pharmacological effects, J Drug Target, 13 (2005) 325-335.

[14] Z. Pang, W. Lu, H. Gao, K. Hu, J. Chen, C. Zhang, X. Gao, X. Jiang, C. Zhu, Preparation and brain delivery property of biodegradable polymersomes conjugated with OX26, J Control Release, 128 (2008) 120-127.

[15] A.R. Jones, E.V. Shusta, Blood-brain barrier transport of therapeutics via receptormediation, Pharm Res, 24 (2007) 1759-1771.

[16] N.C. Phillips, J. Dahman, Immunogenicity of immunoliposomes: reactivity against species-specific IgG and liposomal phospholipids, Immunol Lett, 45 (1995) 149-152.

[17] A. Beduneau, F. Hindre, A. Clavreul, J.C. Leroux, P. Saulnier, J.P. Benoit, Brain targeting using novel lipid nanovectors, J Control Release, 126 (2008) 44-49.

[18] Y. Pellequer, M. Ollivon, G. Barratt, Formulation of liposomes associated with recombinant interleukin-2: effect on interleukin-2 activity, Biomed Pharmacother, 58 (2004) $162-167$.

[19] A.A. Bogdanov, Jr., A.L. Klibanov, V.P. Torchilin, Protein immobilization on the surface of liposomes via carbodiimide activation in the presence of $\mathrm{N}$ hydroxysulfosuccinimide, FEBS Lett, 231 (1988) 381-384.

[20] F.D.A.U.S.D.o.H.a.H. Services., Guidance for Industry: Bioanalytical Method Validation, (2001).

[21] A.J. Bailer, Testing for the equality of area under the curves when using destructive measurement techniques, J Pharmacokinet Biopharm, 16 (1988) 303-309.

[22] J. Yuan, Estimation of variance for AUC in animal studies, J Pharm Sci, 82 (1993) 761763.

[23] Z. Sezgin, N. Yuksel, T. Baykara, Preparation and characterization of polymeric micelles for solubilization of poorly soluble anticancer drugs, Eur J Pharm Biopharm, 64 (2006) 261 268.

[24] A. Beduneau, P. Saulnier, F. Hindre, A. Clavreul, J.C. Leroux, J.P. Benoit, Design of targeted lipid nanocapsules by conjugation of whole antibodies and antibody Fab' fragments, Biomaterials, 28 (2007) 4978-4990.

[25] D.L. Bilbey, H. Salem, M.H. Grossman, The anatomical basis of the straub phenomenon, Br J Pharmacol Chemother, 15 (1960) 540-543. 
[26] G.L. Scherphof, J. Dijkstra, H.H. Spanjer, J.T. Derksen, F.H. Roerdink, Uptake and intracellular processing of targeted and nontargeted liposomes by rat Kupffer cells in vivo and in vitro, Ann N Y Acad Sci, 446 (1985) 368-384.

[27] J.H. Yu, H.J. Kim, S. Lee, S.J. Hwang, W. Kim, C.J. Moon, LC-MS determination and bioavailability study of loperamide hydrochloride after oral administration of loperamide capsule in human volunteers, J Pharm Biomed Anal, 36 (2004) 421-427.

[28] N. Dos Santos, C. Allen, A.M. Doppen, M. Anantha, K.A. Cox, R.C. Gallagher, G. Karlsson, K. Edwards, G. Kenner, L. Samuels, M.S. Webb, M.B. Bally, Influence of poly(ethylene glycol) grafting density and polymer length on liposomes: relating plasma circulation lifetimes to protein binding, Biochim Biophys Acta, 1768 (2007) 1367-1377.

[29] K. Maruyama, PEG-immunoliposome, Biosci Rep, 22 (2002) 251-266.

[30] T.S. Levchenko, R. Rammohan, A.N. Lukyanov, K.R. Whiteman, V.P. Torchilin, Liposome clearance in mice: the effect of a separate and combined presence of surface charge and polymer coating, Int J Pharm, 240 (2002) 95-102.

[31] A.C. Faure, S. Dufort, V. Josserand, P. Perriat, J.L. Coll, S. Roux, O. Tillement, Control of the in vivo biodistribution of hybrid nanoparticles with different poly(ethylene glycol) coatings, Small, 5 (2009) 2565-2575.

[32] J. Huwyler, D. Wu, W.M. Pardridge, Brain drug delivery of small molecules using immunoliposomes, Proc Natl Acad Sci U S A, 93 (1996) 14164-14169.

[33] Y.C. Chen, W.Y. Hsieh, W.F. Lee, D.T. Zeng, Effects of surface modification of PLGAPEG-PLGA nanoparticles on loperamide delivery efficiency across the blood-brain barrier, $\mathrm{J}$ Biomater Appl, 27 (2013) 909-922.

[34] S. Simsek, H. Eroglu, B. Kurum, K. Ulubayram, Brain targeting of Atorvastatin loaded amphiphilic PLGA-b-PEG nanoparticles, J Microencapsul, 30 (2013) 10-20.

[35] E.A. Nance, G.F. Woodworth, K.A. Sailor, T.Y. Shih, Q. Xu, G. Swaminathan, D. Xiang, C. Eberhart, J. Hanes, A dense poly(ethylene glycol) coating improves penetration of large polymeric nanoparticles within brain tissue, Sci Transl Med, 4 (2012) 149ra119.

[36] K. Ulbrich, T. Hekmatara, E. Herbert, J. Kreuter, Transferrin- and transferrin-receptorantibody-modified nanoparticles enable drug delivery across the blood-brain barrier (BBB), Eur J Pharm Biopharm, 71 (2009) 251-256.

[37] W.M. Pardridge, Blood-brain barrier drug targeting: the future of brain drug development, Mol Interv, 3 (2003) 90-105, 151.

[38] R. Sane, S. Agarwal, R.K. Mittapalli, W.F. Elmquist, Saturable active efflux by pglycoprotein and breast cancer resistance protein at the blood-brain barrier leads to nonlinear 
distribution of elacridar to the central nervous system, J Pharmacol Exp Ther, 345 (2013) 111 124.

[39] J.P. Bankstahl, M. Bankstahl, K. Romermann, T. Wanek, J. Stanek, A.D. Windhorst, M. Fedrowitz, T. Erker, M. Muller, W. Loscher, O. Langer, C. Kuntner, Tariquidar and elacridar are dose-dependently transported by P-glycoprotein and Bcrp at the blood-brain barrier: a small-animal positron emission tomography and in vitro study, Drug Metab Dispos, 41 (2013) 754-762. 


\title{
7 SEQUESTRATION OF P-GLYCOPROTEIN INHIBITORS BY NOCARRIERS
}

\begin{abstract}
The crucial tissue localization of P-glycoprotein suggests its important physiological role in the protection of susceptible organs, where it pumps out of the cells an unlimited number of P-glycoprotein substrates from therapeutic drugs to pesticides. Thus prolonged periods of Pglycoprotein inactivity caused by over-doses of P-glycoprotein inhibitors could result in detrimental or even lethal outcomes. This study evaluated then the ability of three nanocarriers to sequester two potent P-glycoprotein inhibitors, elacridar and tariquidar. The transport of rhodamine 123, a P-glycoprotein substrate, across Caco-2 cells was used as a probe of functional activity of P-glycoprotein. Among the various concentrations of Pglycoprotein inhibitors $(0.1-2.0 \mu \mathrm{M})$, elacridar at $0.5 \mu \mathrm{M}$ and tariquidar at $1.00 \mu \mathrm{M}$ abolished any significant directionality in the transport of rhodamine 123 . None of the nanocarriers succeed in impairing the P-gp inhibitory activity of elacridar at $0.5 \mu \mathrm{M}$. In contrast, liposomes made of DMPC and cholesterol were able to partially impair the Pglycoprotein inhibitory activity of tariquidar $1.0 \mu \mathrm{M}$ increasing the efflux of rhodamine 123 from $26.77 \pm 1.90 \%$ to $51.15 \pm 4.49 \%$. Further investigations and improvements could make this formulation a bio-detoxifying agent to deal with toxic profiles caused by over-doses of tariquidar.
\end{abstract}

Keywords: Reversal of P-glycoprotein inhibitors, DMPC:Chol liposomes, bio-detoxifying agents and Caco-2 monolayers. 


\subsection{Introduction}

P-glycoprotein (P-gp), the product of the multidrug resistance gene, is a membrane-bound ATP-dependent efflux transporter [1]. Its strategic localization at the BBB impedes the diffusion of several therapeutic compounds into the brain by actively returning them to the bloodstream [2]. Hence, various studies suggest the use of high doses of potent P-gp inhibitors such as elacridar and tariquidar to overcome the P-gp mediated efflux at the BBB $[3,4]$. However, it is irrefutable that the main physiological role of the P-gp at the BBB is to protect the brain from a variety of xenobiotics and some endogenous metabolites that could penetrate the BBB without any limitation [5]. Thus, a transient P-gp inhibition at the BBB by elacridar or tariquidar could enhance the brain uptake of the therapeutic compounds but could avoid the later uptake and damage caused by xenobiotics that are also P-gp substrates. Then, it is highly desired to develop an approach to re-induce the P-gp-mediated efflux after prolonged periods of inactivity that could be caused by high doses of elacridar and tariquidar. One strategy to re-induce the P-gp mediated efflux involves the use of drugs, namely dexamethasone, rifampicin, doxorubicin, daunorubicin, vinblastine and the the herbal antidepressant St John's wort, which demonstrated to be P-gp inducers [6]. Nevertheless, their pharmacological effects not related to the P-gp re-induction could lead to significant systemic side effects. In contrast, a more suitable strategy would be to administer empty nanocarriers like nanoemulsions or liposomes that can extract the P-gp modulators from the bloodstream and brain avoiding a long exposure and a long-lasting P-gp inhibition [7]. Nanoemulsions are systems of nano-sized oil droplets dispersed and stabilized by one or more emulsifiers in a continuous aqueous phase (oil-in-water) [7, 8]. Liposomes are spherical vesicles made of one or more concentric phospholipid bilayer membranes that delimit the internal hydrophilic core from the external aqueous compartment $[7,8]$. The structural characteristics of nanoemulsions and liposomes allow them to circulate in a hydrophilic environment while capturing a broad range of lipophilic compounds through partition or adsorption mechanisms [8,9]. Since elacridar and tariquidar are mainly lipophilic compounds, their extraction or sequestration using the aforementioned nanocarriers could represent an alternative to achieve a transient $\mathrm{P}$ gp inhibition at the BBB. Alternatively, $\alpha$-tocopherol, which is commonly used as antioxydant in the pharmaceutical formulations, demonstrated its ability to re-induce the P-gp mediated efflux. Using the P-gp over-expressing MDR cell line, H69/LX4, Anderson et al. showed that $\alpha$-tocopherol was able to antagonize the P-gp inhibitory activity of elacridar [10]. 
The Caco-2 cell line, derived from human colorectal adenocarcinoma, is widely accepted as a potent in vitro model that expresses endogenously high levels of P-gp [11]. Therefore, Caco-2 monolayers are a well-suited tool to assess interactions between empty nanocarriers and P-gp modulators.

In this regard, the purpose of this study was to examine the potential of three nanocarriers to sequester elacridar and tariquidar. Sequestration by liposomes, and nanoemulsions containing or not $\alpha$-tocopherol was studied in an in vitro model of Caco-2 cells using rhodamine 123 as P-gp substrate probe.

\subsection{Materials and methods}

\subsubsection{Reagents}

Dulbecco's modified Eagle's medium (DMEM), Hanks' balanced salt solution 1X (HBSS), Dulbecco's phosphate-buffered saline 1X (DPBS), fetal bovine serum (FBS), non-essential amino acids and penicillin streptomycin antibiotics were purchased from Gibco ${ }^{\circledR}$ Life Technologies (France). 4-(2-hydroxyethyl)-1-piperazineethanesulfonic acid (HEPES), D-(+)glucose and rhodamine 123 were obtained from Sigma Aldrich (France). Elacridar was synthesized at the Laboratory of Pharmaceutical Chemistry, University of Bonn (Germany) and tariquidar was purchased from API Services Inc. (USA). 1,2-dimyristoyl-sn-glycero-3phosphocholine (DMPC) was supplied by Thermo Fischer Scientific (France) and cholesterol (Chol) and $\alpha$-tocopherol by Sigma Aldrich (France). Miglyol ${ }^{\circledR} 812$ was obtained from Condea (France) and soy lecithin from Unither Pharmaceuticals (France). HTS Transwell ${ }^{\circledR}-24$ well permeable supports with $0.4 \mu \mathrm{m}$ pore polycarbonate membrane and $6.5 \mathrm{~mm}$ inserts were obtained from Corning (France). All other test compounds were obtained from Sigma Aldrich (France).

\subsubsection{Caco- 2 cell culture}

Caco-2 cells were seeded onto 24 -well polycarbonate filter membranes at a density of 30000 cells $/ \mathrm{cm}^{2}$. The cells were grown in culture medium consisting of DMEM supplemented with $15 \%$ FBS, $1 \%$ non-essential amino acids, $100 \mathrm{U} / \mathrm{mL}$ penicillin and $100 \mu \mathrm{g} / \mathrm{mL}$ streptomycin. 
The culture medium was replaced every two days and the cells were maintained at $37{ }^{\circ} \mathrm{C}$, 95\% relative humidity and $5 \% \mathrm{CO}_{2}$. Permeability studies were conducted with monolayers cultured for 21 days at passage numbers 21 - 28. Physiologically and morphologically welldeveloped Caco-2 cell monolayers with transepithelial electrical resistance (TEER) values greater than $400 \Omega \mathrm{cm}^{2}$ were used for the transport studies.

\subsubsection{Selection of the P-gp inhibitors doses to be reversed}

The transport buffer (TB) used for the bi-directional studies was HBSS containing $10 \mathrm{mM}$ HEPES and 25 mM D-(+)-glucose. Stock solutions of elacridar, tariquidar and rhodamine 123 were prepared in $100 \%$ DMSO at $10 \mathrm{mM}$ and successively diluted in transport buffer. The concentrations of the P-gp inhibitors were in the range of 0.1 to $2.0 \mu \mathrm{M}$ and the concentration of rhodamine 123 in all the studies was $5 \mu \mathrm{M}$. The $\mathrm{pH}$ of apical and basolateral sides was 7.4. Prior to the studies, each monolayer was washed twice with HBSS and TEER was measured to ensure the integrity of the monolayers. The P-gp inhibition studies were initiated by adding the buffer containing the different concentrations of elacridar or tariquidar to apical and basolateral sides (to maintain the P-gp inhibitors concentrations constant during the studies) [12]. Blank transport buffer was added to monolayers used as control. The monolayers were then incubated at $37^{\circ} \mathrm{C}$ for 30 minutes. After the incubation period, buffer containing elacridar or tariquidar was removed and apical and basolateral sides were washed twice with HBSS. Rhodamine 123 was added to the apical side for the apical to basolateral transport (A-B) or to the basolateral side for the basolateral to apical transport (B-A). The transwell was again incubated at $37^{\circ} \mathrm{C}$ for 2 hours. Samples were taken from both, apical and basolateral sides at the end of the 2 hours incubation and concentrations of rhodamine 123 were analyzed using an EnVisionT Xcite Multilabel Reader Perkin Elmer.

The apparent permeability coefficients $\left(P_{\text {app }}\right)$ across Caco-2 cell monolayers in both A-B ( $P_{\text {app }}$ A-B) and B-A ( $\left.P_{\text {app B-A }}\right)$ directions were calculated as:

$$
P_{\text {app }}=(\mathrm{d} A / \mathrm{d} t) \times\left(1 / S \times C_{0}\right)
$$

where, $(\mathrm{d} A / \mathrm{d} t)$ is the flux of rhodamine 123 across the monolayer, $S$, the surface area of the filter membrane and $C_{0}$, the initial concentration in the donor compartment. The $P_{\text {app }}$ values are expressed as $\mathrm{cm} / \mathrm{s}$. 
The efflux ratio (ER) of rhodamine 123 in the presence and absence of the P-gp inhibitors was calculated as:

$$
\mathrm{ER}=P_{\text {app B-A }} / P_{\text {app A-B }}
$$

with $P_{\text {app B-A }}$ and $P_{\text {app A-B }}$ as the mean permeability coefficients obtained for the B-A direction and A-B direction, respectively.

\subsubsection{Time-dependent reversal of the P-gp inhibitory activity of elacridar and tariquidar}

The transport medium and the study procedures listed in the previous section were used to study reversal of P-gp modulators. Caco- 2 monolayers were exposed to elacridar 0.25 and $0.50 \mu \mathrm{M}$ or tariquidar 0.50 and $1.00 \mu \mathrm{M}$ on both sides, apical and basolateral at $37^{\circ} \mathrm{C}$ for 30 minutes. After removal of P-gp inhibitors, the monolayers were washed twice with HBSS and incubated with fresh medium for additional 0, 2, 6, 10, 24 and 48 hours. The P-gp activity was then assessed by measuring the efflux transport (B-A) of rhodamine $1235 \mu \mathrm{M}$ after 2 hours of incubation. The apparent permeability was calculated as percentage of the control, which is the total P-gp mediated efflux of rhodamine $123\left(14.16 \times 10^{-6} \mathrm{~cm} / \mathrm{s}\right)$ (table 1$)$.

\subsubsection{Effect of nanocarriers on P-glycoprotein inhibitory activity of elacridar and tariquidar}

The transport medium and the study procedures from the previous sections were also used in this stage. The studies were started by adding the buffer containing elacridar 0.25 and 0.50 $\mu \mathrm{M}$ or tariquidar 0.50 and $1.00 \mu \mathrm{M}$ to both sides, apical and basolateral. After incubation at $37^{\circ} \mathrm{C}$ for 30 minutes, the P-gp inhibitors were removed and the monolayers were washed twice with HBSS and incubated with the different formulations for 2 hours. Blank transport buffer was added to monolayers used as control. The monolayers were then washed twice with DPBS and rhodamine $1235 \mu \mathrm{M}$ was added to the basolateral side to evaluate the efflux transport (B-A). After 2 hours of incubation, samples were taken from both, apical and basolateral sides and concentrations of rhodamine 123 were analyzed. The apparent permeability was calculated as percentage of the control, which is the total P-gp mediated efflux of rhodamine $123\left(14.16 \times 10^{-6} \mathrm{~cm} / \mathrm{s}\right)($ table 1$)$. 


\subsubsection{Preparation of nanocarriers}

Liposomes were prepared by thin film hydratation method followed by sonication. Briefly, DMPC and cholesterol were weighed and dissolved in chloroform at a molar ratio of 80:20 (Table 2). The organic solvent was removed under a nitrogen stream to form a thin film, which was subjected to freeze-drying (Heto Lyolab 3000) overnight to remove any trace of the organic phase. The dried lipid film was then hydrated at $40^{\circ} \mathrm{C}$ with transport buffer (TB), $\mathrm{pH} 7.4$ to obtain a final phospholipid concentration of $10 \mu \mathrm{mol} / \mathrm{mL}$. The hydration was followed by a 15 minutes bath sonication at $40^{\circ} \mathrm{C}$ to produce multilamellar vesicles (MLV). After a rest of 10 minutes to overcome any structural defects, the MLV suspension was sized by sonication at $40^{\circ} \mathrm{C}$ for 15 minutes using a $13 \mathrm{~mm}$ diameter probe sonicator (Bandelin Sonoplus) at 150 watts. The resulting small unilamellar vesicles (SUV) were finally centrifuged for 10 minutes at $10000 \mathrm{~g}$ to remove the titanium dust originating from the probe. For the preparation of nanoemulsions (Table 2), the lipid phase composed of miglyol and soy lecithin in the absence or presence of $\alpha$-tocopherol and the aqueous phase composed by transport buffer (TB), pH 7.4 were heated up to $40^{\circ} \mathrm{C}$, separately. The lipid phase was injected into the aqueous phase under high shear mixing (Janke \& Kunkel T45 Ultra-turrax). The mixing was carried out for 3 minutes three times.

\subsubsection{Size measurements}

The size of diluted (with PBS pH 7.4) nanocarriers was measured by dynamic light scattering using the NanoZS (Malvern Instrument, France).

\subsubsection{Statistical Analysis}

All the data are presented as mean \pm S.D from six monolayers. The statistical analysis was carried out with the software SigmaStat 3.5. All analyses of statistical significance were examined by the one way analysis of variance (ANOVA) with the Holm-Sidak post hoc test. In all cases, $P<0.05$ was considered to be significant. 


\subsection{Results}

\subsubsection{Selection of the P-gp inhibitors doses to be reversed}

The permeability of rhodamine 123 at a concentration of $5.0 \mu \mathrm{M}$ was measured in two directions, A-B and B-A, in the absence of elacridar and tariquidar. In agreement with the literature [13], the transport rate of rhodamine 123 for B-A direction was significantly higher than the rate for the A-B direction, yielding an ER value of 9.44 (Table 1). In general, for the Caco-2 monolayer, an ER higher than 1.5 indicates the contribution of P-gp mediated efflux [14]. Our results confirmed then the P-gp-mediated efflux of the P-gp substrate probe across Caco-2 monolayers and validated the in vitro model for further studies. Various concentrations of elacridar and tariquidar $(0.1-2.0 \mu \mathrm{M})$ were assessed to identify those doses at which rhodamine 123 does not undergo P-gp efflux. The addition of elacridar and tariquidar at concentrations higher than $0.5 \mu \mathrm{M}$ and $1.0 \mu \mathrm{M}$, respectively, abolished any significant directionality in transport rate (Table 1).

Table 1: Effect of elacridar and tariquidar on the transport of rhodamine 123 across Caco-2 cell monolayers.

\begin{tabular}{cccccc}
\hline \multirow{2}{*}{ Drug } & $\begin{array}{c}\text { Concentration } \\
(\mu \mathrm{M})\end{array}$ & $\begin{array}{c}\text { Papp A - B } \\
\left(\times 10^{-6} \mathrm{~cm} / \mathrm{s}\right)\end{array}$ & $\begin{array}{c}\text { Papp B - A } \\
\left(\times 10^{-6} \mathrm{~cm} / \mathrm{s}\right)\end{array}$ & ER & P-gp substrate \\
\hline Rhodamine 123 & 5.00 & $14.16 \pm 0.73$ & $1.50 \pm 0.30$ & 9.44 & Yes \\
\hline & 0.10 & $9.40 \pm 0.25$ & $1.59 \pm 0.47$ & 5.91 & Yes \\
\cline { 2 - 5 }+ Elacridar & 0.25 & $5.41 \pm 0.52$ & $1.75 \pm 0.11$ & 3.09 & Yes \\
\cline { 2 - 5 } & $\mathbf{0 . 5 0}$ & $\mathbf{3 . 0 7} \pm \mathbf{0 . 2 2}$ & $\mathbf{2 . 0 7} \pm \mathbf{0 . 2 1}$ & $\mathbf{1 . 4 8}$ & --- \\
\cline { 2 - 5 } & 1.00 & $2.78 \pm 0.19$ & $2.39 \pm 0.32$ & 1.16 & --- \\
\hline \multirow{3}{*}{+ Tariquidar } & 2.00 & $2.14 \pm 0.16$ & $3.06 \pm 0.16$ & 0.70 & --- \\
\cline { 2 - 5 } & 0.10 & $11.85 \pm 0.43$ & $1.52 \pm 0.21$ & 7.80 & Yes \\
\cline { 2 - 5 } & 0.25 & $9.96 \pm 0.37$ & $1.60 \pm 0.31$ & 6.22 & Yes \\
\cline { 2 - 5 } & 0.50 & $6.30 \pm 0.33$ & $1.88 \pm 0.14$ & 3.35 & Yes \\
\cline { 2 - 5 } & $\mathbf{1 . 0 0}$ & $\mathbf{3 . 1 6} \pm \mathbf{0 . 2 0}$ & $\mathbf{2 . 1 2} \pm \mathbf{0 . 4 5}$ & $\mathbf{1 . 4 9}$ & --- \\
\hline
\end{tabular}

Data are presented as mean \pm S.D from six monolayers. Involvement of a P-gp mediated efflux mechanism is suggested if the efflux ratio (B-A/A-B) is greater than 1.5.

Although elacridar at $0.25 \mu \mathrm{M}$ and tariquidar at $0.5 \mu \mathrm{M}$ did not shown full P-gp inhibitory activity, we supposed that their reversal could be easily achieved. Thus, elacridar at 0.25 and 
$0.5 \mu \mathrm{M}$ and tariquidar at 0.5 and $1.0 \mu \mathrm{M}$ were chosen to assess the reversal of the P-gp inhibitory activity within 48 hours and after contact with the colloidal particulates.

\subsubsection{Time-dependent reversal of the P-gp inhibitory activity of elacridar and tariquidar}

This set of experiments examined whether the effects of elacridar and tariquidar in Caco-2 cells are reversed within 48 hours (Appendix 4). As seen in figure 1, approximately $50 \%$ of the total P-gp efflux function was restored between 2 and 6 hours after treatment with elacridar at 0.25 or $0.50 \mu \mathrm{M}$. These monolayers recovered $97.2 \pm 4.4 \%$ and $97.3 \pm 4.0 \%$ of the P-gp efflux function 24 and 48 hours after treatment with elacridar 0.25 and $0.5 \mu \mathrm{M}$, respectively. Figure 2 shows the reversal of tariquidar 0.5 and $1.0 \mu \mathrm{M}$. Approximately $50 \%$ of P-gp efflux activity was restored between 2 and 6 hours after treatment with tariquidar $0.5 \mu \mathrm{M}$ and between 10 and 24 hours after treatment with tariquidar $1.0 \mu \mathrm{M}$. P-gp recovered $99.0 \pm$ $2.9 \%$ and $97.8 \pm 3.9 \%$ of its activity only after 48 hours of treatment with tariquidar 0.5 and $1.0 \mu \mathrm{M}$, respectively. These results suggest that while elacridar at a concentration of $0.5 \mu \mathrm{M}$ efficiently impedes the P-gp mediated efflux of rhodamine 123, tariquidar at the same concentration acts as a weak P-gp inhibitor. Nevertheless, after 6 hours, both P-gp inhibitors at the same concentration of $0.5 \mu \mathrm{M}$ displayed the same reversal pattern.

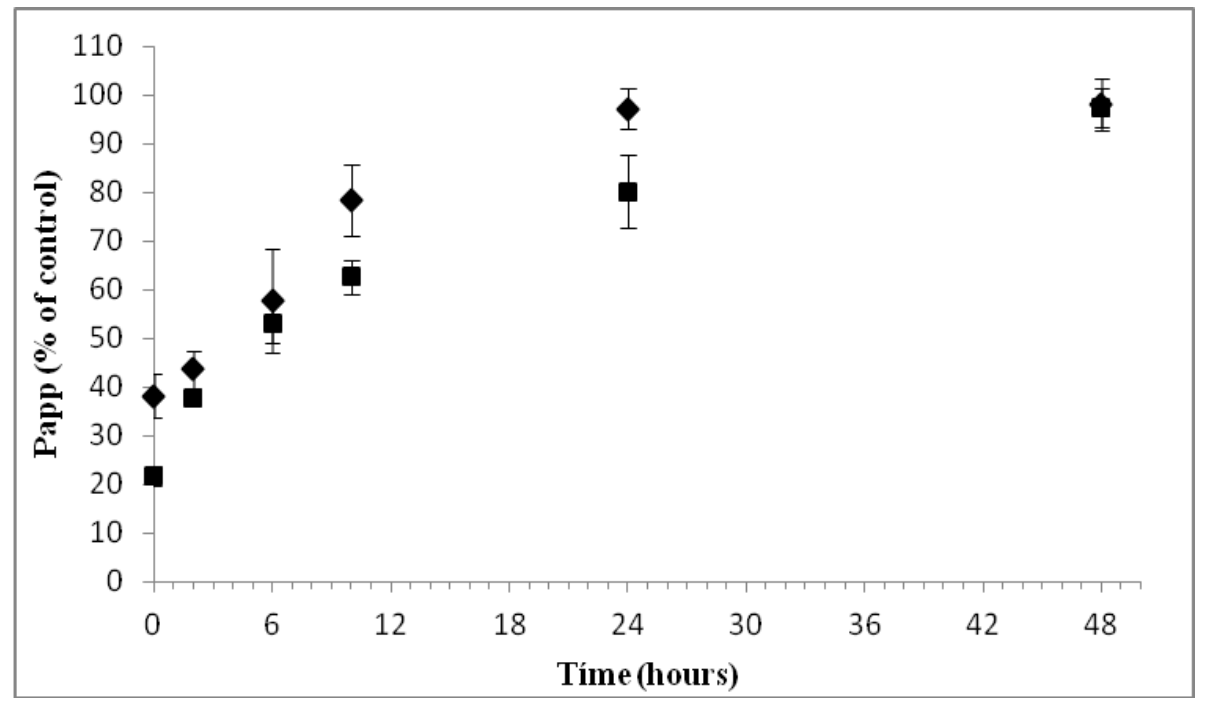

Figure 1. Apparent permeability of rhodamine 123 (mean \pm S.D) - time profiles after pre-treatment of Caco-2 monolayers with elacridar at $0.25 \mu \mathrm{M}$ (rhombus) and $0.50 \mu \mathrm{M}$ (square). Bars represent the S.D. $\mathrm{n}=6$. 


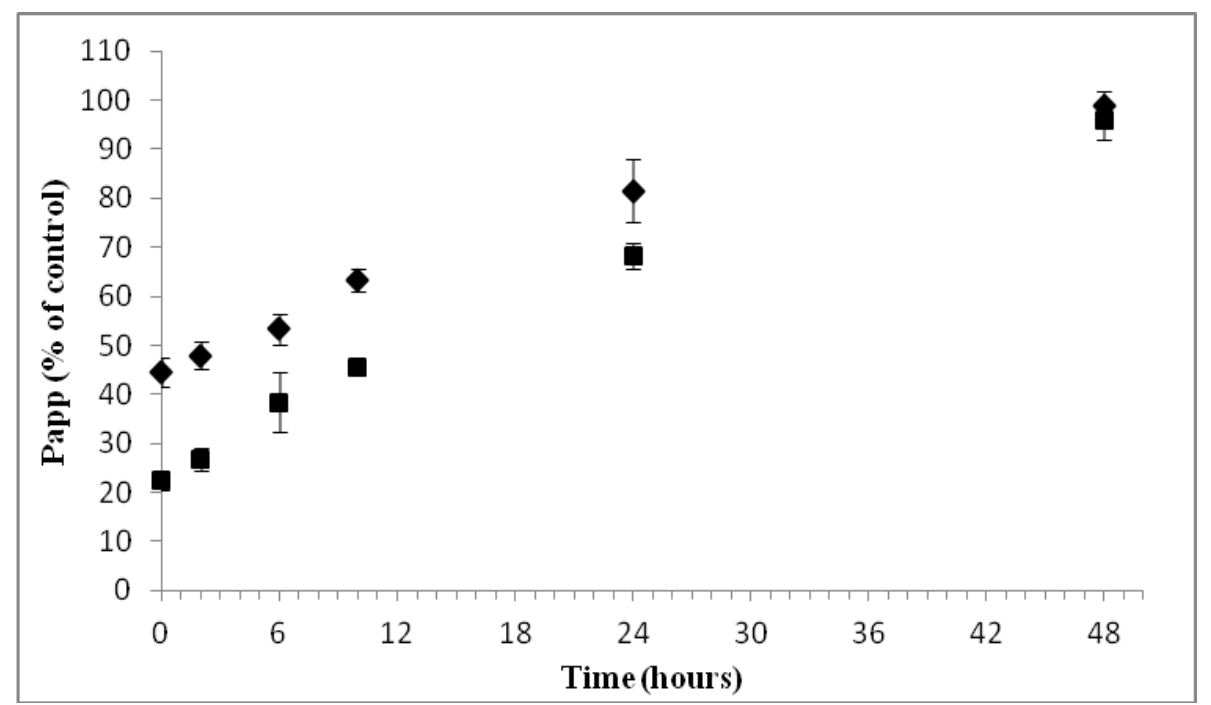

Figure 2: Apparent permeability of rhodamine 123 (mean \pm S.D) - time profiles after pre-treatment of Caco-2 monolayers with tariquidar at $0.50 \mu \mathrm{M}$ (rhombus) and $1.00 \mu \mathrm{M}$ (square). Bars represent the S.D. $\mathrm{n}=6$.

Given the prolonged and late reversal of the P-gp inhibitory activity caused by elacridar and tariquidar, sequestration of both P-gp inhibitors using colloidal particulates was studied immediately after the treatment with both P-gp inhibitors.

\subsubsection{Effect of nanocarriers on P-glycoprotein inhibitory activity of elacridar and tariquidar}

In this stage, we tested the effects of three nanocarriers (Table 2) on the P-gp inhibitory activity of elacridar and tariquidar.

Table 2: Composition and size of the colloidal particulates systems

\begin{tabular}{ccc}
\hline Formulation & Composition & $\begin{array}{c}\text { Mean particle } \\
\text { diameter (nm) }\end{array}$ \\
\hline DMPC:Chol-L & DMPC:Cholesterol (80:20 molar ratio) liposomes & $201 \pm 6.9$ \\
M-Ne & miglyol 812:soy lecithin:TB (1:1:40 \% w/w) nanoemulsion & $232 \pm 3.6$ \\
AT-Ne & $\alpha$-tocopherol:miglyol 812:soy lecithin:TB $(0.5: 1: 1: 40 \%$ w/w) nanoemulsion & $267 \pm 8.5$ \\
\hline
\end{tabular}

Data are presented as mean \pm S.D from three formulations.

After incubation with the corresponding nanocarriers, any significant change in the TEER values was observed, this confirms that these colloidal systems do not damage Caco-2 
monolayers. Figure 3 shows the impact of the three nanocarriers on the P-gp inhitory activity of elacridar, at 0.25 and $0.50 \mu \mathrm{M}$. According to the statistical test, the $\alpha$-tocopherol nanoemulsion significantly increased the P-gp mediated efflux of monolayers pre-treated with elacridar $0.25 \mu \mathrm{M}$. In other words, the total P-gp efflux function increased from $43.62 \pm 3.18$ to $58.99 \pm 3.15 \%$. However, this reversal effect cannot be validated. First, because at this concentration of elacridar, rhodamine 123 still undergoes P-gp efflux and second, because the $\alpha$-tocopherol nanoemulsion failed in reverse the P-gp inhibitory activity of elacridar $0.50 \mu \mathrm{M}$. Unfortunately, none of the other nanocarriers were able to impair the P-gp inhibitory activity of elacridar 0.25 and $0.5 \mu \mathrm{M}$ (Appendix 5).

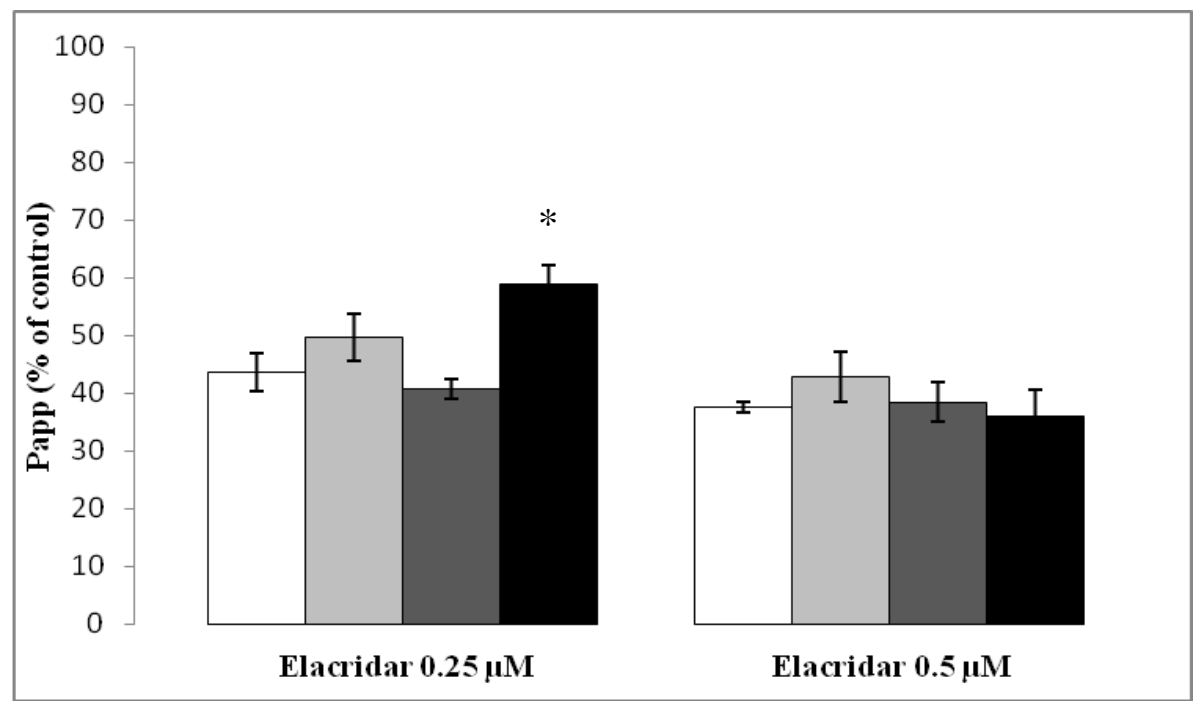

Figure 3: Apparent permeability of rhodamine 123 (mean \pm S.D) after pre-treatment of Caco-2 monolayers with elacridar at $0.25 \mu \mathrm{M}$ or $0.50 \mu \mathrm{M}$ followed by transport buffer (white), DMPC:Chol-L (light gray), M-Ne (dark gray) and AT-Ne (black). Bars represent the S.D. $n=6$.

*Significantly different compared to the $\mathrm{P}_{\text {app }}$ of Caco-2 monolayers treated with elacridar for 30 minutes and blank buffer for two hours.

Figure 4 depicts the effects of DMPC:Chol liposomes, M-Ne and AT-Ne formulations on the P-gp inhibitory activity tariquidar 0.5 and $1.0 \mu \mathrm{M}$. Among the nanocarriers, it was the liposomal formulation, which was able to partially impair the P-gp inhibitory activity of tariquidar $0.5 \mu \mathrm{M}$ increasing the P-gp efflux function from $47.93 \pm 2.32 \%$ to $72.27 \pm 3.69 \%$. The reversal ability of this formulation was certified when monolayers were also pre-treated with tariquidar $1.0 \mu \mathrm{M}$. In this case, the P-gp mediated efflux increased from $26.77 \pm 1.90 \%$ to $51.15 \pm 4.49 \%$. The increase of $25 \%$ of the P-gp efflux function regardless the concentrations of tariquidar, 0.5 or $1.0 \mu \mathrm{M}$ suggest that the sequestration of tariquidar by the 
liposomal formulation reached its saturation plateau region. However, none of the other formulations succeeded in imparining the effects of tariquidar, whether at 0.5 or at $1.0 \mu \mathrm{M}$ (Appendix 5).

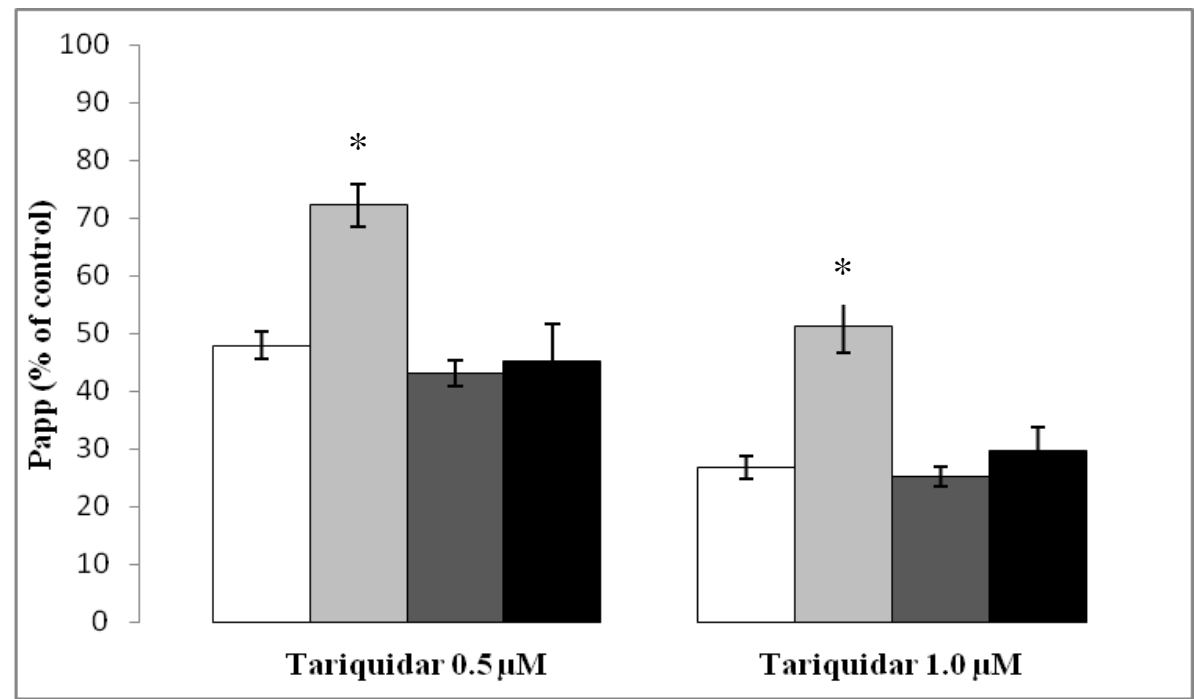

Figure 4: Apparent permeability of rhodamine 123 (mean \pm S.D) after pre-treatment of Caco-2 monolayers with tariquidar at $0.50 \mu \mathrm{M}$ or $1.00 \mu \mathrm{M}$ followed by transport buffer (white), DMPC:Chol-L (light gray), M-Ne (dark gray) and AT-Ne (black). Bars represent the S.D. $n=6$.

*Significantly different compared to the $\mathrm{P}_{\text {app }}$ of Caco-2 monolayers treated with tariquidar for 30 minutes and blank buffer for two hours.

\subsection{Discussion}

Direct modulation of the P-gp-mediated efflux using potent P-gp inhibitors is a logical strategy to improve brain uptake of an unlimited number of P-gp substrates. Recent investigations suggest the use of high doses of P-gp modulators, namely elacridar and tariquidar, to efficiently overcome the P-gp efflux at the BBB $[4,15]$. However, we cannot sidestep that these large doses could result in a long-lasting P-gp inhibition with subsequent toxic or even lethal outcomes. Hence, it would be prudent to set a strategy to rapidly treat overdoses with the aforementioned P-gp inhibitors. The detoxification strategy studied herein is based on the premise that sequestration of elacridar or tariquidar by empty nanocarriers would serve to re-induce the P-gp-mediated efflux in a Caco- 2 cell model. 
The validation studies carried out to confirm the functionality of the in vitro model, indicated that the typical P-gp substrate rhodamine 123 [16], crosses the Caco-2 cell layer with an efflux ratio of 9.44. Since for the Caco-2 monolayer an ER higher than 1.5 suggests the contribution of P-gp mediated efflux, this data confirmed the suitability of the selected experimental conditions for later transport studies. Both P-gp modulators impeded the secretion of rhodamine 123 in a concentration-dependent manner but consistent with previously reported in vitro [17] and in vivo [18] studies, this experiments also reflects the higher potency of elacridar over tariquidar. While elacridar at $0.5 \mu \mathrm{M}$ inhibited the P-gpmediated efflux, tariquidar did it at $1.0 \mu \mathrm{M}$. More importantly, the recovery of the P-gpmediated efflux by the monolayers reached approximately $100 \%$ only 48 hours after treatment with elacridar $0.5 \mu \mathrm{M}$ or tariquidar $1.0 \mu \mathrm{M}$. Because of the late reversal of the P-gp inhibitory activity caused by elacridar and tariquidar, the effects of nanocarriers were studied immediately after the treatment with both P-gp inhibitors.

Unfortunately, in our study both nanoemulsions containing or not $\alpha$-tocopherol were unable to reverse the P-gp inhibitory activity of elacridar and tariquidar. Previously, through a P-gp over-expressing MDR cell line, H69/LX4, $\alpha$-tocopherol displayed its capability to antagonize not only elacridar but also cyclosporine A and verapamil [10]. The authors suggested that $\alpha-$ tocopherol prevented the increase in the membrane fluidity, which is associated to P-gp inhibition. As our $\alpha$-tocopherol nanoemulsion did not yield the same results, absence of full interactions between $\alpha$-tocopherol and the cell membrane could be supposed. In other words, $\alpha$-tocopherol could have presented a major affinity for the surfactant than for elacridar or tariquidar. Additionally, elacridar and tariquidar may have presented difficulties to partition to the droplets of the two "oil-in-water" nanoemulsions.

In contrast, an increase of $25 \%$ of the P-gp efflux function was achieved with DMPC:Chol liposomes, regardless the concentrations of tariquidar, 0.5 or $1.0 \mu \mathrm{M}$. This indicates that the sequestration of tariquidar by the liposomal formulation might reach its saturation plateau region. Over the last years, several observations have highlighted the role of cholesterol on the P-gp activity. Most of the studies reported that P-gp ATP-ase activity and the efflux transport were inhibited by the absence of cholesterol after its depletion or removal from the bilayer membrane and the repletion or addition of cholesterol could stimulate the aforementioned activities [19]. Due to the similarity between the liposomal membrane and the cell membrane, a direct exchange of lipid components is possible between both of them [20]. Then, the transfer of cholesterol from the DMPC:Chol liposomes to the micro-domains where P-gp is located [21] could trigger or re-activate the ATP-ase activity and the consequent 
efflux transport of P-gp substrates. This hypothesis involves the inhibition of the ATP-ase activity by tariquidar which was previously demonstrated by Martin et al [22].

The high lipophilicity of elacridar (clog $\mathrm{P}=5.6$ ) and tariquidar (clog $\mathrm{P}=6.1)$ [23] predestine their mobility within one lipid bilayer and their transfer between biological interfaces and liposomal membranes. It was previously stated that lipophilic drugs, which do not have membrane lipid-like structures are not subject to flip-flop [24]. In contrast, once they are dissolved in the lipid domain of the membrane, they leave the membrane to the aqueous phase (energetic process), where they associate to the acceptor membrane [24]. Applied to our case, this diffusion/partition mechanism suggests that tariquidar was inserted only in the outer leaflet of the plasma membrane. Then it was able to migrate from the surroundings of the micro-domains where P-gp is located [21] to the liposomal membrane. At the same time this hypothesis indicates that elacridar was fully buried into the bilayer, from where was harder to migrate to the liposomal membrane. If this were the right mechanism, the tariquidar uptake efficiency could be further improved by increasing the contact with the acceptor membrane (number of particles per unit volume). Assay conditions like the influence of the liposomal phospholipid concentration and cholesterol concentration should be also investigated.

It is evident that much remains to be studied and clarified in order to use nanocarriers, specifically liposomes, as bio-detoxifying agents in case of P-gp inhibitors overdoses. Nevertheless, the potential of liposomes as reservoirs agents has been widely demonstrated with the sequestration of paraoxon, ${ }^{236} \mathrm{Pu}$-phytate, amitriptyline and haloperidol through enzymatic degradation, chelation, partition/electrostatic interactions and $\mathrm{pH}$ gradients [7]. This last active liposomal loading, where the vesicles with an acidic internal compartment possess ion-trapping properties, is usually suggested for the encapsulation of lipophilic weak bases such as elacridar and tariquidar [25].

The ultimate goal for most detoxifying nanocarriers is drug redistribution. In this light, liposomes must be tailored to maximize the P-gp inhibitor-liposomes association so that unbound drug molecules in the bloodstream will be sequestered upon intravenous dosing. This sequestration then triggers drug molecules in vital organs as the brain to relocate in the blood compartment. For this, the liposomal half-life is paramount to ensure their stay in the bloodstream long enough for the P-gp modulator to be extracted sufficiently from peripheral tissues. Grafting polymers such as DSPE- $\mathrm{PEG}_{2000}-\mathrm{OCH}_{3}$ may shield protein binding onto the liposomal surface and delay opsonization at least 15 hours [26]. These combined characteristics could made liposomes a promising approach in the treatment of P-gp inhibitors 
overdoses. Moreover, the efficacy and safety of the optimal liposomal formulation should be assessed in vitro and in vivo.

\subsection{Conclusions}

In this study, we used nanotechnology for the extraction of tariquidar and elacridar in a Caco2 cell model. A liposomal formulation and two nanoemulsions were tested as bio-detoxifying agents of both P-gp inhibitors. Among the three colloidal particulates, only liposomes composed of DMPC and cholesterol partially impaired the inhibitory activity of tariquidar. Although the mechanism underlying these results is still uncertain, further works aim to optimize the characteristics of liposomes to improve their performance as sequestering agent of tariquidar and elacridar. 


\section{REFERENCES}

[1] R.L. Juliano, V. Ling, A surface glycoprotein modulating drug permeability in Chinese hamster ovary cell mutants, Biochim Biophys Acta, 455 (1976) 152-162.

[2] A.H. Schinkel, P-Glycoprotein, a gatekeeper in the blood-brain barrier, Adv Drug Deliv Rev, 36 (1999) 179-194.

[3] K.W. Ward, L.M. Azzarano, Preclinical pharmacokinetic properties of the P-glycoprotein inhibitor GF120918A (HCl salt of GF120918, 9,10-dihydro-5-methoxy-9-oxo-N-[4-[2(1,2,3,4-tetrahydro-6,7-dimethoxy-2-isoquino linyl)ethyl]phenyl]-4-acridine-carboxamide) in the mouse, rat, dog, and monkey, J Pharmacol Exp Ther, 310 (2004) 703-709.

[4] M. Bauer, M. Zeitlinger, D. Todorut, M. Bohmdorfer, M. Muller, O. Langer, W. Jager, Pharmacokinetics of single ascending doses of the P-glycoprotein inhibitor tariquidar in healthy subjects, Pharmacology, 91 (2012) 12-19.

[5] R.W. Johnstone, A.A. Ruefli, M.J. Smyth, Multiple physiological functions for multidrug transporter P-glycoprotein?, Trends Biochem Sci, 25 (2000) 1-6.

[6] S.F. Zhou, Structure, function and regulation of P-glycoprotein and its clinical relevance in drug disposition, Xenobiotica, 38 (2008) 802-832.

[7] J.C. Leroux, Injectable nanocarriers for biodetoxification, Nat Nanotechnol, 2 (2007) 679684.

[8] L.M. Graham, T.M. Nguyen, S.B. Lee, Nanodetoxification: emerging role of nanomaterials in drug intoxication treatment, Nanomedicine (Lond), 6 (2012) 921-928.

[9] M. Varshney, T.E. Morey, D.O. Shah, J.A. Flint, B.M. Moudgil, C.N. Seubert, D.M. Dennis, Pluronic microemulsions as nanoreservoirs for extraction of bupivacaine from normal saline, J Am Chem Soc, 126 (2004) 5108-5112.

[10] C.E. Van Rensburg, G. Joone, R. Anderson, Alpha-tocopherol antagonizes the multidrug-resistance-reversal activity of cyclosporin A, verapamil, GF120918, clofazimine and B669, Cancer Lett, 127 (1998) 107-112.

[11] G. Englund, F. Rorsman, A. Ronnblom, U. Karlbom, L. Lazorova, J. Grasjo, A. Kindmark, P. Artursson, Regional levels of drug transporters along the human intestinal tract: co-expression of ABC and SLC transporters and comparison with Caco-2 cells, Eur J Pharm Sci, 29 (2006) 269-277.

[12] J. Taipalensuu, S. Tavelin, L. Lazorova, A.C. Svensson, P. Artursson, Exploring the quantitative relationship between the level of MDR1 transcript, protein and function using digoxin as a marker of MDR1-dependent drug efflux activity, Eur J Pharm Sci, 21 (2004) 6975 . 
[13] M.D. Troutman, D.R. Thakker, Efflux ratio cannot assess P-glycoprotein-mediated attenuation of absorptive transport: asymmetric effect of P-glycoprotein on absorptive and secretory transport across Caco-2 cell monolayers, Pharm Res, 20 (2003) 1200-1209.

[14] J.W. Polli, J.L. Jarrett, S.D. Studenberg, J.E. Humphreys, S.W. Dennis, K.R. Brouwer, J.L. Woolley, Role of P-glycoprotein on the CNS disposition of amprenavir (141W94), an HIV protease inhibitor, Pharm Res, 16 (1999) 1206-1212.

[15] E.F. Choo, D. Kurnik, M. Muszkat, T. Ohkubo, S.D. Shay, J.N. Higginbotham, H. Glaeser, R.B. Kim, A.J. Wood, G.R. Wilkinson, Differential in vivo sensitivity to inhibition of P-glycoprotein located in lymphocytes, testes, and the blood-brain barrier, J Pharmacol Exp Ther, 317 (2006) 1012-1018.

[16] R. Yumoto, T. Murakami, Y. Nakamoto, R. Hasegawa, J. Nagai, M. Takano, Transport of rhodamine 123, a P-glycoprotein substrate, across rat intestine and Caco-2 cell monolayers in the presence of cytochrome P-450 3A-related compounds, J Pharmacol Exp Ther, 289 (1999) 149-155.

[17] M. Hubensack, C. Muller, P. Hocherl, S. Fellner, T. Spruss, G. Bernhardt, A. Buschauer, Effect of the ABCB1 modulators elacridar and tariquidar on the distribution of paclitaxel in nude mice, J Cancer Res Clin Oncol, 134 (2008) 597-607.

[18] J.P. Bankstahl, C. Kuntner, A. Abrahim, R. Karch, J. Stanek, T. Wanek, W. Wadsak, K. Kletter, M. Muller, W. Loscher, O. Langer, Tariquidar-induced P-glycoprotein inhibition at the rat blood-brain barrier studied with (R)-11C-verapamil and PET, J Nucl Med, 49 (2008) 1328-1335.

[19] K. Bucher, S. Belli, H. Wunderli-Allenspach, S.D. Kramer, P-glycoprotein in proteoliposomes with low residual detergent: the effects of cholesterol, Pharm Res, 24 (2007) 1993-2004.

[20] V.P. Torchilin, Recent advances with liposomes as pharmaceutical carriers, Nat Rev Drug Discov, 4 (2005) 145-160.

[21] G. Radeva, J. Perabo, F.J. Sharom, P-Glycoprotein is localized in intermediate-density membrane microdomains distinct from classical lipid rafts and caveolar domains, Febs J, 272 (2005) 4924-4937.

[22] C. Martin, G. Berridge, P. Mistry, C. Higgins, P. Charlton, R. Callaghan, The molecular interaction of the high affinity reversal agent XR9576 with P-glycoprotein, Br J Pharmacol, 128 (1999) 403-411.

[23] J.P. Bankstahl, M. Bankstahl, K. Romermann, T. Wanek, J. Stanek, A.D. Windhorst, M. Fedrowitz, T. Erker, M. Muller, W. Loscher, O. Langer, C. Kuntner, Tariquidar and elacridar are dose-dependently transported by P-glycoprotein and Bcrp at the blood-brain barrier: a small-animal positron emission tomography and in vitro study, Drug Metab Dispos, 41 (2013) 754-762. 
[24] A. Fahr, P. van Hoogevest, S. May, N. Bergstrand, S.L. ML, Transfer of lipophilic drugs between liposomal membranes and biological interfaces: consequences for drug delivery, Eur J Pharm Sci, 26 (2005) 251-265.

[25] P. Kannan, K.R. Brimacombe, W.C. Kreisl, J.S. Liow, S.S. Zoghbi, S. Telu, Y. Zhang, V.W. Pike, C. Halldin, M.M. Gottesman, R.B. Innis, M.D. Hall, Lysosomal trapping of a radiolabeled substrate of P-glycoprotein as a mechanism for signal amplification in PET, Proc Natl Acad Sci U S A, 108 (2011) 2593-2598.

[26] N. Bertrand, C. Bouvet, P. Moreau, J.C. Leroux, Transmembrane pH-gradient liposomes to treat cardiovascular drug intoxication, ACS Nano, 4 (2010) 7552-7558. 


\section{GENERAL DISCUSSION AND PERSPECTIVES}

Up-to-date, the extensive research based on P-gp, an essential component of the BBB, has led us to see this efflux transporter from two different standpoints. From a physiological view, Pgp protects the brain from intoxication by endogenous and exogenous harmful lipophilic compounds that otherwise could penetrate the BBB by simple diffusion without any limitation [1]. From a therapeutic view, P-gp limits the penetration of several potent drugs into the CNS, leading to failure therapies which include HIV protease inhibitors, opioids, antiepileptics, antidepressant, antipsychotics and anticancer drugs [2]. Hence, modulation of P-gp represents an interesting approach to enhance the brain uptake of a wide variety of drugs. Nevertheless, any modulation of the efflux transporter has to consider the potential neurotoxicity of such modulation. The ideal approach should inhibit the P-gp at the BBB to let the P-gp substrate (therapeutic compound) enter into the brain and then re-induce the P-gp-mediated efflux to hamper the entry of harmful compounds. However, in spite of the countless studies the effective inhibition of the P-gp at the human BBB is not yet a reality.

One of the main non-invasive strategies that have been attempted to tackle the P-gp-mediated efflux involves the use of chemical entities so-called P-gp modulators. These agents are able to transiently and directly inhibit the P-gp-mediated efflux [3]. Elacridar and tariquidar, thirdgeneration P-gp modulators, significantly increased the brain distribution of several P-gp substrates [4-6]. However, the high plasma protein binding of elacridar [7], suggest the use of high doses of the P-gp modulator to saturate the active efflux of P-gp at the BBB [8]. Unfortunately, at high doses, elacridar increased the concentrations of P-gp substrates such as nelfinavir in the brain but also in the liver [9]. In the meantime, tariquidar failed to produce significant central nervous effects caused by loperamide in healthy patients [10]. This finding prompted the assessment of the pharmacokinetics, tolerability and safety of single ascending doses of tariquidar in healthy subjects [11].

"The dose makes the poison". The contemporary and famous interpretation of Paracelsus, is that dose and effect move together in a predictably linear fashion [12]. Otherwise stated, these high doses of P-gp modulators by themselves or in co-administration with P-gp substrates may predict toxic profiles, thus limiting the use of these agents. The current dilemma is then: How do we improve the usage of these compounds? Or do we continue looking for the ideal P-gp modulator? Various studies propose the use of natural products, the designs of peptidomimetics and dual activity ligands as a fourth-generation of P-gp modulators [13]. In 
contrast, we aimed to introduce a different strategy to efficiently modulate the P-gp-mediated efflux at the BBB using elacridar and tariquidar but avoiding toxic profiles caused by high doses of these agents. For this purpose we took advantage of the possible in vivo intravenous co-administration of low but therapeutic doses of elacridar and tariquidar, under their free form or co-encapsulated in liposomes. The brain distribution of free loperamide was determined as an in vivo probe of full inhibition of the P-gp activity at the BBB.

To assess the in vivo pharmacokinetic interactions and biodistribution after concurrent administration of loperamide and elacridar and/or tariquidar, a specific and sensitive analytical procedure for the simultaneous determination of the three molecules was required. However, the extensive literature survey revealed a lack of methods for the simultaneous estimation of these three compounds. In this light, we developed and validated (FDA guidance for bioanalytical method validation [14]) an LC-MS method for the simultaneous quantitation of the three agents in rat plasma, brain, liver and kidneys. Then, we undertook the evaluation of the concomitant administration of both P-gp modulators and its effects on loperamide in a rat model.

The first obstacle in this part of the project was the limited solubility of both P-gp modulators and loperamide in the reported vehicles for IV administration of these compounds. This poor solubility could originate the presence of free particles, which precipitate in the site of administration and cause embolization and a trivial exposure to the therapeutic agents [15]. In other words, the vehicle selection could strongly influence the pharmacokinetics, biodistribution and pharmacodynamics in vivo studies. For instance, reported vehicles containing saline [5], dextrose and/or ethanol [4] led to the precipitation of both P-gp modulators in our pilot study (Appendix 2). In the same way, a reported mixture of saline and $0.2 \mathrm{M}$ equivalents of $\mathrm{HCl}$ to solubilize loperamide [16], resulted in negligible plasma concentrations (less than $1.0 \% / \mathrm{mL}$ of the IV dose of loperamide) at 5 minutes post-dosing [16]. This could be explained by the precipitation of loperamide in the vehicle as observed in our pilot study (Appendix 1). Moreover, the low $\mathrm{pH}$ (1.4) of this mixture for injectable volumes was considered aggressive to the vein and the surroundings structures and a source of subsequent changes in the loperamide plasma concentrations. To optimize the in vivo exposure to both P-gp modulators and loperamide and to ensure the dose delivery minimizing erroneous results, various vehicles were tested in this study. Among them, tetraglycol yielded a total transparent and yellow solution of elacridar, which did not precipitate even after six 
months. Loperamide and tariquidar were well dissolved separately in a mixture of saline and PEG $_{600}$ (3:1). Subsequent dilutions of both P-gp modulators and loperamide in the mixture of saline and PEG $_{600}$ (3:1) were completely transparent indicating full solubility for an appropriate IV administration. Like this, in our study about $4.0 \% / \mathrm{mL}$ of the IV dose of loperamide was attained at one hour post-dosing. It means that the exposure to loperamide solubilized in a mixture of saline and $\mathrm{PEG}_{600}$ (3:1) was significantly higher than that observed with a mixture of saline and $0.2 \mathrm{M}$ equivalents of $\mathrm{HCl}$ (less than $1.0 \% / \mathrm{mL}$ of the IV dose of loperamide at 5 minutes post-dosing) [16]. Moreover, the updated literature does not mention the modulation of the P-gp-mediated efflux by tetraglycol or $\mathrm{PEG}_{600}$.

The administration of loperamide alone resulted in very low levels $(10.53 \pm 0.51 \mathrm{ng} / \mathrm{g})$ in the brain at one hour post-dosing. However, the co-administration of the P-gp modulators significantly increased the concentration of loperamide in the brain at the same time point. Tariquidar and elacridar, each at $1.0 \mathrm{mg} / \mathrm{kg}$ increased loperamide levels in the brain by 2 $(22.48 \pm 2.93 \mathrm{ng} / \mathrm{g})$ and 3 -fold $(33.84 \pm 3.95 \mathrm{ng} / \mathrm{g})$, respectively. More importantly, the concurrent administration of elacridar plus tariquidar, each at $0.5 \mathrm{mg} / \mathrm{kg}$ increased the brain concentrations of loperamide by 5 -fold $(47.26 \pm 6.09 \mathrm{ng} / \mathrm{g})$. In contrast, the pharmacokinetic parameters of loperamide in the P-gp modulators-treated groups remained unchanged in comparison to the group which received no P-gp modulator. These findings are consistent with the minimal modulation of the cytochrome P4503A4 by elacridar and tariquidar by separate or co-administered [4]. Therefore, the increase of loperamide levels in the brain could not be explained by a modest increase of loperamide in plasma. Instead, it was likely due to the efficient modulation of the P-gp at the BBB by tariquidar and elacridar. The brain uptake of P-gp modulators and loperamide suggest a greater inhibition of the P-gp-mediated efflux by elacridar than by tariquidar and a possible synergistic effect of both P-gp modulators when they are co-administered. The most suitable explanation for this synergistic phenomenon is that the low doses of elacridar may inhibit the P-gp and BCRP transport of tariquidar at the BBB thereby improving its accessibility to the P-gp. Then, the simultaneous binding of tariquidar (on site II, a transport and regulatory site) and elacridar (on site IV, an exclusive regulatory site) [17], significantly hampered the P-gp-mediated efflux of loperamide. To our knowledge, this is the first study demonstrating synergistic modulation of the P-gp-mediated efflux using third-generation P-gp modulators. However, this type of drugdrug phenomenon was previously described using first-generation P-gp modulators [18]. In those studies, cylosporin A and verapamil showed significant synergism in modulating the P- 
gp mediated efflux of a series of P-gp substrates in human acute lymphocytic leukemia cells (CCRF-CEM) [18-20]. Although the mechanisms underlying these observations were not explained by the authors, later it was found that cyclosporine A and verapamil bind different P-gp binding sites [21]. Moreover, in vitro studies demonstrated that progesterone and verapamil are synergistic non-exclusive inhibitors of the ATP-ase activity which is coupled to the P-gp-mediated transport [22]. It is clear that the non-P-gp inhibiting effects of these firstgeneration P-gp modulators made them obsolete but their aforementioned interactions with Pgp emphasize the non-competitive modulation of the P-gp-mediated efflux observed in this work.

The dose-limiting opioid effects of loperamide preclude assessing this strategy with higher doses of loperamide co-administered with higher doses of elacridar plus tariquidar. Future studies may overcome this problem by using radiolabelled [3H or14C] loperamide. In this context, many other P-gp substrates with different therapeutic effects and several doses of elacridar and tariquidar remain to be explored to define the synergistic interaction between both P-gp modulators. Other P-gp modulators can also be used for these studies, provided that the steric hindrance of one does not affect the binding of the other.

The opioid-like clinical signs indicate an important and extremely rapid distribution of the Pgp modulators in the brain and an immediate modulation of the P-gp at the BBB. In this sense, the co-administration of high doses of potent CNS drugs as loperamide (as in our pilot study, data not shown) and other P-gp substrates with narrow therapeutic windows could result in CNS toxic profiles with lethal results. This issue opens two avenues: The first requires the reduction of the P-gp substrate dose, which potentially compromises the therapy via the reduced brain accumulation of the P-gp substrate. The second implies the reduction of the Pgp modulators dose. Since the brain distribution and the permanence of both P-gp modulators are dose-dependent [23], a reduction of their doses may increase their transport by the P-gp and BCRP at the BBB [23] leading them to the loss of their P-gp inhibitory activity. Thus, any of these two avenues fit the purpose. A suitable strategy would involve the maximizing Pgp inhibitory activity of the low doses of P-gp modulators through their controllable delivery across the $\mathrm{BBB}$. These low doses should arrive to the P-gp at the BBB when the concentration of the P-gp substrate at the BBB is high enough to produce a therapeutic effect but not toxic profiles. To avoid another layer of complexity in this approach, the pharmacokinetics of the P-gp substrates should not be altered. 
In this light, we aimed to develop a nanocarrier to timely increase the delivery of elacridar and tariquidar across the BBB. The challenge was then the formulation of liposomes which have the right size and structure to entrap elacridar and tariquidar with high efficiency and in such a way that they do not leak out. On the other hand, it was important to play on the fluidity of the liposomal membrane. A too high liposomal stability is rather disadvantageous than desired. Remaining inside of stable liposomes, encapsulated drugs are not delivered to the targeted tissue. At that point, it was necessary to find the right balance between stability in the bloodstream and a high delivery of both P-gp modulators across the BBB, which must be synchronized with the therapeutic concentrations of the P-gp substrate. In order to choose the formulation that fits better the aforementioned properties for further development of OX26 $\mathrm{F}(\mathrm{ab})_{2}$ immunoliposomes, three types of liposomes co-loaded with elacridar and tariquidar were prepared: Conventional, PEGylated with DSPE-PEG ${ }_{2000}-\mathrm{COOH}$ and PEGylated with DSPE-PEG $2000-\mathrm{OCH}_{3}$ liposomes. For all liposomal formulations, DMPC was used as the main frame based on its rapid drug diffusion due to its transition temperature $\left(23.9^{\circ} \mathrm{C}\right)[24]$ and its high elacridar and tariquidar loading compared to EPC, DPPC or DSPC (Appendix 3).

The rapid absorption of plasma proteins onto the surface of conventional liposomes [25] led to their destabilization and the leakage of elacridar and tariquidar which was not enough to modulate the P-gp activity at the BBB. It was expected that in liposomes functionalized with DSPE-PEG $2000-\mathrm{COOH}$, the negative surface charge of the carboxylic acid could counterbalanced the long circulating properties conferred by PEG to facilitate an effective but short P-gp modulation. However, the rapid clearance and the lowest brain uptake of elacridar and tariquidar indicate that these negatively charged liposomes activated the complement system via the classical pathway [25] before than they could release both P-gp modulators. In contrast, functionalization of liposomes with DSPE- $\mathrm{PEG}_{2000}-\mathrm{OCH}_{3}$ significantly increased the plasma concentrations of elacridar and tariquidar as well as their brain distribution in comparison to the free form of both P-gp modulators. This is based on the ability of neutral PEG chains to avoid the adsorption of plasma proteins onto the liposomal surface [25], thus impeding their uptake by resident phagocytes in the liver and spleen. As a result of this sterically stabilization, 4.8- and 6.1-fold higher concentrations of elacridar and tariquidar, respectively were found in the brain at one hour compared to the concurrent administration of both free P-gp modulators. These results confirm recent studies where it was postulated that as PEG help to slow down the first-pass metabolism, it increases the chance of around $150 \mathrm{~nm}$ sized nanocarriers to deliver the encapsulated drug across the BBB [26]. The opioid-induced behavior in animals receiving these long-circulating liposomes suggests a release of both P-gp 
modulators at 30 minutes post-dosing, which was synchronized enough to increase 2.1-fold the brain uptake of loperamide.

Because the grafting of OX26 F(ab') 2 on conventional and PEGylated with DSPE-PEG $2000-$ $\mathrm{COOH}$ liposomes could accelerate and increase their RES uptake limiting their contact with the targeted tissue, immunoliposomal development was carried out using liposomes bearing DSPE- $\mathrm{PEG}_{2000}-\mathrm{OCH}_{3}$. The long residence of these liposomes in the vascular space and the delivery of both P-gp modulators across the BBB via the TfR may ensure effective doses of these compounds for a full blockage of the P-gp. As previously observed [27], the coupling of OX26 partially reversed the effect of neutral PEGylation, however the plasma levels of both immunoliposomal P-gp modulators were sufficient for contact with the targeted tissue. Data obtained with the immunoliposomes revealed that the release of elacridar and tariquidar also begun at 30 minutes post-dosing but the brain accumulation of both compounds at 1 hour were 2-fold higher as compared to long circulating liposomes. In other words, the prolonged systemic circulation due to PEG stabilization and the improved permeability due to OX26 $\mathrm{F}(\mathrm{ab})_{2}$ grafting led to the most efficient P-gp modulation at the BBB. This in turn, allowed the highest brain uptake of loperamide at one hour. Moreover, the total score for the clinical signs, indicated that the immunoliposomal-induced brain uptake of loperamide was not as abrupt as the one observed immediately after the administration of both free P-gp modulators. Such differences indicate that CNS acute toxicities associated with potent P-gp substrates could be avoided using this drug delivery system (DDS). Additionally, the lack of pharmacokinetic interactions between this DDS and the P-gp substrate used herein augur a promising use of these immunoliposomal P-gp modulators.

There is a clear consensus about the specificity and high brain uptake of OX26 MAb-, Fab'-, and $\mathrm{F}\left(\mathrm{ab}^{\prime}\right)_{2^{-}}$nanocarriers targeting cerebral tissues. The brain accumulation of immunonanocarriers is generally 2 -fold higher than the one achieved with long circulating nanocarriers (0.04 vs $0.02 \%$ of the IV dose/g) at one hour after administration [28]. Although our work showed that the brain uptake of immunoliposomal P-gp modulators was 2-fold higher than that of long circulating liposomes, the net brain uptake was 2.3 and $1.1 \%$ of the IV dose/g for immunoliposomal elacridar and tariquidar, respectively at one hour post-dosing. This indicate that a mechanism different to the transcytosis via the TfR came into play in our study. We could suppose the association of the antibody to the TfR, a diffusion of both P-gp modulators from the liposomes and the subsequent P-gp inhibiton with their extensive accumulation in the brain. This hypothesis does not dismiss but join the transcytosis mechanism. It means that each P-gp modulator could have been taken up via transcytosis. But 
at the same time, the high amounts of P-gp modulators in the bloodstream surrounding the BBB could have saturated the active efflux of the P-gp and acumulated in the brain. This is in agreement with the dose-dependent distribution observed for free elacridar [8] and free tariquidar [23].

In brief, the loading of elacridar and tariquidar in immunoliposomes could result in: (1) Their improved solubility. (2) Their prolonged vascular residence time through sterically stabilization. (3) Their adequate delivery to the BBB by conjugation of OX26 F(ab')2 fragments. (4) Their use at low but therapeutic doses and (5) the synergistic blockage of the Pgp to allow the brain uptake of any P-gp substrate which is intended to treat CNS diseases. However the aforementioned properties depend on the synchronizing therapeutic levels in the brain of both P-gp modulators and the P-gp substrate.

In our study the immunoliposomal-induced brain levels of loperamide at 6 hours were in the same range than those observed with free elacridar plus free tariquidar at one hour. This suggests possible CNS sub-acute toxic incidents caused by P-gp substrates owning a long residual therapeutic activity. Therefore future studies should focus on the latency and residual activity of the P-gp substrate co-administered with immunoliposomal elacridar and tariquidar. One avenue for P-gp substrates with long residual therapeutic activity would be the partial decrease of the vascular residence time of the immunoliposomes co-loaded with elacridar and tariquidar. This could be achieved functionalizing liposomes simultaneously with DSPE$\mathrm{PEG}_{2000}-\mathrm{OCH}_{3}$ and DSPE-PEG $2000-\mathrm{COOH}$ at an optimal ratio and coupling the antibody through DSPE-PEG5000-COOH. This approach could allow enough contact time between the BBB and the immunoliposomes to deliver both P-gp modulators but would shorten the liposomal half-life, avoiding thus a long exposure to elacridar and tariquidar. Nonetheless, our results suggest that liposomes bearing DSPE-PEG $2000-\mathrm{COOH}$ alter the pharmacokinetics of loperamide and perhaps that of other P-gp substrates. Hence, the encapsulation of the P-gp substrate in a similar DDS could avoid liposomes-drug pharmacokinetic interactions. Possible physico-chemically instabilities could be prevented using polymer, lipid, or polymer-lipid hybrid nanocarriers, depending on the hydrophobicity of the P-gp substrate. Previous reports described the ability of nanoparticles [16], polymersomes [29] and nanocapsules [28] bearing OX26 MAb or Fab' fragments to specifically target cerebral tissues. Then, the use of these nanocarriers co-loaded with elacridar plus tariquidar and the desired P-gp substrate could lead to improved therapeutic results provided that the delivery of the three agents is synchronized. This nanotechnology may be also modulated and adapted to target other receptors localized on the BBB such as the insulin receptor. Given that high doses of insulin are required to target 
the insulin receptor and that an overdose of insulin could cause hypoglycemia, some studies promote the use of the murine 83-14 monoclonal antibody to target the insulin receptor with successful results [30]. The low-density lipoprotein receptor (LDLR) [31] and the LDLRrelated protein (LRP) [32] at the $\mathrm{BBB}$ can bind multiple ligands. Among them, the apolipoprotein E covalently attached to loperamide-loaded nanoparticles significantly facilitated the transport of loperamide across the BBB via the LDLR and LRP [33].

Remaining to be improved, the decrease in the loading efficiency of both P-gp modulators during the immunoliposomal formulation suggested us that if these agents could pass the membrane and get outside of the liposomes, the same way back in was not hampered. Liposomes were then proposed as a tool to sequester both P-gp modulators in case of overdoses. Liposomes made of DMPC and cholesterol had no effect on the P-gp inhibitory activity of elacridar. In contrast, they were able to partially impair the P-gp inhibitory activity of tariquidar $1.0 \mu \mathrm{M}$ increasing the P-gp-mediated efflux of rhodamine 123 from $26.77 \pm 1.90$ $\%$ to $51.15 \pm 4.49 \%$ across a Caco- 2 cells model. The most plausible explanation for this transfer is that tariquidar was inserted only in the outer leaflet of the plasma membrane. Then it was able to migrate from the surroundings of the micro-domains where P-gp is located [34], to the liposomal membrane. In the meantime, this explanation suppose that elacridar was fully buried in the plasma membrane, from where was harder to migrate to the liposomal membrane. The use of liposomes as bio-detoxifying agents for elacridar and tariquidar is still beginning and has to be elaborated and optimized onward until it can be used for real cases. However, further studies should involve the influence of the liposomal composition. Since cholesterol has a tendency to stiffen the fatty acid chains in the liposomal membrane [35], an increase in the fluidity of the liposomal membrane by regulating the amount of cholesterol could result in a greater sequestration of tariquidar.

To be effective, the liposomes must remain in the bloodstream long enough to sequester the $\mathrm{P}$-gp modulator and the liposome-P-gp modulator complex must also remain stable until it is removed from the bloodstream. The most successful strategy to increase the liposomal halflife and stability is by surface modification of the liposomes. Grafting polymers such as DSPE-PEG $2000-\mathrm{OCH}_{3}$ may shield protein binding onto the liposomal surface and delay opsonization. Furthermore, it cannot be neglected that the ion-trapping properties of liposomes towards ionizable compounds (achieved with transmembrane $\mathrm{pH}$ gradients) could help to sequester weak bases such as tariquidar and elacridar [36]. This dual strategy, surface 
modification and transmembrane $\mathrm{pH}$ gradient, has been previously used to trap and limit the toxicity of drugs like doxorubicin [37] and diltiazem [38], which are weak bases.

Another alternative for the sequestration of tariquidar and elacridar involves the use of lipid nanocapsules. These nanocarriers consisting of an oil-filled core with a surrounding polymer (PEG) shell could lead to a significant sequestration of both P-gp modulators as observed with some other hydrophobic model drugs [39].

The small size and long residence time of lipoproteins in the bloodstream as well as their ability to transport lipids and hydrophobic molecules have promoted them as potential drug delivery systems [40]. The use of lipoproteins from species different to the human one could result in the trapping of the P-gp modulator, followed by activation of the RES and the elimination of the lipoprotein-P-gp modulator complex from the bloodstream.

In summary, this thesis proposes different approaches for full exploitation of two thirdgeneration P-gp modulators, elacridar and tariquidar. According to the findings described in this manuscript we conclude that: (1) The development of an LC-MS method for the simultaneous quantitation of loperamide, elacridar and tariquidar represents a helpful tool for in vivo pharmacokinetic and tissue distribution studies using these two P-gp modulators and loperamide, as P-gp substrate probe. (2) The co-administration of tariquidar and elacridar at low but therapeutic doses does not modify their plasma concentrations or those of the P-gp substrate but resulted in the greatest P-gp blockage at the BBB as a result of their noncompetitive modulatory activity. Because of the possible synergism between both P-gp modulators, low doses of these agents may improve the effectiveness of CNS pharmacotherapies without treatment-related side effects or toxicity. (3) The co-encapsulation of elacridar and tariquidar in targeted sterically stabilized immunoliposomes improves the half-lives and brain distribution of both compounds. Consequently, the brain uptake of the free P-gp substrate is significantly enhanced without any modification of its pharmacokinetics or tissue distribution. This formulation represents a step forward to modulate the P-gp at the BBB and allow the brain uptake of any P-gp substrate which is intended to treat CNS diseases and (4) The partial impairment of the P-gp inhibitory activity of tariquidar by liposomes, supports the use of this nanocarrier as a bio-detoxifying approach for the treatment of tariquidar overdoses. 


\section{References}

[1] R.W. Johnstone, A.A. Ruefli, M.J. Smyth, Multiple physiological functions for multidrug transporter P-glycoprotein?, Trends Biochem Sci, 25 (2000) 1-6.

[2] A.H. Schinkel, P-Glycoprotein, a gatekeeper in the blood-brain barrier, Adv Drug Deliv Rev, 36 (1999) 179-194.

[3] S. Fellner, B. Bauer, D.S. Miller, M. Schaffrik, M. Fankhanel, T. Spruss, G. Bernhardt, C. Graeff, L. Farber, H. Gschaidmeier, A. Buschauer, G. Fricker, Transport of paclitaxel (Taxol) across the blood-brain barrier in vitro and in vivo, J Clin Invest, 110 (2002) 1309-1318.

[4] E.F. Choo, D. Kurnik, M. Muszkat, T. Ohkubo, S.D. Shay, J.N. Higginbotham, H. Glaeser, R.B. Kim, A.J. Wood, G.R. Wilkinson, Differential in vivo sensitivity to inhibition of P-glycoprotein located in lymphocytes, testes, and the blood-brain barrier, J Pharmacol Exp Ther, 317 (2006) 1012-1018.

[5] M. Hubensack, C. Muller, P. Hocherl, S. Fellner, T. Spruss, G. Bernhardt, A. Buschauer, Effect of the ABCB1 modulators elacridar and tariquidar on the distribution of paclitaxel in nude mice, J Cancer Res Clin Oncol, 134 (2008) 597-607.

[6] C. Kuntner, J.P. Bankstahl, M. Bankstahl, J. Stanek, T. Wanek, G. Stundner, R. Karch, R. Brauner, M. Meier, X. Ding, M. Muller, W. Loscher, O. Langer, Dose-response assessment of tariquidar and elacridar and regional quantification of P-glycoprotein inhibition at the rat blood-brain barrier using (R)-[(11)C]verapamil PET, Eur J Nucl Med Mol Imaging, 37 (2010) 942-953.

[7] K.W. Ward, L.M. Azzarano, Preclinical pharmacokinetic properties of the P-glycoprotein inhibitor GF120918A (HCl salt of GF120918, 9,10-dihydro-5-methoxy-9-oxo-N-[4-[2(1,2,3,4-tetrahydro-6,7-dimethoxy-2-isoquino linyl)ethyl]phenyl]-4-acridine-carboxamide) in the mouse, rat, dog, and monkey, J Pharmacol Exp Ther, 310 (2004) 703-709.

[8] R. Sane, S. Agarwal, R.K. Mittapalli, W.F. Elmquist, Saturable active efflux by pglycoprotein and breast cancer resistance protein at the blood-brain barrier leads to nonlinear distribution of elacridar to the central nervous system, J Pharmacol Exp Ther, 345 (2013) 111 124.

[9] N.N. Salama, E.J. Kelly, T. Bui, R.J. Ho, The impact of pharmacologic and genetic knockout of P-glycoprotein on nelfinavir levels in the brain and other tissues in mice, J Pharm Sci, 94 (2005) 1216-1225.

[10] D. Kurnik, G.G. Sofowora, J.P. Donahue, U.B. Nair, G.R. Wilkinson, A.J. Wood, M. Muszkat, Tariquidar, a selective P-glycoprotein inhibitor, does not potentiate loperamide's opioid brain effects in humans despite full inhibition of lymphocyte P-glycoprotein, Anesthesiology, 109 (2008) 1092-1099. 
[11] M. Bauer, M. Zeitlinger, D. Todorut, M. Bohmdorfer, M. Muller, O. Langer, W. Jager, Pharmacokinetics of Single Ascending Doses of the P-Glycoprotein Inhibitor Tariquidar in Healthy Subjects, Pharmacology, 91 (2013) 12-19.

[12] D. Fagin, Toxicology: The learning curve, Nature, 490 (2012) 462-465.

[13] A. Palmeira, E. Sousa, M.H. Vasconcelos, M.M. Pinto, Three decades of P-gp inhibitors: skimming through several generations and scaffolds, Curr Med Chem, 19 (2012) 1946-2025.

[14] F.D.A.U.S.D.o.H.a.H. Services., Guidance for Industry: Bioanalytical Method Validation, (2001).

[15] P.V. Turner, C. Pekow, M.A. Vasbinder, T. Brabb, Administration of substances to laboratory animals: equipment considerations, vehicle selection, and solute preparation, J Am Assoc Lab Anim Sci, 50 (2011) 614-627.

[16] M.J. Zamek-Gliszczynski, D.W. Bedwell, J.Q. Bao, J.W. Higgins, Characterization of SAGE Mdr1a (P-gp), Bcrp, and Mrp2 knockout rats using loperamide, paclitaxel, sulfasalazine, and carboxydichlorofluorescein pharmacokinetics, Drug Metab Dispos, 40 (2012) 1825-1833.

[17] C. Martin, G. Berridge, C.F. Higgins, P. Mistry, P. Charlton, R. Callaghan, Communication between multiple drug binding sites on P-glycoprotein, Mol Pharmacol, 58 (2000) 624-632.

[18] X.F. Hu, T.J. Martin, D.R. Bell, M. de Luise, J.R. Zalcberg, Combined use of cyclosporin A and verapamil in modulating multidrug resistance in human leukemia cell lines, Cancer Res, 50 (1990) 2953-2957.

[19] Y. Ishida, Y. Shimada, M. Shimoyama, Synergistic effect of cyclosporin A and verapamil in overcoming vincristine resistance of multidrug-resistant cultured human leukemia cells, Jpn J Cancer Res, 81 (1990) 834-841.

[20] K. Osann, P. Sweet, L.M. Slater, Synergistic interaction of cyclosporin A and verapamil on vincristine and daunorubicin resistance in multidrug-resistant human leukemia cells in vitro, Cancer Chemother Pharmacol, 30 (1992) 152-154.

[21] J. Rautio, J.E. Humphreys, L.O. Webster, A. Balakrishnan, J.P. Keogh, J.R. Kunta, C.J. Serabjit-Singh, J.W. Polli, In vitro p-glycoprotein inhibition assays for assessment of clinical drug interaction potential of new drug candidates: a recommendation for probe substrates, Drug Metab Dispos, 34 (2006) 786-792.

[22] S. Orlowski, L.M. Mir, J. Belehradek, Jr., M. Garrigos, Effects of steroids and verapamil on P-glycoprotein ATPase activity: progesterone, desoxycorticosterone, corticosterone and verapamil are mutually non-exclusive modulators, Biochem J, 317 ( Pt 2) (1996) 515-522. 
[23] J.P. Bankstahl, M. Bankstahl, K. Romermann, T. Wanek, J. Stanek, A.D. Windhorst, M. Fedrowitz, T. Erker, M. Muller, W. Loscher, O. Langer, C. Kuntner, Tariquidar and elacridar are dose-dependently transported by P-glycoprotein and Bcrp at the blood-brain barrier: a small-animal positron emission tomography and in vitro study, Drug Metab Dispos, 41 (2013) 754-762.

[24] S. Mabrey, J.M. Sturtevant, Investigation of phase transitions of lipids and lipid mixtures by sensitivity differential scanning calorimetry, Proc Natl Acad Sci U S A, 73 (1976) 38623866.

[25] M.L. Immordino, F. Dosio, L. Cattel, Stealth liposomes: review of the basic science, rationale, and clinical applications, existing and potential, Int J Nanomedicine, 1 (2006) 297 315.

[26] Y.C. Chen, W.Y. Hsieh, W.F. Lee, D.T. Zeng, Effects of surface modification of PLGAPEG-PLGA nanoparticles on loperamide delivery efficiency across the blood-brain barrier, $\mathrm{J}$ Biomater Appl, 27 (2011) 909-922.

[27] A. Beduneau, P. Saulnier, F. Hindre, A. Clavreul, J.C. Leroux, J.P. Benoit, Design of targeted lipid nanocapsules by conjugation of whole antibodies and antibody Fab' fragments, Biomaterials, 28 (2007) 4978-4990.

[28] A. Beduneau, F. Hindre, A. Clavreul, J.C. Leroux, P. Saulnier, J.P. Benoit, Brain targeting using novel lipid nanovectors, J Control Release, 126 (2008) 44-49.

[29] Z. Pang, W. Lu, H. Gao, K. Hu, J. Chen, C. Zhang, X. Gao, X. Jiang, C. Zhu, Preparation and brain delivery property of biodegradable polymersomes conjugated with OX26, J Control Release, 128 (2008) 120-127.

[30] Y.C. Kuo, H.F. Ko, Targeting delivery of saquinavir to the brain using 83-14 monoclonal antibody-grafted solid lipid nanoparticles, Biomaterials, 34 (2013) 4818-4830.

[31] P. Candela, F. Gosselet, F. Miller, V. Buee-Scherrer, G. Torpier, R. Cecchelli, L. Fenart, Physiological pathway for low-density lipoproteins across the blood-brain barrier: transcytosis through brain capillary endothelial cells in vitro, Endothelium, 15 (2008) 254-264.

[32] K. Yamada, T. Hashimoto, C. Yabuki, Y. Nagae, M. Tachikawa, D.K. Strickland, Q. Liu, G. Bu, J.M. Basak, D.M. Holtzman, S. Ohtsuki, T. Terasaki, T. Iwatsubo, The low density lipoprotein receptor-related protein 1 mediates uptake of amyloid beta peptides in an in vitro model of the blood-brain barrier cells, J Biol Chem, 283 (2008) 34554-34562.

[33] K. Michaelis, M.M. Hoffmann, S. Dreis, E. Herbert, R.N. Alyautdin, M. Michaelis, J. Kreuter, K. Langer, Covalent linkage of apolipoprotein e to albumin nanoparticles strongly enhances drug transport into the brain, J Pharmacol Exp Ther, 317 (2006) 1246-1253. 
[34] G. Radeva, J. Perabo, F.J. Sharom, P-Glycoprotein is localized in intermediate-density membrane microdomains distinct from classical lipid rafts and caveolar domains, Febs J, 272 (2005) 4924-4937.

[35] C. Kirby, J. Clarke, G. Gregoriadis, Effect of the cholesterol content of small unilamellar liposomes on their stability in vivo and in vitro, Biochem J, 186 (1980) 591-598.

[36] P. Kannan, K.R. Brimacombe, W.C. Kreisl, J.S. Liow, S.S. Zoghbi, S. Telu, Y. Zhang, V.W. Pike, C. Halldin, M.M. Gottesman, R.B. Innis, M.D. Hall, Lysosomal trapping of a radiolabeled substrate of P-glycoprotein as a mechanism for signal amplification in PET, Proc Natl Acad Sci U S A, 108 (2011) 2593-2598.

[37] L.D. Mayer, J. Reamer, M.B. Bally, Intravenous pretreatment with empty pH gradient liposomes alters the pharmacokinetics and toxicity of doxorubicin through in vivo active drug encapsulation, J Pharm Sci, 88 (1999) 96-102.

[38] N. Bertrand, C. Bouvet, P. Moreau, J.C. Leroux, Transmembrane pH-gradient liposomes to treat cardiovascular drug intoxication, ACS Nano, 4 (2010) 7552-7558.

[39] A.B. Dhanikula, N.M. Khalid, S.D. Lee, R. Yeung, V. Risovic, K.M. Wasan, J.C. Leroux, Long circulating lipid nanocapsules for drug detoxification, Biomaterials, 28 (2007) 1248-1257.

[40] N. Sabnis, A.G. Lacko, Drug delivery via lipoprotein-based carriers: answering the challenges in systemic therapeutics, Ther Deliv, 3 (2012) 599-608. 


\section{APPENDICES}

\section{Appendix 1}

Solubility of loperamide in previously reported vehicles $\left(25^{\circ} \mathrm{C}\right)$

\begin{tabular}{|c|c|c|}
\hline Vehicle & Vehicle pH & Loperamide \\
\hline Water:Tween 80 (99:1) & 7.6 & - \\
\hline Water:Ethanol (97:3) & 7.4 & $+/-(0.5 \mathrm{mg} / \mathrm{mL})$ \\
\hline Saline:0.2M HCl & 1.4 & - \\
\hline Saline:PEG 600 (3:1) & 7.4 & $+(2.0 \mathrm{mg} / \mathrm{mL})$ \\
\hline
\end{tabular}

Appendix 2

Solubility of elacridar and tariquidar in previously reported vehicles $\left(25^{\circ} \mathrm{C}\right)$

\begin{tabular}{|c|c|c|c|}
\hline Vehicle & Vehicle $\mathrm{pH}$ & Elacridar & Tariquidar \\
\hline Water:dextrose (97:3) & 7.0 & - & - \\
\hline Saline:ethanol (80:20) & 7.4 & - & - \\
\hline Tetraglycol & $8.5-9.0$ & $+(20.0 \mathrm{mg} / \mathrm{mL})$ & - \\
\hline Saline:PEG 600 (3:1) & 7.4 & $+(2.0 \mathrm{mg} / \mathrm{mL})$ & $+(2.0 \mathrm{mg} / \mathrm{mL})$ \\
\hline
\end{tabular}




\section{Appendix 3}

Characterization of elacridar-tariquidar liposomal formulations $(\mathrm{n}=3)$

\begin{tabular}{cccccc}
\hline $\begin{array}{c}\text { Liposomal } \\
\text { composition }\end{array}$ & Molar ratio & $\begin{array}{c}\text { Mean particle } \\
\text { diameter }(\mathrm{nm})\end{array}$ & $\begin{array}{c}\text { Zeta potential } \\
(\mathrm{mV})\end{array}$ & $\begin{array}{c}\text { Elacridar loading } \\
\text { efficiency }(\%)\end{array}$ & $\begin{array}{c}\text { Tariquidar loading } \\
\text { efficiency }(\%)\end{array}$ \\
\hline EPC & 100 & $138.2 \pm 2.9$ & $0.3 \pm 0.2$ & $61.1 \pm 2.5$ & $59.6 \pm 1.8$ \\
DMPC & $\mathbf{1 0 0}$ & $\mathbf{1 0 2 . 6} \pm \mathbf{2 . 3}$ & $\mathbf{1 . 7} \pm \mathbf{0 . 8}$ & $\mathbf{6 4 . 3} \pm \mathbf{3 . 3}$ & $\mathbf{6 2 . 2} \pm \mathbf{0 . 9}$ \\
DPPC & 100 & $291.5 \pm 3.6$ & $1.6 \pm 0.3$ & $49.1 \pm 3.2$ & $46.6 \pm 3.7$ \\
DSPC & 100 & $1096.0 \pm 10.2$ & $1.9 \pm 0.7$ & $28.4 \pm 5.8$ & $34.1 \pm 4.5$ \\
\hline
\end{tabular}


Appendix 4

Apparent permeability (A - B) of rhodamine 123 (mean \pm S.D) after pre-treatment of Caco-2 monolayers with elacridar and tariquidar $(n=6)$.

\begin{tabular}{ccccc}
\hline Time (hours) & Elacridar $0.25 \mu \mathrm{M}$ & Elacridar $0.50 \mu \mathrm{M}$ & Tariquidar $0.50 \mu \mathrm{M}$ & Tariquidar $1.0 \mu \mathrm{M}$ \\
\hline 0 & $5.41 \pm 0.63$ & $3.09 \pm 0.50$ & $6.30 \pm 0.33$ & $3.16 \pm 0.55$ \\
2 & $6.18 \pm 0.55$ & $5.33 \pm 0.16$ & $6.79 \pm 0.40$ & $3.79 \pm 0.33$ \\
6 & $8.17 \pm 1.49$ & $7.53 \pm 0.61$ & $7.55 \pm 0.44$ & $5.44 \pm 0.88$ \\
10 & $11.09 \pm 1.05$ & $8.87 \pm 0.50$ & $8.95 \pm 0.32$ & $6.46 \pm 0.16$ \\
24 & $13.76 \pm 0.58$ & $11.35 \pm 1.05$ & $11.54 \pm 0.90$ & $9.65 \pm 0.38$ \\
48 & $13.89 \pm 0.77$ & $13.78 \pm 0.56$ & $14.02 \pm 0.42$ & $13.56 \pm 0.55$ \\
\hline
\end{tabular}

\section{Appendix 5}

Apparent permeability (A - B) of rhodamine 123 (mean \pm S.D) after pre-treatment of Caco-2 monolayers with elacridar and tariquidar by transport buffer (control), DMPC:Chol-L, M-Ne and AT-Ne $(n=6)$.

\begin{tabular}{ccccc}
\hline Formulation & Elacridar $0.25 \mu \mathrm{M}$ & Elacridar $0.50 \mu \mathrm{M}$ & Tariquidar $0.50 \mu \mathrm{M}$ & Tariquidar $1.0 \mu \mathrm{M}$ \\
\hline Control & $6.18 \pm 0.55$ & $5.33 \pm 0.16$ & $6.79 \pm 0.40^{*}$ & $3.79 \pm 0.33^{*}$ \\
DMPC:Chol-L & $7.03 \pm 0.59$ & $6.07 \pm 0.62$ & $10.23 \pm 0.52$ & $7.24 \pm 0.64$ \\
M-Ne & $5.76 \pm 0.25$ & $5.45 \pm 0.50$ & $6.10 \pm 0.32$ & $3.56 \pm 0.25$ \\
AT-Ne & $8.35 \pm 0.45^{*}$ & $5.11 \pm 0.64$ & $6.40 \pm 0.93$ & $4.19 \pm 0.60$ \\
\hline
\end{tabular}

* Significantly different compared to the $\mathrm{P}_{\text {app }}$ of Caco-2 monolayers treated with the P-gp modulator for 30 minutes and blank buffer (control) for two hours. 


\begin{abstract}
Although the P-glycoprotein (P-gp) represents an obstacle in several central nervous system (CNS) pharmacotherapies, the P-gp also protects the brain from intoxication by endogenous and exogenous harmful lipophilic compounds that otherwise could penetrate the blood-brain barrier (BBB) by simple diffusion. Therefore, any modulation of the efflux transporter has to consider the potential neurotoxicity of such modulation. Early studies showed that elacridar and tariquidar, two third-generation P-gp modulators, increase the distribution of several P-gp substrates in the brain. Unfortunately, recent studies suggest the use of high doses of elacridar and tariquidar to efficiently modulate the P-gp at the BBB. Nevertheless, when co-administered with P-gp substrates, these high doses may be associated with pharmacokinetic interactions and toxic profiles, thus limiting the use of these compounds.

Hence, this thesis aimed to attain a transient but efficient modulation of the P-gp at the BBB using elacridar and tariquidar but avoiding the use of large doses of these compounds. For this purpose we took advantage of the possible in vivo intravenous co-administration of low but therapeutic doses of elacridar and tariquidar, under their free form or co-encapsulated in liposomes. The brain distribution of free loperamide was determined as an in vivo probe of full inhibition of the P-gp activity at the BBB.

The concurrent administration of both free P-gp modulators does not modify their plasma concentrations or those of the P-gp substrate but significantly increased the brain uptake of loperamide as a result of their non-competitive modulatory activity. Moreover, the coencapsulation of elacridar and tariquidar in targeted sterically stabilized immunoliposomes improved the half-lives and brain distribution of both compounds. Consequently, the brain uptake of free loperamide was significantly enhanced without any modification of its pharmacokinetics or tissue distribution. Moreover, the partial impairment of the modulatory activity of tariquidar by empty liposomes, supports the use of this nanocarrier as a bio-detoxifying approach for the treatment of tariquidar overdoses.

In summary, this thesis proposes different approaches for full exploitation of elacridar and tariquidar. The findings described in this manuscript should open interesting avenues to achieve an efficient overcoming of the P-gp at the BBB and succeed CNS pharmacotherapies.
\end{abstract}

Keywords: P-glycoprotein, blood-brain barrier, elacridar, tariquidar, co-administration, and liposomes. 


\section{RESUME}

La présence de la glycoprotéine $\mathrm{P}$ (P-gp) dans la barrière hémato-encéphalique (BHE) conduit à l'échec de nombreuses thérapies ciblant le système nerveux central (SNC). Cependant la P-gp protège aussi le cerveau contre des composés nocifs, essentiellement lipophiles, endogènes et exogènes susceptibles de passer la BHE par diffusion simple. Par conséquent, toute inhibition de la P-gp qui vise à améliorer la distribution des agents pharmacologiques dans le cerveau doit prendre en compte la neurotoxicité potentielle de cette inhibition. Les premiers travaux ont montré que l'elacridar et le tariquidar, deux modulateurs de la P-gp de troisième génération, augmentaient la distribution dans le cerveau de plusieurs de ses substrats. Malheureusement, d'autres études plus récentes, suggèrent l'utilisation de doses élevées de l'elacridar et du tariquidar pour moduler efficacement l'activité de la P-gp dans la BHE. Néanmoins, ces doses élevées en coadministration avec des substrats de la $\mathrm{P}$-gp peuvent être associées à des interactions pharmacocinétiques et à des profils toxiques, limitant ainsi l'utilisation de ces inhibiteurs.

Dans ce contexte, l'objectif principal de cette thèse est d'obtenir une modulation transitoire mais efficace de la P-gp dans la BHE par administration intraveineuse de doses faibles mais thérapeutiques de l'elacridar et du tariquidar sous leur forme libre ou co-encapsulé dans les liposomes. Le lopéramide, substrat de la P-gp, a été également administré sous sa forme libre comme une preuve in vivo d'une inhibition efficace de la P-gp dans la BHE.

L'administration simultanée de ces deux modulateurs de la P-gp n'a pas modifié leurs concentrations plasmatiques ou celles du lopéramide, mais a entraîné une importante distribution du lopéramide dans le cerveau en raison de leur activité inhibitrice non- compétitive. De plus, la co-encapsulation de l'elacridar et du tariquidar dans des immunoliposomes stabilisées stériquement a amélioré la demi-vie et la distribution dans le cerveau des ceux deux composés. Par conséquent, la distribution dans le cerveau du lopéramide a été considérablement augmentée, sans aucune modification de sa pharmacocinétique ou distribution tissulaire. Par ailleurs, la diminution partielle de l'activité inhibitrice du tariquidar par des liposomes vides suggère l'utilisation de ce nanovecteur comme une approche de bio-détoxification pour le traitement des surdoses de tariquidar. En résumé, cette thèse propose différentes approches pour exploiter pleinement l'elacridar et le tariquidar. Les résultats décrits dans ce manuscrit devraient ouvrir des pistes intéressantes pour atteindre une inhibition efficace de la P-gp dans la BHE et pour réussir des thérapies ciblant le système nerveux central.

Mots-clés: Glycoprotéine P, barrière hémato-encéphalique, elacridar, tariquidar, coadministration, et liposomes. 